\title{
Effects of a Manikin on the Capture Efficiency and Protection Efficiency of a Small Rectangular Hood
}

Brian Scott Geissler

Follow this and additional works at: https://researchrepository.wvu.edu/etd

\section{Recommended Citation}

Geissler, Brian Scott, "Effects of a Manikin on the Capture Efficiency and Protection Efficiency of a Small Rectangular Hood" (2017). Graduate Theses, Dissertations, and Problem Reports. 5658.

https://researchrepository.wvu.edu/etd/5658

This Dissertation is protected by copyright and/or related rights. It has been brought to you by the The Research Repository @ WVU with permission from the rights-holder(s). You are free to use this Dissertation in any way that is permitted by the copyright and related rights legislation that applies to your use. For other uses you must obtain permission from the rights-holder(s) directly, unless additional rights are indicated by a Creative Commons license in the record and/ or on the work itself. This Dissertation has been accepted for inclusion in WVU Graduate Theses, Dissertations, and Problem Reports collection by an authorized administrator of The Research Repository @ WVU.

For more information, please contact researchrepository@mail.wvu.edu. 


\title{
Effects of a Manikin on the Capture Efficiency and Protection Efficiency of a Small Rectangular Hood
}

\section{Brian Scott Geissler}

\author{
Dissertation submitted to \\ The Benjamin M. Statler College of Engineering and Mineral Resources \\ At West Virginia University \\ in partial fulfillment of the requirements for the degree of \\ Doctor of Philosophy \\ in \\ Occupational Safety and Health
}

\author{
Steven Guffey, Ph.D., Chair \\ Xiaopeng Ning, Ph.D. \\ Xinjian He, Ph.D. \\ Feng Yang, Ph.D. \\ Christopher Coffey, Ph.D. \\ Department of Industrial and Management Systems Engineering
}

\author{
Morgantown, West Virginia \\ 2017
}

Keywords: Ventilation, Capture Hood, Capture Efficiency, Protection Efficiency, PIV, CPC, Tracer Gas, Manikin, Hood Orientation

Copyright 2017 Brian Scott Geissler 


\title{
ABSTRACT \\ Effects of a Manikin on the Capture Efficiency and Protection Efficiency of a Small Rectangular Hood
}

\author{
Brian Scott Geissler
}

The primary indicator of capturing hood effectiveness is widely assumed to be the "capture velocity" measured normal to the center of the hood face, at the furthest location of the contaminant source. The velocity required at this distance $\left(\mathrm{V}_{\mathrm{x}}\right)$ is thought to correspond to the appropriate flow (Q) required to capture the contaminant. The adequacy of $\mathrm{V}_{\mathrm{x}}$ as a surrogate for hood effectiveness has long been poorly understood and has been little studied. Few considerations of potentially disruptive parameters, such as draft velocity, hood orientation, and operator presence are made during the design phase.

In this study, an anatomically correct heated, breathing, and moving manikin was used as a surrogate for a human hood operator. Velocity profiles of the capture envelope were obtained by particle image velocimetry (PIV) at three orientations $\left(0^{\circ}, 90^{\circ}, 180^{\circ}\right)$, with respect to the cross drafts $(30,60$, and $120 \mathrm{fpm})$ generated inside a large wind tunnel. The capturing hood fan speed was set to maintain the $\mathrm{Q}$ of nominal $\mathrm{V}_{\mathrm{x}}$ values of 50,100, and $200 \mathrm{fpm}$, as measured 11 inches away from the hood face, in a controlled environment.

A condensation particle counter (CPC) was used to compare the capture efficiency and protection efficiency of the rectangular hood with the traditional, expensive, and time-consuming tracer gas method. Salt aerosols and Freon 134-A were released, at separate occasions, 11 inches away from the hood face. Measurements were taken within the duct $\left(\mathrm{C}_{\text {duct }}\right)$ and between the mouth and nose $\left(\mathrm{C}_{\text {BreathingZone }}\right)$ of the manikin. Duct measurements $\left(\mathrm{C}_{\text {duct } 100}\right)$ were also collected when the contaminant was directly fed into the duct, and breathing zone measurements were also conducted

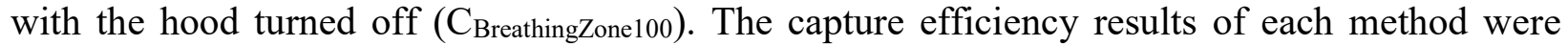
compared, and no significant difference between the methods was found.

With the CPC method established as a viable method, studies were conducted to test the effects of operator presence, movement, hood orientation, and cross drafts under the same conditions as the PIV study. All effects, except for manikin movement, were found to have a significant effect on hood performance. Manikin movement did, however, have a significant effect on contaminant concentrations within the breathing zone of the operator. 


\section{Acknowledgements}

I would like to thank my committee members for serving and providing invaluable advice. I would like to specifically thank Dr. Guffey for his patience, guidance, and belief in me.

I would also like to directly thank Dr. He for providing advice, lending me equipment, and helping with funding the overall project.

Thank you to Raphael Dodrill for meeting with me several times over the years to help diagnose, build, and calibrate what feels like countless items.

Thank you to Lisa Kogan for lending your expertise to assistance with developing MATLAB software for PIV analysis.

Finally, I want to thank my wife Wan, for always providing me love and support. 


\section{Table of Contents}

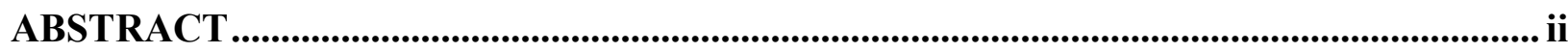

Acknowledgements ................................................................................................................. iii

Chapter 1: Introduction....................................................................................................................... 1

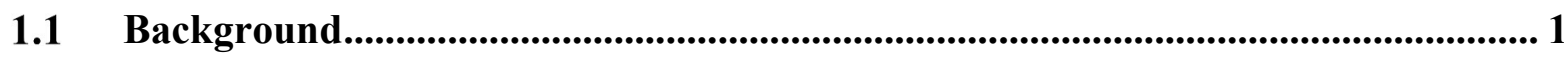

1.1.1 Capture Velocity ................................................................................................... 2

1.1.2 Capture Efficiency .................................................................................................... 3

1.1.3 Protection Efficiency..............................................................................................5

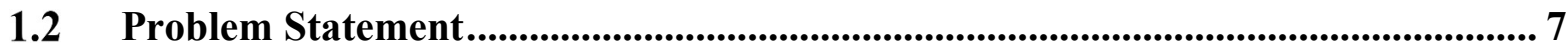

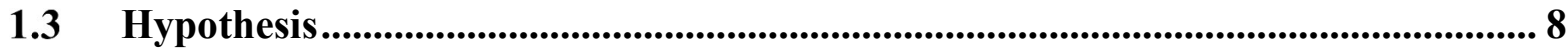

1.4 Research Objectives ....................................................................................................... 9

Chapter 2: Literature Review ........................................................................................................ 10

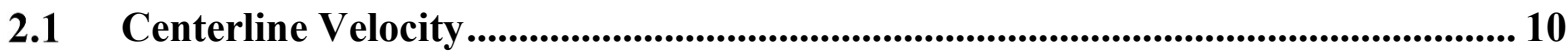

2.2 Capture Efficiency ...................................................................................................... 13

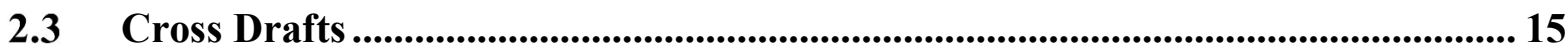

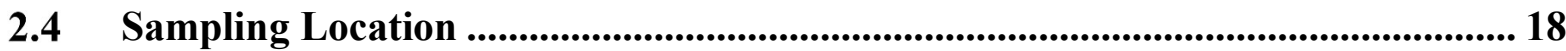

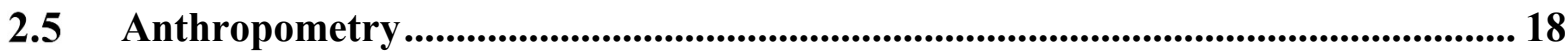

2.6 Manikin Studies Compared to Human Subjects.......................................................... 20

2.7 Body Movement...................................................................................................................... 21

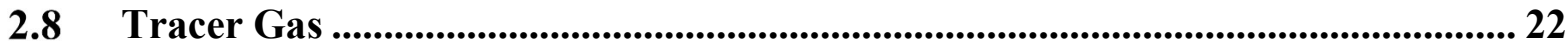

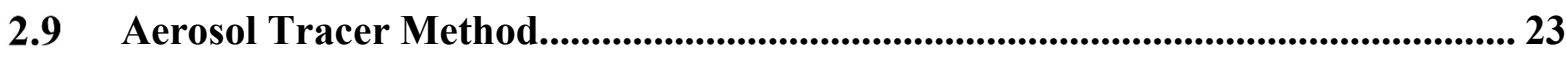

2.10 Presence of a Workbench .............................................................................................. 24

Chapter 3: Apparatus .................................................................................................................... 25

3.1 Wind Tunnel and its Control System ......................................................................... 25

3.2 Exterior Hood and its Control System ........................................................................ 27

3.3 Pitot Traverse System ....................................................................................................... 28

3.3.1 Pitot Traverse Validation .......................................................................................... 30

3.4 Hood Centerline Velocity Measurement System.......................................................... 30

3.5 Environmental Measurements ................................................................................... 30

3.6 Tracer Gas Release System .............................................................................................. 31 
3.6.1 Tracer Gas Release Rate Validation ........................................................... 32

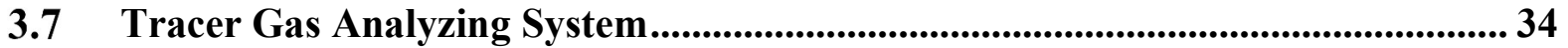

3.7.1 Tracer Gas Analyzing System Validation................................................... 34

3.8 Aerosol Release System........................................................................................ 35

3.9 Aerosol Analyzing System ........................................................................................ 36

3.10 PIV Particle Seeding ..................................................................................... 38

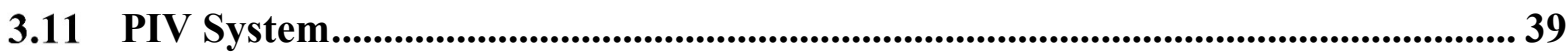

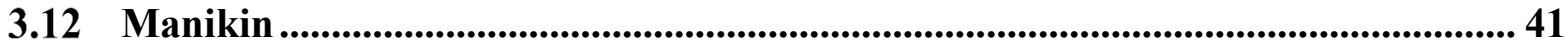

3.12.1 Manikin Heating …........................................................................................................ 42

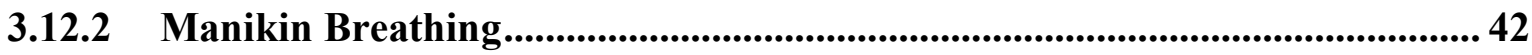

3.12.3 Manikin Movements ................................................................................. 44

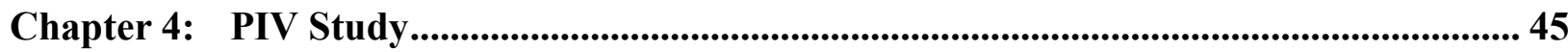

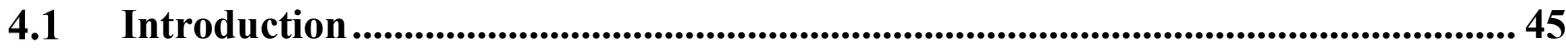

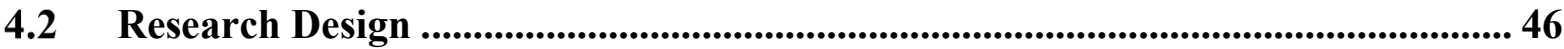

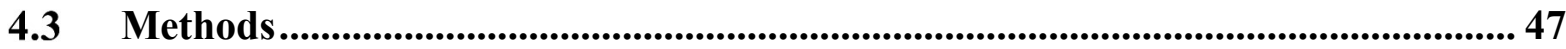

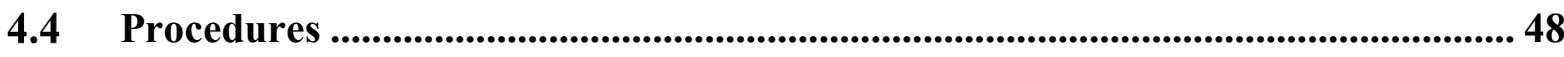

4.4.1 PIV Analyzing System Preparation ...................................................................... 48

4.4.2 Calibration and Validation ............................................................................. 48

4.4.3 Environmental Measurements.................................................................... 48

4.4.4 Hood and Wind Tunnel Control Systems Preparation ................................... 48

4.4.5 Particle Seeding Release System Preparation .................................................. 49

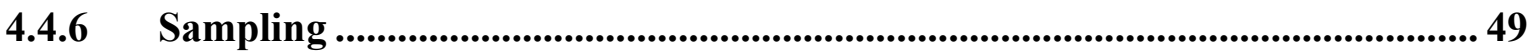

4.4.7 Velocity Measurements ....................................................................................... 49

4.4.8 Analyzing Samples ................................................................................................. 49

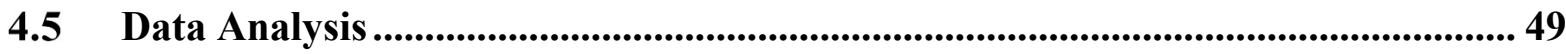

4.6 Results .................................................................................................................... 50

4.6.1 Effects of Manikin Presence on Centerline Velocity with Varying Cross

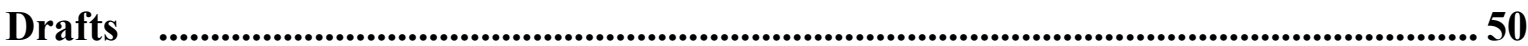

4.6.2 Variable Effects on Velocities in Capture Envelope...................................... 77

4.7 Study Summary .................................................................................................................... 81

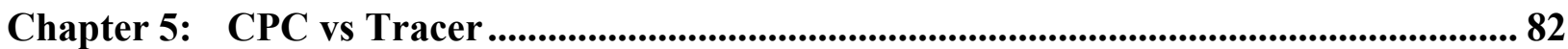




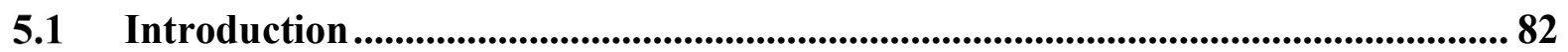

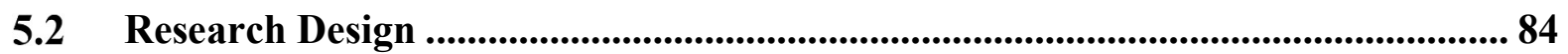

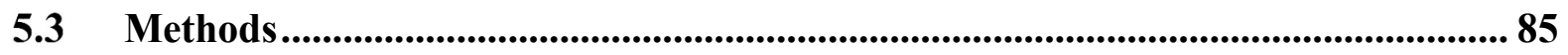

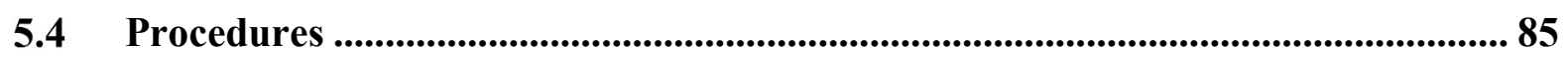

5.4.1 Calibration and Validation ...................................................................................... 85

5.4.2 Tracer Gas Analyzing System Preparation ............................................................ 86

5.4.3 Environmental Measurements.......................................................................... 86

5.4.4 Hood and Wind Tunnel Control Systems Preparation ....................................... 86

5.4.5 Tracer Gas and Aerosol Release System Preparation ............................................ 86

5.4.6 Sampling .................................................................................................................... 86

5.4.7 Velocity Measurements ............................................................................................ 87

5.4.8 Analyzing Samples ................................................................................................. 87

5.5 Data Analysis ............................................................................................................... 87

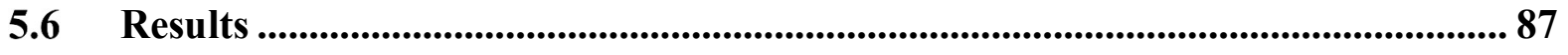

5.7 Study Summary .............................................................................................................. 90

Chapter 6: Manikin Movements ...................................................................................................... 91

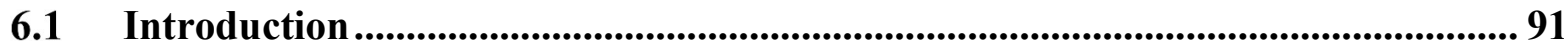

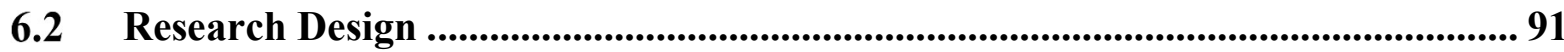

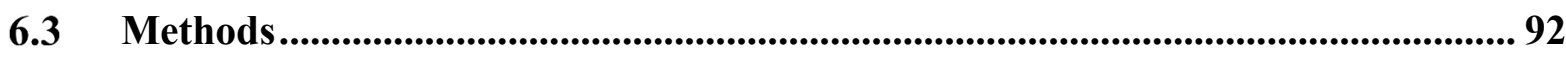

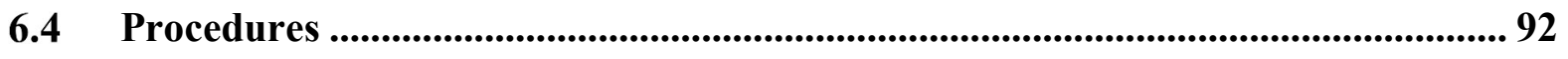

6.4.1 Calibration and Validation ..................................................................................93

6.4.2 Environmental Measurements...............................................................................93

6.4.3 Hood and Wind Tunnel Control Systems Preparation ...................................... 93

6.4.4 Aerosol Release System Preparation...................................................................... 93

6.4.5 Sampling .................................................................................................................. 93

6.4.6 Velocity Measurements ........................................................................................... 94

6.4.7 Analyzing Samples ............................................................................................... 94

6.5 Data Analysis ............................................................................................................. 94

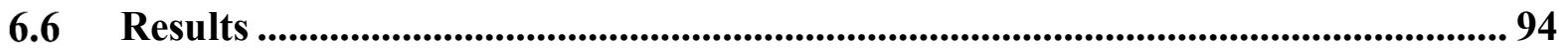

6.6.1 Means Analysis of Manikin Movement Effect .................................................... 95

6.6.2 Variables Affecting Capture Efficiency ................................................................. 102 
6.6.3 Variables Affecting Protection Efficiency ......................................................... 104

6.6.4 Variables Affecting Protection Factor ............................................................. 105

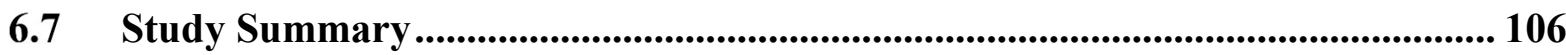

Chapter 7: Operator Presence \& Hood Orientation ................................................................ 108

7ntroduction ................................................................................................................... 108

7.2 Research Design ................................................................................................. 109

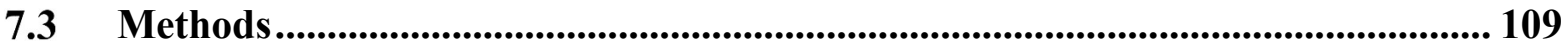

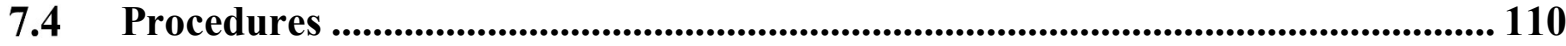

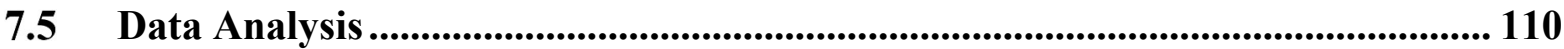

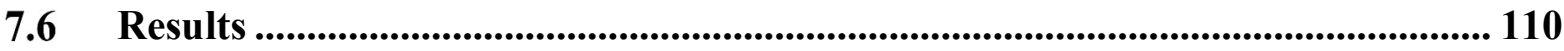

7.6.1 Effects of Operator Presence on Capture Efficiency ....................................... 112

7.6.2 Effects of Hood Orientation on Capture Efficiency.................................... 114

7.6.3 Statistical Analysis of Capture Efficiency...................................................... 114

7.6.4 Effects of Hood Orientation on Protection Factor.......................................... 115

7.6.5 Statistical Analysis of Protection Factor ........................................................ 116

7.6.6 Statistical Analysis of Breathing Efficiency.................................................... 118

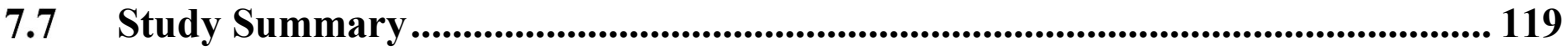

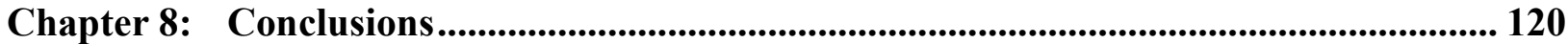

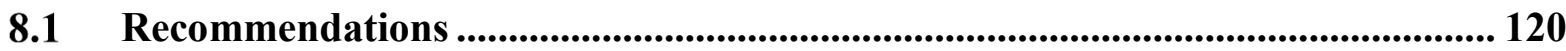

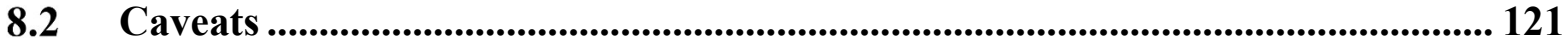

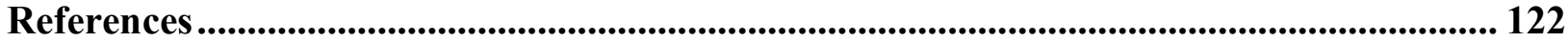

Appendix A - Capture Envelope Stats ..................................................................... 128

Appendix B - Cross Draft Validation ............................................................................................. 138 


\section{List of Figures}

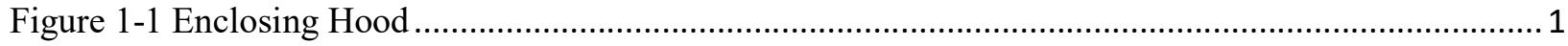

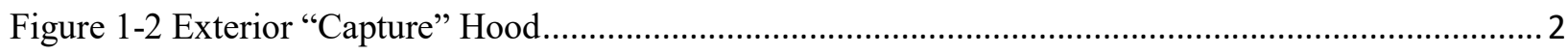

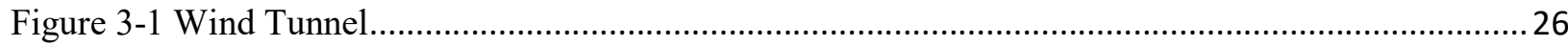

Figure 3-2 Balnor Series 15H Inverter Motor Controller .............................................................26

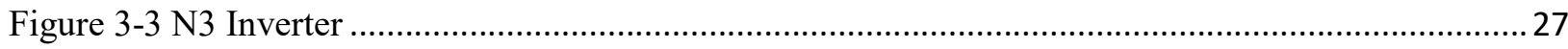

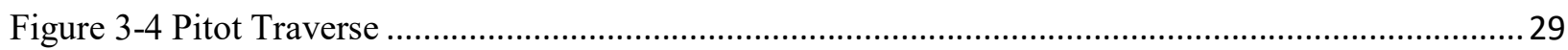

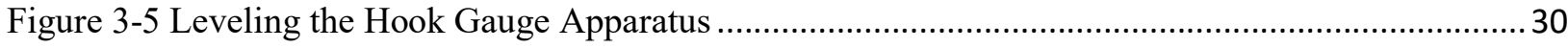

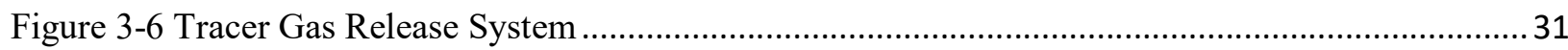

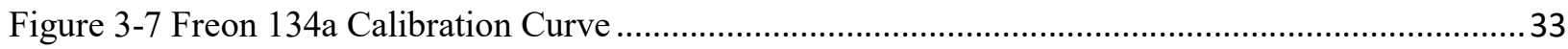

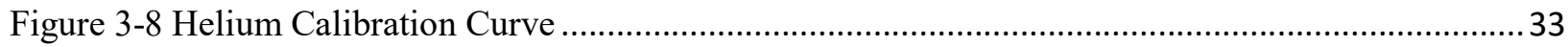

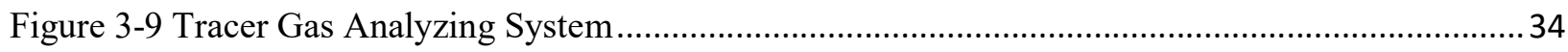

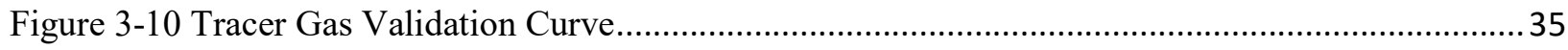

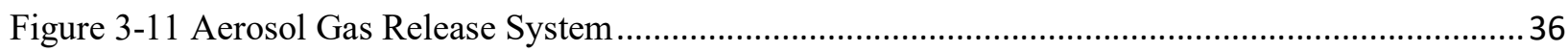

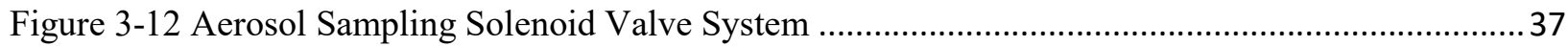

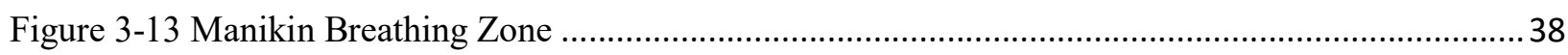

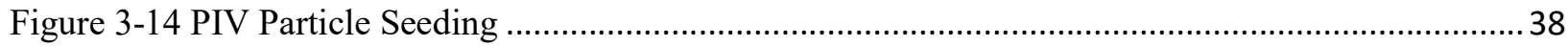

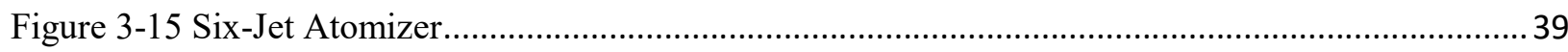

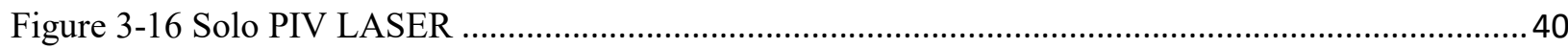

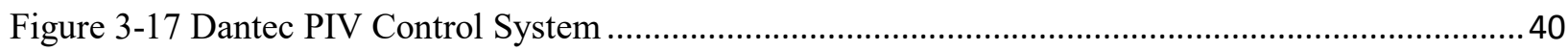

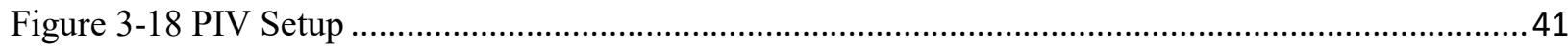

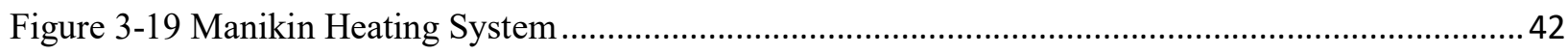

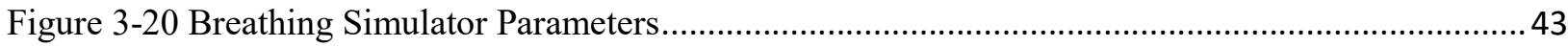

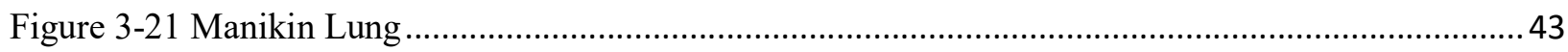

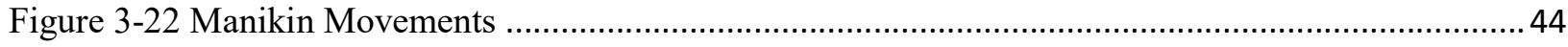

Figure 4-1 PIV Capture Envelope Measurements ................................................................................... 46

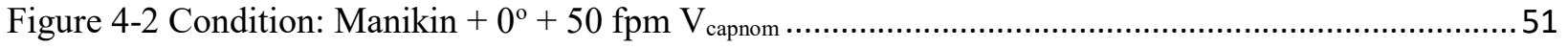

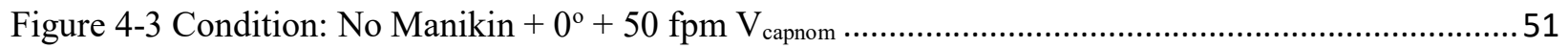

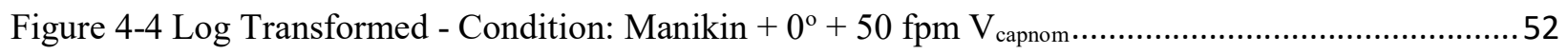

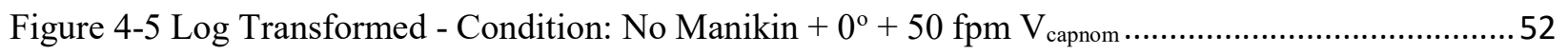

Figure 4-6 Condition: Manikin $+0^{\circ}+100 \mathrm{fpm} \mathrm{V}_{\text {capnom }}$....................................................................... 54

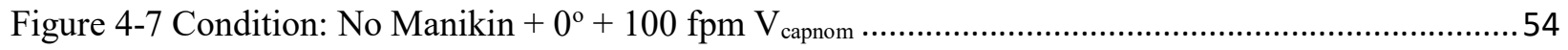

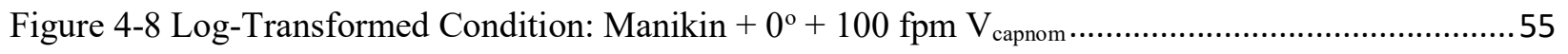

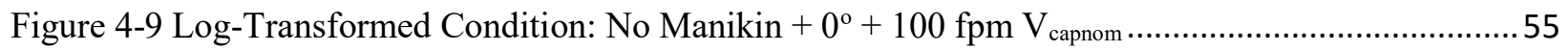

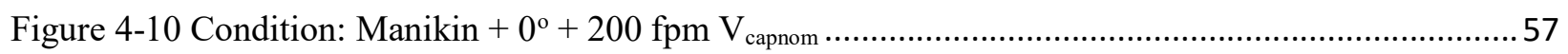

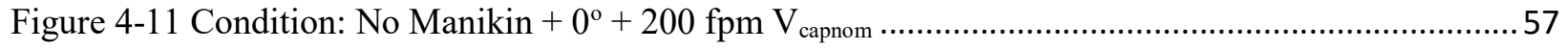

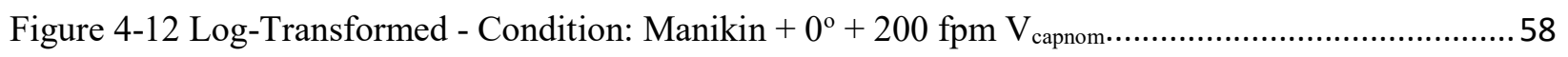

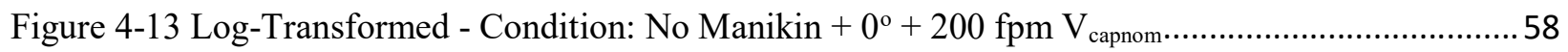

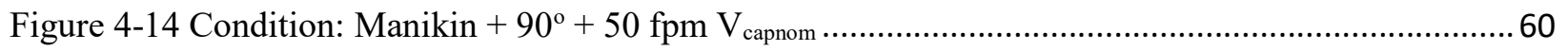

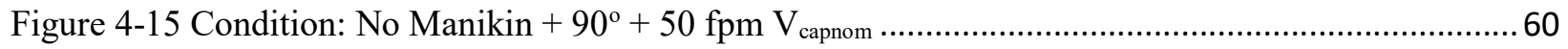

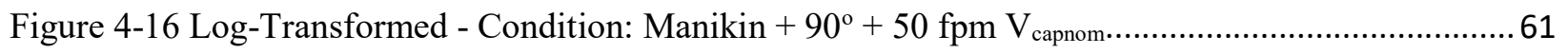




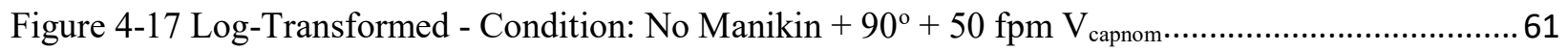

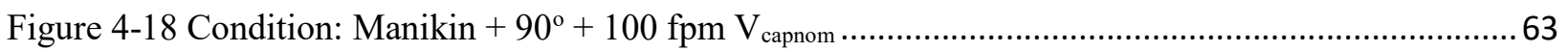

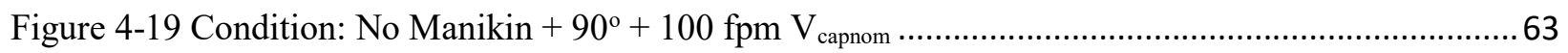

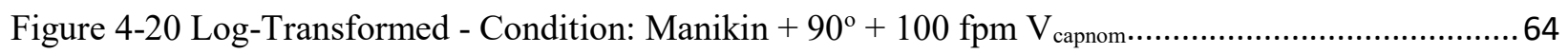

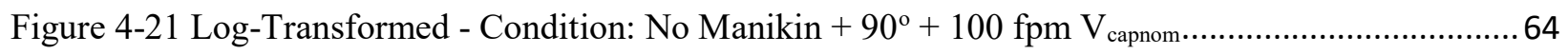

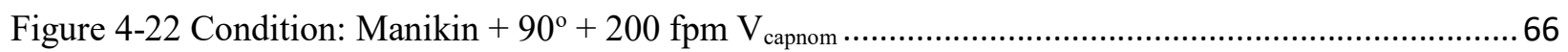

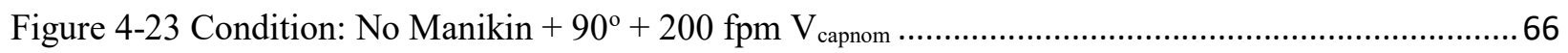

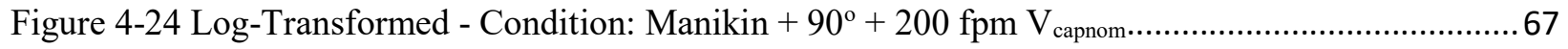

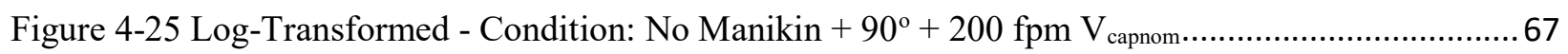

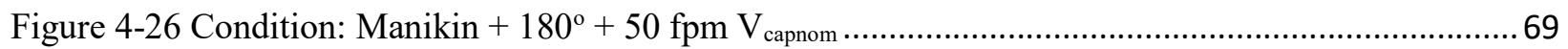

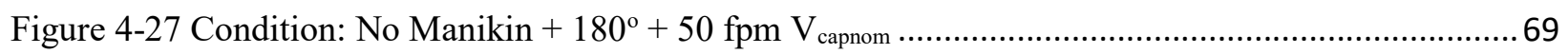

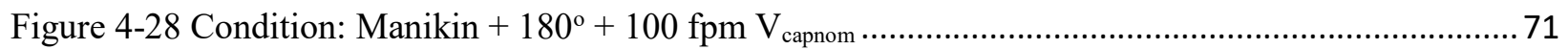

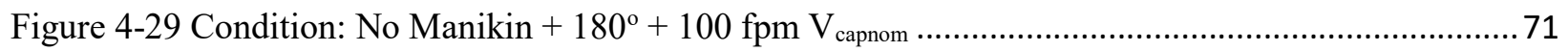

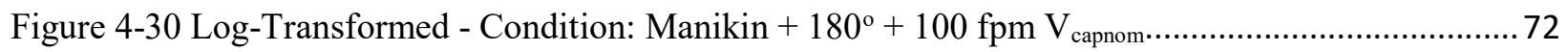

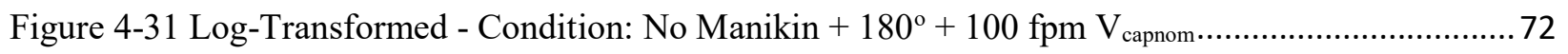

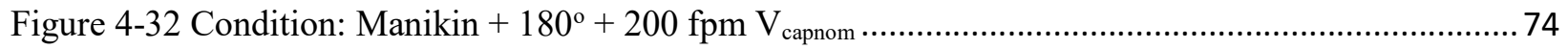

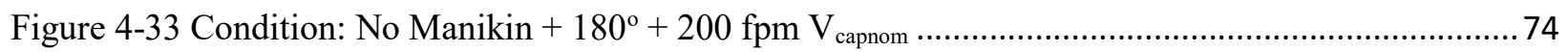

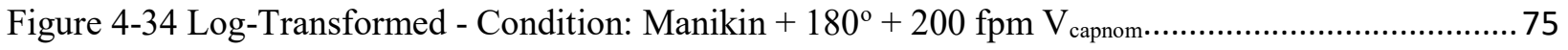

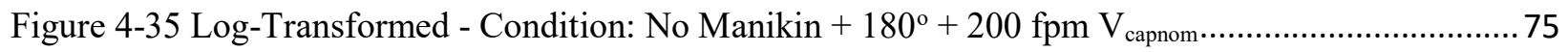

Figure 4-36 Summary Chart of Variable Effects on 11" Capture Velocity ............................................. 76

Figure 4-37 Effects of Manikin Presence Throughout Capture Envelope at $0^{\circ}$.......................................77

Figure 4-38 Effects of Manikin Presence Throughout Capture Envelope at $90^{\circ}$.....................................78

Figure 4-39 Effects of Manikin Presence Throughout Capture Envelope at $180^{\circ}$.................................... 79

Figure 5-1 CPC vs Tracer Capture Efficiency Comparison................................................................ 88

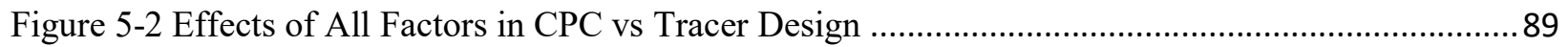

Figure 6-1 Effects of Manikin Movement on Duct Concentration .......................................................95

Figure 6-2 Detailed Effects of Manikin Movement on Duct Concentration............................................96

Figure 6-3 Effects of Manikin Movement on Breathing Concentration ..................................................97

Figure 6-4 Detailed Effects of Manikin Movement on Breathing Concentration.....................................98

Figure 6-5 Effects of Manikin Movement on Breathing Protection Factor ..............................................99

Figure 6-6 Detailed Effects of Manikin Movement on Breathing Protection Factor............................... 99

Figure 6-7 Effects of Manikin Movement on Breathing Efficiency .................................................... 100

Figure 6-8 Detailed Effects of Manikin Movement on Breathing Efficiency........................................100

Figure 6-9 Effects of Manikin Movement on Capture Efficiency ….................................................... 101

Figure 6-10 Detailed Effects of Manikin Movement on Capture Efficiency..........................................101

Figure 6-11 Actual by Predicted Plot for Capture Efficiency ............................................................ 102

Figure 6-12 Actual by Predicted Plot for Breathing Efficiency.......................................................... 104

Figure 6-13 Actual by Predicted Plot for Breathing Factor ............................................................... 105

Figure 6-14 Prediction Profiler for Manikin Movement Model ......................................................... 107

Figure 7-1 Effects of Operator Presence on Capture Efficiency with Respect to Cross Draft .................113

Figure 7-2 Effects of Operator Presence on Capture Efficiency with Respect to Capture Velocity ........ 113

Figure 7-3 Effects of Hood Orientation on Capture Efficiency .......................................................... 114 
Figure 7-4 Effects of Hood Orientation on Protection Factor........................................................... 116

Figure 7-5 Actual by Predicted Plot of Breathing Protection Factor ................................................... 116

Figure 7-6 Actual by Predicted Plot of Breathing Efficiency ............................................................. 118 


\section{List of Tables}

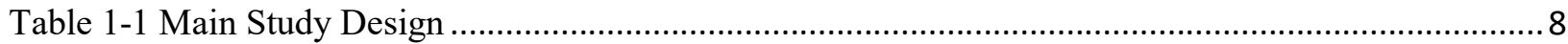

Table 2-1 Range of Capture Velocities...................................................................................... 12

Table 2-2 Average Stature of Men and Women in the US by Percentile …….......................................19

Table 4-1 PIV Study Design ........................................................................................................

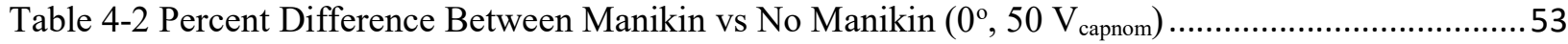

Table 4-3 Percent Difference Between Manikin vs No Manikin $\left(0^{\circ}, 100 \mathrm{~V}_{\text {capnom }}\right)$......................................56

Table 4-4 Percent Difference Between Manikin vs No Manikin $\left(0^{\circ}, 200 \mathrm{~V}_{\text {capnom }}\right)$......................................5 59

Table 4-5 Percent Difference Between Manikin vs No Manikin $\left(90^{\circ}, 50 \mathrm{~V}_{\text {capnom }}\right)$.....................................62

Table 4-6 Percent Difference Between Manikin vs No Manikin $\left(90^{\circ}, 100 \mathrm{~V}_{\text {capnom }}\right)$....................................65

Table 4-7 Percent Difference Between Manikin vs No Manikin $\left(90^{\circ}, 200 \mathrm{~V}_{\text {capnom }}\right)$...................................68

Table 4-8 Percent Difference Between Manikin vs No Manikin $\left(180^{\circ}, 50 \mathrm{~V}_{\text {capnom }}\right)$...................................70

Table 4-9 Percent Difference Between Manikin vs No Manikin $\left(180^{\circ}, 100 \mathrm{~V}_{\text {capnom }}\right)$.................................73

Table 4-10 Percent Difference Between Manikin vs No Manikin $\left(180^{\circ}, 200 \mathrm{~V}_{\text {capnom }}\right)$................................76

Table 4-11 Percent Difference Between Manikin vs No Manikin - Capture Envelope ...............................8 80

Table 4-12 Statistically Significant Effects Throughout Capture Envelope …………………………........ 80

Table 5-1 CPC vs Tracer Design - Single Replication....................................................................... 84

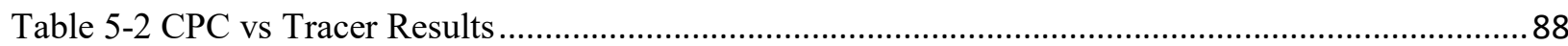

Table 6-1 Manikin Movement Full Design - Single Replication .........................................................92

Table 6-2 Manikin Movement Results...............................................................................................95

Table 6-3 Summary of Fit for Capture Efficiency ………………………………………………..... 102

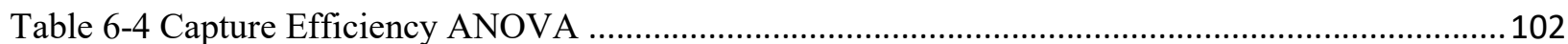

Table 6-5 Capture Efficiency Effects Test......................................................................................103

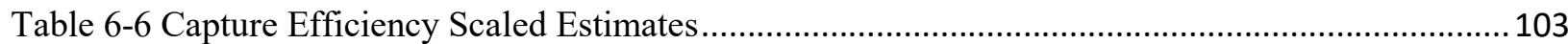

Table 6-7 Summary of Fit for Protection Efficiency ……………………………………………..... 104

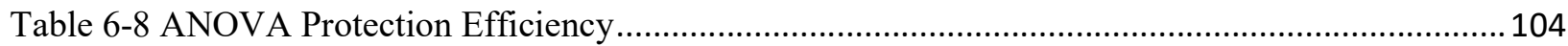

Table 6-9 Summary of Fit for Breathing Protection Factor ................................................................ 105

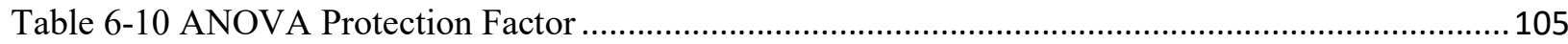

Table 6-11 Protection Factor Effects Test .......................................................................................... 106

Table 6-12 Protection Factor Least Squares Mean ................................................................................. 106

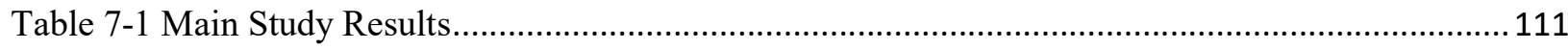

Table 7-2 Summary of Fit - Capture Efficiency............................................................................114

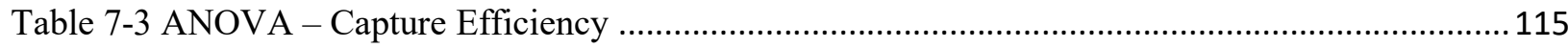

Table 7-4 Effects Test - Capture Efficiency..................................................................................115

Table 7-5 Summary of Fit Breathing Protection Factor.....................................................................117

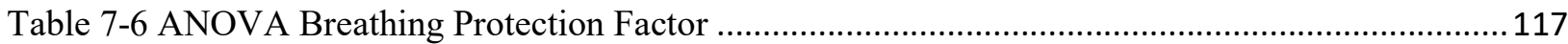

Table 7-7 Breathing Protection Factor Effects Test........................................................................117

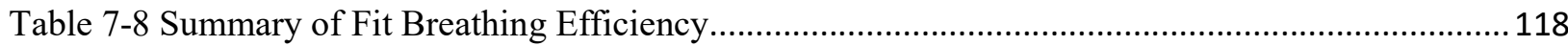

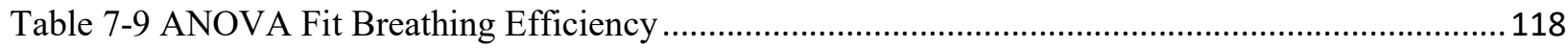

Table 7-10 Breathing Efficiency Effects Tests ................................................................................119 


\section{Nomenclature}

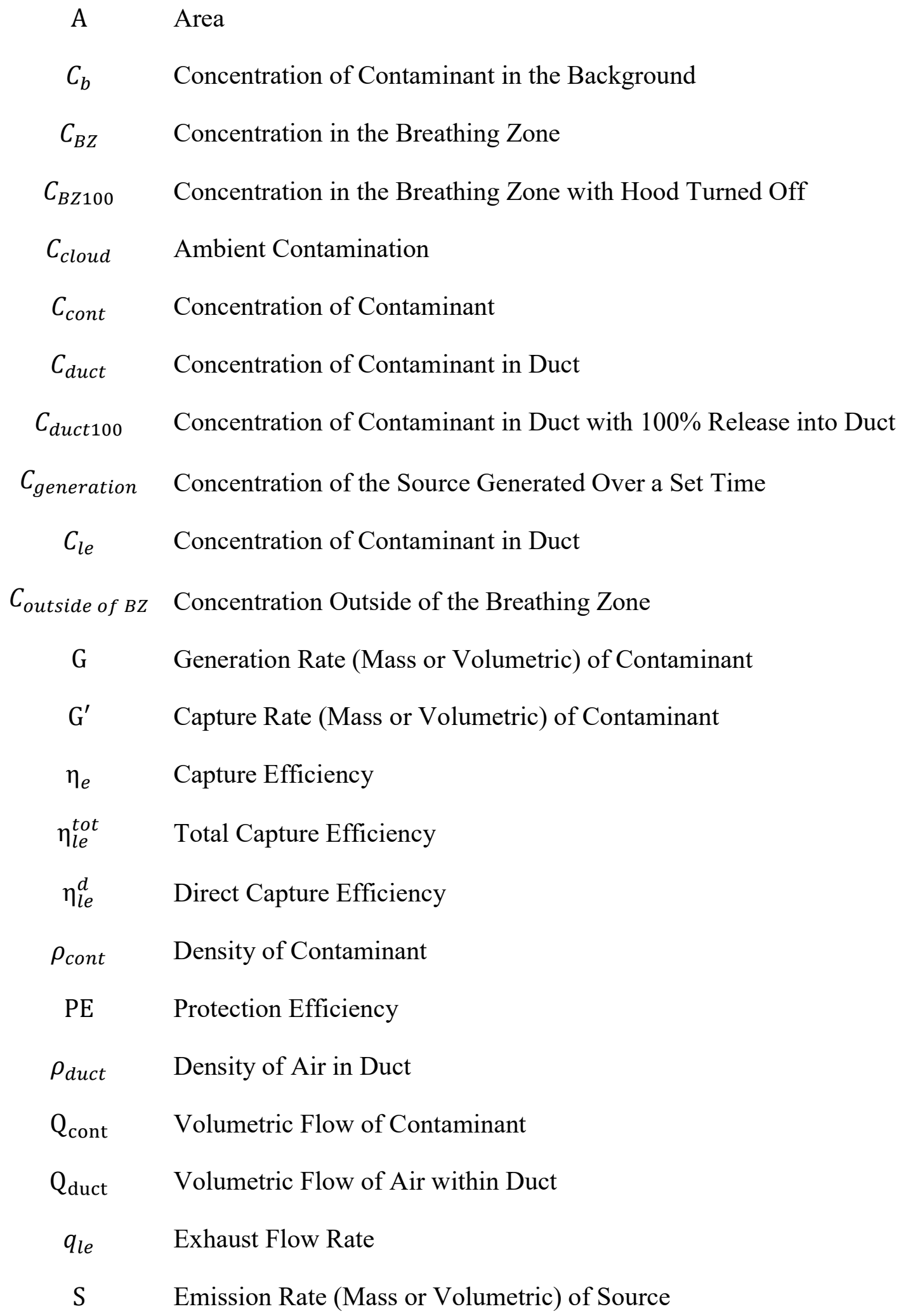




$\begin{array}{cl}S_{i n, l e} & \text { Contaminant Returned After Initially Exiting Control Box } \\ S_{l e} & \text { Capture Rate (Mass or Volumetric) of LEV } \\ S_{s, l e} & \text { Contaminant Directly Captured } \\ \mathrm{V}_{\text {cap }} & \text { Capture Velocity } \\ \mathrm{V}_{\mathrm{draft}} & \text { Crossdraft Velocity } \\ \mathrm{X} & \text { Distance of Furthest Point of Source from Hood Face }\end{array}$




\section{Chapter 1 : Introduction}

\subsection{Background}

Inhalation is the most common and most hazardous route of entry for toxic substances for workers in industry. Whenever elimination and substitution aren't viable options, the next step in the hazard control hierarchy is implementation of engineering controls, of which ventilation is the primary engineering control for airborne contaminants.

ACGIH (2001) considers there to be two primary types of local exhaust ventilation (LEV) hood designs for contaminant control: enclosing and exterior (also called "capturing"). Enclosing hoods (Figure 1-2) enclose the contamination source, reducing the likelihood of operator exposure; laboratory fume hoods are an example of an enclosing hood. Enclosing hoods generally restrict access, and they greatly reduce operator mobility, especially whenever heavy/bulky equipment is necessary. Conversely, exterior hoods (Figure 1-3) are LEV systems in which the contaminant source is located outside of the hood, generally at or near the face.

While both LEV systems are commonly used throughout industry, exterior hoods are more common (Burgess and Murrow, 1976; Ellenbecker, Gampel, and Burgess, 1983). An exterior "capturing" hood will be the primary focus of this study.

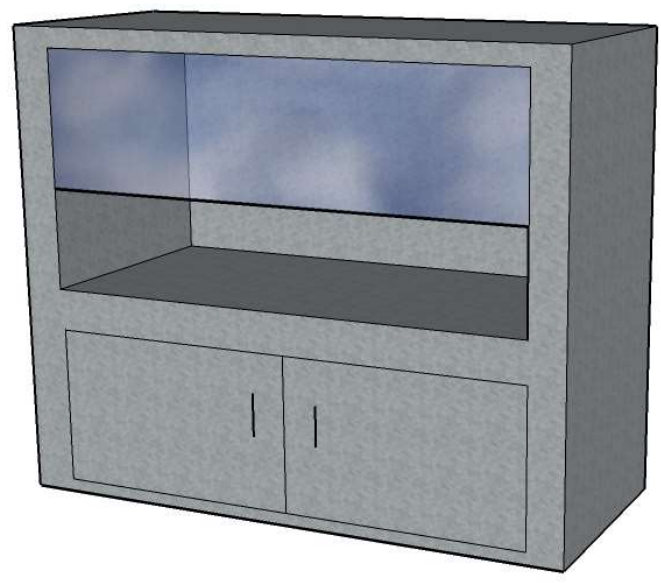

Figure 1-1 Enclosing Hood 


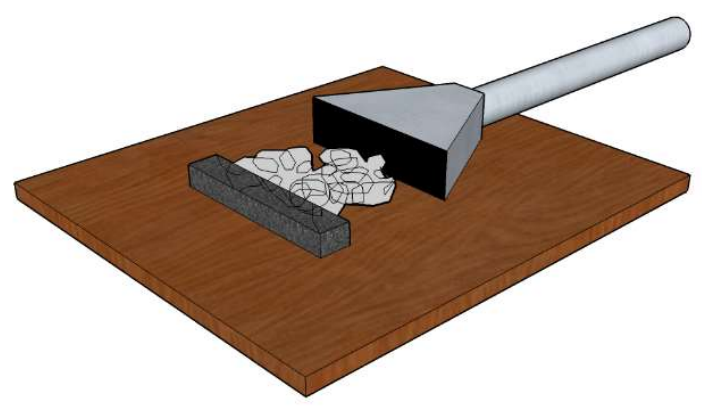

Figure 1-2 Exterior "Capture” Hood

\subsubsection{Capture Velocity}

For capturing hoods, the primary indicator of hood effectiveness is widely assumed to be the "capture velocity" measured normal to the center of the hood face at the furthest location of the contaminant source $(A C G I H, 2001)$. The velocity $\left(V_{x}\right)$ required at this distance is thought to correspond to the flow (Q) required to capture the contaminant. The ACGIH (2001) definition of capture velocity is "the minimum hood-induced air velocity necessary to capture and convey the contaminant into the hood." The appropriate value of $\mathrm{V}_{\mathrm{x}}$ is assumed to change with conditions that are thought to affect its adequacy, such as generation rate of the contaminant $(\mathrm{G})$, contaminant toxicity, hood size, production rate, and disturbing air currents (ACGIH, 2001).

However, as Flynn and Ellenbecker (1986) stated, "As a design parameter, capture velocity is not an adequate measure of how well the hood performs." This may be because capture velocity is a measurement based on qualitative considerations rather than quantitative verification. Additionally, there are far more factors that impact the flow of air than what are commonly considered. Furthermore, the factors thought to affect hood efficacy are likely to change over the course of the hood's lifetime, even potentially hour-to-hour.

The effectiveness of a hood is defined by both its ability to protect the worker (protection efficiency) and by its ability to protect everyone else in the room (capture efficiency). The quantitative relationship between protection efficiency and capture efficiency is unclear. The adequacy of capture velocity as a surrogate for hood effectiveness is poorly understood and has been little studied. The most straight-forward way to determine hood efficacy is by using tracer 
gas tests under the influence of a diverse range of potentially disruptive parameters, such as draft velocity, hood separation distance, and the presence of a worker.

\subsubsection{Capture Efficiency}

In the 1980s, several important quantitative studies of capture hood efficiency were conducted (Ellenbecker, Gampel, and Burgess, 1983; Hampl, 1984; Hampl, 1986; Flynn and Ellenbecker, 1986; Fletcher and Johnson, 1986; Conroy and Ellenbecker, 1989). For each study, a tracer gas was released at some distance in front of the hood face and its capture concentration was measured downstream within the duct. The duct concentration for varying conditions was then compared to a $100 \%$ concentration reference. Complete capture was simulated by releasing the contaminant well inside the hood or by releasing it directly into the duct. The ratio of conditional concentration relative to the complete capture reference is the capture efficiency of the LEV system.

Ellenbecker, Gempel, and Burgess (1983) defined capture efficiency as "the fraction of airborne contaminants generated by a source that is captured by the LEV system controlling it." Hence, capture efficiency $\left(\eta_{\mathrm{e}}\right)$ can be calculated as follows:

$$
\eta_{e}=\frac{G^{\prime}}{G}
$$

Where:

$$
\begin{aligned}
& \mathrm{G}^{\prime}=\text { Capture (mass or volumetric) rate of contaminant } \\
& \mathrm{G}=\text { Generation (mass or volumetric) rate of contaminant }
\end{aligned}
$$

If the concentration is measured as it is metered into the source, $\mathrm{G}$ can be estimated from:

$$
G=\rho_{\text {cont }} Q_{\text {cont }} C_{\text {cont }}
$$

If the concentration is measured after mixing with the hood airflow in the downstream duct $\left(\mathrm{C}_{\text {duct }}\right)$, the density of the mixture will generally have a density negligibly different from air, and $\mathrm{G}$ can be estimated from:

$$
G=\rho_{d u c t} Q_{d u c t} C_{d u c t 100 \%}
$$

Where: 


$$
\mathrm{C}_{\text {duct } 100}=\text { Concentration in duct at } 100 \% \text { capture efficiency }
$$

Likewise, G' can be estimated from:

$$
G^{\prime}=\rho_{d u c t} Q_{d u c t} C_{d u c t}
$$

Where:

$$
\mathrm{C}_{\text {duct }}=\text { Concentration in duct when uncertain all } \mathrm{G} \text { has entered }
$$

Hence, $\eta_{\mathrm{e}}$ can be computed as:

$$
\eta_{e}=\frac{\rho_{d u c t} Q_{d u c t} C_{d u c t}}{G}
$$

If the generation rate is known and can be controlled, the capture efficiency can be computed from:

$$
\eta_{e}=\frac{C_{d u c t}}{C_{d u c t 100 \%}}
$$

The equations above, generally referred to simply as "capturing efficiency" $\left(\eta_{\mathrm{e}}\right)$, are more specifically described as "total capture efficiency" ( $\left.\eta_{l e}^{\text {tot }}\right)$ by Madsen, Breum, and Nielsent (1993). Although essentially the same, they expand upon the components:

$$
\eta_{l e}^{t o t}=\left(\frac{S_{l e}}{S}\right)=\frac{q_{l e} \times c_{l e}}{S}
$$

Where:

$$
\begin{aligned}
\mathrm{S} & =\text { Emission rate (mass or volumetric) of source } \\
\mathrm{S}_{\mathrm{le}} & =\text { Capture rate (mass or volumetric) of LEV } \\
\mathrm{q}_{\mathrm{le}} & =\text { Exhaust flow rate } \\
\mathrm{c}_{\mathrm{le}} & =\text { Concentration in exhaust duct }
\end{aligned}
$$

The key contribution of the Madsen, Breum, and Nielsent (1993) study was to develop a better understanding of Jansson's (1982) theory of "direct capture efficiency" $\left(\eta_{l e}^{d}\right)$ and its difference from total capture efficiency. They defined the direct capturing efficiency by instituting an "imaginary" control box that encloses the generation point of a contaminant and the face of the 
LEV system. Through a series of derivations, factoring in recirculation of contaminant that initially escaped the control box only to return, they formulated an equation as follows:

$$
\eta_{l e}^{d}=\left(\frac{S_{S, l e}}{S}\right)=\frac{S_{l e}-S_{i n, l e}}{S}=\eta_{l e}^{t o t}-\frac{S_{i n, l e}}{S}
$$

Where:

$$
\begin{aligned}
\mathrm{S}_{\mathrm{s}, \mathrm{le}} & =\text { Contaminant directly captured } \\
\mathrm{S}_{\mathrm{in}, \mathrm{le}} & =\text { Contaminant returned after initially exiting control box }
\end{aligned}
$$

While direct capturing efficiency is an attractive theory, it is not a practical quantification method. This is due to the inconsistent nature of air flows and the inability to accurately determine how much contaminant left the capture box and returned. Further complicating this theory is the possibility of contaminant exiting and entering the capture box more than once, due to air disturbances. As the authors noted, despite numerical and experimental methods, "no method to obtain a consistent estimate of direct capture efficiency is achieved in this study." Since the total capture efficiency is only a slight overestimation of direct capture efficiency, total capture efficiency will be used in this study.

Whenever there is a buildup of contamination within the background, the generally preferred method of calculating capture efficiency is the one used by Niemelä, R., Lefevre, A., Muller, J., \& Aubertin, G. (1991):

$$
\eta_{e}=\frac{C_{d u c t}-C_{b}}{C_{d u c t 100 \%}-C_{b}}
$$

Where:

$$
\mathrm{C}_{\mathrm{b}}=\text { Concentration of contaminant in the background }
$$

\subsubsection{Protection Efficiency}

While capture efficiency quantifies the effectiveness of a hood in removing contaminants from the room, another important factor is measuring the effectiveness the hood has on removing contaminants within the operator's breathing zone. This protection factor is often referred to as the protection efficiency (PE). The PE for a capturing hood system can be found by comparing the concentration in the breathing zone $\left(\mathrm{C}_{\mathrm{BZ}}\right)$ over a set time to the concentration outside of the breathing zone ( $\mathrm{C}_{\text {outside of } \mathrm{BZ}}$ ) over this same time period. The PE can be written as follows: 


$$
P E=1-\frac{C_{B Z}}{C_{\text {outside of } B Z}}
$$

The concentration outside of the BZ has been calculated several different ways. Perhaps the most common approach considers the concentration within the duct, but it seems to ignore the remaining ambient contamination $\left(\mathrm{C}_{\text {cloud }}\right)$. Ignoring $\mathrm{C}_{\text {cloud }}$ would underestimate the $\mathrm{PE}$ for all but controlled systems reaching $100 \%$ capture efficiency.

$$
C_{\text {Outside of BZ }}=C_{\text {cloud }}+C_{\text {duct }}
$$

Although experimentally measuring $\mathrm{C}_{\text {cloud }}$ would be impractical, it can be calculated as follows:

$$
\begin{gathered}
C_{\text {generation }}=C_{d u c t 100}=C_{d u c t}+C_{B Z}+C_{\text {cloud }} \\
C_{\text {cloud }}=C_{d u c t 100}-C_{d u c t}-C_{B Z}
\end{gathered}
$$

Where:

$$
\begin{aligned}
\mathrm{C}_{\text {generation }}= & \text { Concentration of the source generated over a set time } \\
\mathrm{C}_{\text {duct100 }}= & \text { Concentration in duct at } 100 \% \text { capture efficiency } \\
\mathrm{C}_{\text {duct }} & \text { Concentration in duct, experimentally recorded }
\end{aligned}
$$

$\mathrm{C}_{\text {duct100, }} \mathrm{C}_{\text {duct, }}$ and $\mathrm{C}_{\mathrm{BZ}}$ can all be measured experimentally, in order to determine the $\mathrm{C}_{\text {cloud. }}$ Equation 1-13 can be rewritten as:

$$
P E=1-\frac{C_{B Z}}{C_{d u c t 100}-C_{B Z}}
$$

An alternative way of determining the relative effectiveness of a hood in controlling breathing concentrations, is to compare $\mathrm{C}_{\mathrm{BZ}}$ with the concentration in the breathing zone when the hood is turned off $\left(\mathrm{C}_{\mathrm{BZ} 100}\right)$. Conceptually, this is like measuring the effectiveness of a respirator. The general idea is to measure the exposure to the contaminant with the control method in place and compare it to the exposure to the contaminant without any controls. This can be written as: 


$$
P E=1-\frac{C_{B Z}}{C_{B Z 100}}
$$

\subsection{Problem Statement}

As Johnson, Fletcher, and Saunders (1996) pointed out, “systems are usually designed and tested without reference to the worker they are intended to protect." Thus, consideration of the effect the presence of the hood operator has on the hood design is not considered. Technicians design exterior hoods based on capture velocity under ideal conditions (ACGIH, 2001). To counter these concerns, this study aimed to test the impacts of realistic environmental factors on the capture efficiency and protection efficiency of an exterior hood. Though several studies (Ljungqvist, 1979; Kim and Flynn, 1992; Johnson, Fletcher, and Saunders, 1996; Welling, Andersson, Rosen, Räisänen, Mielo, Marttinen, and Niemelä, 2000; Welling, Kulmala, Andersson, Rosen, Räisänen, Mielo, Niemelä, 2001; El-Sotouhy, 2008) have shown the presence of human subjects to significantly alter air currents, no other capture efficiency study has included the presence of human subjects. Only one study (Kasberger, 2012) has included a manikin. That study did not consider the effects of the manikin's presence, manikin movements, orientation, and was affected by FTIR equipment failure.

A common hood (see Figure 1-2) described in the Industrial Ventilation manual (ACGIH, 2001) was selected for this study. As is appropriate for this specific design, the following equation was used to determine the required exhaust flow rate for this rectangular exterior hood when located on a workbench. The equation was used as an initial approximation, before being validated in a controlled environment with an anemometer.

$$
Q=V\left(5 X^{2}+A\right)
$$

Where:

$$
\begin{aligned}
& \mathrm{Q}=\text { Required exhaust flow rate }(\mathrm{cfm}) \\
& \mathrm{V}=\text { Capture velocity at } \mathrm{X}(\mathrm{fpm}) \\
& \mathrm{A}=\text { Hood face area (Length } \mathrm{X} \text { Width) } \\
& \mathrm{X}=\text { Distance of furthest point of source from hood face }(\mathrm{ft})
\end{aligned}
$$




\subsection{Hypothesis}

The main study was full factorial involving four factors: $V_{\text {cap }}, V_{\text {draft, }}$ orientation, and operator presence. These four factors had three, four, three, and two levels, respectively. The tests were randomized over two replications, resulting in 144 total treatments. Table 1-1 illustrates the levels of factors in the main study.

Table 1-1 Main Study Design

\begin{tabular}{cccc}
\hline $\mathrm{V}_{\text {cap }}(\mathrm{fpm})$ & $\mathrm{V}_{\text {draft }}(\mathrm{fpm})$ & Orientation $\left(^{\circ}\right)$ & $\begin{array}{c}\text { Operator } \\
\text { Present }\end{array}$ \\
\hline 50 & 0 & 0 & Yes \\
100 & 30 & 90 & No \\
200 & 60 & 180 & \\
& 120 & & \\
\hline
\end{tabular}

The null hypothesis is that the capture efficiency and protection efficiency are not affected by the capture velocity $\left(\mathrm{V}_{\text {cap }}\right)$, draft velocity $\left(\mathrm{V}_{\text {draft }}\right)$, the hood orientation, operator presence, or interactions between these factors. The alternative hypothesis is that the capture efficiency and protection efficiency are affected by at least one of the independent variables mentioned or the interactions between them.

Hypothesis model:

$$
\begin{gathered}
Y=\mu+\alpha_{i}+\beta_{j}+\gamma_{k}+\delta_{l}+\alpha \beta_{i j}+\alpha \gamma_{i k}+\alpha \delta_{i l}+\beta \gamma_{j k}+\beta \delta_{j l}+\gamma \delta_{k l}+\alpha \beta \gamma_{i j k} \\
+\alpha \beta \delta_{i j l}+\beta \gamma \delta_{j k l}+\alpha \beta \gamma \delta_{i j k l}+\varepsilon_{i j k l}
\end{gathered}
$$

Where:

$$
\begin{aligned}
\mu & =\text { Parametric mean } \\
\alpha & =\text { Effect of } \mathrm{V}_{\text {cap }} \\
\beta & =\text { Effect of } \mathrm{V}_{\text {draft }} \\
\gamma & =\text { Effect of orientation } \\
\delta & =\text { Effect of operator presence } \\
\alpha \beta & =\text { Effect of interaction between } \mathrm{V}_{\text {cap }} \text { and } \mathrm{V}_{\text {draft }} \\
\alpha \gamma & =\text { Effect of interaction between } \mathrm{V}_{\text {cap }} \text { and orientation } \\
\alpha \delta & =\text { Effect or interaction between } \mathrm{V}_{\text {cap }} \text { and operator presence } \\
\beta \gamma & =\text { Effect of interaction between } \mathrm{V}_{\text {draft }} \text { and orientation } \\
\beta \delta & =\text { Effect of interaction between } \mathrm{V}_{\text {draft }} \text { and operator presence }
\end{aligned}
$$


$\gamma \delta=$ Effect of interaction between orientation and operator presence

$\alpha \beta \gamma=$ Effect of interaction between $V_{\text {cap }}, V_{\text {draft, }}$, and orientation

$\alpha \beta \delta=$ Effect of interaction between $V_{\text {cap }}, V_{\text {draft, }}$, and operator presence

$\beta \gamma \delta=$ Effect of interaction between $V_{\text {draft, }}$, orientation, and operator presence

$\alpha \beta \gamma \delta=$ Effect of interaction between all factors

$\varepsilon=$ Unexpected deviation from parametric mean ("error")

\subsection{Research Objectives}

This study had the following objectives:

1. Experimentally investigate the effects of $\mathrm{V}_{\text {cap }}, \mathrm{V}_{\text {draft, }}$, orientation, and operator presence on the capture efficiency and protection efficiency of a small rectangular capturing hood

2. Experimentally investigate the effects of operator movement on the capture efficiency and protection efficiency of a small rectangular capturing hood

3. Experimentally investigate the differences in capture efficiency and protection efficiency responses between tracer gas method and aerosol tracing with a condensation particle counter (CPC)

4. Experimentally investigate the effects of $\mathrm{V}_{\text {cap }}, \mathrm{V}_{\text {draft, }}$ orientation, and operator presence on the centerline velocity and capture envelope using particle imaging velocimetry (PIV)

5. Experimentally investigate the association between capture velocity and the capture and protection efficiencies 


\section{Chapter 2 : Literature Review}

\subsection{Centerline Velocity}

The first design parameters for exterior hoods were based on the pioneering work of DallaValle (1930). Using a wide array of capturing hoods, he mapped the velocity contours and streamlines for the entire exterior flow field of each unit. Based on his experiments, he developed unique models for each setup, primarily at the centerline, normal to the hood face. The equations associated with each setup developed a similar trailing velocity curve, showing a continuous velocity drop as measurements were taken further and further away from the face of the hood. DallaValle's work spurred the introduction of several other models (Silverman, 1942; DallaValle, 1952; Fletcher, 1977; Fletcher, 1978; Garrison, 1981; Flynn and Ellenbecker, 1985; Flynn and Ellenbecker, 1986; Flynn and Ellenbecker, 1987; Conroy, Ellenbecker, and Flynn, 1988), involving more capturing systems and the utilization of more and more advanced velocity measurement technology.

Aside from DallaValle's (1930; 1952) contributions, perhaps the most widely accepted models were developed by Fletcher (1977) and Garrison (1981). Focusing primarily on unflanged hoods, Fletcher (1977) found that previously developed centerline velocity equations failed to appropriately model hoods of all aspect ratios, and thus he incorporated them within his models. Similarly, Garrison (1981) developed empirical formulas for centerline velocity, while factoring in hood dimensions for both flanged and unflanged hoods. All of the aforementioned models were developed and tested under ideal, controlled conditions.

While centerline capture velocity is the primary mode of design for exterior hoods listed in the Industrial Ventilation manual (ACGIH, 2001), it is only discussed very briefly within the text. In fact, there are only two paragraphs discussing the concept of capture velocity, a table that assists with determining the appropriate capture velocity required in controlling a contaminant under various conditions, and a series of equations that assist the designer in determining what hood flow is required to meet the appropriate capture velocity for their respective type of hood. The table that lists the minimum control velocities is drawn from the Local Exhaust Ventilation Hood Design chapter from Brandt's (1947) Industrial Health Engineering text, is 70 years old. 
Table 2-1 is recreation of the minimum control velocity table, as found within the Industrial Ventilation manual (ACGIH, 2001). There are four capture velocity ranges, within the table, that are to be selected by the designer based on the contaminant generation velocity and the magnitude of ambient air disturbances. The problem with this technique is that there is a great deal of subjectivity in the wording. For example, whenever the contamination is "released at low velocity into moderately still air", a capture velocity of 100-200 fpm is required. This is a significantly large range. The only assistance of when it is wise to choose the lower end versus the upper end, for these set of conditions, is knowing whether or not the contaminant is toxic or not. While $200 \mathrm{fpm}$ is the safer decision, in this specific scenario, it may not be the most efficient. If $100 \mathrm{fpm}$ is sufficient to reduce the contaminant below permissible exposure levels, then running the fan high enough to produce $200 \mathrm{fpm}$ at significant distances from the hood face would greatly impact energy costs.

There are several other issues with using this system to design an exterior hood system. This technique assumes the contaminant source will always be the same, that the generation rate of the source will always be the same, that drafts present at the time of the initial design will be consistent throughout its lifetime, and that the operator knows where to place the contamination source relative to the hood. This approach also fails to factor in the potential effects of a worker's presence, specifically in settings with higher ambient air movement. Additionally, as Burgess, Ellenbecker, and Treitman (2004) note, there are conditions, such as high velocity generation in low motion air and low velocity generation in rapid motion air, that aren't even covered within this technique. 
Condition of Dispersion of Contamination
Capture

Example
Velocity

(fpm)
Released with practically no velocity into quiet air

Released at low velocity into moderately still air

Active generation into zone of rapid air motion
Evaporation from tanks; degreasing, etc.

50-100

Spray booths; intermittent container

filling; low speed conveyor transfers;

welding; plating; pickling

Spray painting in shallow booths; barrel

filling; conveyor loading; crushers

Released at high initial velocity into zone at very rapid air

Grinding; abrasive blasting; tumbling 500-2000 motion

In each category above, a range of capture velocity is shown. The proper choice of values depends on several factors:

\section{Lower End of Range}

1. Room air currents minimal or favorable to capture

2. Contaminants of low toxicity or of nuisance value only

3. Intermittent, low production

4. Large hood-large air mass in motion

Source: Industrial Ventilation (ACGIH, 2001).

\section{Upper End of Range}

1. Disturbing room air currents

2. Contaminants of high toxicity

3. High production, heavy use

4. Small hood local control only 


\subsection{Capture Efficiency}

Ellenbecker, Gempel, and Burgess (1983) were the first to develop a system to measure capture efficiency specifically for exterior hoods. Along with their methods and theoretical contributions, they carried out a series of preliminary studies in both laboratory and industrial settings. Due to the impracticality of sampling all of mineral oil tracer within the duct, they placed the source within the exhaust hood as close as possible to the duct; they used this reference as a calibration for $100 \%$ capture. All other tests were compared to this reference as means of determining the efficiency under varying conditions. During their laboratory tests, the primary variables tested were the distance (x) of the source from the face of the hood and the face velocity. In order to account for various hood areas, the normalized separation distance $(\mathrm{x} / \sqrt{ } \mathrm{A})$ was used. They found that the capture efficiency decreased the further the source was separated from the hood face, regardless of the face velocity. Also, as expected, they found a reduction in efficiency as the face velocity decreased. The industrial setting portion of the study verified their laboratory studies. In addition to the conditions tested in the laboratory, they also tested the impacts of cross drafts caused by a cooling fan that was regularly used during the summer in their lab. They found a sharp reduction in capture efficiency, whenever the cooling fan was on. Specifically, the hood operated at $90 \%$ capture efficiency even when the source was up to one meter away from the face of the hood, whenever the fan was off versus $40 \%$ capture efficiency, whenever the fan was on. None of the studies included human subjects or manikins.

Fletcher and Johnson (1986) conducted capturing efficiency tests on various exterior hoods, focusing primarily on the correlation with capturing velocity. They found that as the contaminant source was pulled further away from the hood, the capturing efficiency dropped; this was provided that the source was not directed away from the hood and emitted at a low flow. They also found that the capturing efficiency decreased as the hood face length-to-width aspect ratio increased. This study did not consider cross drafts, human or manikin presence, or various other realistic factors. Cross drafts, for example, have been found to be the primary factor in capturing efficiency determination in other studies (Woods and McKarns, 1995). Note that Fletcher and Johnson (1986) also used undiluted dichlorodifluoromethane (R-12), which is significantly heavier than air. 
Flynn and Ellenbecker (1986) developed a computer model to predict the capture efficiency of flanged circular exterior hoods in the presence of cross drafts normal to the face of the hood. Later, they compared experimental values with the theoretical models. Sulfur hexafluoride $\left(\mathrm{SF}_{6}\right)$ was the tracer gas used and the variables adjusted included varying cross drafts, hood flows, hood dimensions, and source separation from the face of the hood, to determine the critical distance for capture of the contaminant. They determined the capture efficiency by comparing the concentration of the tracer gas in the duct under the various conditions to the concentration of the tracer gas in the duct whenever the source was held directly at the face of the hood. The capture efficiency was simply the ratio of the concentration of the test sample to the full capture concentration. They found capture efficiency to be highly related to the separation distance of the source from the face, hood flow rate, and the cross drafts. However, their experimental air flows (35-140 cfm) were quite low for sources extending beyond a couple inches from the hood face. They extended the source up to 5.5" from the hood face. The $\mathrm{SF}_{6}$ was undiluted, and thus was significantly heavier than air.

Conroy and Ellenbecker (1989) developed a model that predicted the dividing velocity streamline in front of a flanged slot hood in the presence of a uniform cross draft. Their model predicted $100 \%$ capturing efficiency, in the absence of cross drafts. However, they noted the unrealistic nature of this setup. They found that the capturing efficiency decreased significantly, as the cross draft velocity increased; this was especially true for lower face velocities. The most efficient setup they discovered for a 15 " by 1.5 " slot hood, factoring in cross drafts, was with a face velocity of 3,000 fpm and a slight cross draft of $20 \mathrm{fpm}$. This yielded an efficiency of $97 \%$. They found that even with the same high face velocity, a higher cross draft (200 fpm) reduced the efficiency of the same hood to $67 \%$. They continued on to use their model to illustrate the impacts of cross drafts on capturing efficiency on state-of-the-art designs. They used the ventilation design manual to determine the maximum air flow $\left(250 \mathrm{cfm} / \mathrm{ft}^{2}\right)$ suggested for their specific hood. After adjusting their parameters to meet the suggested air flow, they subjected the hood to varying cross drafts. While the capturing efficiency remained reasonably high (91\%) with a moderate cross draft (50 fpm), the efficiency of a supposed maximum flow slot hood dropped to $61 \%$ in the presence of very high $(200 \mathrm{fpm})$ cross drafts. They modeled the higher cost efficiency rated $\left(150 \mathrm{cfm} / \mathrm{ft}^{\wedge} 2\right)$ design, using the same set of parameters and found a drop from $84 \%$ to $48 \%$ capture efficiency. Depending on the contaminant, $84-91 \%$ efficient may not 
be adequate, but regardless of source, 48-61\% capturing efficiency is unacceptable. It should be noted that while $200 \mathrm{fpm}$ is fairly uncommon in enclosed work areas, it is not unusual for work environments with open exterior doors to meet or exceed this value (Baldwin and Maynard, 1998). In order to validate their model, Conroy and Ellenbecker (1989) conducted tracer gas experiments in a wind tunnel. Neither their model nor wind tunnel studies considered the effects of human workers or even a bluff body to alter the currents.

Kasberger (2012) conducted a study on the capture efficiency of a flanged and unflanged rectangular capturing hood. He used a heated manikin that breathed and oriented it so cross draft flows were directed towards the manikin's back and towards the hood face. He varied the fan frequency to obtain capture velocities 11 " away from the hood face of 40, 100, and $140 \mathrm{fpm}$. He carried out these studies in the presence of drafts of 10 and $60 \mathrm{fpm}$. He found that the system was highly effective for all cases tested. However, there were several issues with his study. He found that the capture efficiency for the hood in the vast majority of his setups to be greater than $100 \%$ efficient, which is impossible. Also, while his Freon 134-a tracer gas was diluted with helium, his mixture was not neutrally buoyant within air. Additionally, the FTIR system used to analyze his samples was unreliable, at the time of his study. The cross draft velocities in his study were also quite low. The manikin was stationary in all of his studies.

To the author's knowledge, no capture efficiency studies have been conducted on exterior hoods whenever considering the effects of operator presence, let alone disruptive air currents associated with operator movement. Kasberger's (2012) study is the only known study on exterior hoods to even consider the presence of any bluff body, and his study did not consider the

effects of the operator, the orientation of the hood, or movements of the worker. Additionally, his study had several noted equipment failure issues causing erratic, greater than $100 \%$ efficiency results.

\subsection{Cross Drafts}

The Industrial Ventilation manual (ACGIH, 2001) states that "Important sources of air motion are (1) Thermal air currents, especially from hot processes or heat-generating operations. (2) Motion of machinery, as by a grinding wheel, belt conveyor, etc. (3) Material motion, as in dumping or container filling. (4) Movements of the operator. (5) Room air currents (which are 
usually taken at $50 \mathrm{fpm}$ minimum and may be much higher). (6) Rapid air movement caused by spot cooling and heating equipment." Kim and Flynn (1992) further stated that "Air currents are introduced by (1) wakes around the worker's body, workpiece, tools, and work table; (2) drafts from air condition, make up air, local pedestal fans, or heaters; and (3) various characteristics of the contaminant source." It stands to reason that such currents could be disruptive to ventilation systems, especially the more turbulent the flow.

The effects cross drafts on the capture efficiency of exterior hoods were previously mentioned (Ellenbecker, Gempel, and Burgess, 1983; Flynn and Ellenbecker, 1986; Conroy and Ellenbecker, 1989). However, all of these studies tested only the impacts of drafts normal to the face of the hood without the presence of human subjects or manikins. Of the six important sources of air motion listed within the Industrial Ventilation manual, only two were considered amongst these studies. The interaction of multiple air motions is probable in industrial settings.

Kim and Flynn (1991) used flow visualization and hot-film anemometry to show and measure the air flow patterns around a manikin. The key finding of the study was that the wake zones around the manikin were not uniform. The wake zone around the torso extended much further downstream than the wake zone around the head. The net flow above the chest was a downwash; from the torso, downwash and vortex shedding were both found; and below the torso, vortex shedding was primarily observed. A reasonable conjecture would be that a contamination source could easily mix between the wake zones and end up within the worker's breathing zone. This was supported by Guffey and Barnea (1994) and later by Tseng, Huang, Chen, and Chang (2006) and Tielemans, Schneider, Goede, Tischer, Warren, Kromhout, and Cherrie. (2008). Guffey and Barnea (1994) found, using a tracer gas, that contaminant concentrations in the breathing zone were higher with the presence of a manikin than samples taken in the same locations without the presence of a manikin.

Welling, et. al. (2001) measured the reverse flow region created in front of a human subject in a free stream system with cross drafts of $0.1,0.3$, and $0.5 \mathrm{~m} / \mathrm{s}$ directed at the subject's back. A point source contaminant was placed on a table in front of the human subject and concentrations were measured at the nose. As expected, the length of the reverse flow region was shortest at 0.1 
$\mathrm{m} / \mathrm{s}$ and increased in length as the cross draft was increased to $0.5 \mathrm{~m} / \mathrm{s}$. The reverse flow region ranged from 0.5-1.4 meters. The experimental results closely matched their numerical model.

Guffey, Flanagan, and Belle (2001) studied the effects of operator orientation within the presence of cross drafts in a free stream system. A manikin holding an undiluted $\mathrm{SF}_{6}$ source, emitting at $0.1 \mathrm{l} / \mathrm{min}$, six inches away from its body was subjected to cross drafts of $10,22,47$, and $80 \mathrm{fpm}$ at its front, back, and side. Contaminant concentrations at the chest were found to be consistently higher than they were at the nose, regardless of manikin orientation. Whenever the manikin's back faced the draft, chest concentrations were 2.9 times the concentrations of the nose. Concentrations were always the highest, whenever the flow was directed towards the manikin's back. This was especially true as the wind velocity increased. For example, the concentrations at the nose were found to be $1.2,4.4,73$, and $136 \mathrm{ppm}$ with cross drafts of 0.05 , $0.11,0.24$, and $0.41 \mathrm{~m} / \mathrm{s}$, respectively. However, as previously mentioned, $\mathrm{SF}_{6}$ is considerably heavier than air; this could have had a potential impact on how much contaminant reached the nose. In a similar study, comparing a human subject with an unheated manikin, Welling, et. al. (2000) also found concentrations to be the highest, whenever the flow was directed towards the back of study subject.

Huang, Chen, Chen, Chen, Yeh, and Chen (2001) used a laser Doppler anemometer to measure the streamline patterns of a circular hood in various cross draft velocities. With the laser, they were able to visualize the dividing streamline that encloses the capturing envelope. Additionally, they were able to visualize all streamlines within the envelope entering the hood. The physical properties of the envelope were found to be primarily dependent on the ratio between the cross draft velocity and the hood suction velocity. Essentially, as the cross draft velocity increased, the capturing envelope was reduced, provided the suction velocity was unchanged. Conversely, as the hood suction rate was increased, the capturing envelope size increased, provided the cross draft velocity remained constant. This general concept certainly wasn't new (Fletcher and Johnson, 1986), but the Doppler anemometer provided data to develop equations to help approximate the dividing streamline. Velocity ratios (Vcross/Vsuction) between 0.05 and 0.4 were tested, and they found that similar ratios, regardless of scale, resulted in roughly the same capturing envelopes. This study did not include human subjects or manikins. 
In an effort to isolate background air movements within industrial and commercial settings, Baldwin and Maynard (1998) conducted a survey of drafts in various indoor workplaces. They found an overall average ambient indoor velocity of $0.3 \mathrm{~m} / \mathrm{s}$, skewed greatly to the right. However, it is important to note that a large portion of their surveys were conducted in workplaces unlikely to require and thus contain ventilation systems. Although highly inconsistent, the locations more likely to house ventilation systems and competing currents often averaged flows exceeding $0.3 \mathrm{~m} / \mathrm{s}$. For this study, steady-state drafts of 30, 60, and $120 \mathrm{fpm}$ (approximately $0.15,0.3$, and $0.6 \mathrm{~m} / \mathrm{s}$ ) were used to best mimic the bulk range of industrial work conditions.

\subsection{Sampling Location}

While capture efficiency is a good quantitative approach to determining how effective the LEV unit is at exhausting the contaminant, it is also important to know specifically how much of the contaminant leakage enters the operator's breathing zone (ie., the protection efficiency - PE). OSHA (1999) defines the breathing zone as "a hemisphere forward of the shoulders within a radius of approximately six to nine inches." Six to nine inches away from the breathing zone includes, of course, the nose and mouth, but it also includes the shoulders, upper chest, and the rest of the face. If this definition is valid, samples taken at a worker's collar, lapel, or upper chest would be representative of those taken at the nose or mouth. However, this has consistently been proven not to be true (Donaldson and Stringer, 1980; Cohen, Chang, Harley, and Lippmann, 1982; Malek, Daisy, and Cohen, 1999). In fact, studies that have sampled from all previously mentioned locations (Elnahas, 2005; El-Sotouhy, 2008) have found great variation amongst each location. To best avoid unrepresentative results, for this study samples were taken directly on the face, between the mouth and nose.

\subsection{Anthropometry}

Several studies (Cohen, et. al., 1982; Malek, et. al., 1999) have found that samples taken at the chest yielded significantly higher concentrations of contaminant than found when sampling at the nose. Elnahas, 2005 also found much (100\%) higher concentrations in samples taken at the chest than samples taken at the nose, for a standing heated manikin. Conversely, whenever the manikin was seated, he found (50\%) higher concentrations at the nose than at the chest. 
However, in El-Sotouhy's (2008) replicated study using human subjects, he found higher concentrations at the chest, regardless of posture. Lastly, Chatterjee, Williams, Walford, and King (1969) found, when sampling for lead at two locations on the chest of a worker in a battery factory, that the sample location five inches higher on the chest yielded $22 \%$ less lead than the lower location.

It seems reasonable to think, if contaminant concentrations are consistently higher below the shoulders, those who are shorter in stature may potentially be more exposed, whenever using the same system. Military standard 1472G 4.4.4 (MIL-STD-1472G 4.4.4, 2012) states "Equipment, systems, and subsystems shall be designed to accommodate the central 90 percent of the anticipated user population." This seems to be a consistently overlooked aspect of design, within ventilation engineering.

In 2012 the CDC (Fryar, Gu, and Ogden) measured the anthropometry of a highly diverse group of men $(n=5647)$ and women $(n=5971)$ ages 20 and older. The $50^{\text {th }}$ percentile in stature for men 20 years and older was 5' 9.3 '. Whenever factoring in just men ages $20-59(3,715)$, the average was 5 '9.55." The $50^{\text {th }}$ percentile in stature for women 20 years and older was 5'3.8'. Whenever factoring in just women ages 20-59 $(\mathrm{n}=3942)$, the average was 5'4.1." It is reasonable to use these approximations to model the workforce found within various industries throughout the United States. The mean stature of the $5^{\text {th }}, 50^{\text {th }}$, and $95^{\text {th }}$ percentiles for men and women are located in Table 2-2. The manikin was adjusted to 5' 6" to reflect the approximate net mean of the heights of all men and women.

Table 2-2 Average Stature of Men and Women in the US by Percentile

\begin{tabular}{ccc} 
Percentile & Men & Women \\
\hline $5^{\text {th }}$ & $5^{\prime} 4.3^{\prime \prime}$ & $4^{\prime} 11.3^{\prime \prime}$ \\
$50^{\text {th }}$ & $5^{\prime} 9.3^{\prime \prime}$ & $5^{\prime} 3.8^{\prime \prime}$ \\
$95^{\text {th }}$ & $6^{\prime} 2.1^{\prime \prime}$ & $5^{\prime} 8.4^{\prime \prime}$
\end{tabular}

Source: CDC (Fryar, et. al., 2012) 


\subsection{Manikin Studies Compared to Human Subjects}

Fletcher and Johnson (1989) compared tracer gas concentrations in the breathing zones of an unheated, non-breathing manikin to that of a human subject seated at a work station bench in front of an LEV hood. They found that the concentrations in the breathing zone of the manikin were negligible in comparison to those found for the human subject. They theorized this was likely due to thermal effects of the body, rather than flow reversal. In order to test their theory of the thermal effects on contaminant dispersion, Johnson, Fletcher, and Saunders (1996) analyzed various features of manikins, including two-dimensional versus three-dimensional, heated versus non-heated, and breathing versus non-breathing, in the present of a low-speed draft. The manikin studies were then compared to the presence of the low-speed draft around a human subject. They found that only a three-dimensional heated manikin was a reasonable surrogate for a human subject; this included the unheated breathing manikin. They concluded that the inclusion of breathing, even with the presence of heat, provided unrealistic flow patterns, whenever compared to a human subject. They concluded that the effects of expiration were negligible because the exhalation did not break the thermal boundary layer. The thermal boundary layer was found to move upward at a flow of $0.2 \mathrm{~m} / \mathrm{s}$.

Heist (2003) and Elnahas (2005) also found significant effects of heat on the flow patterns of air, especially at lower velocity ranges. In contrast to the Johnson, Fletcher, and Saunders (1996) study, Elnahas (2005) did find a significant effect of breathing on flow patterns, with inclusion of thermal effects. He also found posture to be an important factor, when comparing the contaminant concentration found within the breathing zone. His study was verified using human subjects in a later study (El-Sotouhy, 2008). The importance of factoring in posture was also found to be significant in a prior study (Brohus, 1997).

The only consistent finding amongst manikin studies seems to be that the thermal effects of the human body are quite significant on air flow patterns immediately located around the body. There seems to be some disagreement on whether breathing simulation significantly effects flow patterns Elnahas (2005) or not Johnson, Fletcher, and Saunders (1996). It is impossible to fully mimic all of the variables of the presence of an actual human, so it was decided to work with a heated, breathing, and moving anatomically correct manikin representing the net mean of the heights of all men and women in the US (Fryar, Gu, and Ogden, 2012). 


\subsection{Body Movement}

There are very few studies that consider the effects of worker movement (Ljungqvist, 1979; Kim and Flynn, 1992; Welling et. al., 2000; Welling et. al, 2001; Guffey et. al., 2001). Ljungqvist (1979) took pictures of a human subject with their back facing a uniform flow of 0.2$0.25 \mathrm{~m} / \mathrm{s}$. The pictures show a reverse flow formed in front of the subject that could potentially result in drawing the contaminant within the breathing zone. Conversely, Kim and Flynn (1992) reported a reduction in breathing zone concentration when factoring in a worker's motion; however, data within their full factorial study shows no consistent impact, neither in increase or reduction, on breathing zone concentrations.

Welling, et. al. (2000) considered the effects of arm movements and body heat, with a human subject and an unheated manikin subjected to drafts of $0.1,0.3$, and $0.5 \mathrm{~m} / \mathrm{s}$ directed towards their back. Concentrations were found to be higher for the human subject with arm movements versus a stationary stance; however, this was not found to be significant.

Contaminant concentrations at the nose of the human subject were found to be higher than that of the manikin. Again, this was not found to significant. It should be noted that the methodology for testing the impacts of arm movement involved symmetrical arm-waving motions unrealistic in worker simulation.

In addition to the cross draft portion of the Welling, et. al. (2001) study, previously mentioned, they measured the impacts of human movement on the reverse flow region. The subjects were in free stream systems with drafts ranging from 0.1 to $0.5 \mathrm{~m} / \mathrm{s}$. Whenever the subject was stationary, the wake zones extended from 0.4 to 1.4 meters, as the drafts increased. Whenever the subject moved their arms, the wake zones extended from 0.5 to 1.2 meters, at the same draft intervals.

Guffey, et. al. (2001) studied the effects of worker motion in a free stream using a $60 \%$ sized anthropometrically correct manikin with its back facing the free stream draft. They rotated the manikin through an 80 degree arc at slow and fast motions and compared the contaminant concentrations obtained at the chest, nose, and ear under these conditions to the concentrations obtained when the manikin didn't move at all. They found that the concentrations at the nose and ear significantly dropped as the manikin moved faster, while concentrations at the chest 
essentially remained the same, under most of the tested conditions. They hypothesized that this was due to the nose and ears periodically exiting the wake zone. However, a clear increase in concentration in the nose (no movement: $125 \mathrm{ppm}$, slow: $127 \mathrm{ppm}$, fast: $159 \mathrm{ppm}$ ) and ear (no movement: $54 \mathrm{ppm}$, slow: $86 \mathrm{ppm}$, and fast: $110 \mathrm{ppm}$ ) can be seen, with a $0.41 \mathrm{~m} / \mathrm{s}$ cross-draft, a condition not uncommon within industry. It should also be noted that the manikin was not heated, did not breathe, and was of uncommon stature. Additionally, the tracer gas used was much heavier than air. It is possible that any or all of these components may have had a skewed impact on the results.

\subsection{Tracer Gas}

Hampl (1986) stated that "measurement of the total contaminant generation rate or the hood escape rate is extremely difficult or even impossible without a complete enclosure of the process area." Other issues arise with the potential accumulation of hazardous materials. As Hampl (1984) indicated, cross contamination of samples is also quite possible. This is why the tracer gas technique is so useful. It helps fully monitor single source issues, even in a multi-source environment, from the point of accumulation to exhaust. However, it is likely this technique is limited to evaluating only the effectiveness of systems with gas, fume, vapor, or fine particle generation (Hampl, 1984).

Hitchin and Wilson (1967) suggested that in order for a tracer gas to be effective, it must be reasonably neutrally buoyant in air and hold similar diffusive properties. Additionally, they stated that it is important that the tracer gas should be absent from ambient conditions, nonreactive to the environment, and easily identifiable even at low concentrations. They also stressed the human factors and safety elements of the gas, noting that it shouldn't be toxic, explosive, or pungent. Hampl (1984) further suggests that the tracer be dispersed similar to the contaminant in which it is modeling.

Niemelä et. al., (1991) compared the mean residence time of three tracer gases, $\mathrm{SF}_{6}$ (specific gravity $=5.1$, nitrous oxide $(1.53)$, and helium $(0.14)$, in a $31 \mathrm{~m}^{3}$ test room, and they calculated the capture efficiency of a rectangular exterior hood. They found similar residence results amongst the tracer gases, especially $\mathrm{SF}_{6}$ and nitrous oxide. However, noticeable differences were found between the heavy $\mathrm{SF}_{6}$ and light helium. They suggested the stagnant zone near the tracer 
release as a possible explanation for the difference. $\mathrm{SF}_{6}$ was captured at a slightly $(10 \%)$ lower rate than the other gases, but increasing the generation rate negated any difference.

An example of possible effects of using a non-neutrally buoyant tracer gas can be referenced in the study of Guffey et. al. (2001). Using undiluted $\mathrm{SF}_{6}$ as a tracer gas, they consistently found higher concentrations at the chest than within the breathing zone, regardless of system configuration. It is important to note that the generation rate of the tracer gas was quite low. Their results, indicating a lingering effect, were similar to the low momentum $\mathrm{SF}_{6}$ release results in the Niemelä et. al., (1991) study.

Kim and Flynn (1992) conducted a tracer gas study with an unheated and non-breathing manikin inside of a paint booth. Using a mixture of $\mathrm{SF}_{6}$ and helium, they tested the effect generation momentum has on contaminant concentration at the mouth. They found that as they increased the generation rate, the concentration of the tracer gas at the mouth reduced. As expected, they also found reductions as distance was increased between the subject and the source.

For this setup, a neutrally buoyant tracer mixture of helium and Freon 134a was used. The generation momentum was moderately low.

\subsection{Aerosol Tracer Method}

Hampl (1984) theorized that it is likely that the tracer gas technique is limited to evaluating only the effectiveness of systems with gas, fume, vapor, or fine particle generation. Few studies have considered aerosol tracers as a method for determining hood effectiveness (Bemer et. al., 1998; Dunn et. al, 2014).

Bemer et. al. (1998) conducted an experiment comparing the tracer gas method with the aerosol tracer method. They released helium diluted in air as well as aerosols varying in particle size inside of a $30 \mathrm{~m}^{3}$ ventilated cabinet, in front of a $20 \mathrm{~cm} \mathrm{X} 20 \mathrm{~cm}$ opening. They found similar results between the methods whenever the aerosol particle diameters were less than 30 micrometers, the particles were emitted slowly, and the capture was direct with short transferring periods to the capturing system. This study did not consider the effects of cross drafts, the effects 
of varying hood fan rates, the effects of orientation, or the effects of operator presence. In short, this study only considered ideal conditions.

Dunn et. al. (2014) compared the leakage of a chemical fume hood using tracer gas, tracer nanoparticle, and nanopowder methods. Contaminants were released inside the hood and measurements were conducted in a manikin's breathing zone and across the face of the hood. The tests were conducted with average hood face velocities of 60,80 , and $100 \mathrm{fpm}$. The tracer and nanoparticle methods had significant leaks across the left side of the hood, the side closest to the room's air supply. Nevertheless, these two methods were well correlated. This study was not conducted in a controlled environment. An air intake system and an air conditioning unit were referenced as potential factors. Thus, air current effects on the system would have been inconsistent. This study was conducted inside of an enclosing hood, rather than a capturing hood.

\subsection{Presence of a Workbench}

Equation 1-15, previously established as the model used to design a rectangular exterior hood located on top of a table, is given within the Industrial Ventilation manual (ACGIH, 2001). In order to model the same hood if it were freely suspended in the air, the distance multiplier would need to be increased from five to 10 . This indicates that the presence of a workbench is beneficial for the assistance of capturing a contaminant; which has been supported by many studies (Thomas, 1950; Hemeon, 1963; Garrison, 1989; Kim and Flynn, 1992; Lewis, 2010). For that reason, the presence of a workbench will be assumed for this study. 


\section{Chapter 3 : Apparatus}

The apparatus consisted of the wind tunnel and its control system, the exterior hood and its control system, the pitot traverse system, the hood centerline velocity measurement system, environmental measurement equipment, the tracer gas release system, the tracer gas analyzing system, the aerosol release system, the aerosol analyzing system, the particle image velocimetry (PIV) system and particle seeding

\subsection{Wind Tunnel and its Control System}

The wind tunnel (See Figure 3-1) is a three-part system, consisting of an initial flow straightening chamber, a sampling work station, the plenum chamber, exhaust duct system, and the fan and its frequency control system. As shown in Figure 3-1, the dimensions of the wind tunnel work station are 28' 3 ' long, 12'0" wide, and 9'0" tall. The side walls and the ceiling are constructed from 2" x 6" studs and covered with dry wall. The floor is plywood covered with linoleum, both resting on a 1" Styrofoam ${ }^{\circledR}$ insulation. The Styrofoam ${ }^{\circledR}$ thermal insulation is intended to reduce the temperature difference between the flooring and the air moving through the wind tunnel. Rising heat may disrupt the airflow patterns throughout the wind tunnel and thus the transport of the contaminant/air mixture released from the source. To avoid issues with the cross-draft boundary layer, all studies were conducted with both the hood and subject as close as possible to the center of the room. Leaks in the wind tunnel were detected using colored bubbles and smoke and then sealed. 


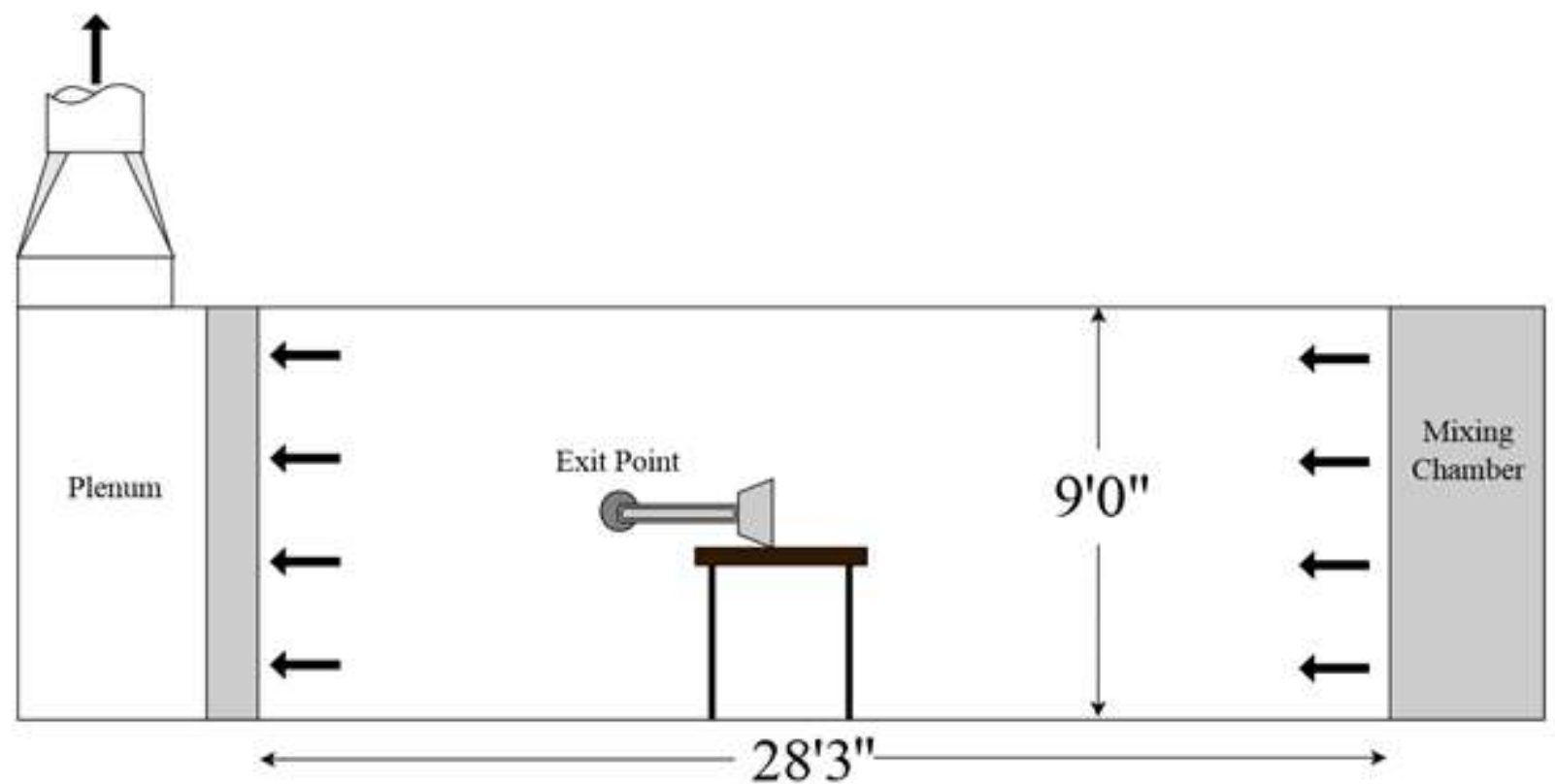

Figure 3-1 Wind Tunnel

$\mathrm{V}_{\text {draft }}$ is created by a separate fan in which the output is set by adjusting a Baldor Series $15-\mathrm{H}$ inverter motor controller (See Figure 3-2) to the desired frequency.

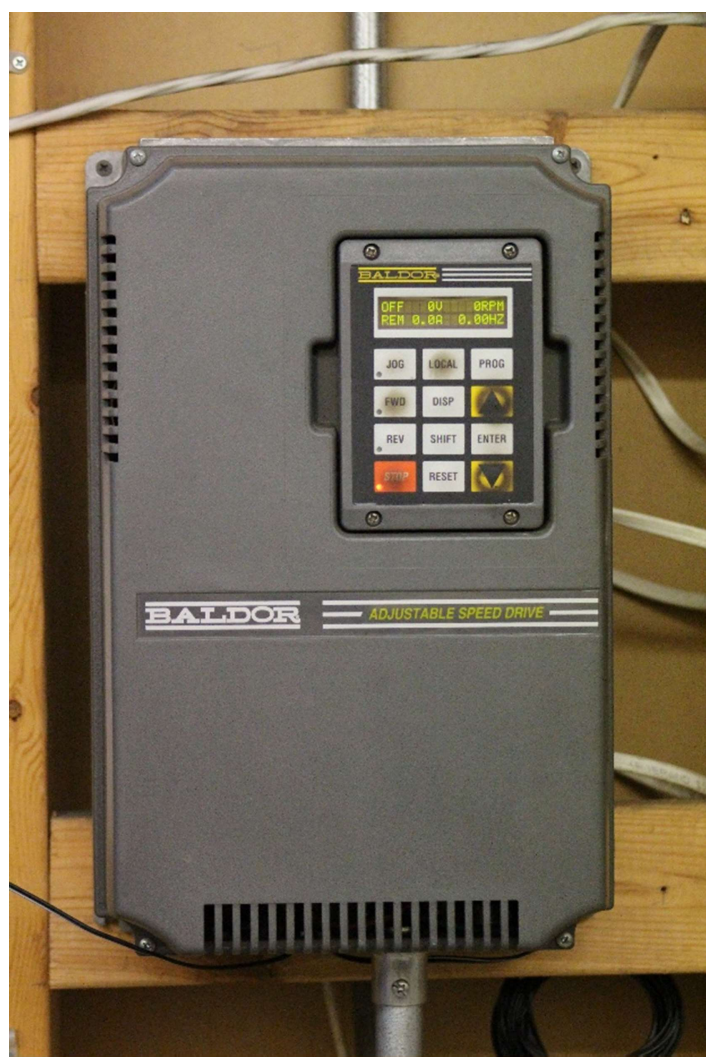

Figure 3-2 Balnor Series 15H Inverter Motor Controller 
Pitot measurements across the single large duct exhausting the wind tunnel were collected with a calibrated PVM-100 micromanometer (TSI Inc. - Shoreview, MN) at different fan rotation rates, which were adjusted by changing the controller frequency $(\varpi)$. A regression model, used to predict $\mathrm{V}_{\text {draft }}$ values:

$$
V_{\text {draft }}=(0.0719 \times \varpi)-1.1703
$$

Where:

$$
\begin{aligned}
\mathrm{V}_{\text {draft }} & =\text { Draft Velocity }(\mathrm{fpm}) \\
\varpi & =\text { Inverter Motor Controller Frequency }(\mathrm{RPM})
\end{aligned}
$$

This method was cross-validated with a calibrated constant temperature anemometer.

\subsection{Exterior Hood and its Control System}

The exterior hood that was used for all tests was a rectangular capturing hood (Nordfab Systems, Inc. - Thomasville, NC) that is 12" long, 6" wide, and 9" deep. The duct connected directly to the hood is 6 " in diameter. The hood rested three and a half inches above a work bench. Air flow through the capture system was induced by a Model 250 APP4 CL.L. BCN-SW fan (TCF Aerovent Company - Brookings, SD) and was regulated with a Teco N3 Inverter (See Figure 3-3), which displays rotation rate (๘) in units of Hz..

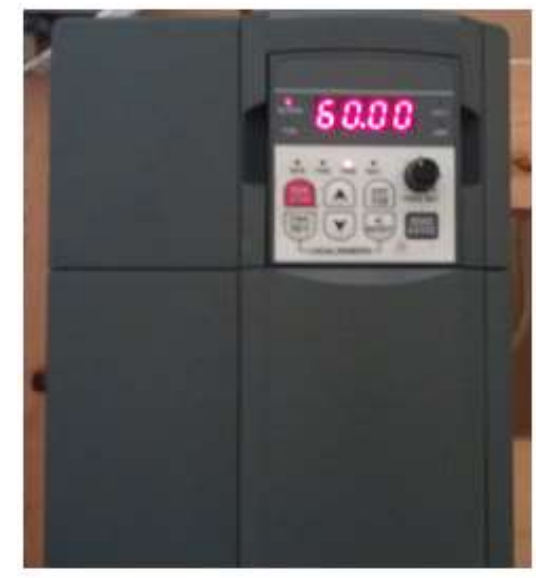

Figure 3-3 N3 Inverter 


\subsection{Pitot Traverse System}

The pitot traverse method, as described in the Industrial Ventilation (ACGIH, 2001), was used to measure the velocity pressure, and thus, the volumetric flow rate across the duct. The face velocity and approximate capture velocities were then computed using this data. Two perpendicular diameters were traversed at 10 points each (see Figure 3-4). Additionally, as recommended, the traverse location was greater than 7.5 " downstream of the nearest disturbance. The velocities at each of these points was measured using the density factor. The density factor was computed using the ideal gas laws and the measured duct temperature and barometric pressure and humidity within the room. 

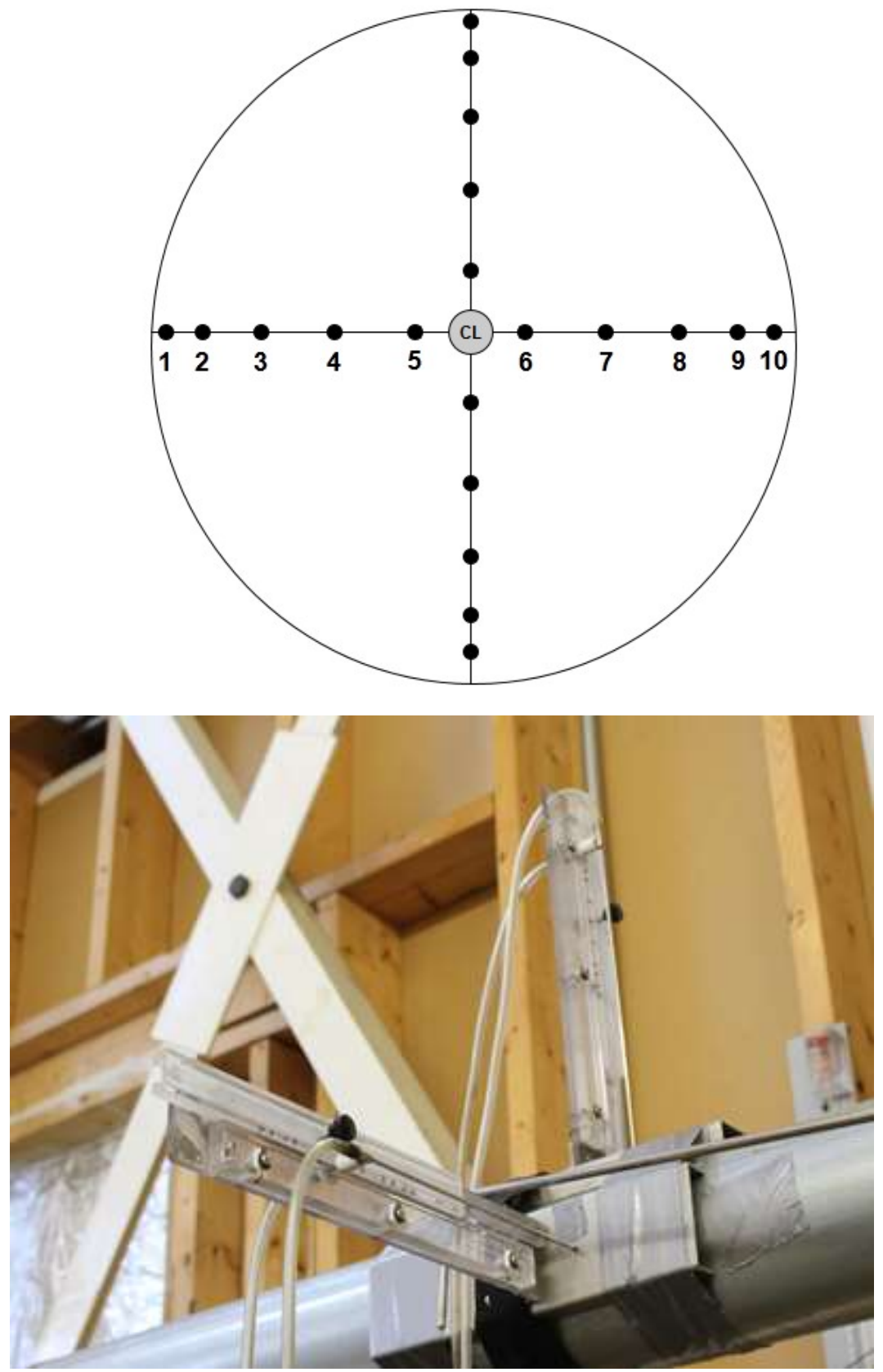

Figure 3-4 Pitot Traverse

A PVM-100 micromanometer (TSI Inc. - Shoreview, MN) was used to measure the velocity pressure at points 1-20 (See Figure 3-4) and the static pressure at the centerline. Data from this process was automatically downloaded into custom-written software, HvMeasurement (Guffey, 2014). 


\subsubsection{Pitot Traverse Validation}

Before and after the experiments were carried out, the micromanometer was calibrated using a Dwyer 1425 series hook gauge equipped with two micrometers and a piston used to adjust the level displacement. A magnetic angle locator and a spirit level were used to determine when the hook gauge was level (See Figure 3-5).
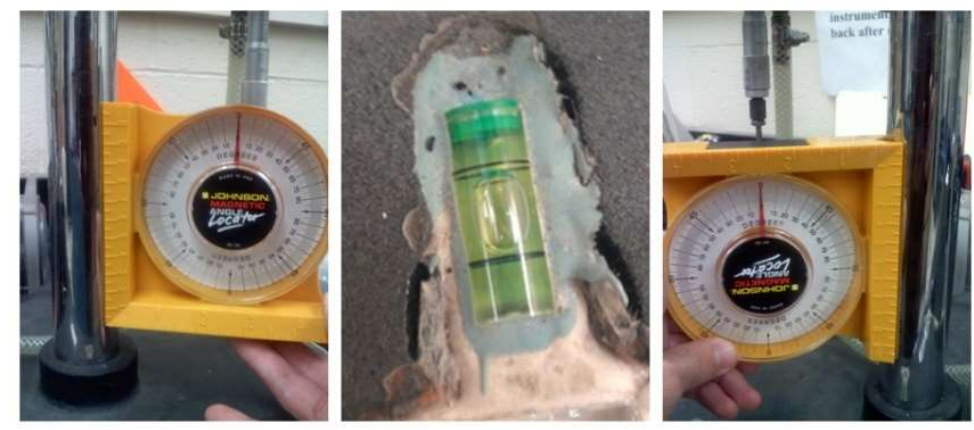

Figure 3-5 Leveling the Hook Gauge Apparatus

\subsection{Hood Centerline Velocity Measurement System}

Hood centerline velocity measurements, turbulent intensities, and cross draft measurements were conducted with an Anemosonic ${ }^{\mathrm{TM}}$ UA30 (TSI Inc.) sonic anemometer and a VelociCalc (TSI Inc.) hotwire anemometer. Both anemometers were validated by comparison with a Dantec 54T30 constant temperature anemometer (Skovlunde, Denmark) that was calibrated with a TSI 1125 flow calibration device. They were even further validated by hood face velocity measurements, as determined from the pitot traverse using the calibrated PVM-100 micromanometer (TSI Inc. - Shoreview, MN). All equipment was compared at the hood face and

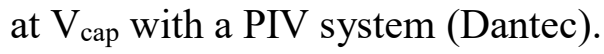

For the $\mathrm{V}_{\text {cap }}$ measurements, the anemometers were in a line normal to the center of the hood face at the furthest point of the generation source, in a controlled environment. The benefit of the PIV system is that it can measure up to 65 points along the centerline, up to a distance of 11.2 ", simultaneously. Both systems will be used to validate the $\mathrm{V}_{\text {draft }}$ estimated velocities.

\subsection{Environmental Measurements}

Prior to each test date, wet and dry bulb temperatures were taken with a Psychro-Dyne psychrometer (Environmental Techtonics Corp.), to calculate the relative humidity. The 
atmospheric pressure was taken with a mercury barometer, which in combination of the relative humidity, were used to determine the density of the air. Surface temperatures within the wind tunnel were measured with an infrared thermometer. Ambient temperatures will be measured with an Ertco laboratory thermometer (Sn: 8859).

\subsection{Tracer Gas Release System}

Freon 134a and helium gas were released from gas cylinders located directly outside of the wind tunnel, passed through separate gas flow meters, and mixed upstream of the meters (See Figure 3-6). To achieve neutral buoyancy, helium gas must be drawn at a 3:1 ratio with Freon 134a. The gas flow rate of helium was regulated with an Aalborg flow meter and the flow rate of Freon 134a was regulated with an Aalborg flow controller (GFC-10). To ensure proper mixing, the source is located over $200 \mathrm{D}$ downstream of the mixing point.

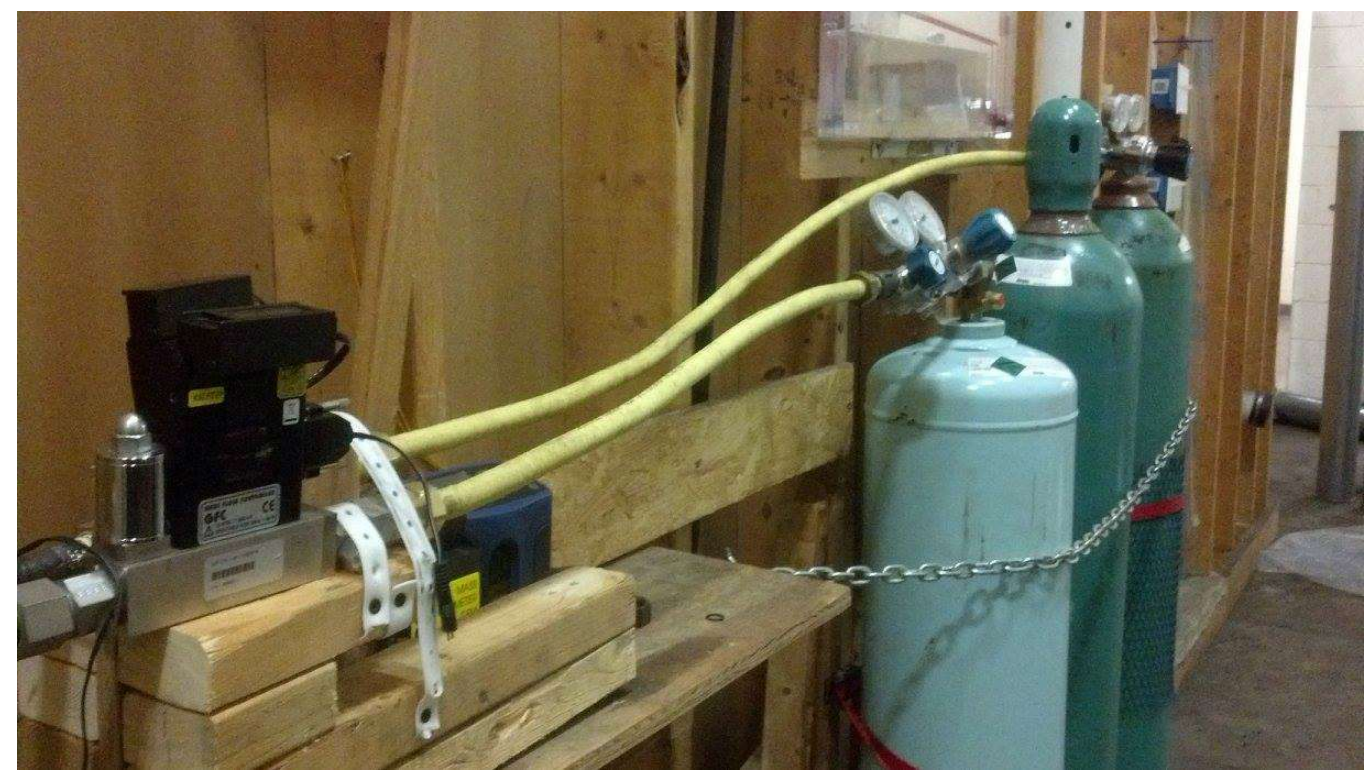

Figure 3-6 Tracer Gas Release System

Half-inch Gastite (Portland, TN) corrugated stainless steel tubing (CSST) was used for all gas transfer prior to the source inlet. CSST was selected due to its strength, relative flexibility, and sealant reliability. All gas lines and fittings were tested and verified with the soap bubble method.

The source release point is the same mechanism used by Kasberger (2012). It is a rectangular box 12.375 " in length, 1.375 " in width, and 1.375 " in height. The tracer exited the 
source the source through 91 drilled holes, each 3/16 inch in diameter. The source was squared off, centered, and released across the face of the hood.

\subsubsection{Tracer Gas Release Rate Validation}

The Freon 134a mass flow controller and the helium mass flow meter were calibrated three times on different days using a Bios Defender 510 DryCal (Bios International Corporation Butler, NJ). The level of Freon was randomized each day. The Freon 134a display consistently differed from the DryCal, but as shown in Figure 3-7, the Freon display was highly linear with the DryCal value $\left(\mathrm{R}^{2}=1\right)$. Based on linear regression of the calibration values, the approximate of the true flow rate of Freon was:

$$
G_{\text {Freon }}=0.2009(\text { MeterDisplay })-0.000002
$$

Figure 3-7 is a representative calibration of the Freon 134a controller. To accurately achieve the constant flow rate of $1 \mathrm{~L} / \mathrm{min}$ of Freon 134a, as used in preliminary studies, the display needed to read 5.00 L/min. All measurements taken when the Freon 134a controller displayed 5.00 L/min fell within $0.0039 \mathrm{~L} / \mathrm{min}$ of $1.00 \mathrm{~L} / \mathrm{min}(\mathrm{STD}=0.00082 \mathrm{~L} / \mathrm{min})$. This same system was used for each respective amount of Freon 134a used.

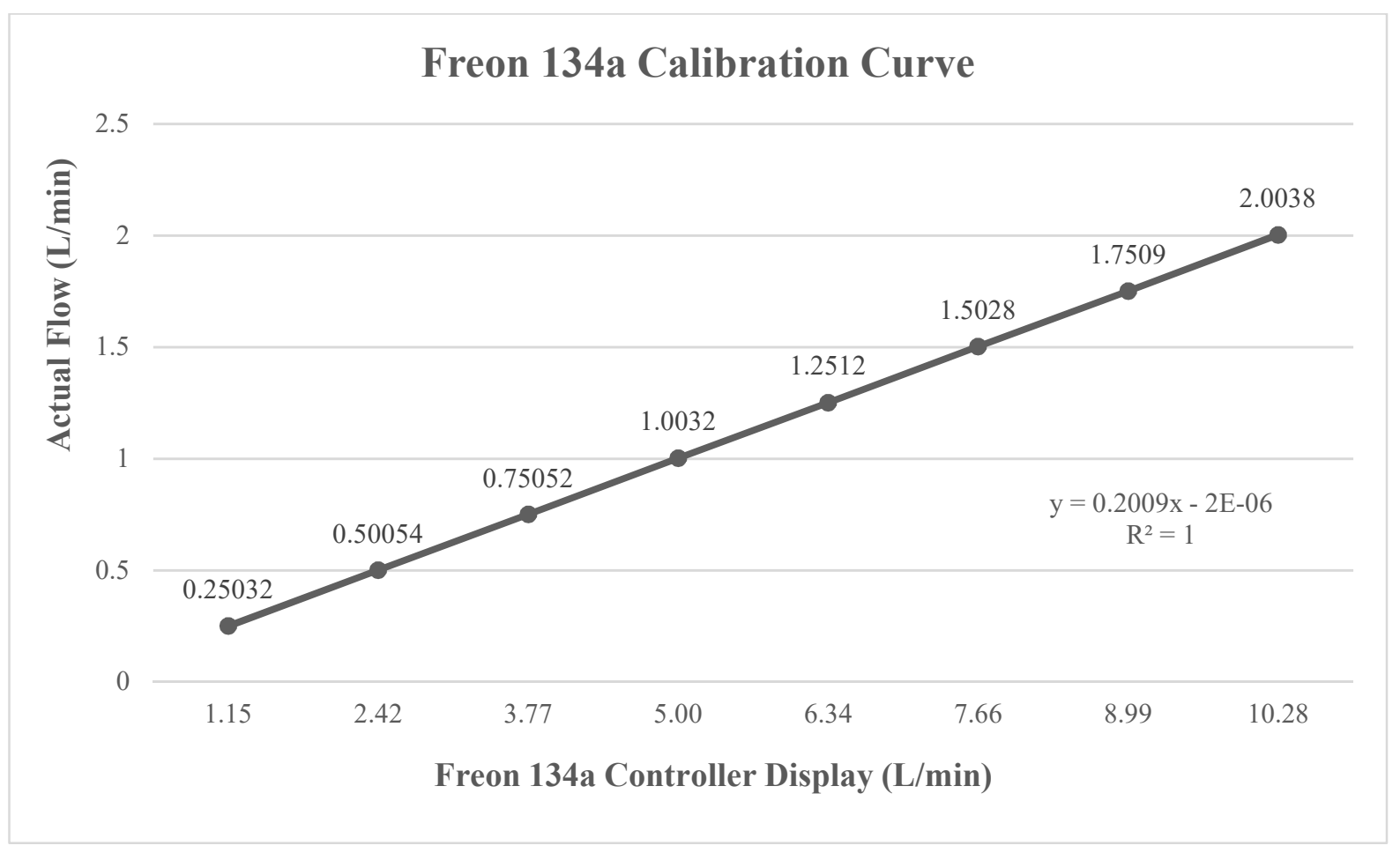




\section{Figure 3-7 Freon 134a Calibration Curve}

The same validation process as used for the Freon 134a controller was used for the helium mass flow meter, only at higher concentrations. The display on the helium flow meter was found to be far more accurate than the Freon 134a controller display. The degree of accuracy for any individual measurement was no worse than $0.0088 \mathrm{~L} / \mathrm{min}$ for any reference flow rate. As shown in Figure 3-8, the helium display was highly linear with the DryCal value $\left(\mathrm{R}^{2}=1\right)$. Based on linear regression of the calibration values, the approximate of the true flow rate of helium was:

$$
G_{\text {Helium }}=1.0353(\text { MeterDisplay })-0.0367
$$

To accurately achieve a constant flow rate of $3 \mathrm{~L} / \mathrm{min}$ of helium, which was also used in preliminary studies, the display needed to read $2.93 \mathrm{~L} / \mathrm{min}$. All measurements taken when the helium meter displayed $3.00 \mathrm{~L} / \mathrm{min}$ were actually much closer to $3.06 \mathrm{~L} / \mathrm{min}(\mathrm{STD}=0.028$ $\mathrm{L} / \mathrm{min}$ ). This same system was used for each respective amount of helium used. All changes to both systems were given direct read measurements to ensure they followed along the linear progression.

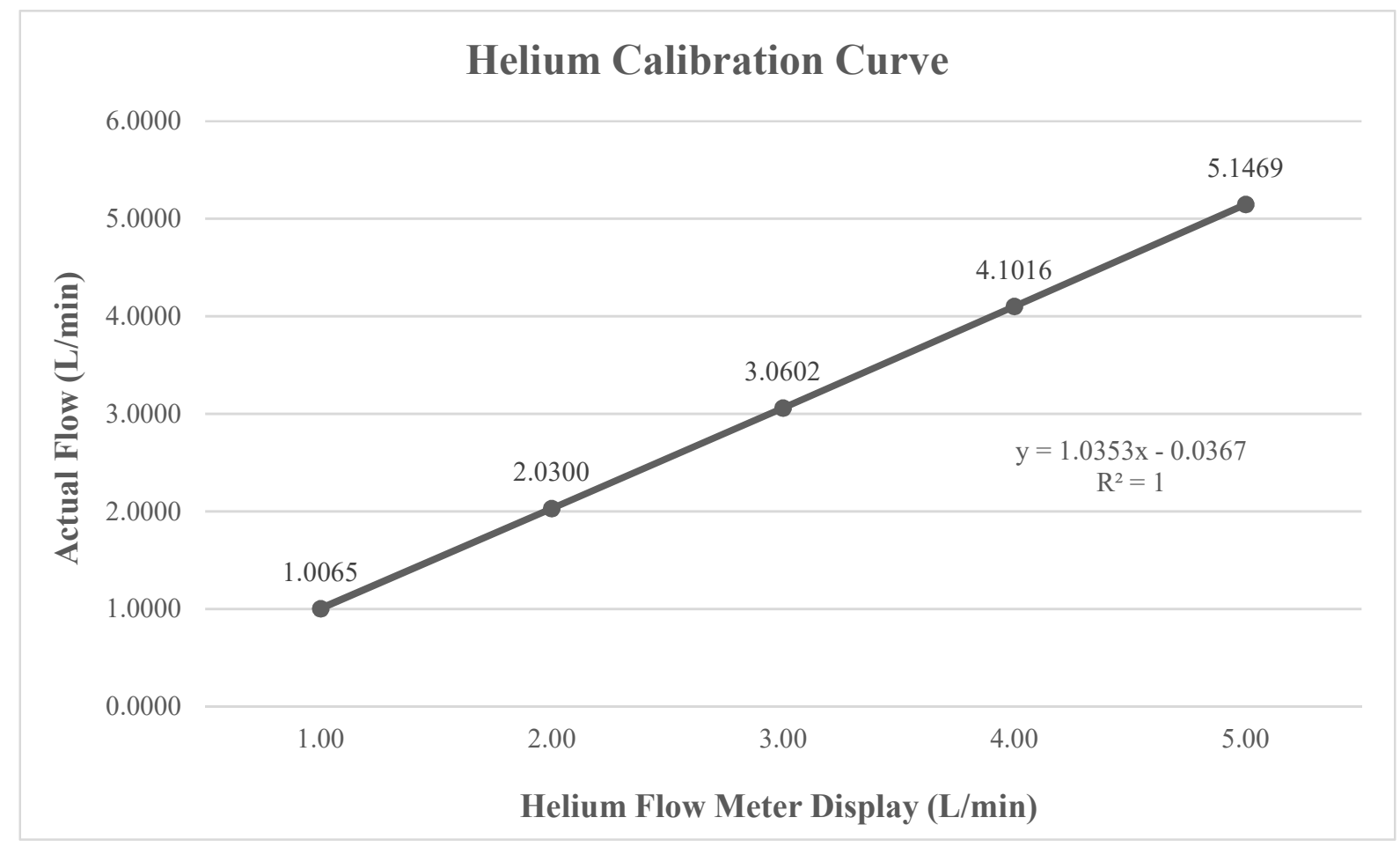

Figure 3-8 Helium Calibration Curve 


\subsection{Tracer Gas Analyzing System}

All breathing zone, duct, and validation tracer samples were drawn by low-flow SKC pumps into Tedlar ${ }^{\circledR}$ bags and analyzed with the FTIR system (See Figure 3-9) and its accompanying software.

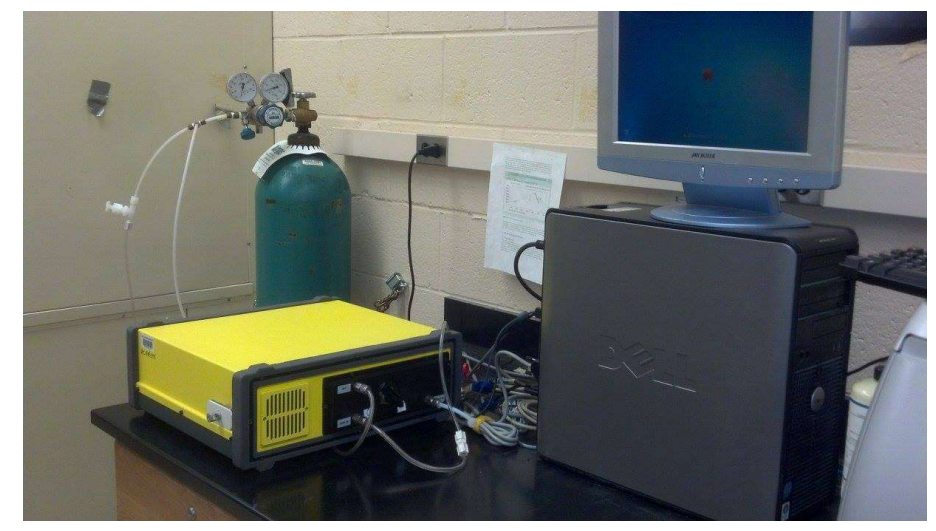

Figure 3-9 Tracer Gas Analyzing System

Prior to any measurements, the FTIR needs a warmup period for the sample cell to reach $50^{\circ} \mathrm{C}$. This temperature is displayed by Gasmet Technologies' Calcmet ${ }^{\mathrm{TM}}$ software. Once the sample cell reaches the desired temperature, the system was purged with nitrogen for a couple minutes. After purging the system, ambient air was pumped into the machine for two minutes. The ambient air in the system was used to establish a background that was be used as the baseline for all samples conducted during that study session. Ambient air was used as the background, rather than nitrogen, because water vapor generates residual error. When comparing contaminant sources containing water vapor with a background devoid of water vapor, desired detection gases are skewed.

\subsubsection{Tracer Gas Analyzing System Validation}

Calibration "span" gases were used to construct reference points for Freon 134a over a wide range of concentrations. These reference points were cross-validated by creating known concentrations of Freon 134a in Tedlar ${ }^{\mathbb{B}}$ bags with gas-tight syringes and measuring them with them with the FTIR (see Figure 3-10). 


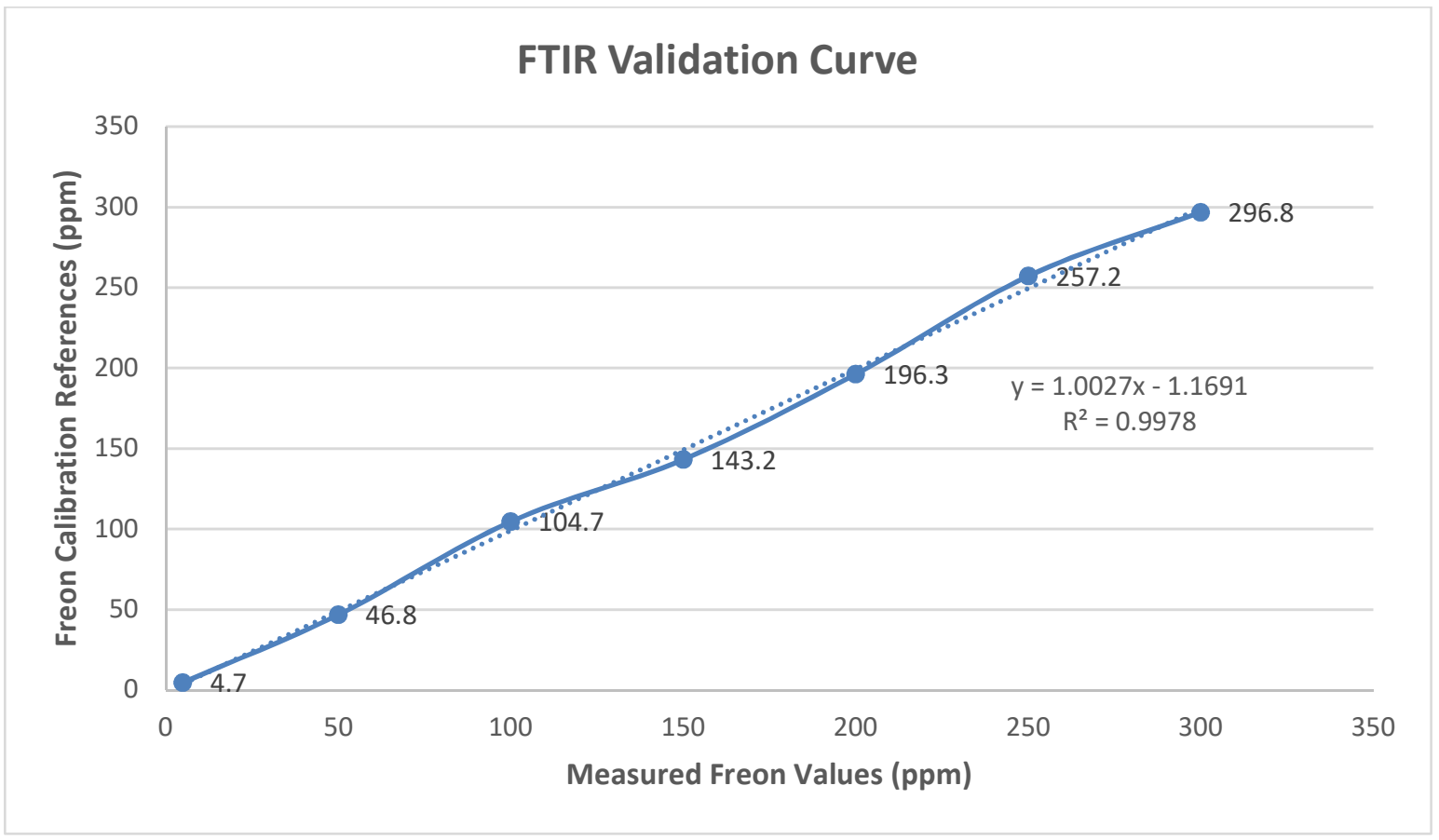

Figure 3-10 Tracer Gas Validation Curve

The validity of the sampling bags was checked by placing full bags under water and checking for air bubbles. The bags were further validated by vacuuming all contents and checking to see if air leaked into the bag over time. Bags were purged three times between each usage. Additionally, all pumps used during sampling and validation process were validated by pumping known concentrations from one bag to another and verifying the contents of both bags were identical.

\subsection{Aerosol Release System}

The black rectangular object at the top of the Figure 3-11 is the exterior hood. The thin rectangular object at the bottom of the picture is the release point of the tracer source. The holes in the contaminant source are spread throughout, in order promote proper dispersion. The blue object on the left is the TSI 8026 particle generator, which connects to the rectangular contaminant underneath source box, at the bottom of the picture. The reservoir below the particle generator is filled with salt water, and is released as a non-toxic aerosol. The white unit on the right is the TSI 3007 condensation particle counter (CPC). The particle generator and the CPC are shown on the workbench for modeling purposes only. 


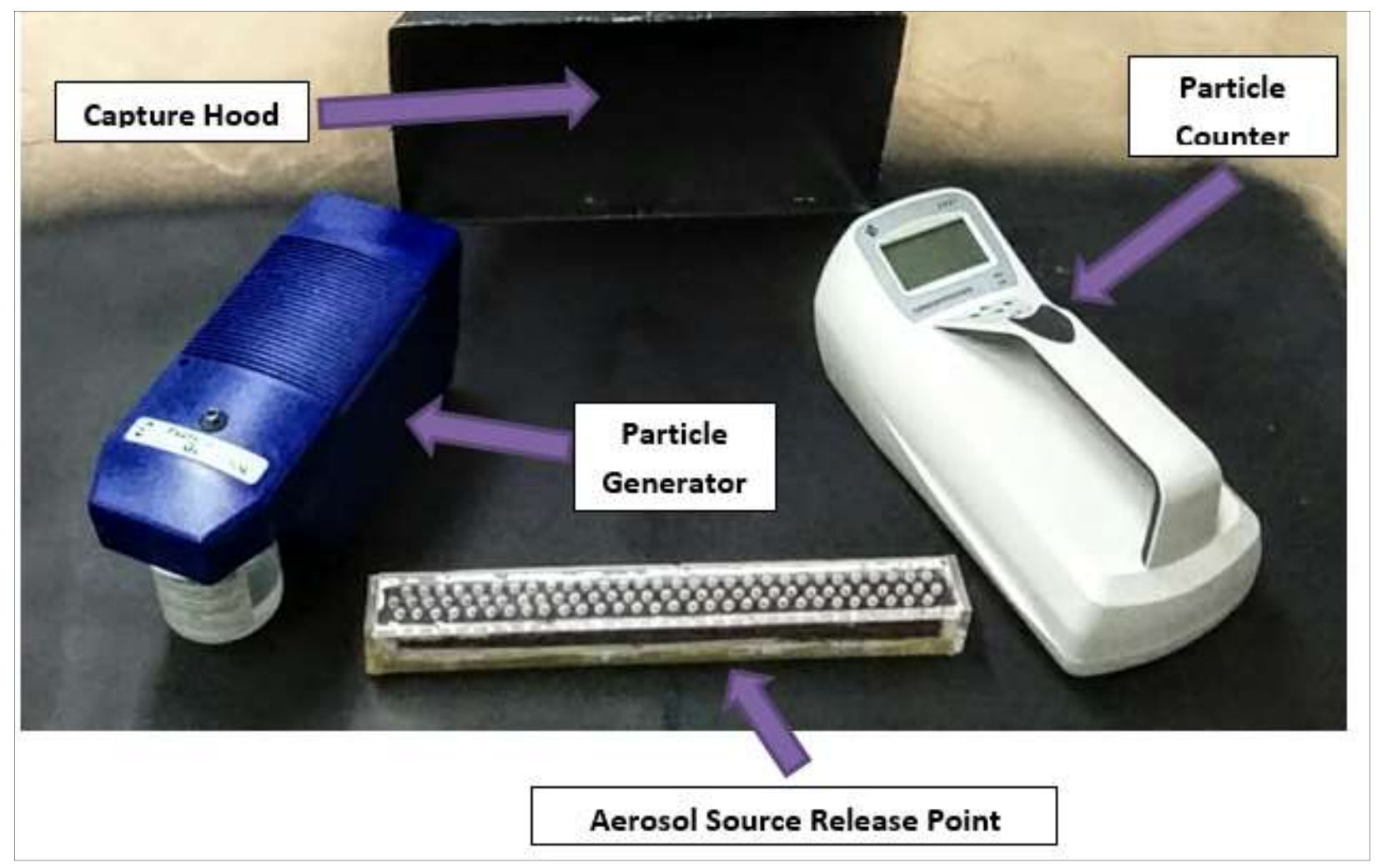

Figure 3-11 Aerosol Gas Release System

\subsection{Aerosol Analyzing System}

As illustrated in Figure 3-11, the CPC was the measurement device for the aerosol system. The accompanying software with the CPC is Aerosol Instrument Manager ${ }^{\circledR}$. Particle concentrations can be measured real-time or recorded over set durations. The software is particularly useful for visualizing trends. This is especially useful in determining when contaminants have traveled long distances through tubing.

The particle counter was attached to a custom-made solenoid valve system, as illustrated in Figure 3-12. 


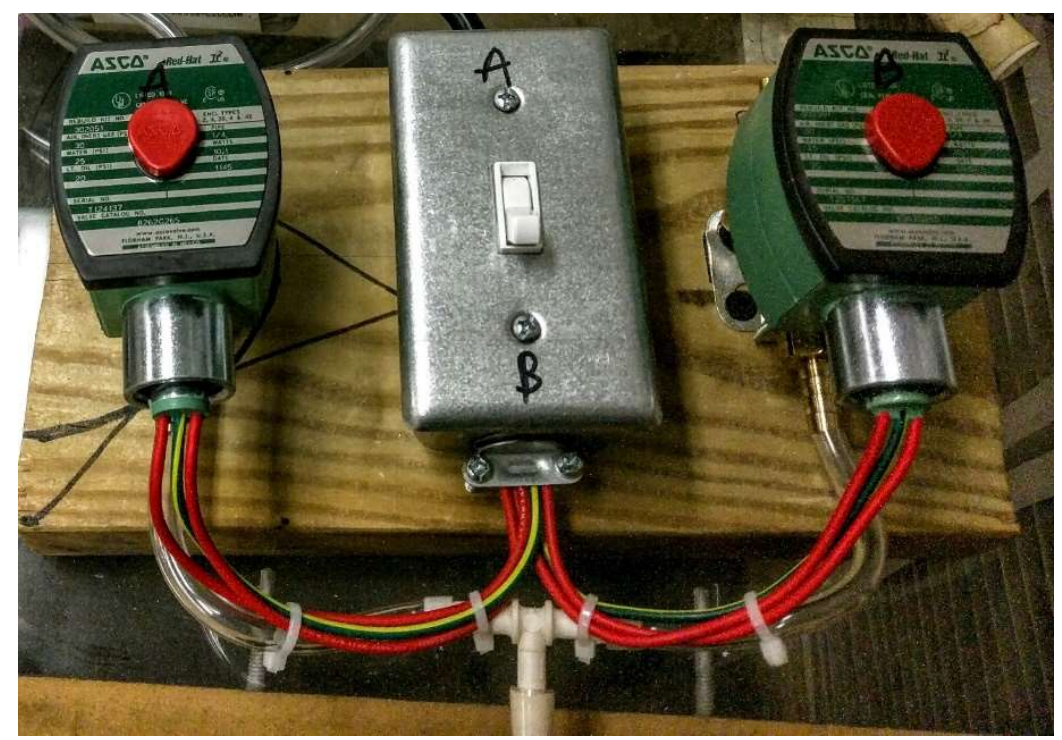

Figure 3-12 Aerosol Sampling Solenoid Valve System

This allowed toggling between sampling in the worker's breathing zone and sampling within the duct. The sampling lines were tested before and after tests to verify there was no particle loss. This was conducted by measuring the particle count directly at the particle generator and at the other length of the line. The response time between toggles was approximately 30 seconds for roughly a 15 ' line. As previously mentioned, this was easily visible with the accompanying software. Each test was allowed appropriate time to reach steady-stead before recording. Each individual sample was recorded for two minutes. Preliminary studies found that approximately 20 seconds of data recording was necessary to obtain reliable results. Two minutes was allowed for each condition, as means of reducing outliers. HEPA filters located at the entrance and exit of the wind tunnel provided a controlled environment. Ambient concentrations were very near zero.

Figure 3-13 illustrates the breathing zone location on the manikin linked to solenoid valve A. The tape acted as both an adhesive and a mark for maintaining a constant measurement location. 


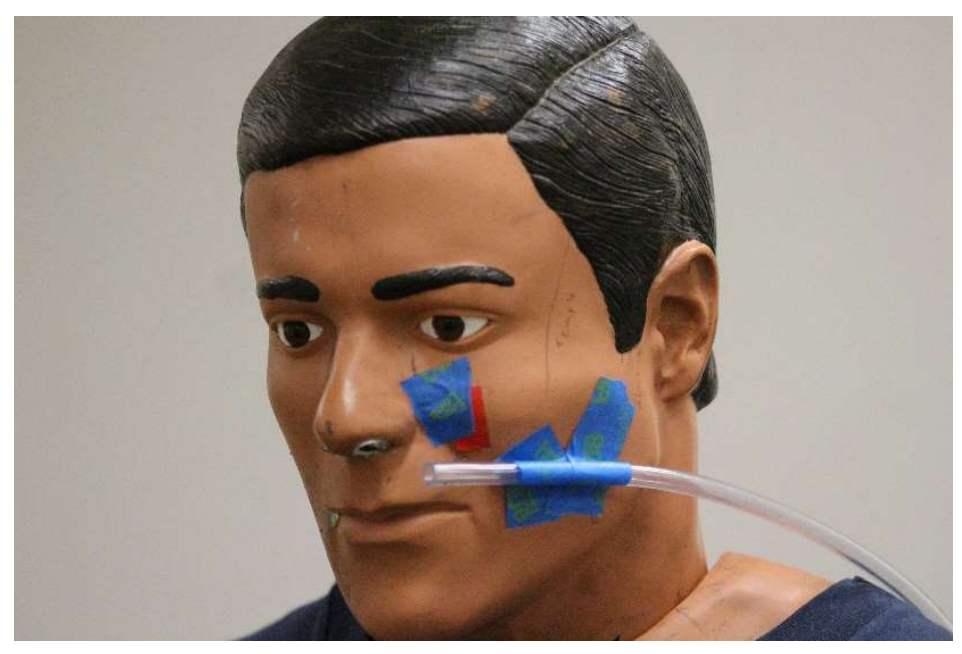

Figure 3-13 Manikin Breathing Zone

\subsection{PIV Particle Seeding}

Figure 3-14 illustrates the particle seeding process for the PIV system. Olive oil particles generated by a Six-Jet Atomizer 9306 (TSI, inc.) were fed into the mixing chamber to provide sufficient particle counts in the 1-5 micron range. Olive oil particles have long been established as PIV particle seeding (Raffel, M., Willert, C. E., \& Kompenhans, J, 1998). The mixing chamber consisted of a French drain piping system wrapped into a sharp U-shape. An additional fan was placed inside the chamber to ensure thorough mixing. The particles then entered through slots prior to entering the testing chamber.

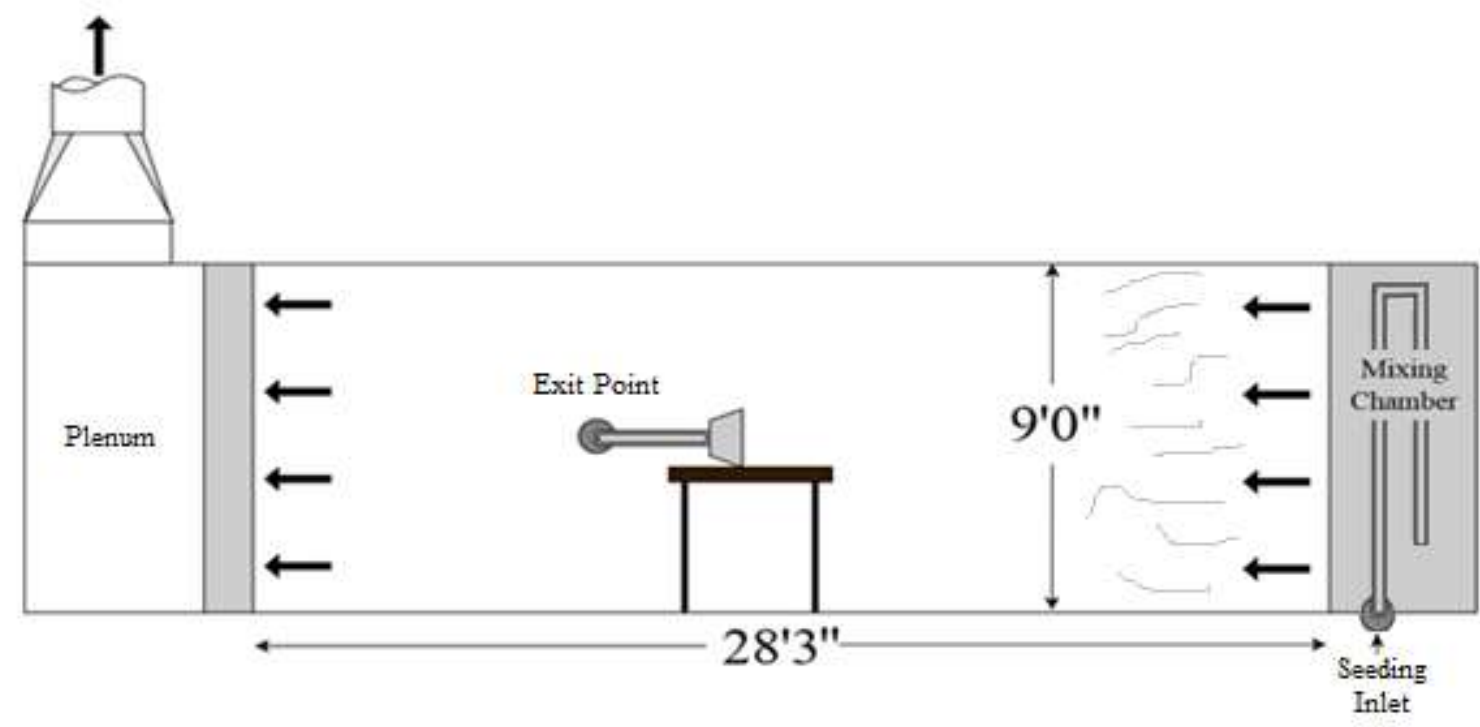

Figure 3-14 PIV Particle Seeding 
Figure 3-15 illustrates the particle seeding release point. The extending pipe is a lead into the French drain system within the mixing chamber.

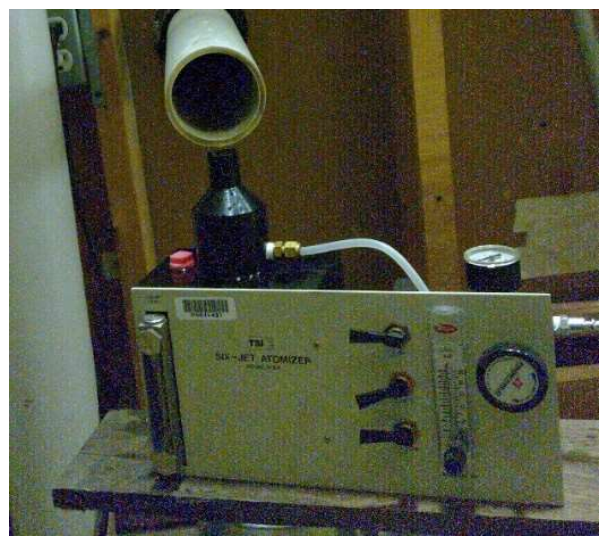

Figure 3-15 Six-Jet Atomizer

\subsection{PIV System}

The PIV system consisted of a Solo III-15Hz LASER (New Wave Research, Freemont, CA), a HiSense Type 13 camera, and a Dantec Dynamics FlowMap 1500 control system. The LASER (Figure 3-16) pulses in bursts of $1000 \mathrm{~ms}$. The displacement of particles, as measured by the camera, results in the corresponding two-dimentional velocity. The Nikon AF FX NIKKOR $24 \mathrm{~mm} \mathrm{f} / 2.8 \mathrm{D}$ fixed zoom lens provided approximately a $360 \mathrm{X} 288 \mathrm{~mm}$ window of observation. The camera system was calibrated by placing a metric ruler in line with where the laser sheet would pass. Measuring the displacement between select points provides a scaling factor. All velocities within the window were then calculated based on the displacement according to the calibrated scale. Figures 3-16 and 3-17 illustrate the LASER and control system, respectively. 


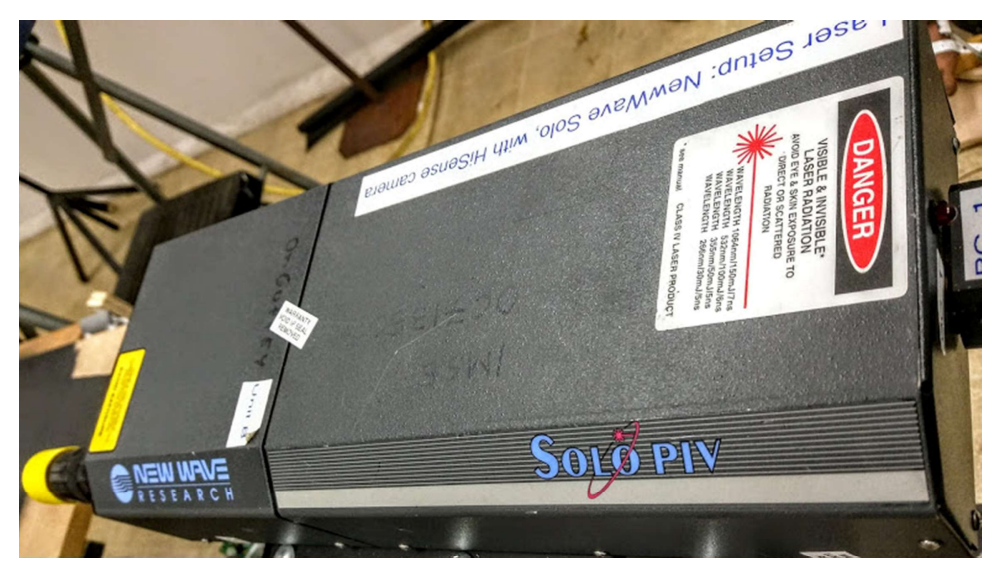

Figure 3-16 Solo PIV LASER

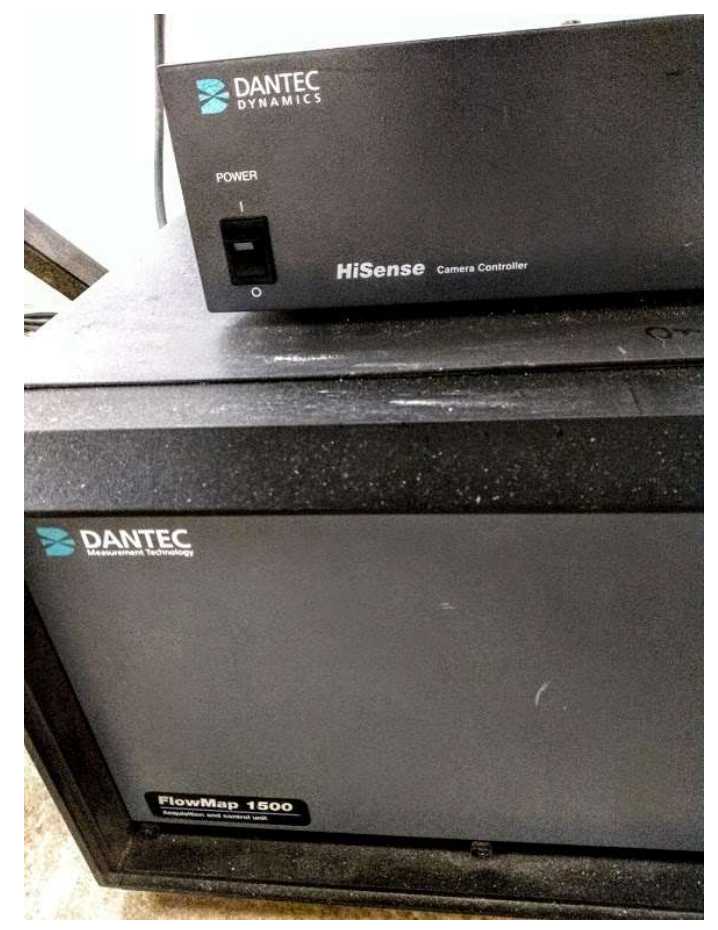

Figure 3-17 Dantec PIV Control System

The camera system for the PIV was placed on tracks, so that the camera could easily be moved when changing the orientation. The camera was mounted from above and shot straight downward, perpendicular to the LASER sheet, as illustrated in Figure 3-18. 


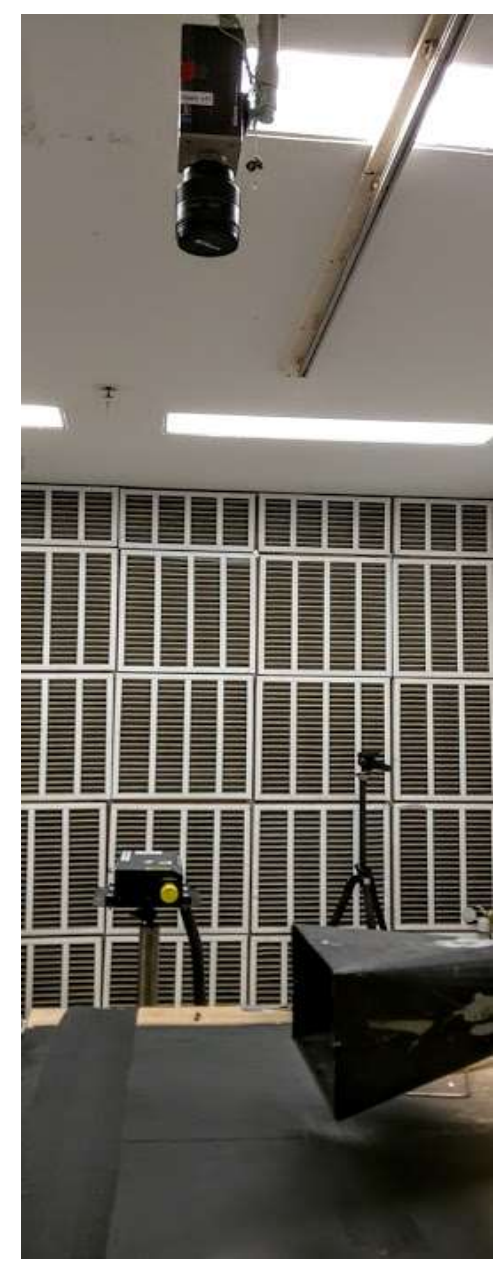

Figure 3-18 PIV Setup

The table surrounding the hood was painted black matte to prevent reflective disturbances and to provide the best particle imaging. This also provided the opportunity to run the LASER at maximum intensity, which yields the largest particle count.

Dantec Dynamics FlowMap software was used for camera calibration and data collection. The cross-correlation data files were then extracted and analyzed within MATLAB.

\subsection{Manikin}

The manikin used in this study was intended to be a surrogate for a human. The manikin was designed to stand at the net mean height of all men and women in the US (Fryar, Gu, and Ogden, 2012). The manikin had a shoulder breadth of 14 " and a head breadth of 6 ". The manikin was 
also heated, breathed, and for the orientation capture study and manikin movement studies, it moved its arms and torso.

\subsubsection{Manikin Heating}

Figure 3-19 illustrates the manikin's heating element. Heated wires are circulated throughout the torso and arms of the manikin. The heating element is controlled and insulation is installed to maintain a relatively consistent skin temperature. Skin temperatures were taken at both forearms and directly in the center of the manikin's chest for each sample. The manikin's skin temperature was consistently within $2^{\circ} \mathrm{C}$ of that of human skin exposed to the same environmental conditions.
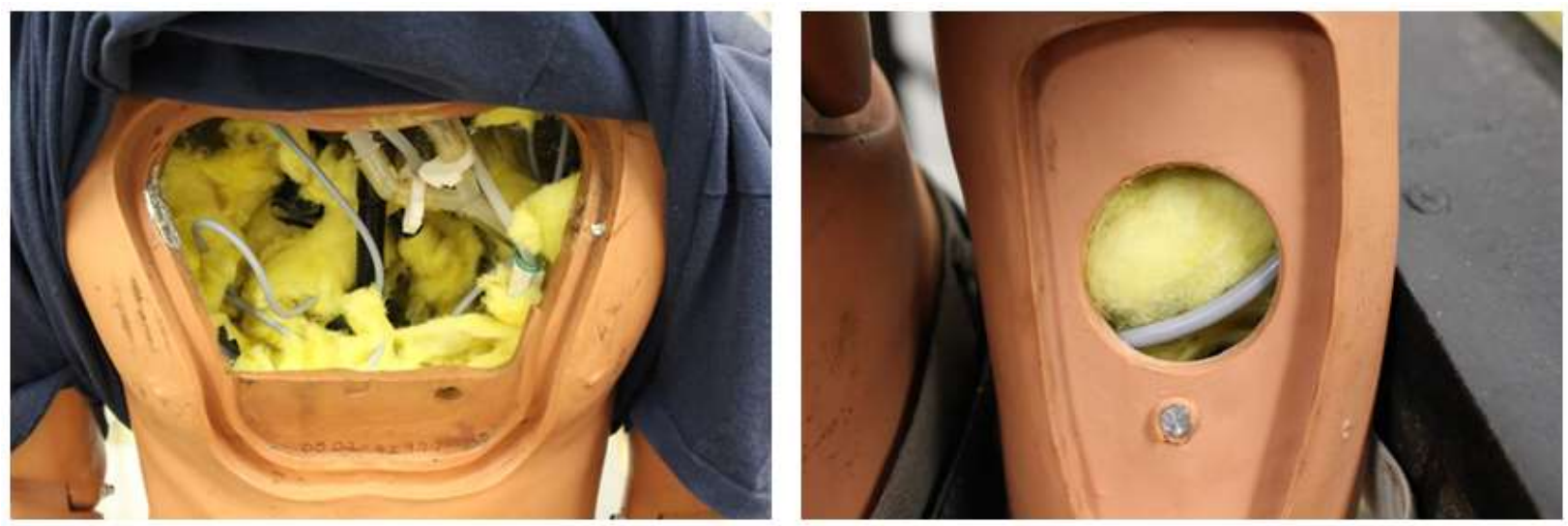

Figure 3-19 Manikin Heating System

\subsubsection{Manikin Breathing}

A Series 1101 Breathing Simulator (Hans Rudolph, Inc., 2010) was used to accurately simulate human breathing (see Figure 3-20), based on parameters hand-provided by NIOSH. 


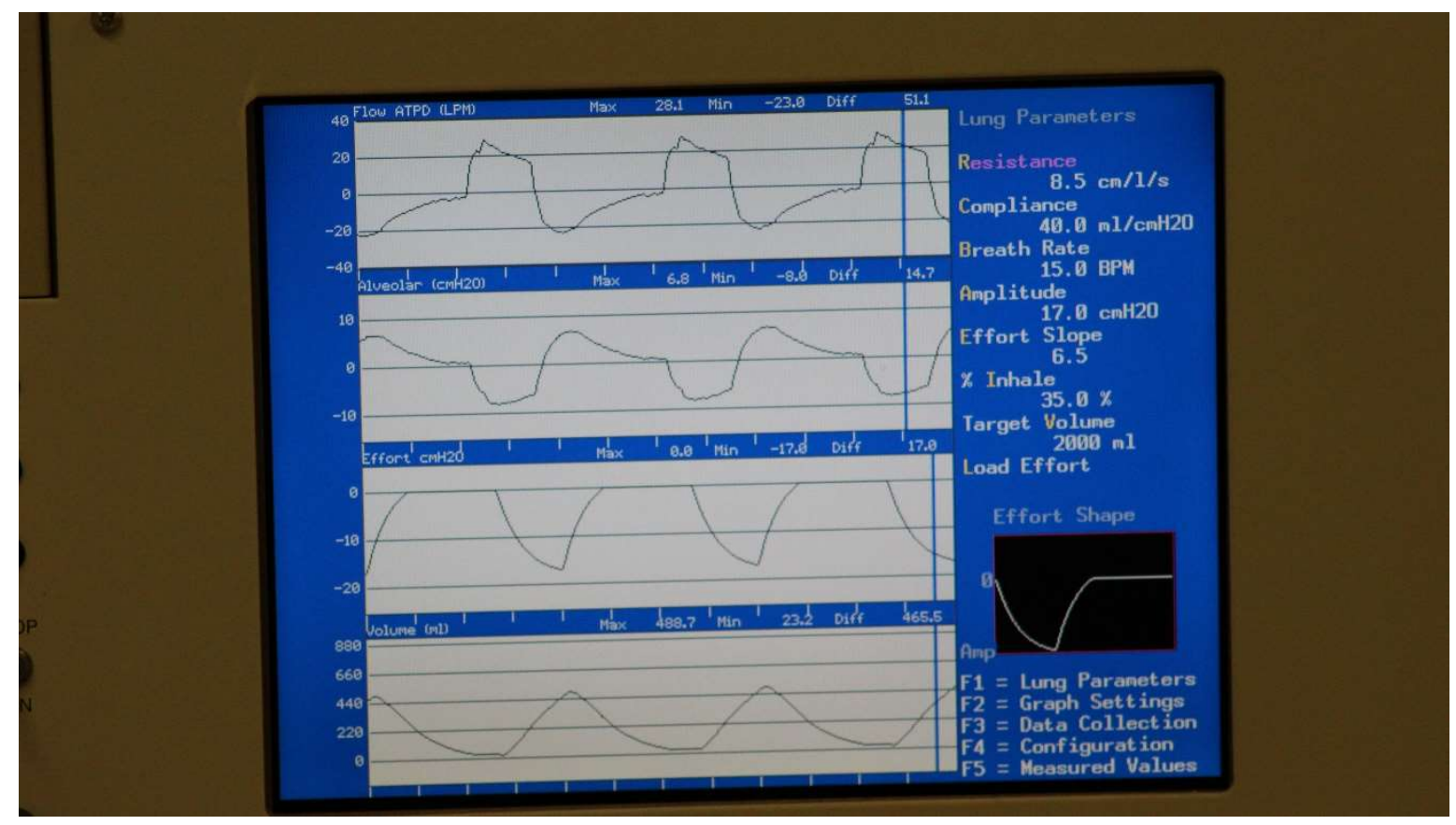

Figure 3-20 Breathing Simulator Parameters

A custom box and filter was used to act as a lung, as illustrated in Figure 3-21.

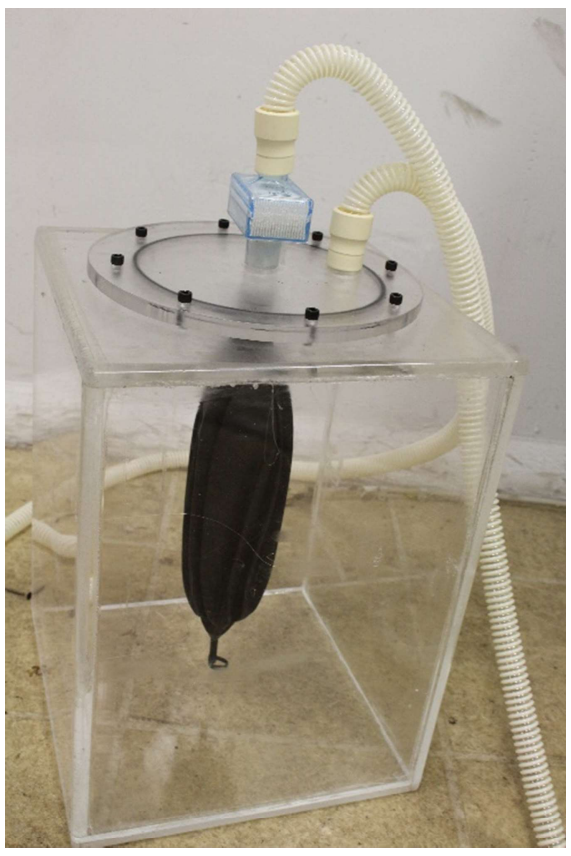

Figure 3-21 Manikin Lung 


\subsubsection{Manikin Movements}

The manikin was positioned on a turntable and mounted to the workbench with straps and linkages connected to ACDelco $25942547 \mathrm{GM}$ windshield wiper motors (see Figure 3-22). The motors were powered by Kastar LCD AC Adapters 12V 6A and controlled by uniquegoods PWM DC Motor Speed Controllers, set to $30 \mathrm{rpm}$ per arm.

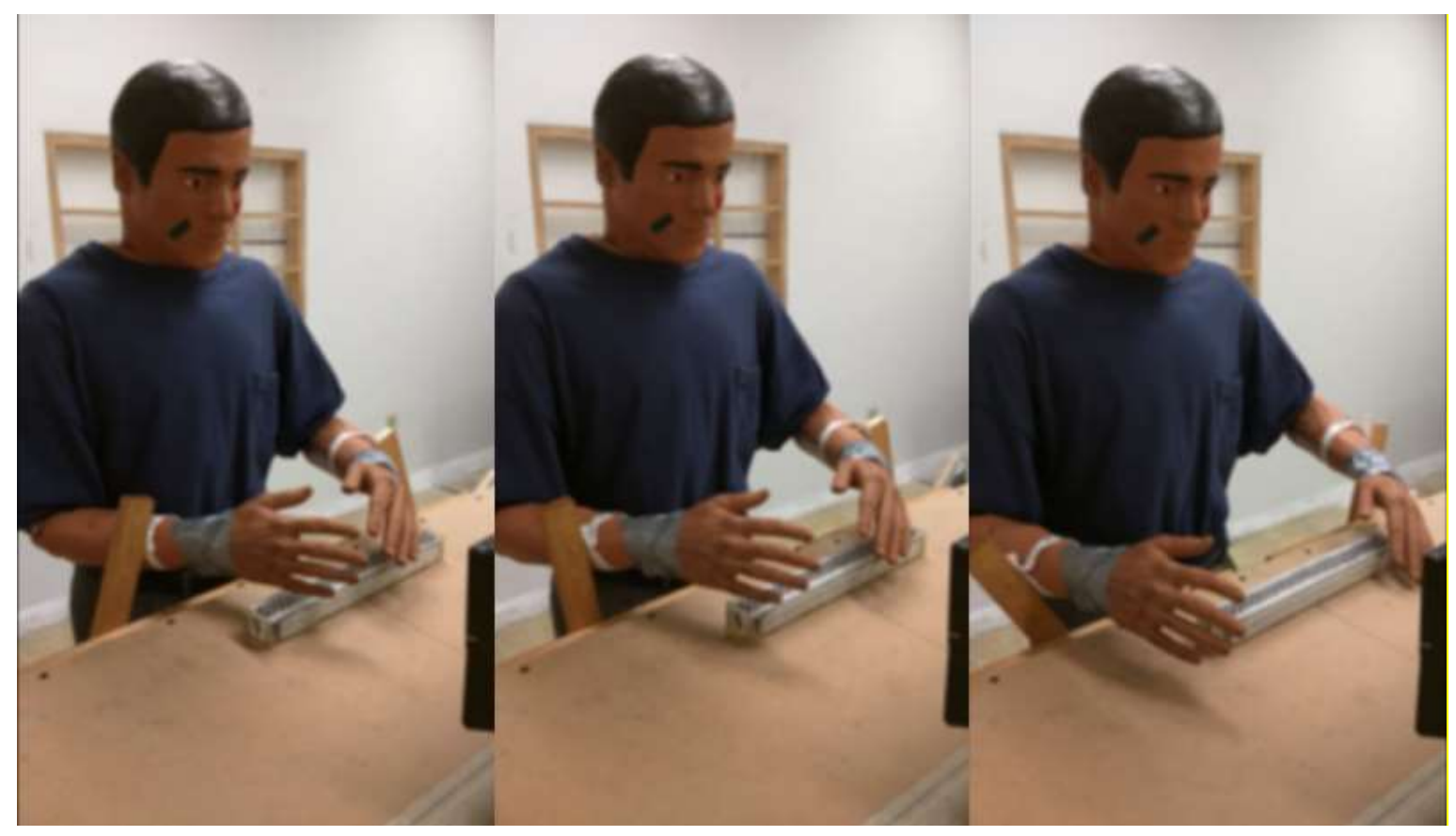

Figure 3-22 Manikin Movements 


\section{Chapter 4 : PIV Study}

\subsection{Introduction}

Centerline velocity measurements have long been used (DallaValle, 1930) as the primary parameter used for exterior capture hood design. Over the years several other centerline velocity models (Silverman, 1942; DallaValle, 1952; Fletcher, 1977; Fletcher, 1978; Garrison, 1981; Flynn and Ellenbecker, 1985; Flynn and Ellenbecker, 1986; Flynn and Ellenbecker, 1987; Conroy, Ellenbecker, and Flynn, 1988; Lewis, 2010) have been created. These models include various capturing systems and a wide range of velocity measurement technology. With the exception of Lewis (2010), these models have largely been generated under ideal conditions, without the presences of a hood operator, cross drafts, or varying orientations.

The effects of worker orientation with respect to cross drafts has been little studied (Guffey, Flanagan, and Belle, 2001). However, since the presence of a manikin was found to have a significant effect in Lewis' (2010) study at the 0-degree orientation, it is reasonable to believe that the hood orientation with-respect-to the operator has a significant effect on capture velocity as well.

This study considered not only the effects of orientation and manikin presence on capture velocity, but the entire capture envelope was measured as well. To the author's knowledge, no studies have been conducted to determine the effects of hood orientation on capture velocity or capture envelope velocities. No studies were found that considered the interactions of operator presence with hood orientation. Further, no studies were found that considered the effects of operator presence or hood orientation with respect to varying fan capturing levels. These factors are important considerations, because the Industrial Ventilation manual (ACGIH, 2001) that technicians use to design exterior hood systems does not mention how to factor worker presence or hood orientation into the overall hood design.

In this PIV study, half of the treatments included a heated, breathing manikin set at a marked position facing the capture hood face. The position was constant with respect to the hood, regardless of hood orientation. The manikin was removed entirely from the capturing hood system for the other half of the treatments. 
Olive oil particles were used as the seeding for the PIV system to analyze. Centerline and other select velocities throughout the capture envelope were collected and analyzed with the Dantec's Dynamics FlowMap 1500 control system. Data was extracted from the software and further analyzed in MATLAB.

\subsection{Research Design}

The PIV study was a randomized full factorial design with two replications. The primary dependent variable of this study is the velocity measurements along the centerline, normal to the hood face, at various distances $\left(\mathrm{V}_{\mathrm{x}}\right)$. The dependent centerline velocity at 11 " was of particular interest since this centerline point corresponded with the location of the source in previous studies. This dependent variable was recorded as the capture velocity $\left(\mathrm{V}_{\text {cap }}\right)$.

In addition to the centerline velocity measurements, spot measurements were collected at the locations illustrated in Figure 4-1. These dependent velocity measurements were designed to demonstrate the effects of various experimental conditions on the entire capture envelope of the hood system.

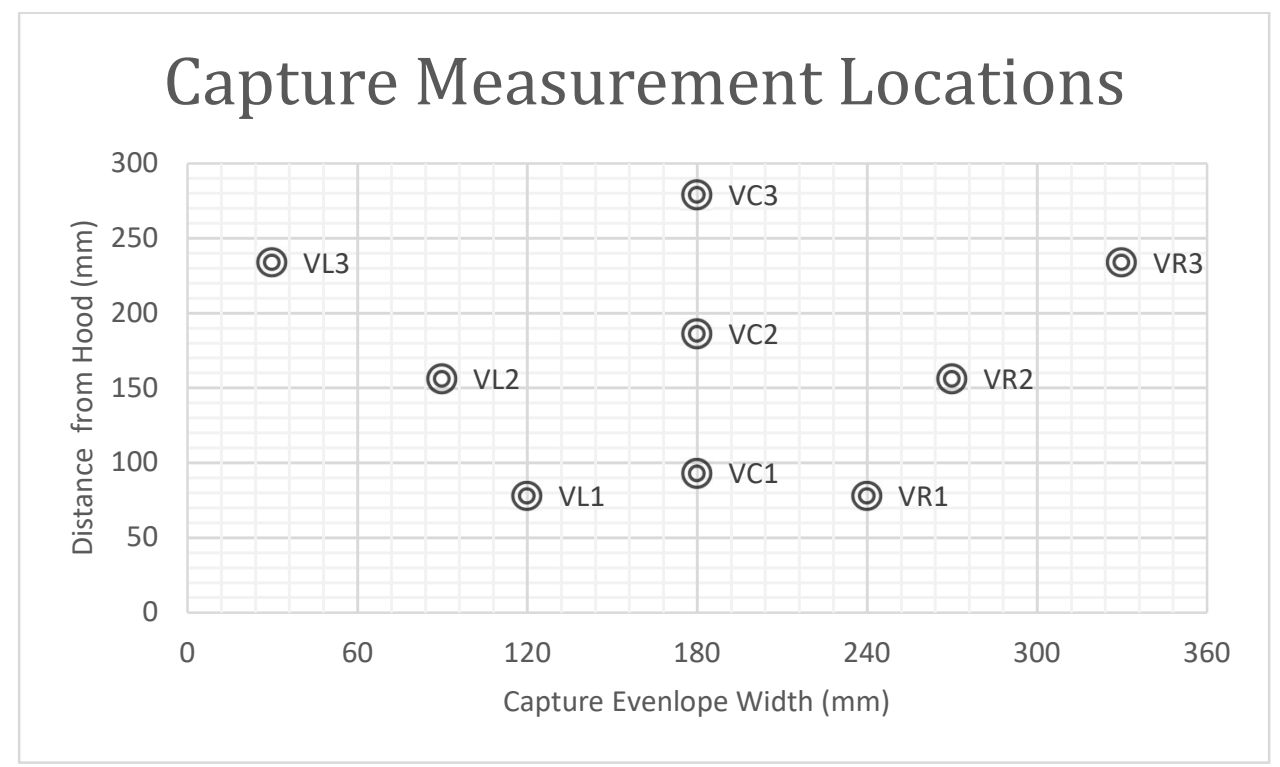

Figure 4-1 PIV Capture Measurement Locations

The independent variables include three levels of draft velocity $\left(\mathrm{V}_{\text {draft }}\right)$, three levels of nominal capture velocity $\left(\mathrm{V}_{\text {cap }}\right)$, three levels of hood orientation, and two levels of manikin presence. The three levels of $\mathrm{V}_{\text {draft }}$ were 30,60 , and $120 \mathrm{fpm}$. The three levels of $\mathrm{V}_{\text {cap }}$ were 50 , 
100 , and $200 \mathrm{fpm}$. The three levels of hood orientation were $0^{\circ}, 90^{\circ}$, and $180^{\circ}$, with cross drafts blowing at the operator's back, side, and front, respectively. The two levels of manikin presence were present and not present. With three levels of $\mathrm{V}_{\text {draft, }}$ three levels of $\mathrm{V}_{\text {cap }}$, three levels of hood orientation, two levels of manikin presence, and two replications, there were 108 total randomized treatments within this study. The PIV study design is shown in Table 4-1.

Table 4-1 PIV Study Design

\begin{tabular}{cccc}
\hline $\mathrm{V}_{\text {cap }}(\mathrm{fpm})$ & $\mathrm{V}_{\text {draft }}(\mathrm{fpm})$ & Orientation $\left(^{\circ}\right)$ & $\begin{array}{c}\text { Operator } \\
\text { Present }\end{array}$ \\
\hline 50 & 30 & 0 & Yes \\
100 & 60 & 90 & No \\
200 & 120 & 180 & \\
\hline
\end{tabular}

\subsection{Methods}

Olive oil particles generated by a Six-Jet Atomizer 9306 (TSI, inc.) were fed into the mixing chamber, located in front of the working area of the wind tunnel. The mixing chamber consisted of a French drain piping system wrapped into a sharp U-shape. An additional fan was placed inside the chamber to ensure well-mixing of the particles, for even distribution. The particles were then released through even slots prior to entering the testing chamber, with assistance from the wind tunnel fan (see Figure 3-14).

The velocity of the capture envelop was measured by firing the Solo III-15Hz LASER (Figure 3-16), recording the particle displacement with a HiSense Type 13 camera, and recording the data with Dantec's Dynamics FlowMap 1500 control system. The orientation of the design can be seen in Figure 3-18.

Each individual capture from the PIV yielded 4977 data points spanning across a $(79 * 63$ $\mathrm{mm}$ ) capture envelope. Each condition consisted of 50 captures, for a total of 248,850 data points per treatment. The average hood face velocity alone, for a single condition, consisted of approximately 3,000 data points. The average velocity throughout the capture envelope consisted of 200 data points per each individual point throughout the capture envelope. The volume of data collected for each condition is $400 \%$ more than what was found to be necessary to obtain consistent results during preliminary trials. 


\subsection{Procedures}

The testing procedures for this study are grouped as follows:

- PIV Analyzing System Preparation

- Calibration and Validation

- Environmental Measurements

- Hood and Wind Tunnel Control Systems Preparation

- Particle Seeding Release System Preparation

- Sampling

- Velocity Measurements

- Analyzing Samples

\subsubsection{PIV Analyzing System Preparation}

1. Turn on PIV system (camera, laser, computer, and software) and allow it to warm up (will beep to prompt ready)

2. Sync laser with computer system to allow remote access.

3. Ensure laser is set to maximum intensity, provided sufficiently dark room and background

\subsubsection{Calibration and Validation}

1. Focus camera lens

2. Calibrate camera with metric ruler level with camera at laser cross sectional area

3. Calibrate PVM-100 micromanometer using process described in section 3.3.3.1

4. Periodically validate micromanometer accuracy

5. Ensure light is off at all time and validate lowest setting F-stop on camera lens

\subsubsection{Environmental Measurements}

1. Wet the cotton wick of the psychrometer with distilled water

2. Turn psychrometer on inside the wind tunnel as it is enclosed

3. Record wet bulb and dry bulb temperatures

4. Record atmospheric pressure with mercury barometer

5. Record temperature of manikin's arms and chest

\subsubsection{Hood and Wind Tunnel Control Systems Preparation}

1. Turn on the hood and wind tunnel fans 
2. Adjust inverter controllers to meet desired testing conditions

\subsubsection{Particle Seeding Release System Preparation}

1. Ensure sufficient olive oil in atomizer reservoir

2. Turn on fan in mixing chamber

3. Turn on wind tunnel before releasing six jets of olive oil particles

\subsubsection{Sampling}

1. Fire laser and monitor camera, cross correlation, and streamlines in live stream before recording

2. Once streamlines and cross correlation lines are smooth and there are clear individual particles, PIV system is ready for sampling

3. Fire laser to record 50 averaged samples per condition

\subsubsection{Velocity Measurements}

1. Measure pitot traverse method for two perpendicular lines of 10 points plus centerlines.

2. Enter all velocity pressure and static pressure data into HvMeasurement software to calculate the average volumetric flow rate and face velocity.

3. Compare face velocity measured with PIV to ensure approximately the same as face velocity found with pitot traverse method

4. If face velocity measurements are significantly different, return to 4.4 .2

\subsubsection{Analyzing Samples}

1. Highlight all individual velocities recorded in sample and right-click to obtain average cross correlation for entire set of data

2. Extract data to text file or spreadsheet for additional analysis

\subsection{Data Analysis}

Dantec Dynamics FlowMap software provided a cross correlation of the vectors throughout the capture envelope. This data was extracted to MATLAB where two separate programs were generated to analyze the velocities throughout the centerline and various select velocities throughout the capture envelope (see Figure 4-1). Binary differences in conditions were analyzed using the percent difference (Equation 4-1).

$$
\% \text { Difference }=\left(\frac{\left|V_{1}-V_{2}\right|}{\frac{V_{1}+V_{2} \mid}{2}}\right) \times 100
$$


JMP was used to perform ANOVA and accompanying effects test for the velocity points throughout the entire capture envelope.

\subsection{Results}

The results of the PIV study are listed in two main subsections: the effects of manikin presence and hood orientation on the centerline velocity and points within the capture envelope.

\subsubsection{Effects of Manikin Presence on Centerline Velocity with Varying Cross Drafts}

The centerline velocity results in this section are categorized by hood orientation and nominal capture velocity. The graphical representation of the data illustrates the normalized ratio of the measured velocity across the centerline $\left(V_{x}\right)$ over the average face velocity $\left(V_{\text {face }}\right)$ for each respective condition. Each normalized graph with the presence of a manikin is compared with the same conditions without the presence of a manikin. Since the denominator of the Y-axis $\left(\mathrm{V}_{\text {face }}\right)$ is significantly larger than velocities extending beyond 11", all datasets without negative (escaping velocity) are accompanied by a log-transformed graph. The two datasets were then compared by calculating the percent difference (see Equation 4-1).

Figure 4-2 and Figure 4-3 represent the manikin present and no manikin present conditions at the 0-degree orientation, with a nominal $50 \mathrm{fpm}$ capture velocity. Figure 4-4 and Figure 4-5 represent the log-transformed versions of the same data. The effect of the manikin's presence under these conditions is calculated as the percent difference and listed in Table 4-2. The effect of the manikin at the $0^{\circ}$ orientation and a nominal $50 \mathrm{fpm}$ capture velocity is modest with a 30 fpm cross draft, modest with a $60 \mathrm{fpm}$ cross draft, until several inches away from the hood face, and large throughout with a $120 \mathrm{fpm}$ cross draft. The results for the $60 \mathrm{fpm}$ cross draft are consistent with what Lewis (2010) found for his $50 \mathrm{fpm}$ cross draft with a manikin and table present. 


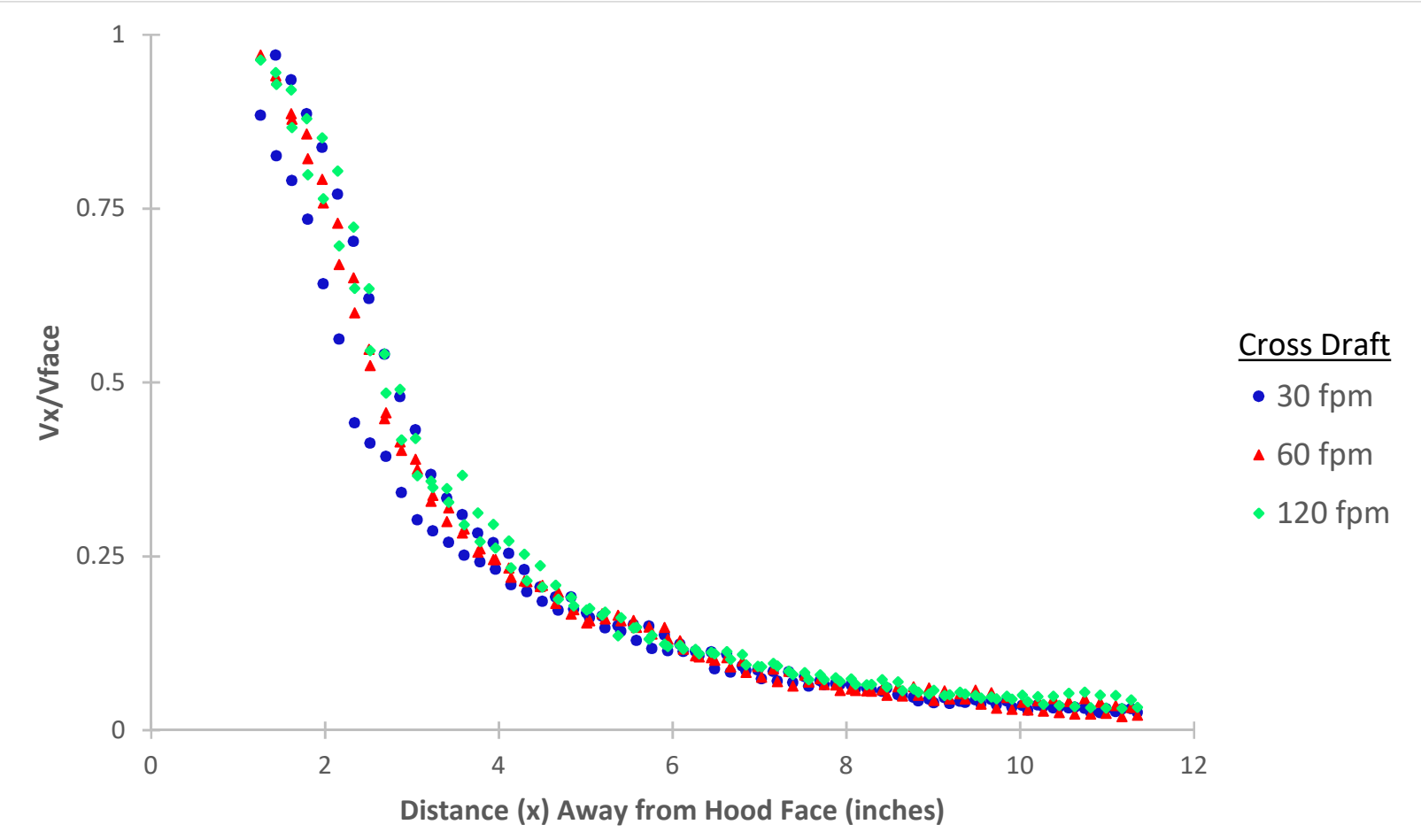

Figure 4-2 Condition: Manikin $+0^{\circ}+50 \mathrm{fpm} \mathrm{V}_{\text {capnom }}$

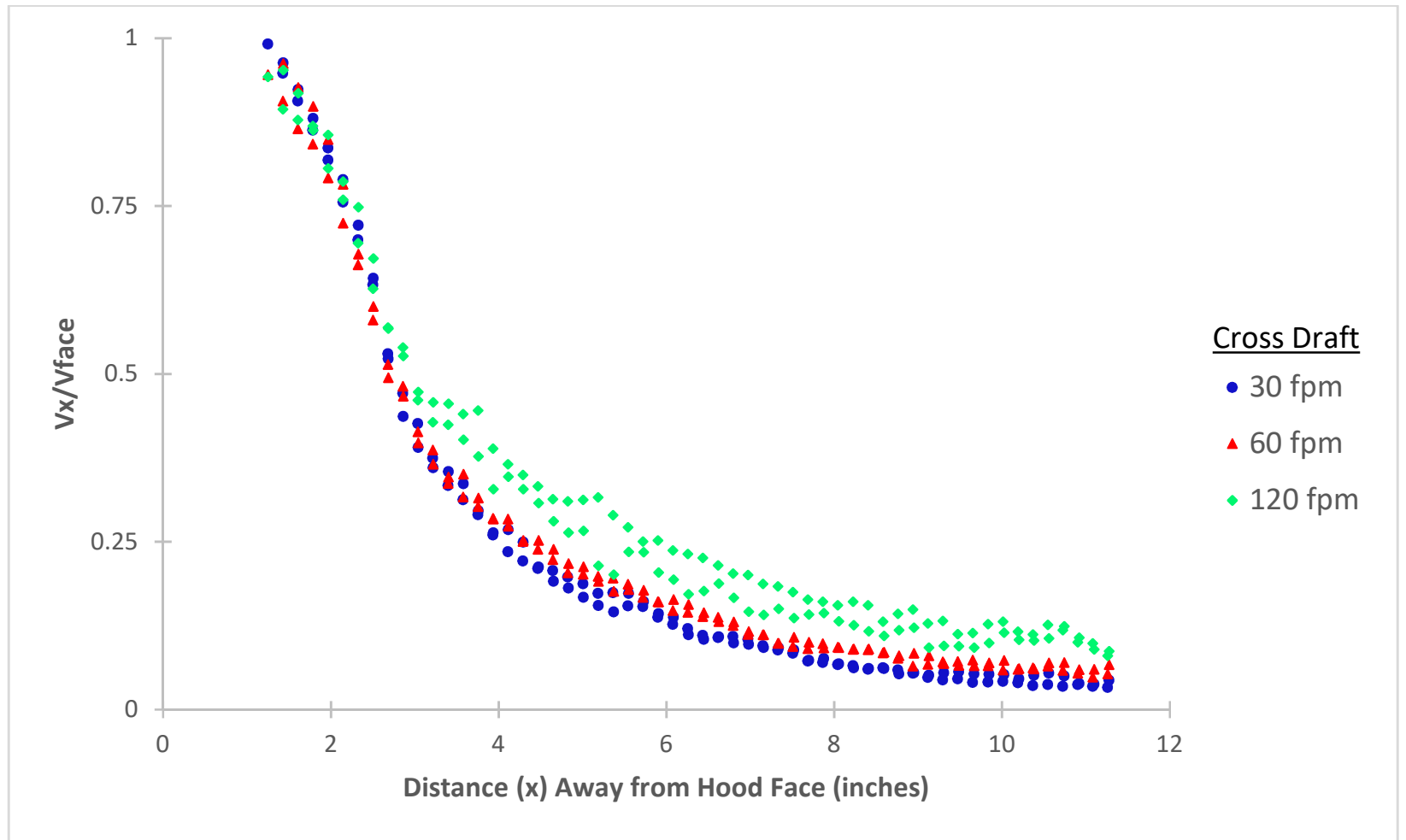

Figure 4-3 Condition: No Manikin $+0^{\circ}+50 \mathrm{fpm} \mathrm{V}_{\text {capnom }}$ 


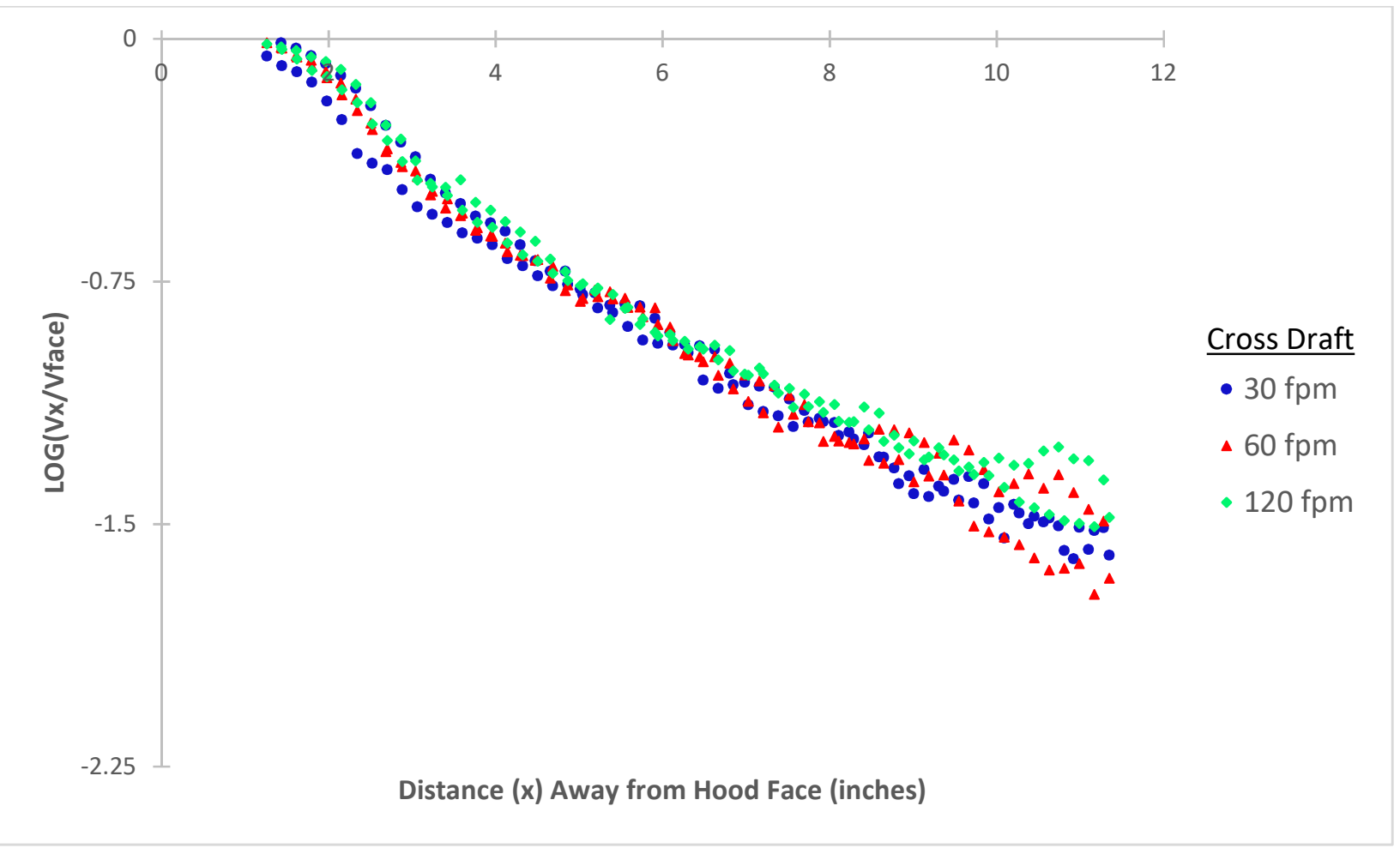

Figure 4-4 Log Transformed - Condition: Manikin + $0^{\circ}+50 \mathrm{fpm} \mathrm{V}_{\text {capnom }}$

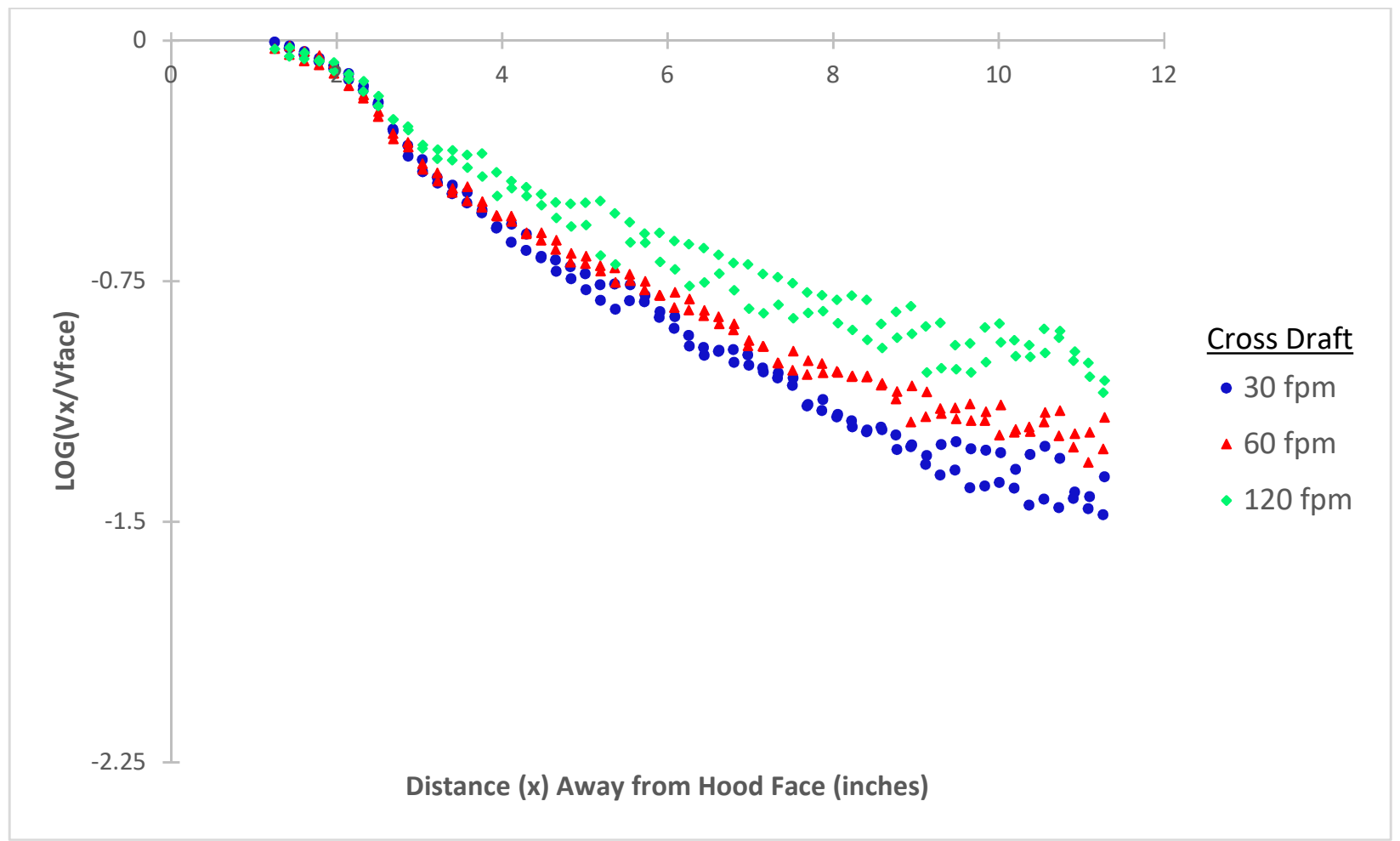

Figure 4-5 Log Transformed - Condition: No Manikin $+0^{\circ}+50 \mathrm{fpm} \mathrm{V}_{\text {capnom }}$ 
Table 4-2 Percent Difference Between Manikin vs No Manikin ( $\left.0^{\circ}, 50 \mathrm{~V}_{\text {capnom }}\right)$

\begin{tabular}{cccc}
\hline \multicolumn{3}{c}{ Cross Draft } \\
\hline X(in) & $30 \mathrm{fpm}$ & $60 \mathrm{fpm}$ & $120 \mathrm{fpm}$ \\
\hline 2 & 21.6 & 16.0 & 10.3 \\
3 & 22.1 & 19.7 & 27.8 \\
4 & 12.2 & 22.8 & 34.7 \\
5 & 13.2 & 23.8 & 53.3 \\
6 & 16.9 & 27.1 & 62.8 \\
7 & 26.5 & 36.9 & 59.4 \\
8 & 13.2 & 49.4 & 74.9 \\
9 & 25.0 & 38.3 & 91.5 \\
10 & 28.4 & 62.3 & 97.4 \\
11 & 30.0 & 70.9 & 88.2 \\
\hline
\end{tabular}

Figure 4-6 and Figure 4-7 represent the manikin present and no manikin present conditions at the 0-degree orientation, with a nominal $100 \mathrm{fpm}$ capture velocity. Figure 4-8 and Figure 4-9 represent the log-transformed versions of the same data. The effect of the manikin's presence under these conditions is calculated as the percent difference and listed in Table 4-3. The effect of the manikin at the $0^{\circ}$ orientation and a nominal $100 \mathrm{fpm}$ capture velocity is modest with a 30 fpm cross draft, modest with a $60 \mathrm{fpm}$ cross draft, until several inches away from the hood face, and large throughout with a $120 \mathrm{fpm}$ cross draft. 


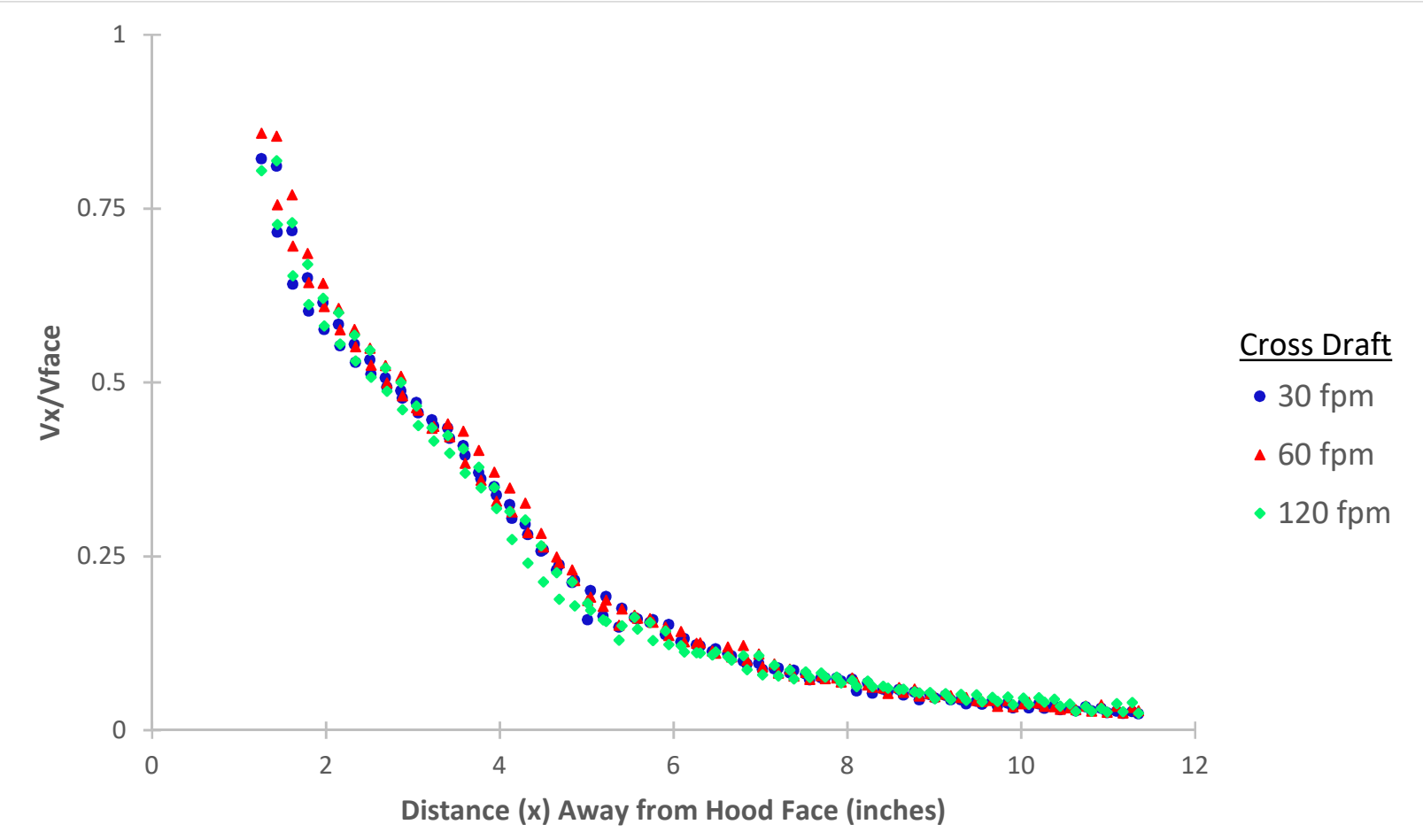

Figure 4-6 Condition: Manikin $+0^{\circ}+100 \mathrm{fpm} \mathrm{V}_{\text {capnom }}$

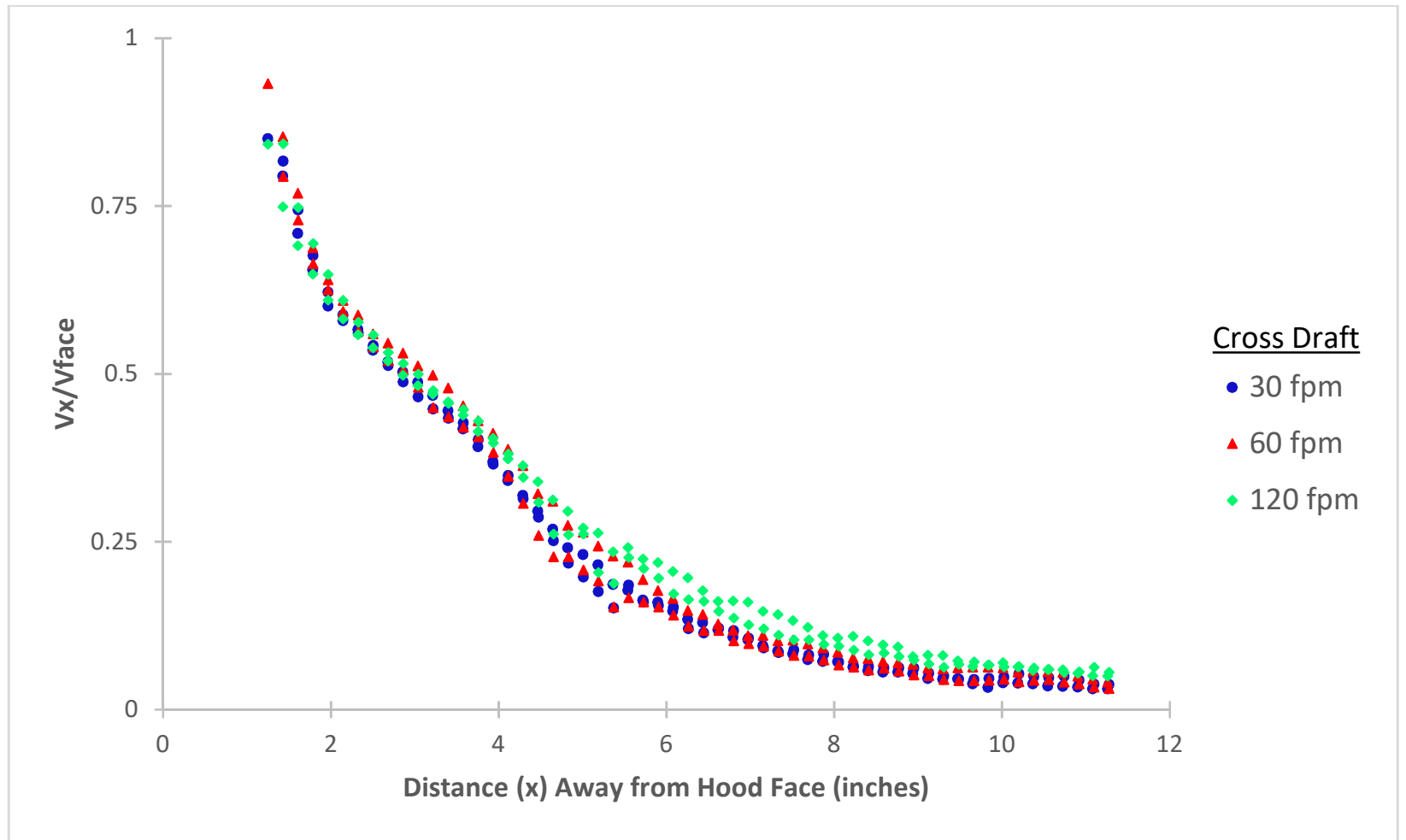

Figure 4-7 Condition: No Manikin $+0^{\circ}+100 \mathrm{fpm} \mathrm{V}_{\text {capnom }}$ 


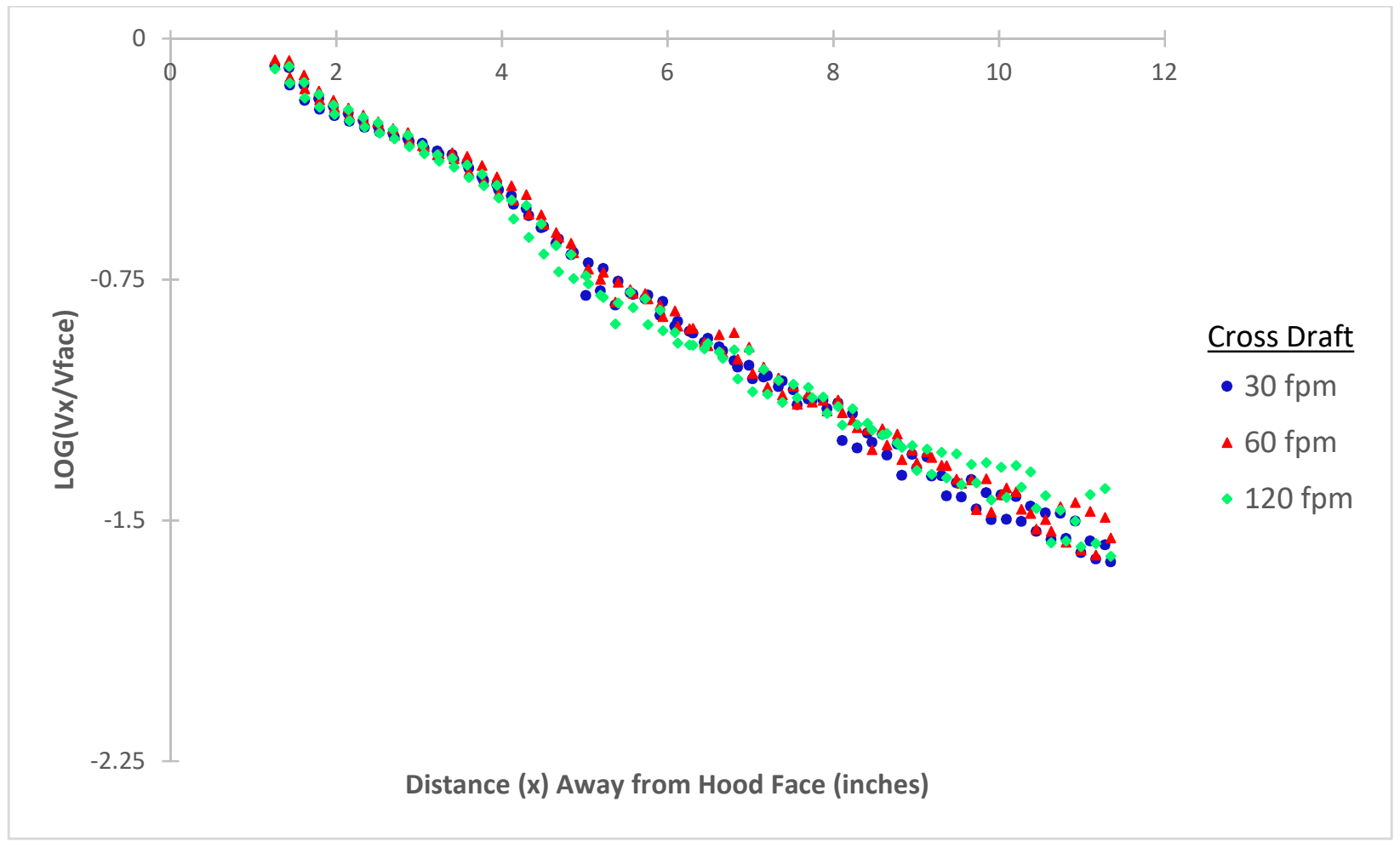

Figure 4-8 Log-Transformed Condition: Manikin $+0^{\circ}+100 \mathrm{fpm} \mathrm{V}_{\text {capnom }}$

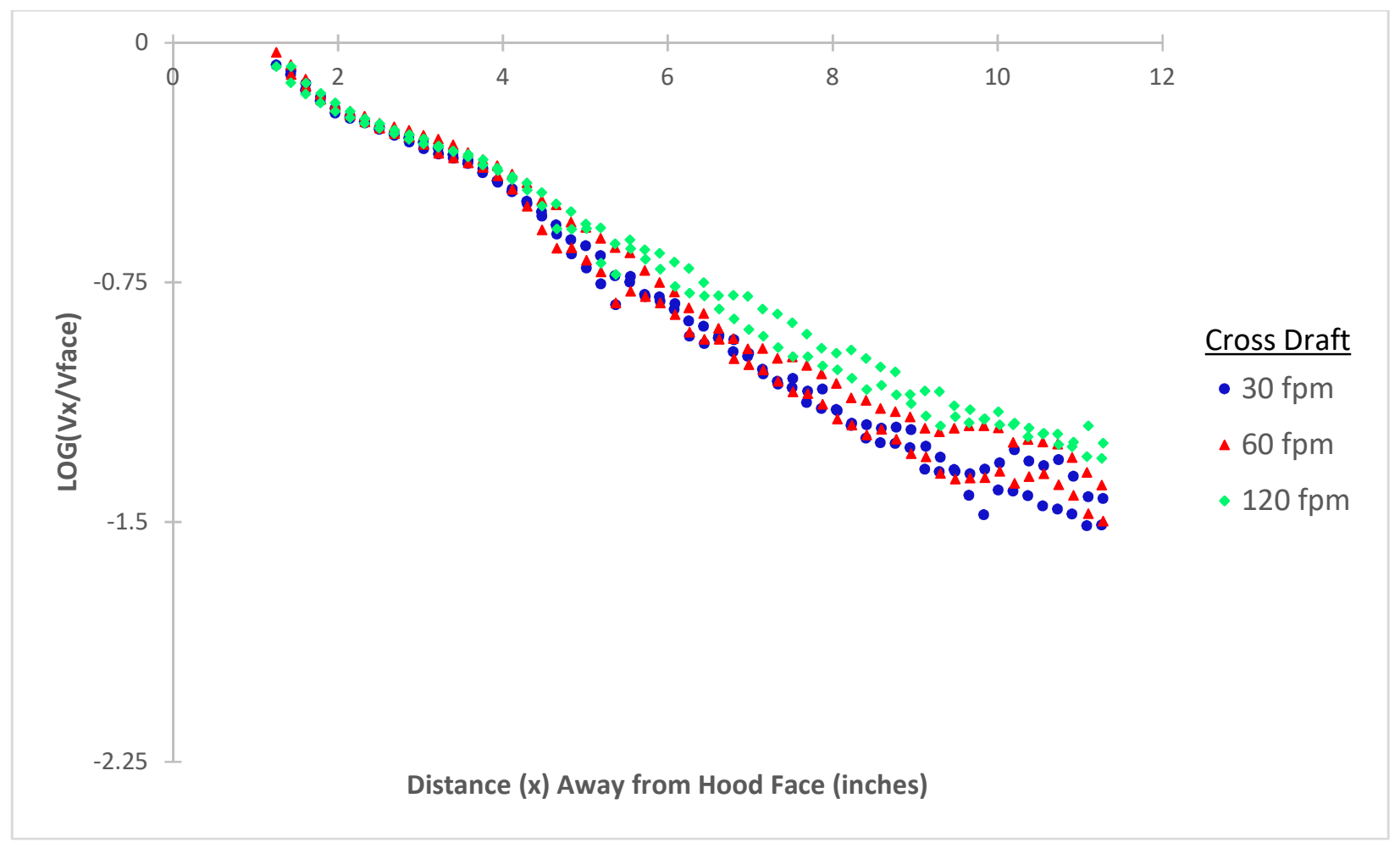

Figure 4-9 Log-Transformed Condition: No Manikin $+0^{\circ}+100 \mathrm{fpm} \mathrm{V}_{\text {capnom }}$ 
Table 4-3 Percent Difference Between Manikin vs No Manikin $\left(0^{\circ}, 100 \mathrm{~V}_{\text {capnom }}\right)$

\begin{tabular}{cccc}
\hline \multicolumn{3}{c}{ Cross Draft } \\
\hline $\mathrm{X}$ (in) & $30 \mathrm{fpm}$ & $60 \mathrm{fpm}$ & $120 \mathrm{fpm}$ \\
\hline 2 & 2.7 & 1.2 & 4.6 \\
3 & 2.8 & 7.2 & 8.3 \\
4 & 6.7 & 12.7 & 18.2 \\
5 & 17.7 & 22.4 & 40.0 \\
6 & 8.7 & 15.2 & 43.8 \\
7 & 14.1 & 4.1 & 42.5 \\
8 & 9.2 & 6.1 & 40.1 \\
9 & 17.7 & 17.7 & 42.7 \\
10 & 23.3 & 32.4 & 46.1 \\
11 & 31.4 & 36.3 & 63.2 \\
\hline
\end{tabular}

Figure 4-10 and Figure 4-11 represent the manikin present and no manikin present conditions at the 0-degree orientation, with a nominal $200 \mathrm{fpm}$ capture velocity. Figure 4-12 and Figure 4-13 represent the log-transformed versions of the same data. The effect of the manikin's presence under these conditions is calculated as the percent difference and listed in Table 4-4. The effect of the manikin at the $0^{\circ}$ orientation and a nominal $200 \mathrm{fpm}$ capture velocity is negligible with a $30 \mathrm{fpm}$ cross draft, negligible with a $60 \mathrm{fpm}$ cross draft, and modest with a 120 fpm cross draft, until several inches away from the hood face. 


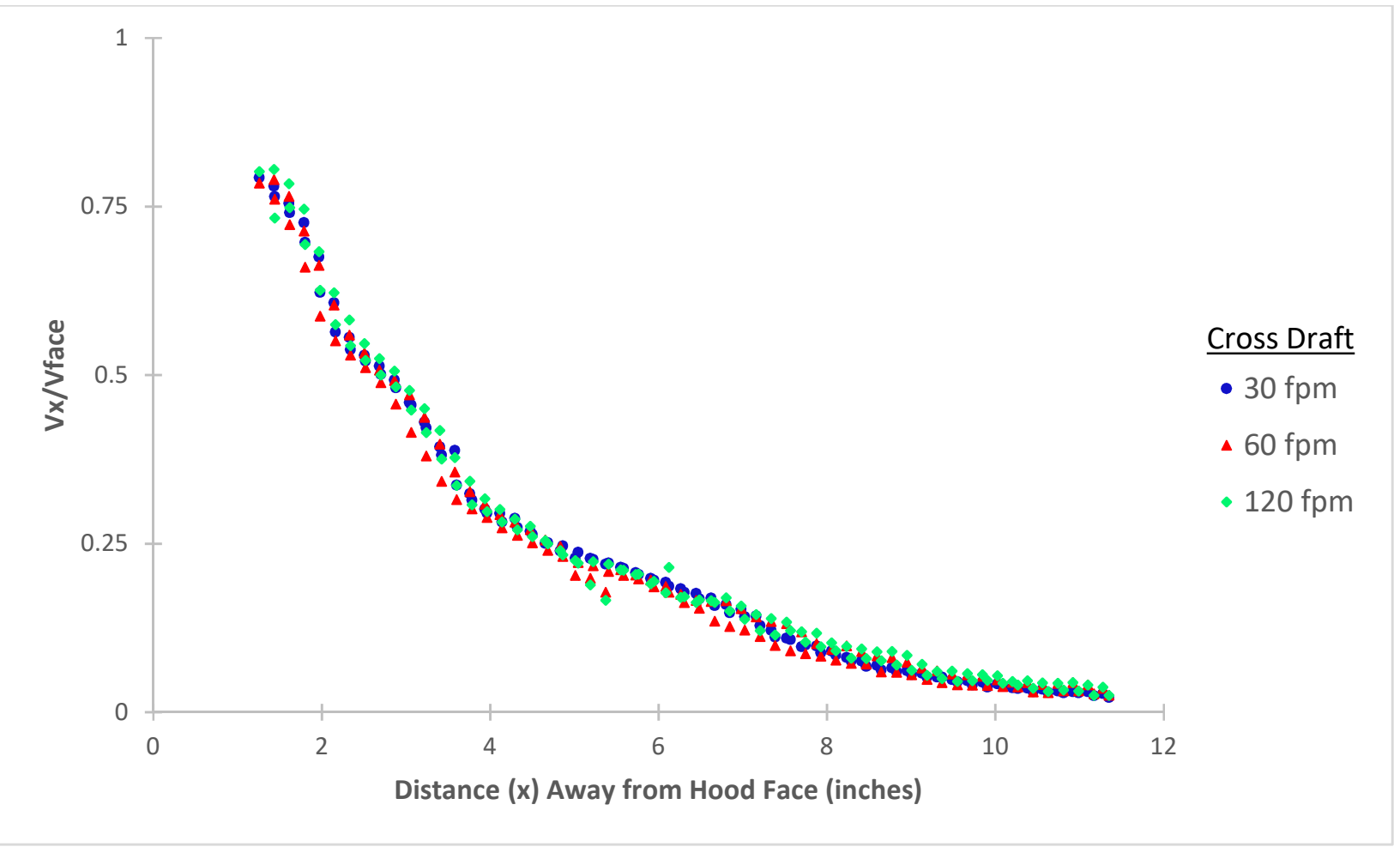

Figure 4-10 Condition: Manikin $+0^{\circ}+200 \mathrm{fpm} \mathrm{V}_{\text {capnom }}$

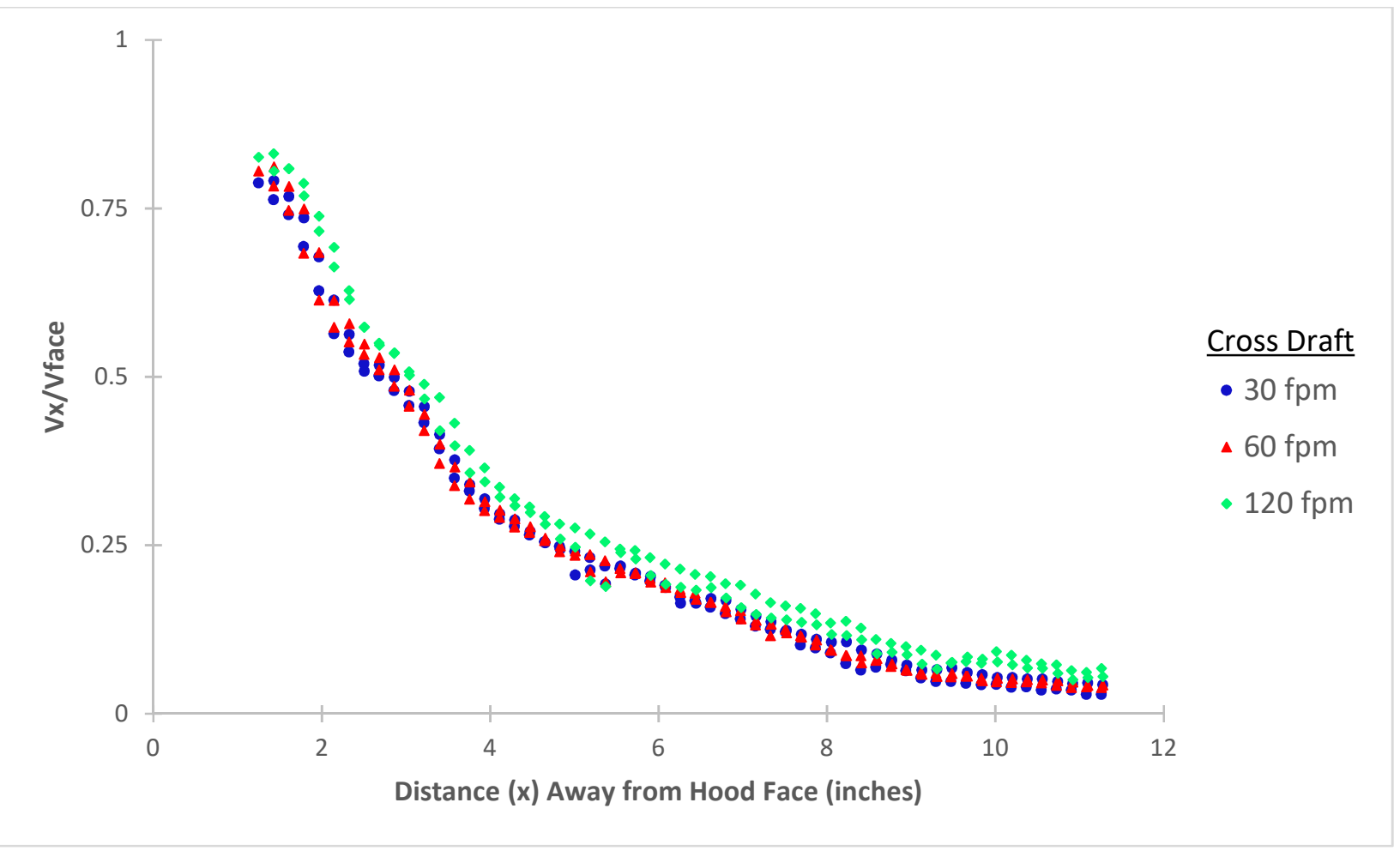

Figure 4-11 Condition: No Manikin $+0^{\circ}+200 \mathrm{fpm} \mathrm{V}_{\text {capnom }}$ 


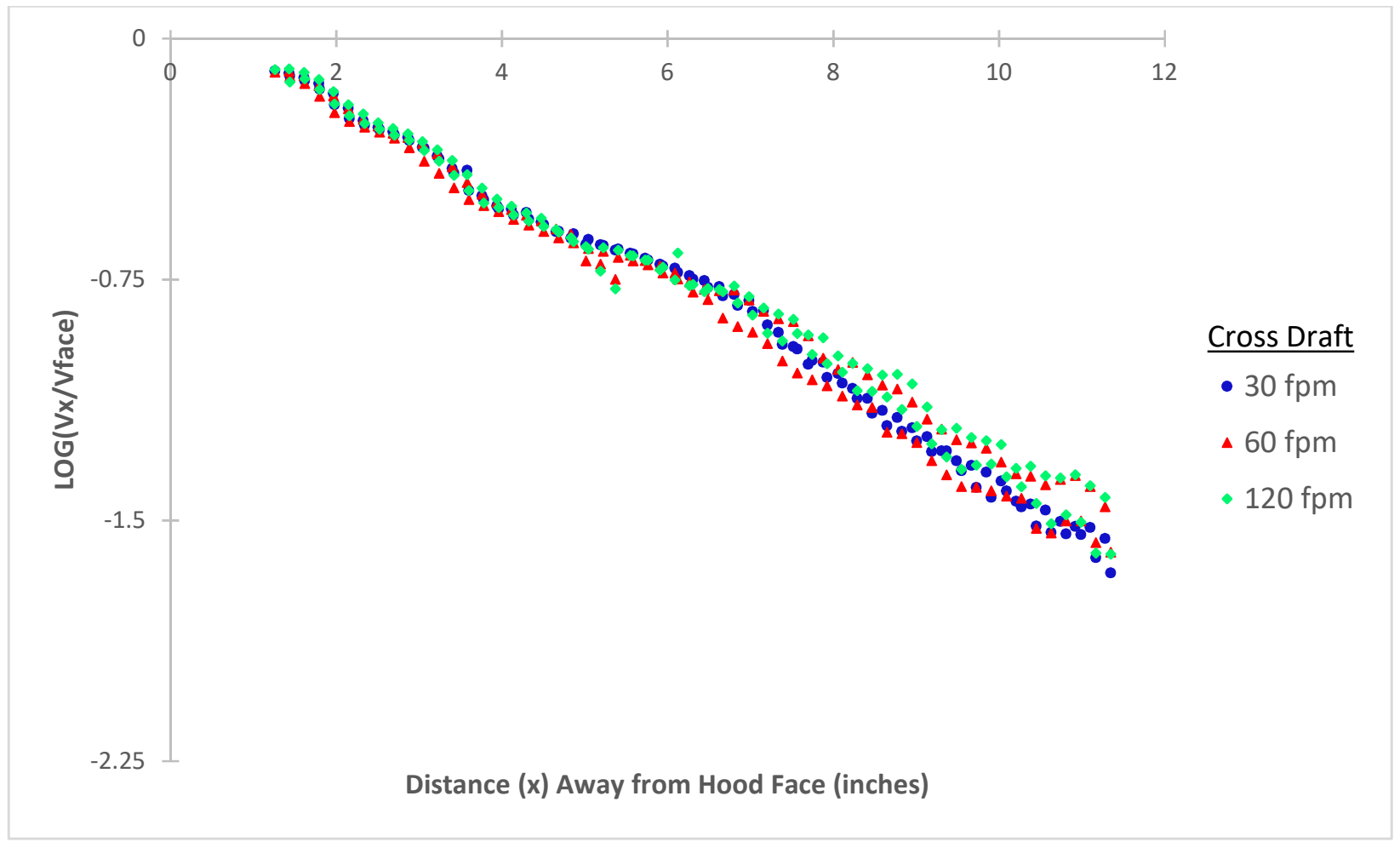

Figure 4-12 Log-Transformed - Condition: Manikin $+0^{\circ}+200 \mathrm{fpm} \mathrm{V}_{\text {capnom }}$

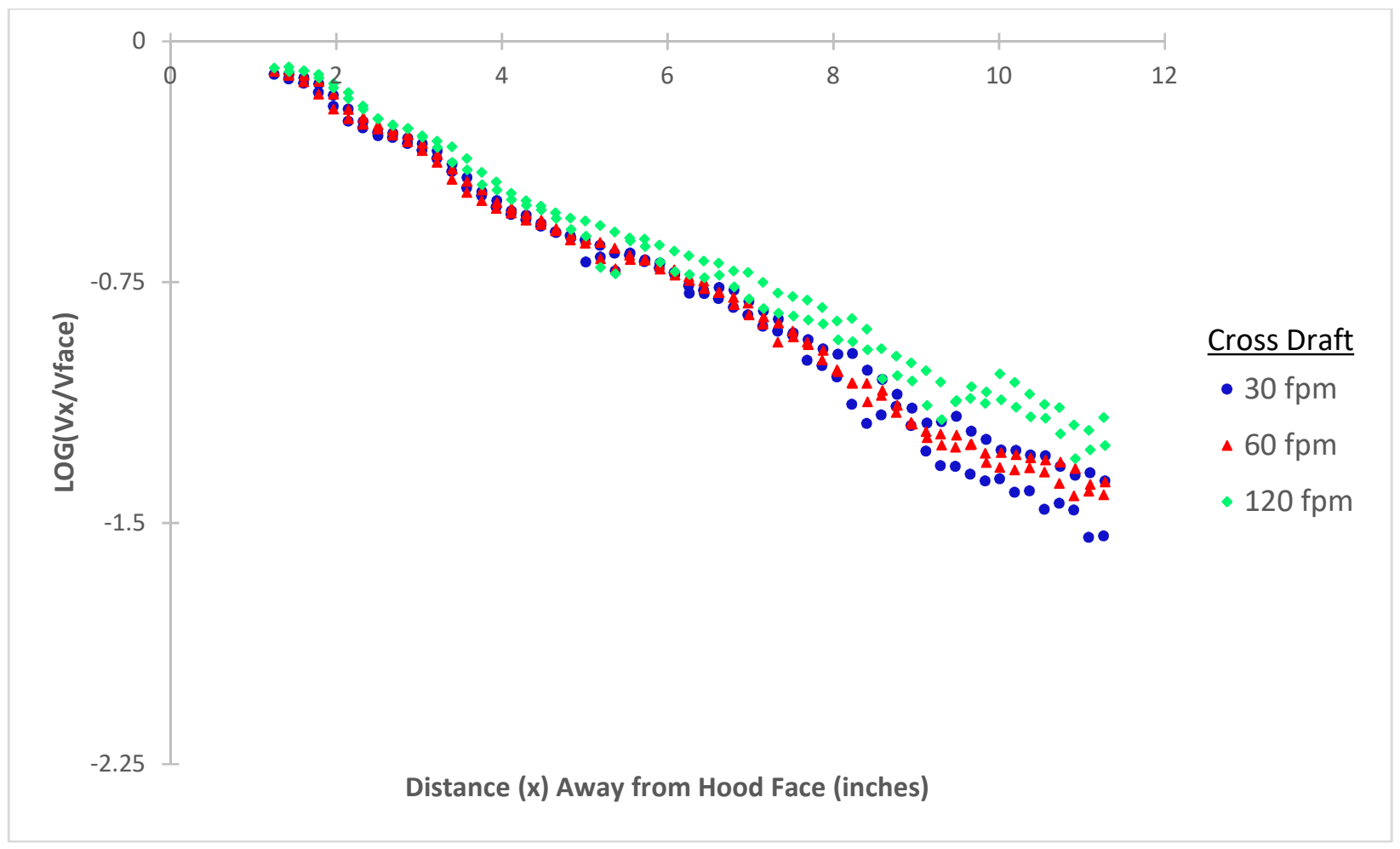

Figure 4-13 Log-Transformed - Condition: No Manikin $+0^{\circ}+200 \mathrm{fpm} \mathrm{V}_{\text {capnom }}$ 
Table 4-4 Percent Difference Between Manikin vs No Manikin ( $\left.0^{\circ}, 200 \mathrm{~V}_{\text {capnom }}\right)$

\begin{tabular}{cccc}
\hline \multicolumn{3}{c}{ Cross Draft } \\
\hline $\mathrm{X}$ (in) & $30 \mathrm{fpm}$ & $60 \mathrm{fpm}$ & $120 \mathrm{fpm}$ \\
\hline 2 & 0.5 & 3.8 & 10.5 \\
3 & 2.2 & 5.6 & 8.7 \\
4 & 4.3 & 3.0 & 14.4 \\
5 & 4.3 & 11.5 & 15.8 \\
6 & 1.5 & 3.5 & 12.9 \\
7 & 0.4 & 6.5 & 16.4 \\
8 & 11.2 & 10.2 & 25.9 \\
9 & 14.6 & 0.3 & 24.7 \\
10 & 17.7 & 15.1 & 53.4 \\
11 & 29.4 & 12.7 & 41.2 \\
\hline
\end{tabular}

Figure 4-14 and Figure 4-15 represent the manikin present and no manikin present conditions at the 90-degree orientation, with a nominal $50 \mathrm{fpm}$ capture velocity. Figure 4-16 and Figure 4-17 represent the log-transformed versions of the same data. The effect of the manikin's presence under these conditions is calculated as the percent difference and listed in Table 4-5. The effect of the manikin at the $90^{\circ}$ orientation and a nominal $50 \mathrm{fpm}$ capture velocity is negligible with a $30 \mathrm{fpm}$ cross draft, modest with a $60 \mathrm{fpm}$ cross draft, and modest with a 120 fpm cross draft, until several inches away from the hood face. 


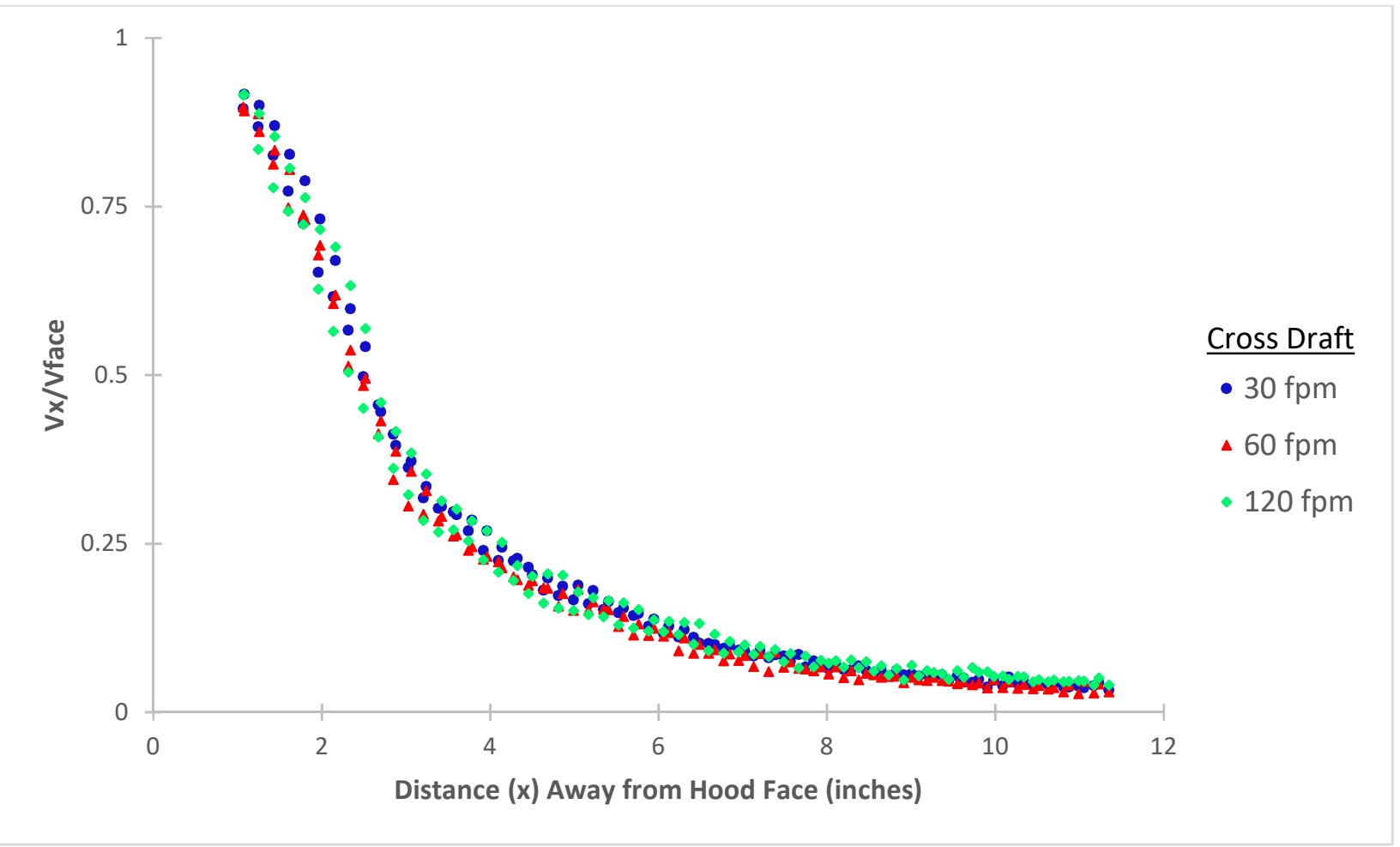

Figure 4-14 Condition: Manikin $+90^{\circ}+50 \mathrm{fpm} \mathrm{V}_{\text {capnom }}$

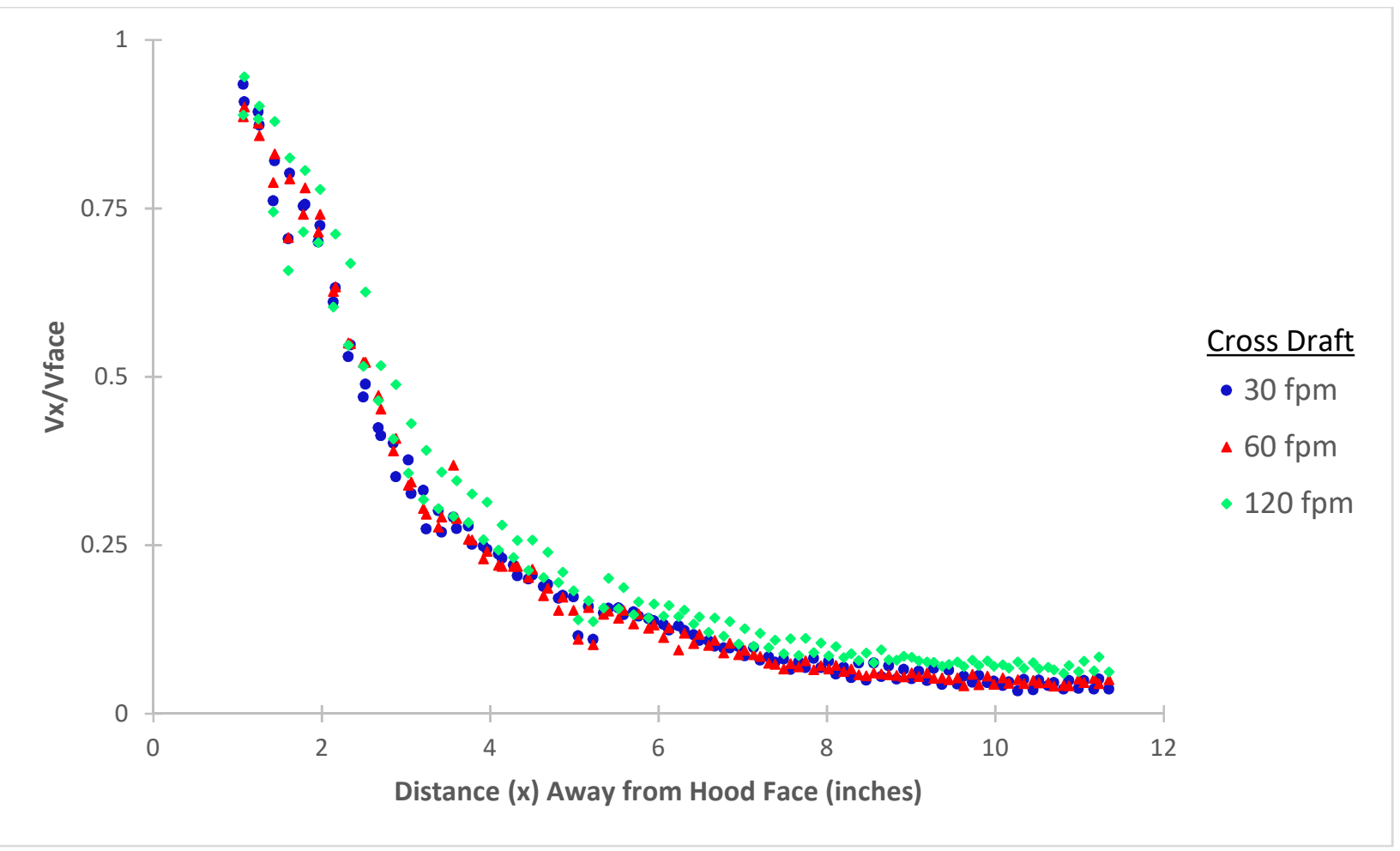

Figure 4-15 Condition: No Manikin $+90^{\circ}+50 \mathrm{fpm} \mathrm{V}_{\text {capnom }}$ 


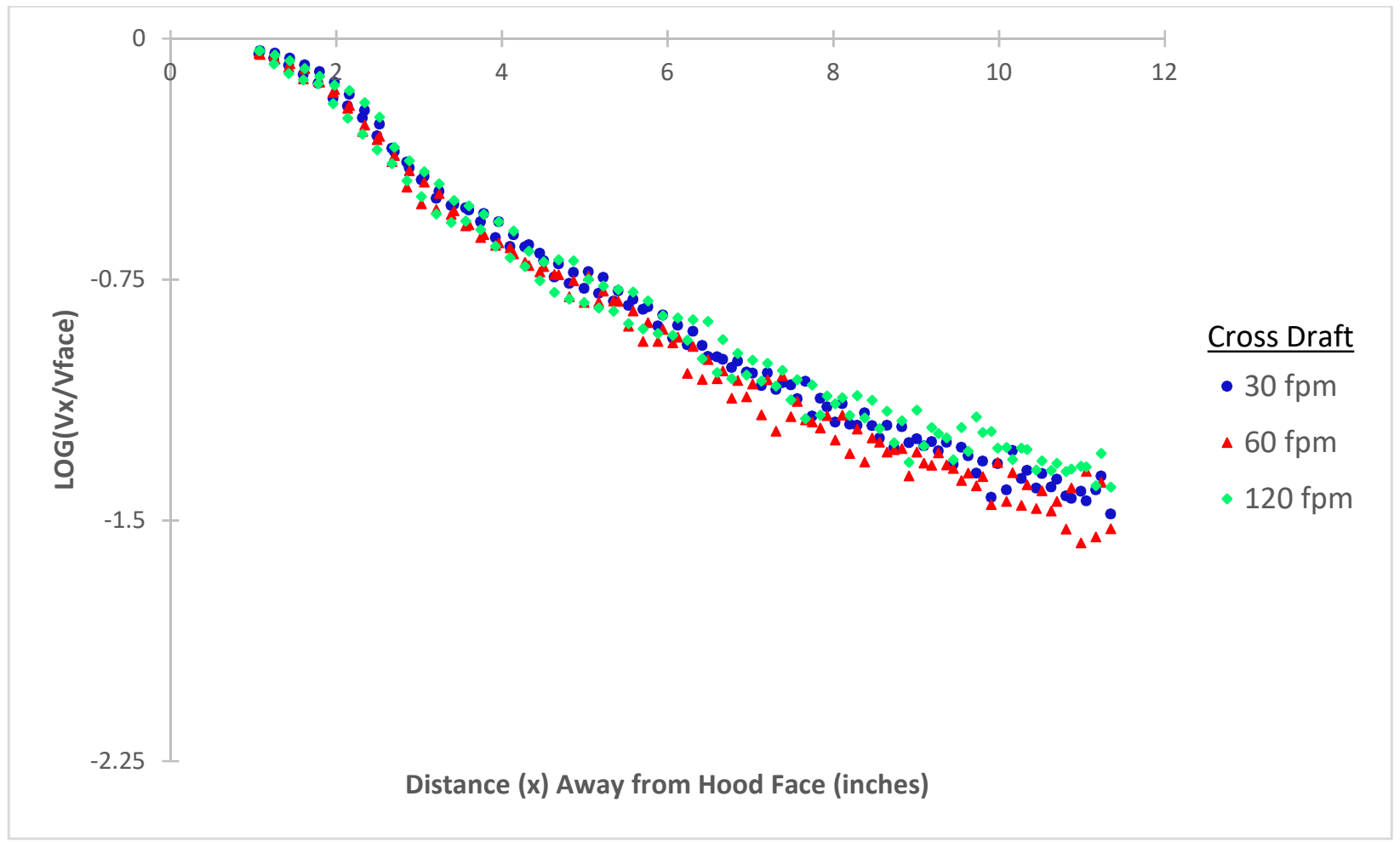

Figure 4-16 Log-Transformed - Condition: Manikin $+90^{\circ}+50 \mathrm{fpm} \mathrm{V}_{\text {capnom }}$

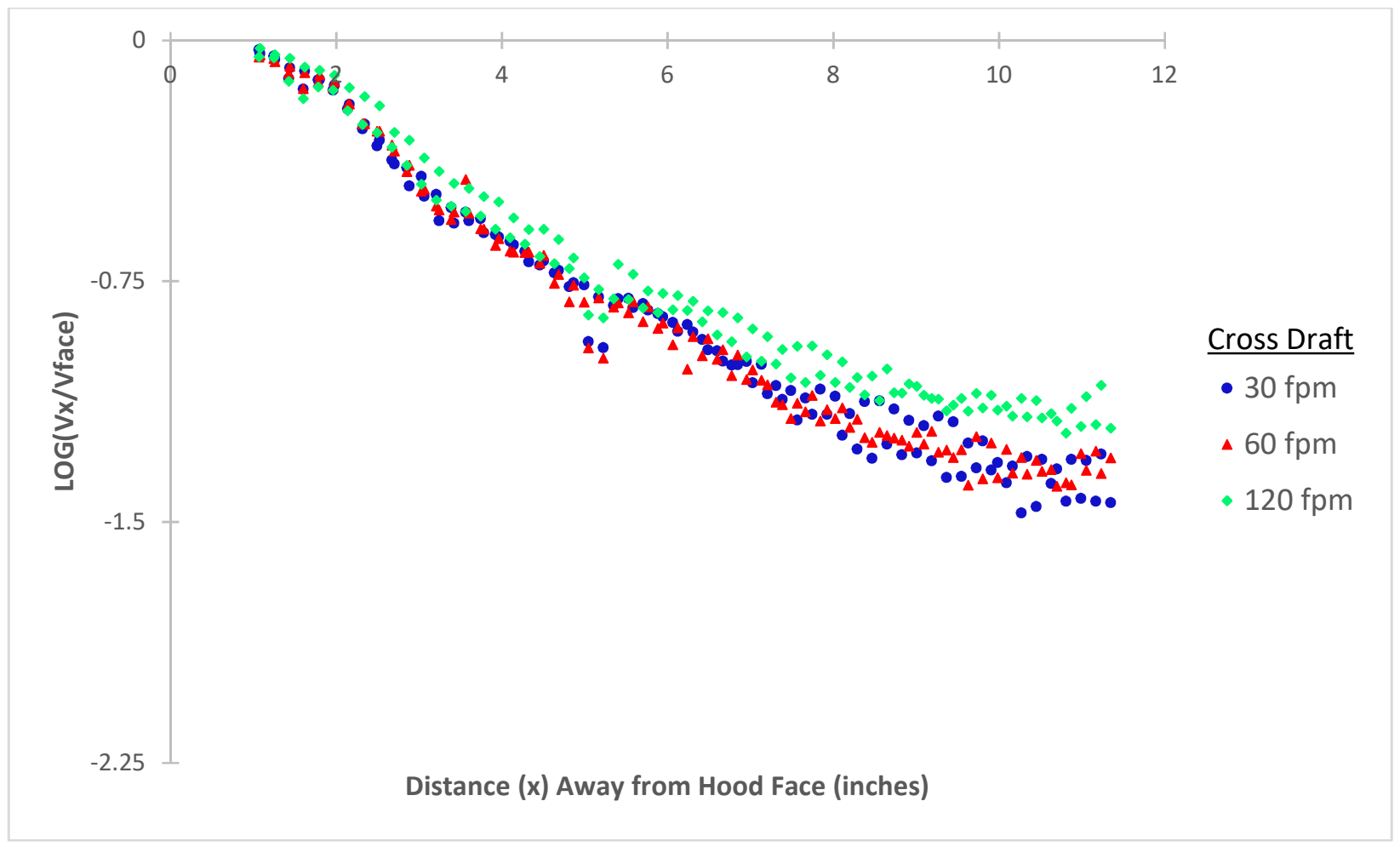

Figure 4-17 Log-Transformed - Condition: No Manikin $+90^{\circ}+50 \mathrm{fpm} \mathrm{V}_{\text {capnom }}$ 
Table 4-5 Percent Difference Between Manikin vs No Manikin $\left(90^{\circ}, 50 \mathrm{~V}_{\text {capnom }}\right)$

\begin{tabular}{cccc}
\hline \multicolumn{3}{c}{ Cross Draft } \\
\hline X(in) & $30 \mathrm{fpm}$ & $60 \mathrm{fpm}$ & $120 \mathrm{fpm}$ \\
\hline 2 & 2.9 & 6.0 & 9.4 \\
3 & 4.4 & 2.9 & 10.7 \\
4 & 3.3 & 2.7 & 14.5 \\
5 & 20.6 & 23.4 & 2.1 \\
6 & 4.7 & 4.2 & 18.3 \\
7 & 1.8 & 12.3 & 19.1 \\
8 & 0.1 & 11.4 & 21.8 \\
9 & 4.8 & 18.9 & 35.7 \\
10 & 3.9 & 14.0 & 29.4 \\
11 & 13.5 & 32.8 & 36.9 \\
\hline
\end{tabular}

Figure 4-18 and Figure 4-19 represent the manikin present and no manikin present conditions at the 90-degree orientation, with a nominal 100 fpm capture velocity. Figure 4-20 and Figure 4-21 represent the log-transformed versions of the same data. The effect of the manikin's presence under these conditions is calculated as the percent difference and listed in Table 4-6. The effect of the manikin at the $90^{\circ}$ orientation and a nominal $100 \mathrm{fpm}$ capture velocity is negligible with a $30 \mathrm{fpm}$ cross draft, negligible with a $60 \mathrm{fpm}$ cross draft, and modest with a 120 fpm cross draft, until several inches away from the hood face. 


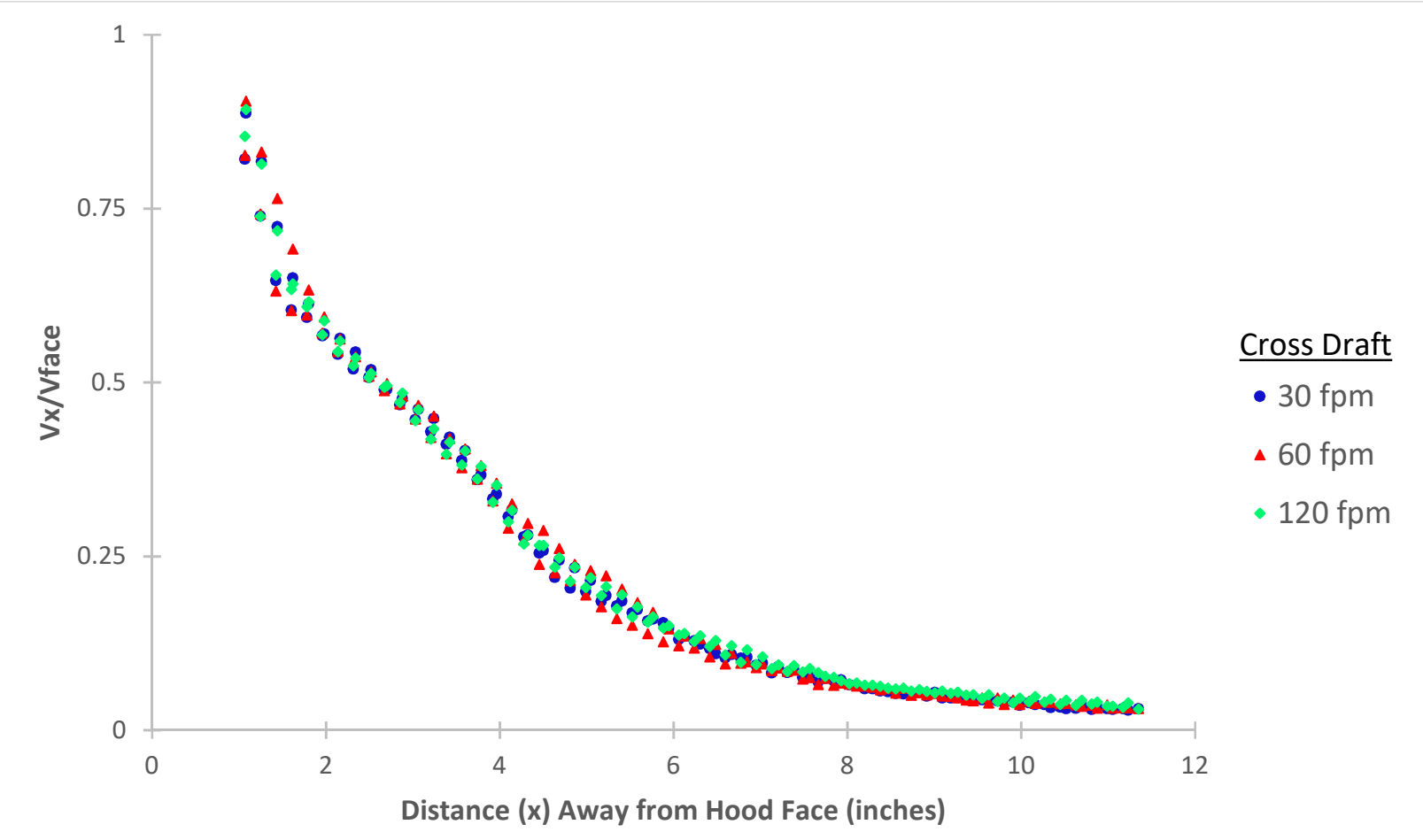

Figure 4-18 Condition: Manikin $+90^{\circ}+100 \mathrm{fpm} \mathrm{V}_{\text {capnom }}$

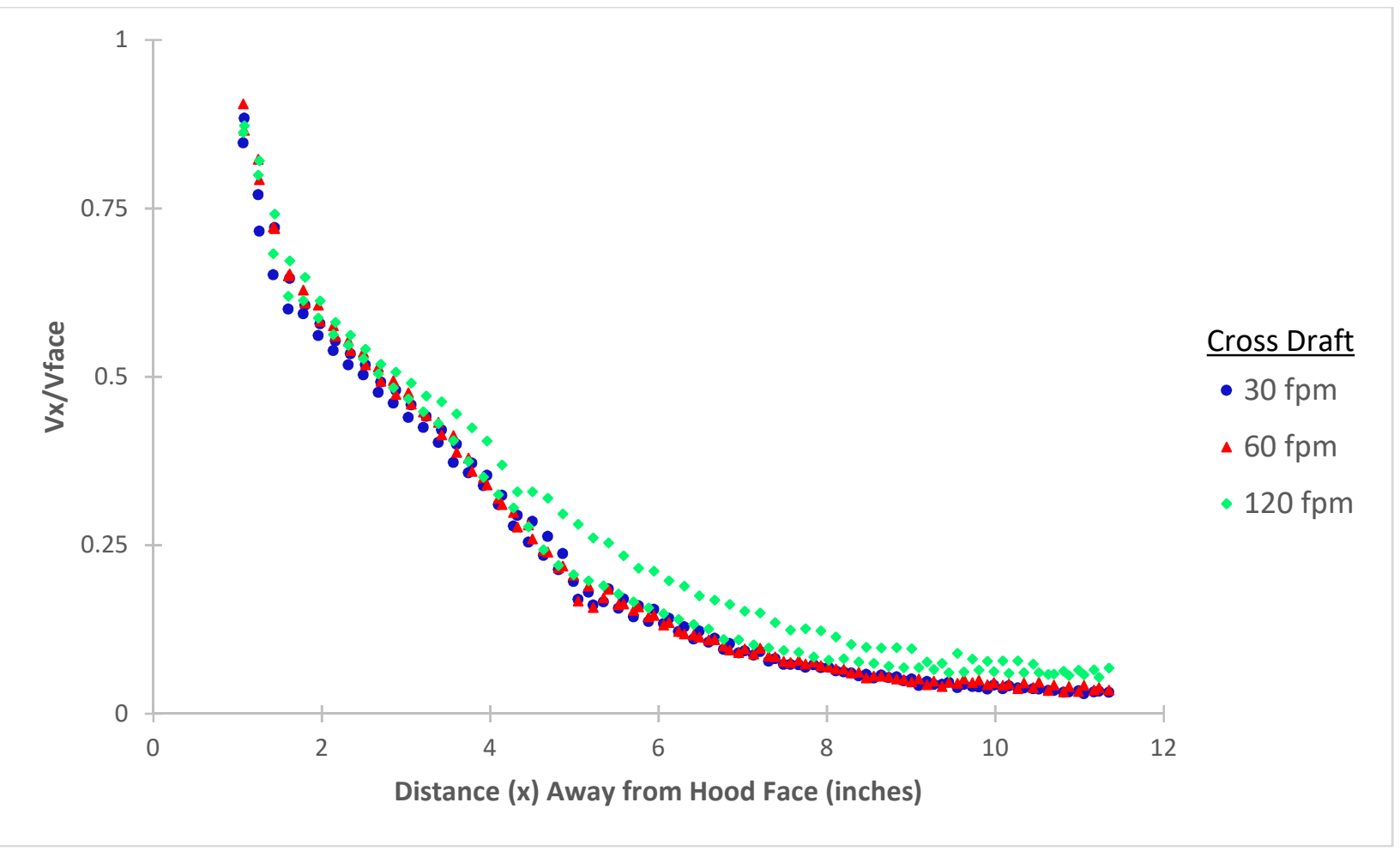

Figure 4-19 Condition: No Manikin $+90^{\circ}+100 \mathrm{fpm} \mathrm{V}_{\text {capnom }}$ 


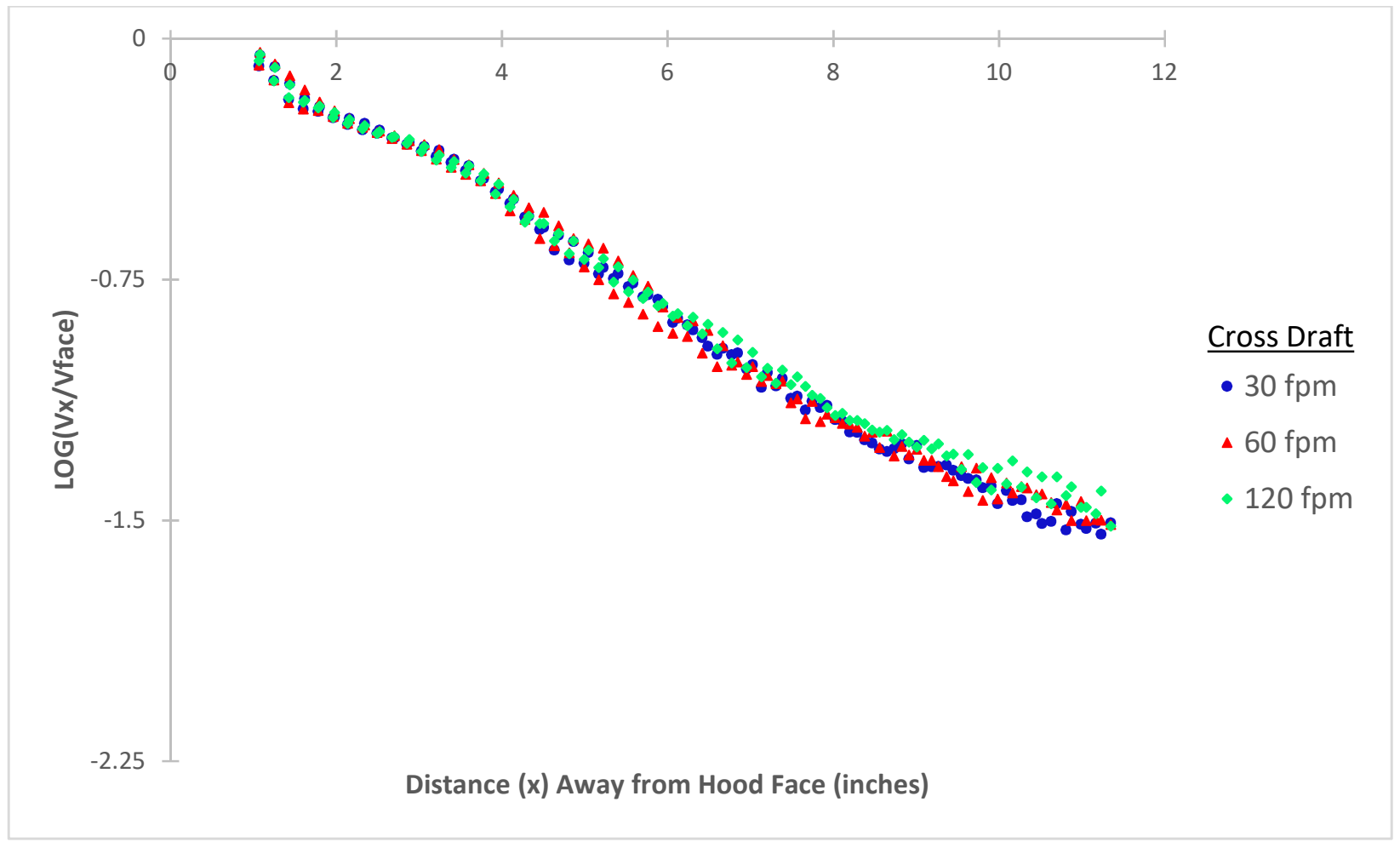

Figure 4-20 Log-Transformed - Condition: Manikin $+90^{\circ}+100 \mathrm{fpm} \mathrm{V}_{\text {capnom }}$

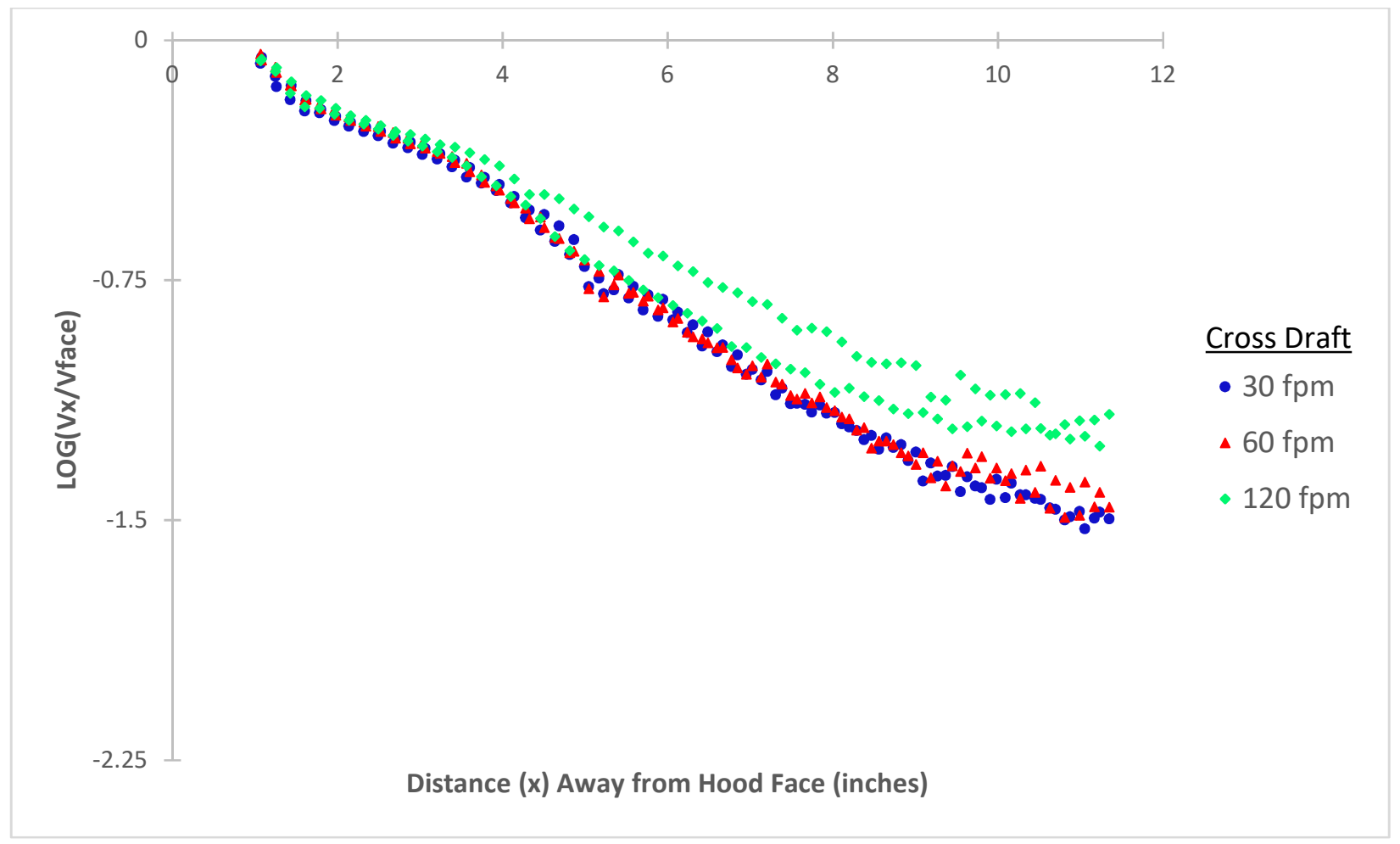

Figure 4-21 Log-Transformed - Condition: No Manikin $+90^{\circ}+100 \mathrm{fpm} \mathrm{V}_{\text {capnom }}$ 
Table 4-6 Percent Difference Between Manikin vs No Manikin $\left(90^{\circ}, 100 \mathrm{~V}_{\text {capnom }}\right)$

\begin{tabular}{cccc}
\hline \multicolumn{3}{c}{ Cross Draft } \\
\hline X(in) & $30 \mathrm{fpm}$ & $60 \mathrm{fpm}$ & $120 \mathrm{fpm}$ \\
\hline 2 & 0.2 & 2.0 & 3.6 \\
3 & 1.2 & 2.3 & 5.5 \\
4 & 3.0 & 0.8 & 10.6 \\
5 & 12.7 & 12.9 & 13.7 \\
6 & 3.4 & 4.0 & 22.4 \\
7 & 3.3 & 0.8 & 26.8 \\
8 & 1.9 & 4.9 & 35.4 \\
9 & 3.1 & 5.6 & 40.6 \\
10 & 6.4 & 12.0 & 47.0 \\
11 & 2.6 & 7.2 & 47.2 \\
\hline
\end{tabular}

Figure 4-22 and Figure 4-23 represent the manikin present and no manikin present conditions at the 90-degree orientation, with a nominal 200 fpm capture velocity. Figure 4-24 and Figure 4-25 represent the log-transformed versions of the same data. The effect of the manikin's presence under these conditions is calculated as the percent difference and listed in Table 4-7. The effect of the manikin at the $90^{\circ}$ orientation and a nominal $200 \mathrm{fpm}$ capture velocity is negligible with a $30 \mathrm{fpm}$ cross draft, negligible with a $60 \mathrm{fpm}$ cross draft, and modest with a 120 fpm cross draft, until several inches away from the hood face. 


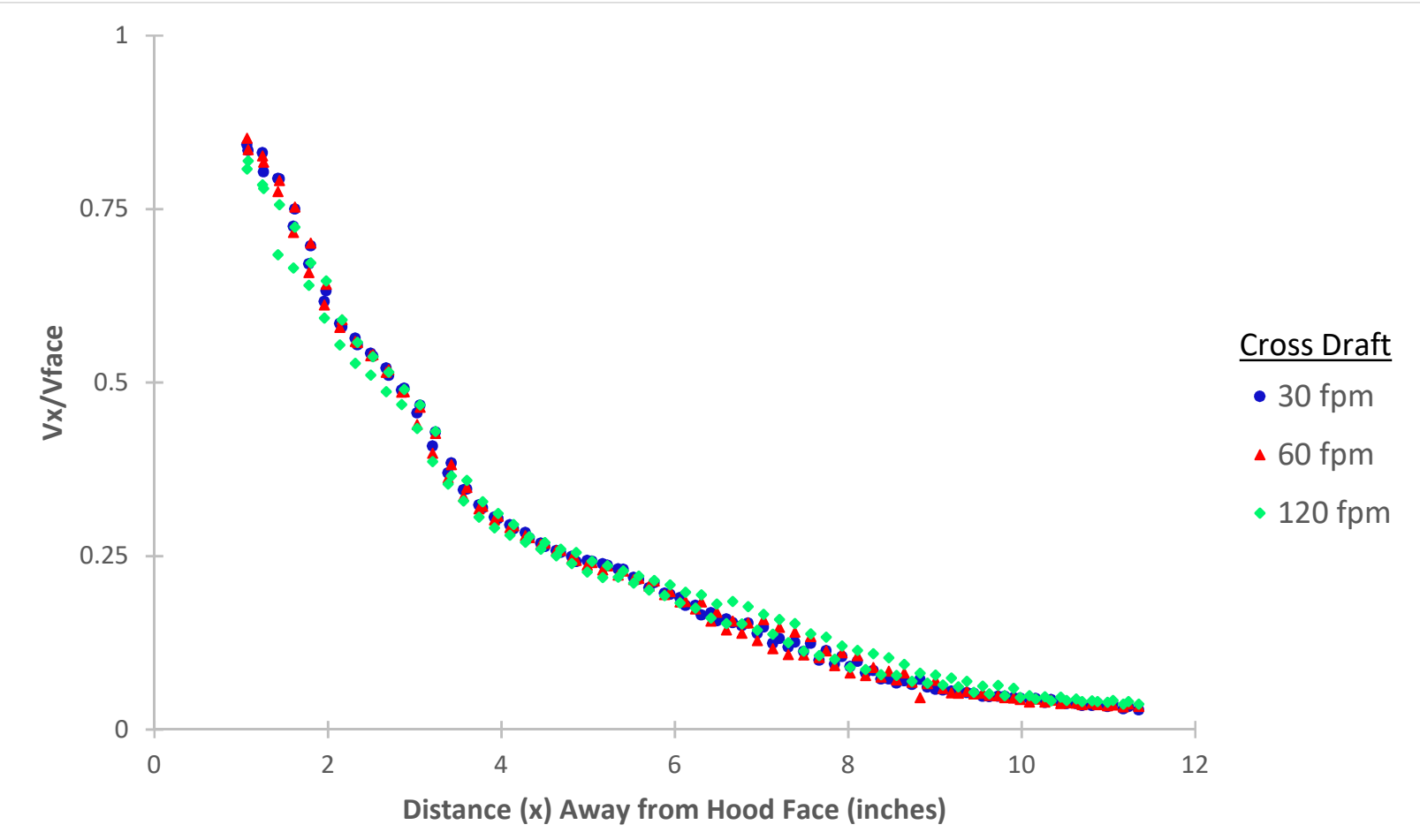

Figure 4-22 Condition: Manikin $+90^{\circ}+200 \mathrm{fpm} \mathrm{V}_{\text {capnom }}$

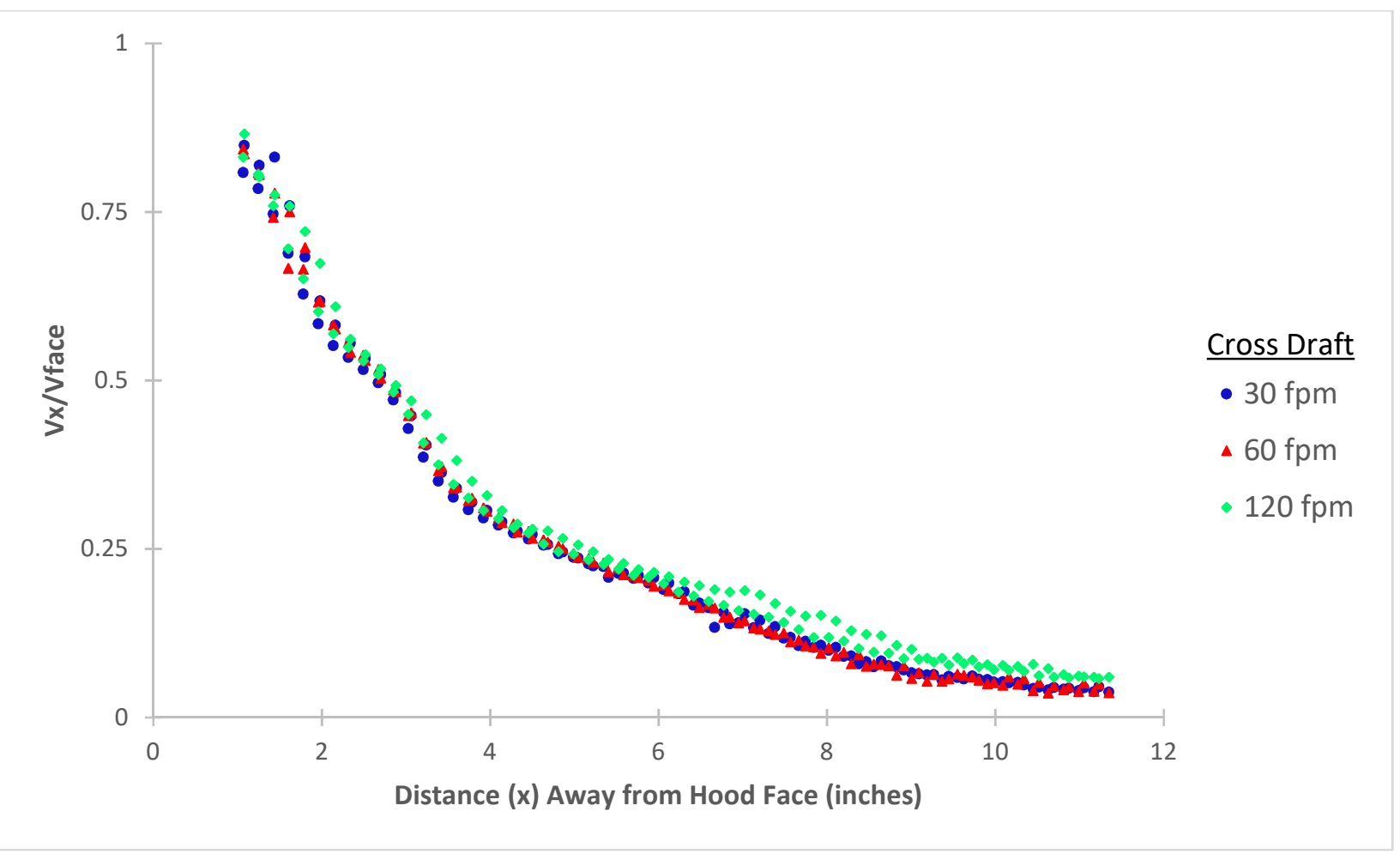

Figure 4-23 Condition: No Manikin $+90^{\circ}+200 \mathrm{fpm} \mathrm{V}_{\text {capnom }}$ 


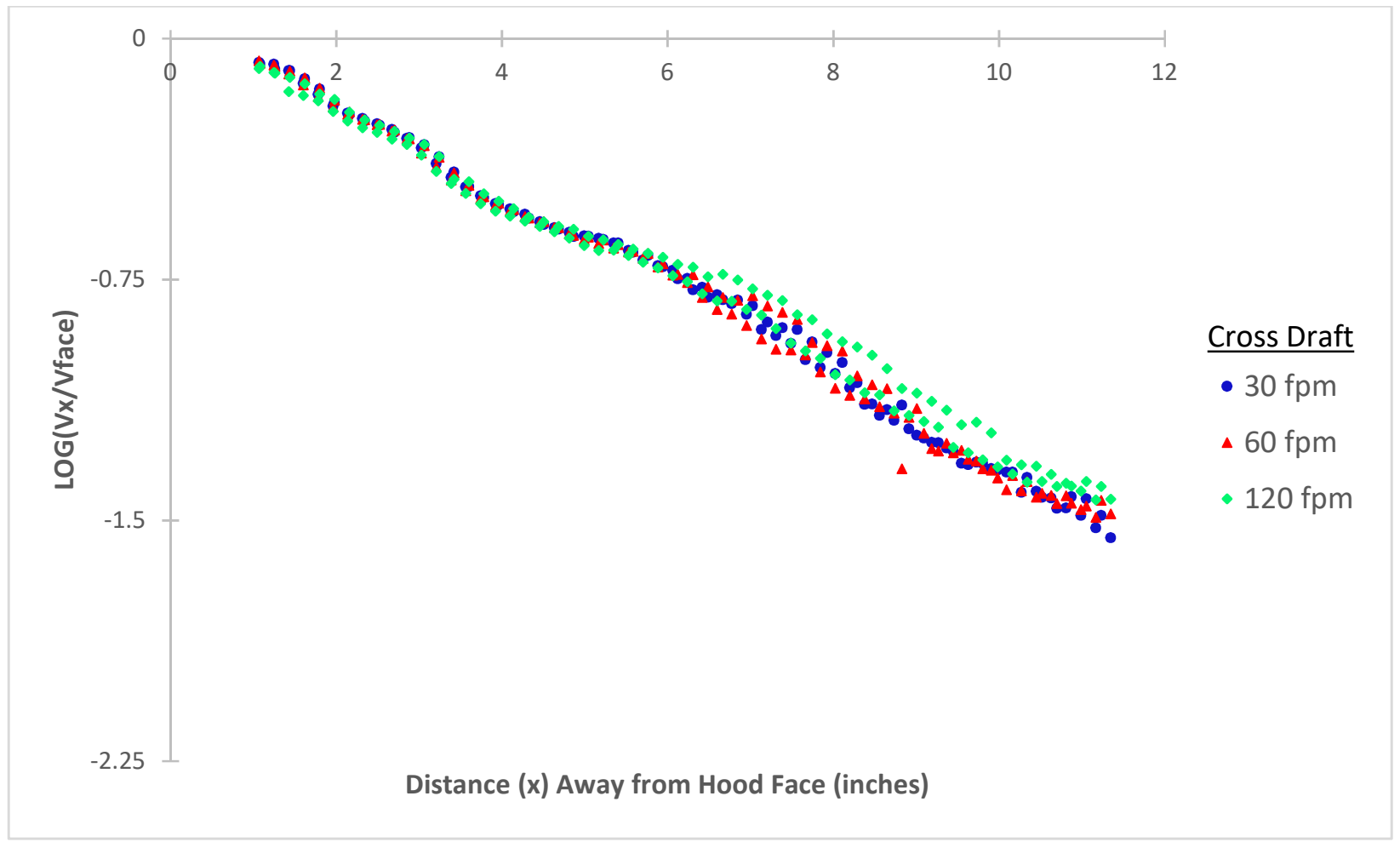

Figure 4-24 Log-Transformed - Condition: Manikin $+90^{\circ}+200 \mathrm{fpm} \mathrm{V}_{\text {capnom }}$

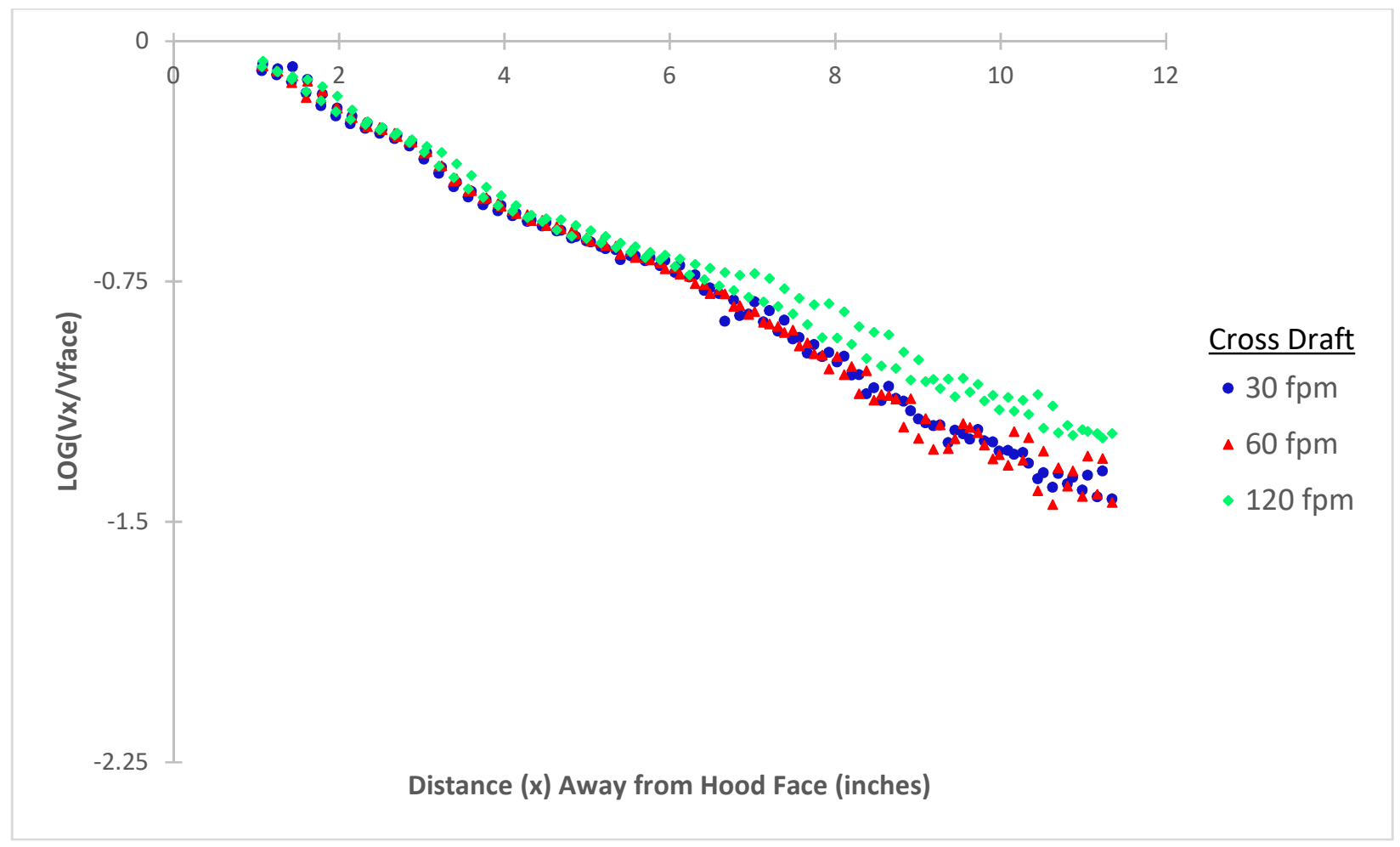

Figure 4-25 Log-Transformed - Condition: No Manikin $+90^{\circ}+200 \mathrm{fpm} \mathrm{V}_{\text {capnom }}$ 
Table 4-7 Percent Difference Between Manikin vs No Manikin $\left(90^{\circ}, 200 \mathrm{~V}_{\text {capnom }}\right)$

\begin{tabular}{cccc}
\hline \multicolumn{3}{c}{ Cross Draft } \\
\hline X(in) & $30 \mathrm{fpm}$ & $60 \mathrm{fpm}$ & $120 \mathrm{fpm}$ \\
\hline 2 & 3.8 & 1.6 & 2.8 \\
3 & 5.3 & 0.4 & 1.9 \\
4 & 1.3 & 1.2 & 5.5 \\
5 & 2.4 & 0.7 & 6.0 \\
6 & 5.4 & 4.3 & 6.7 \\
7 & 3.0 & 0.9 & 11.4 \\
8 & 7.7 & 3.7 & 24.8 \\
9 & 13.7 & 1.7 & 25.6 \\
10 & 15.8 & 18.3 & 43.5 \\
11 & 16.9 & 17.9 & 40.7 \\
\hline
\end{tabular}

Figure 4-26 and Figure 4-27 represent the manikin present and no manikin present conditions at the 180-degree orientation, with a nominal $50 \mathrm{fpm}$ capture velocity. There are no log-transformed graphs for these conditions, because there are negative velocity values present. These negative velocity values represent measurements in which the velocity is actually moving away from the hood face. These points indicate that the cross draft velocity has overcome the hood capture velocity at those respective points.

The effect of the manikin's presence under these conditions is calculated as the percent difference and listed in Table 4-8. The effect of the manikin at the $180^{\circ}$ orientation and a nominal $50 \mathrm{fpm}$ capture velocity is sporadically large several inches away from the hood face with a 30 fpm cross draft, large with a $60 \mathrm{fpm}$ cross draft, and very large with a $120 \mathrm{fpm}$ cross draft. 


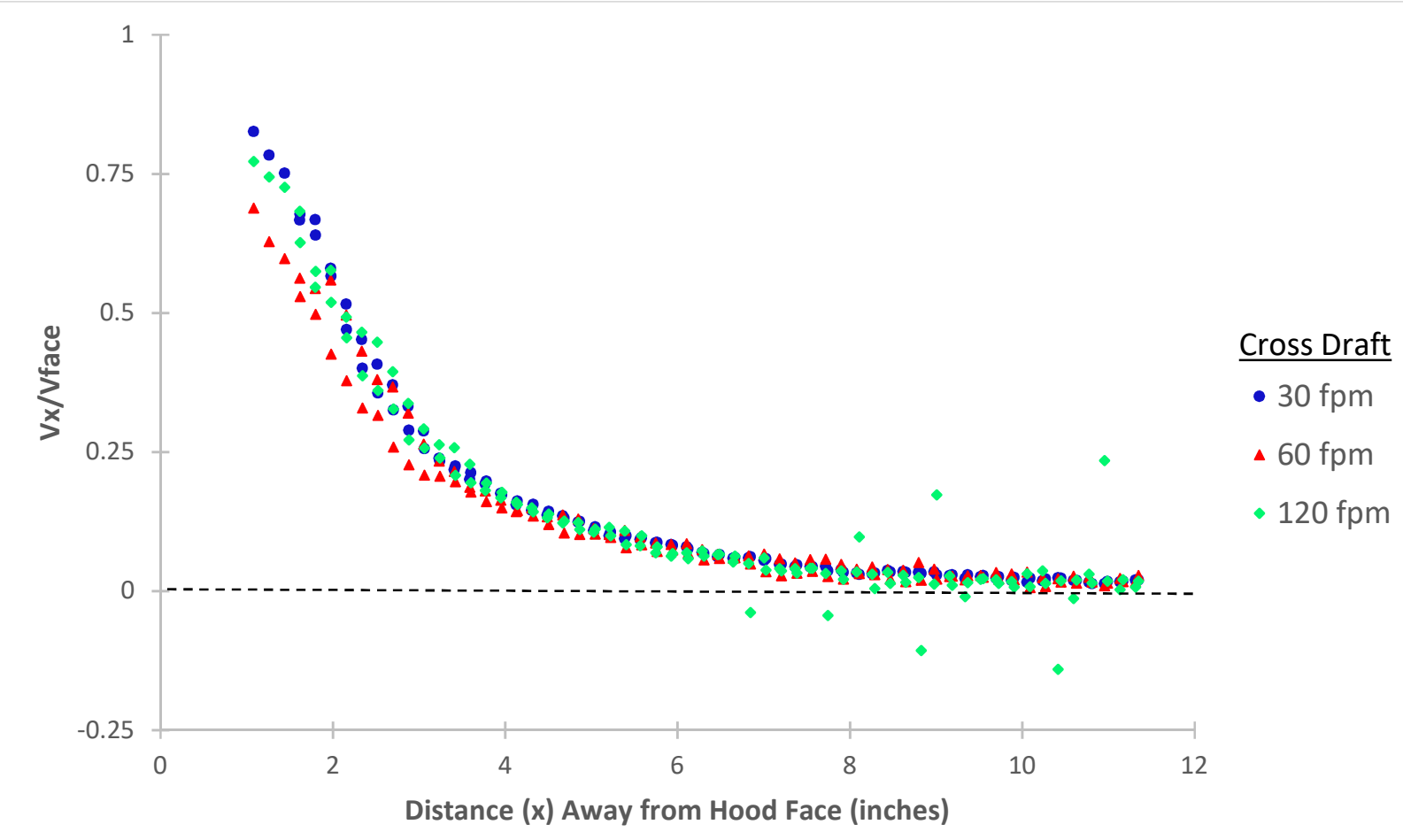

Figure 4-26 Condition: Manikin $+180^{\circ}+50 \mathrm{fpm} \mathrm{V}_{\text {capnom }}$

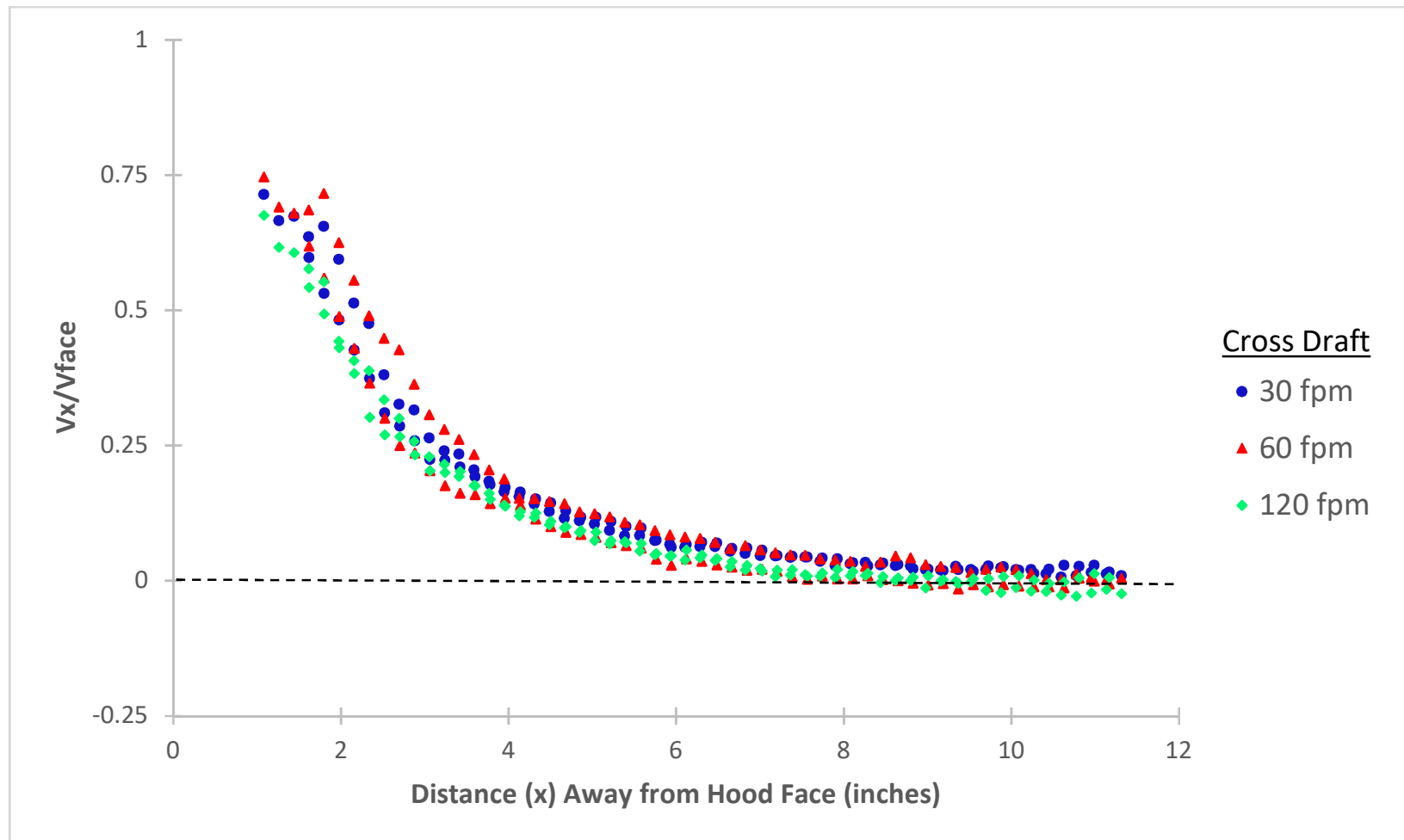

Figure 4-27 Condition: No Manikin $+180^{\circ}+50 \mathrm{fpm} \mathrm{V}_{\text {capnom }}$ 
Table 4-8 Percent Difference Between Manikin vs No Manikin $\left(180^{\circ}, 50 \mathrm{~V}_{\text {capnom }}\right)$

\begin{tabular}{cccc}
\hline \multicolumn{3}{c}{ Cross Draft } \\
\hline $\mathrm{X}$ (in) & $30 \mathrm{fpm}$ & $60 \mathrm{fpm}$ & $120 \mathrm{fpm}$ \\
\hline 2 & 6.2 & 12.3 & 22.5 \\
3 & 10.8 & 7.8 & 23.7 \\
4 & 3.3 & 8.8 & 21.6 \\
5 & 0.9 & 4.6 & 27.4 \\
6 & 18.6 & 22.6 & 28.9 \\
7 & 9.3 & 25.4 & 80.5 \\
8 & 3.7 & 56.8 & 131.9 \\
9 & 41.1 & 93.6 & 207.1 \\
10 & 1.6 & 115.8 & 230.6 \\
11 & 35.8 & 111.4 & 214.4 \\
\hline
\end{tabular}

Figure 4-28 and Figure 4-29 represent the manikin present and no manikin present conditions at the 180-degree orientation, with a nominal 100 fpm capture velocity. Figure 4-30 and Figure 4-31 represent the log-transformed versions of the same data. The effect of the manikin's presence under these conditions is calculated as the percent difference and listed in Table 4-9. The effect of the manikin at the $180^{\circ}$ orientation and a nominal $100 \mathrm{fpm}$ capture velocity is moderate at distance with a $30 \mathrm{fpm}$ cross draft, moderate at distance with a $60 \mathrm{fpm}$ cross draft, and modest with a $120 \mathrm{fpm}$ cross draft, until several inches away from the hood face. 


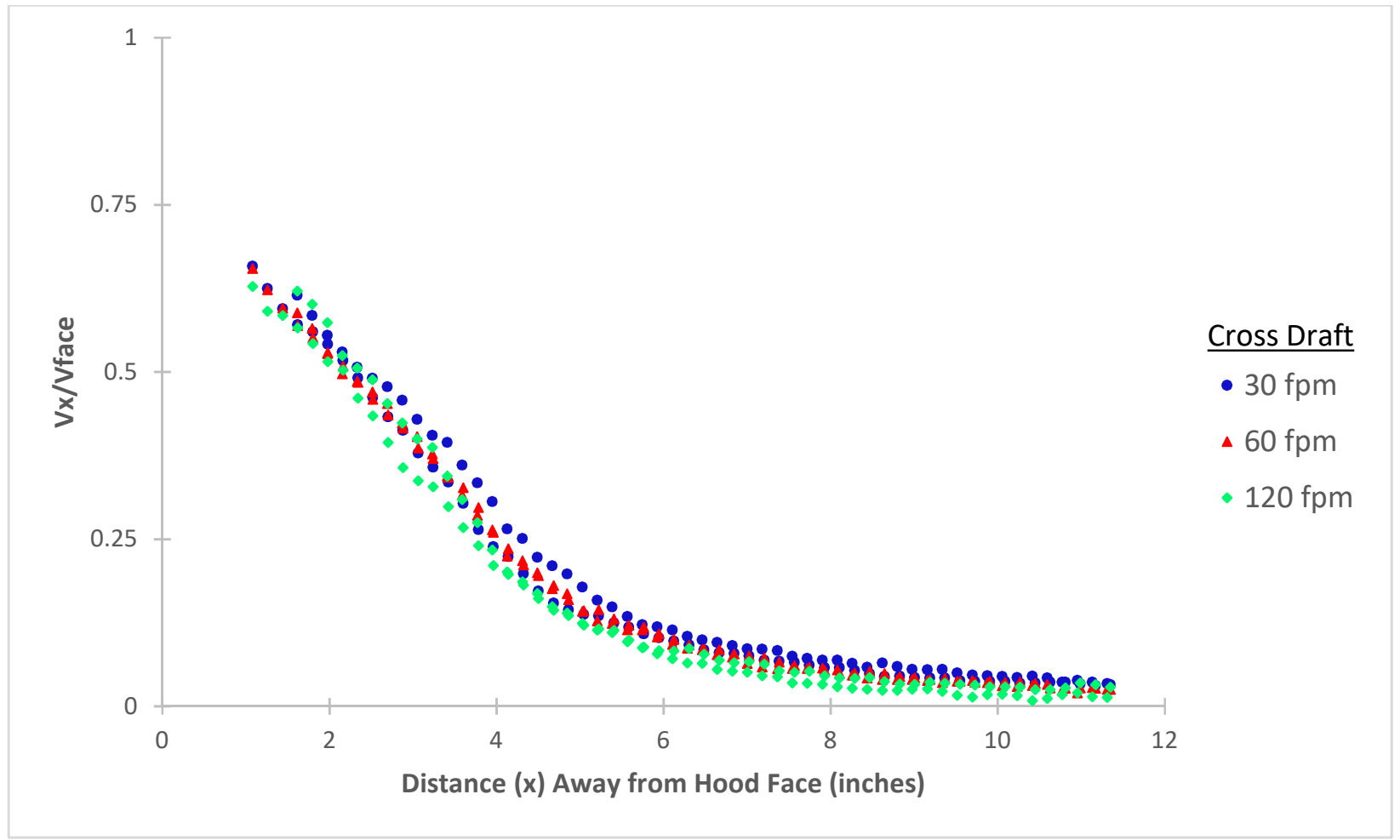

Figure 4-28 Condition: Manikin $+180^{\circ}+100 \mathrm{fpm} \mathrm{V}_{\text {capnom }}$

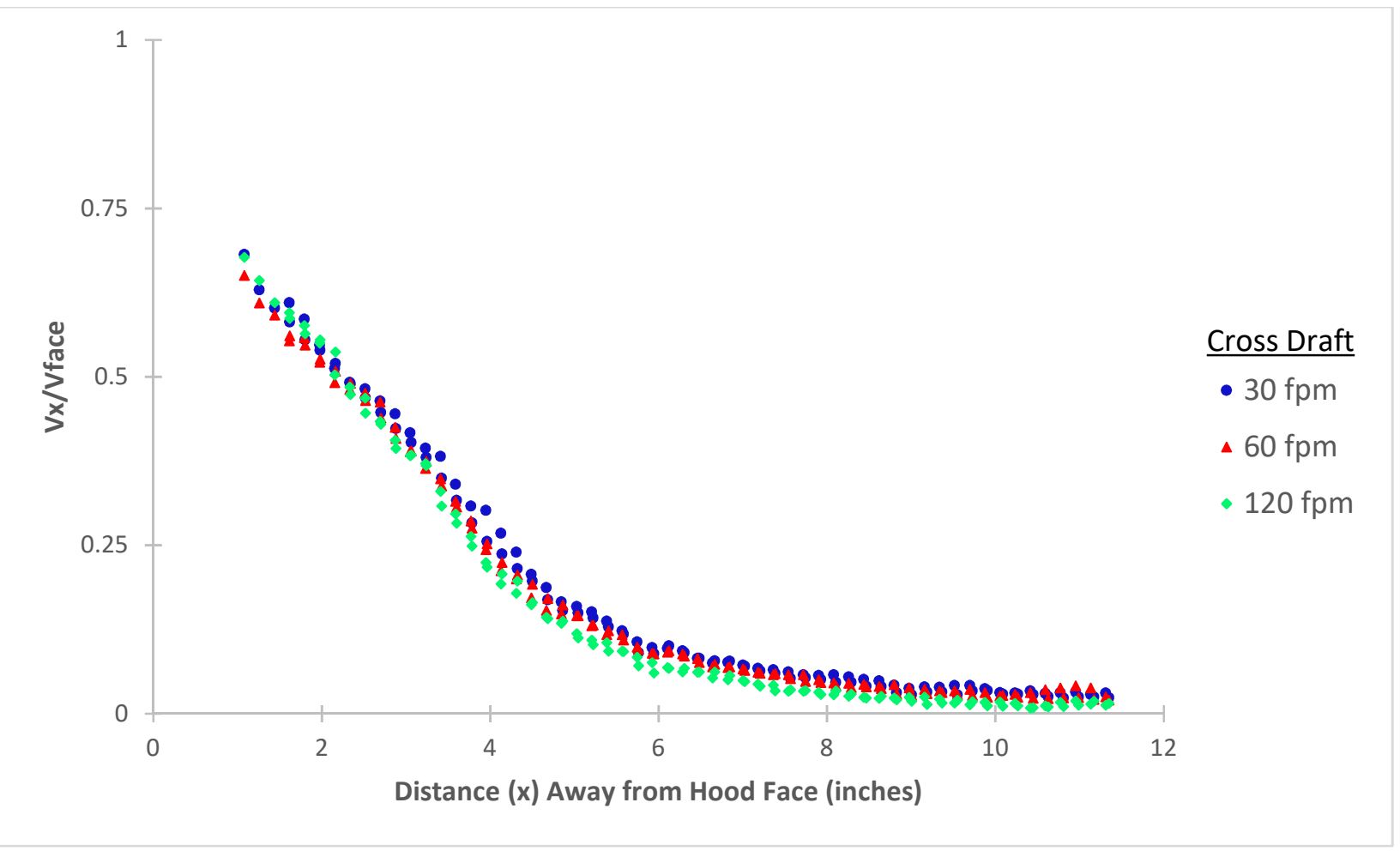

Figure 4-29 Condition: No Manikin $+180^{\circ}+100 \mathrm{fpm} \mathrm{V}_{\text {capnom }}$ 


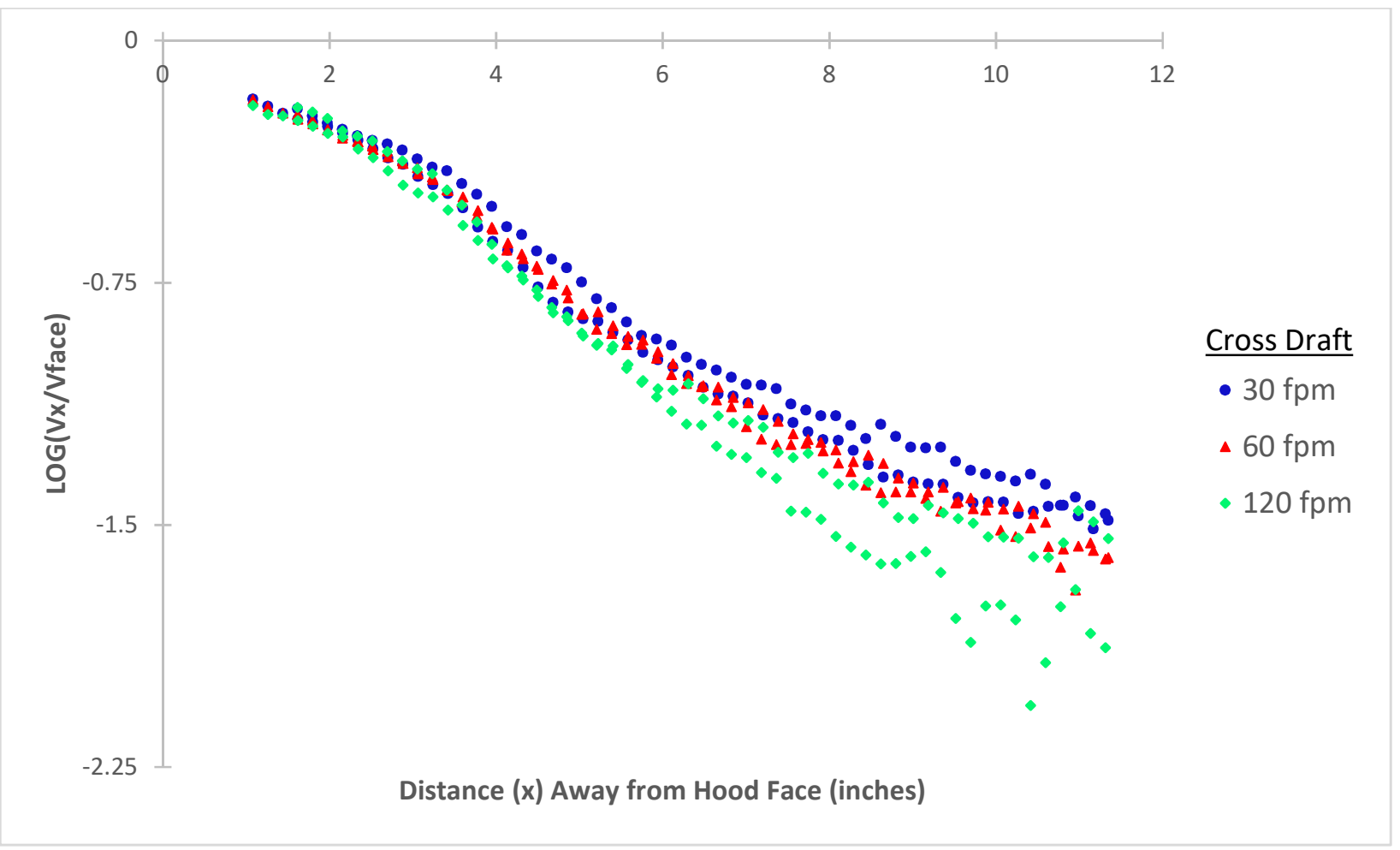

Figure 4-30 Log-Transformed - Condition: Manikin $+180^{\circ}+100 \mathrm{fpm} \mathrm{V}_{\text {capnom }}$

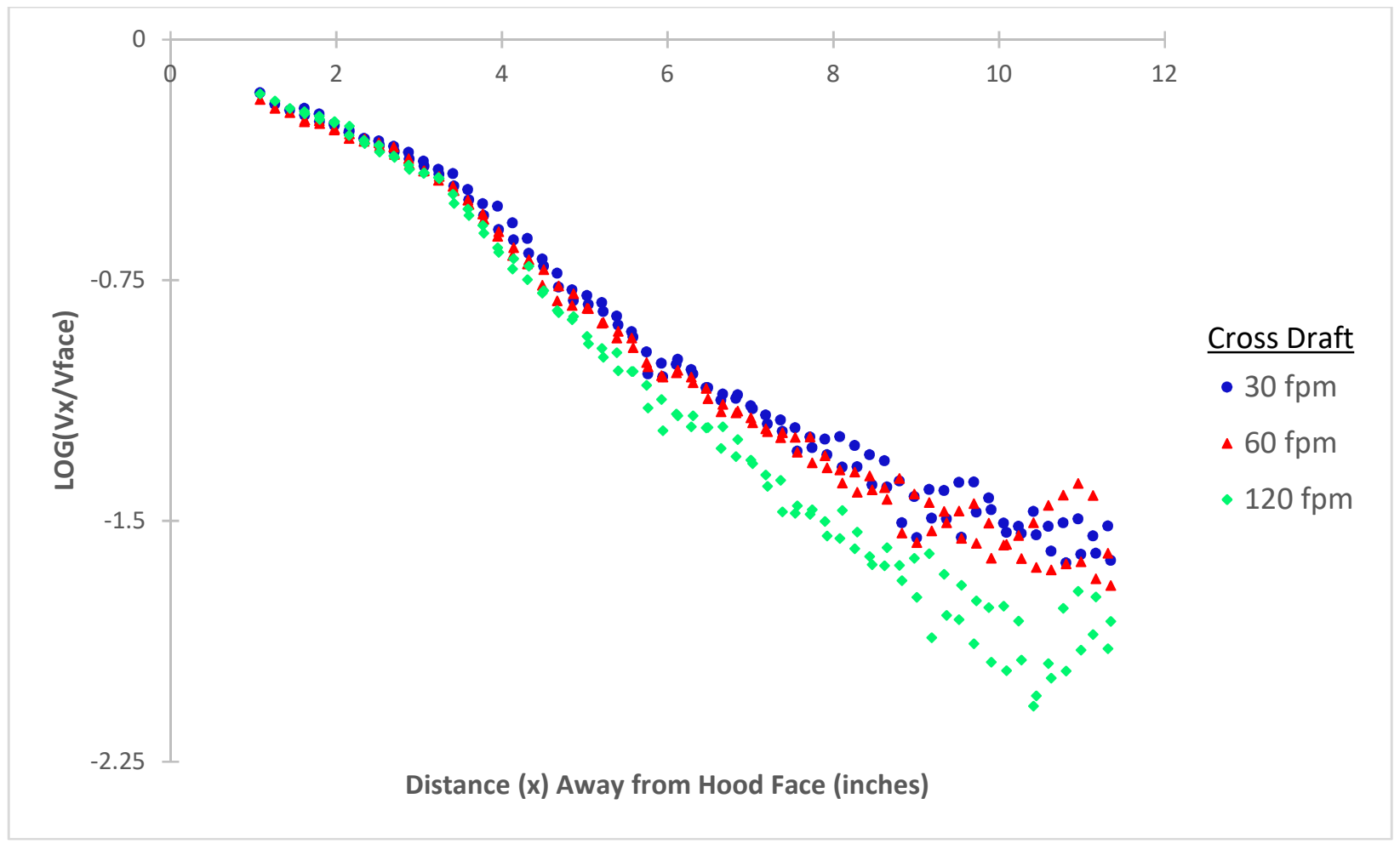

Figure 4-31 Log-Transformed - Condition: No Manikin $+180^{\circ}+100 \mathrm{fpm} \mathrm{V}_{\text {capnom }}$ 
Table 4-9 Percent Difference Between Manikin vs No Manikin (180 $\left.100 \mathrm{~V}_{\text {capnom }}\right)$

\begin{tabular}{cccc}
\hline \multicolumn{3}{c}{ Cross Draft } \\
\hline $\mathrm{X}$ (in) & $30 \mathrm{fpm}$ & $60 \mathrm{fpm}$ & $120 \mathrm{fpm}$ \\
\hline 2 & 0.9 & 0.8 & 1.4 \\
3 & 1.4 & 1.4 & 4.0 \\
4 & 2.3 & 5.6 & 0.7 \\
5 & 2.3 & 2.2 & 6.0 \\
6 & 6.6 & 3.9 & 12.8 \\
7 & 12.4 & 6.8 & 19.7 \\
8 & 19.2 & 16.8 & 14.2 \\
9 & 39.5 & 23.2 & 31.5 \\
10 & 30.4 & 20.9 & 50.6 \\
11 & 23.6 & 32.0 & 53.8 \\
\hline
\end{tabular}

Figure 4-32 and Figure 4-33 represent the manikin present and no manikin present conditions at the 180-degree orientation, with a nominal $200 \mathrm{fpm}$ capture velocity. Figure 4-34 and Figure 4-35 represent the log-transformed versions of the same data. The effect of the manikin's presence under these conditions is calculated as the percent difference and listed in Table 4-10. The effect of the manikin at the $180^{\circ}$ orientation and a nominal $200 \mathrm{fpm}$ capture velocity is negligible with a $30 \mathrm{fpm}$ cross draft, moderate and sporadically large with a $60 \mathrm{fpm}$ cross draft, and moderate and sporadically large with a $120 \mathrm{fpm}$ cross draft. 


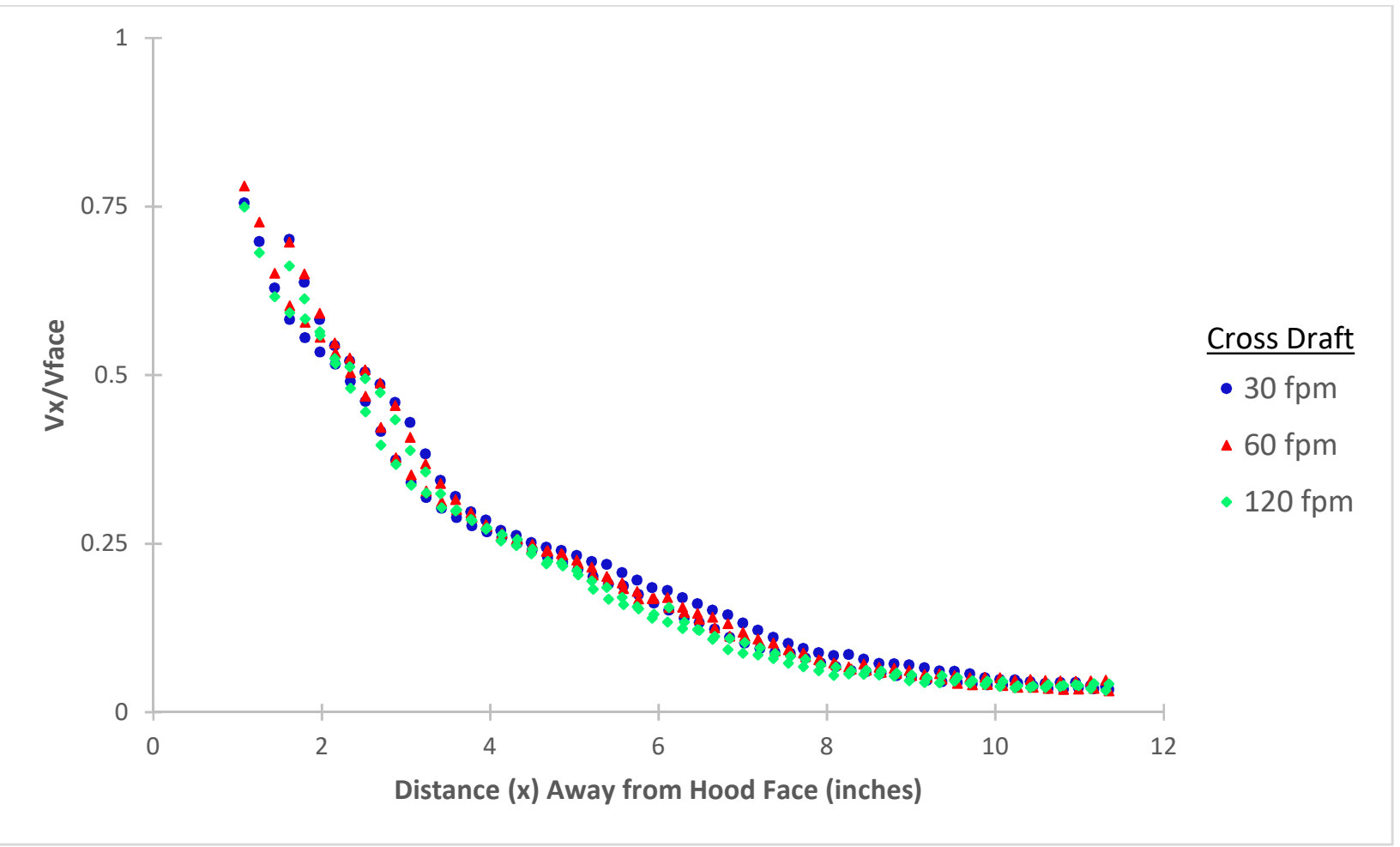

Figure 4-32 Condition: Manikin $+180^{\circ}+200 \mathrm{fpm} \mathrm{V}_{\text {capnom }}$

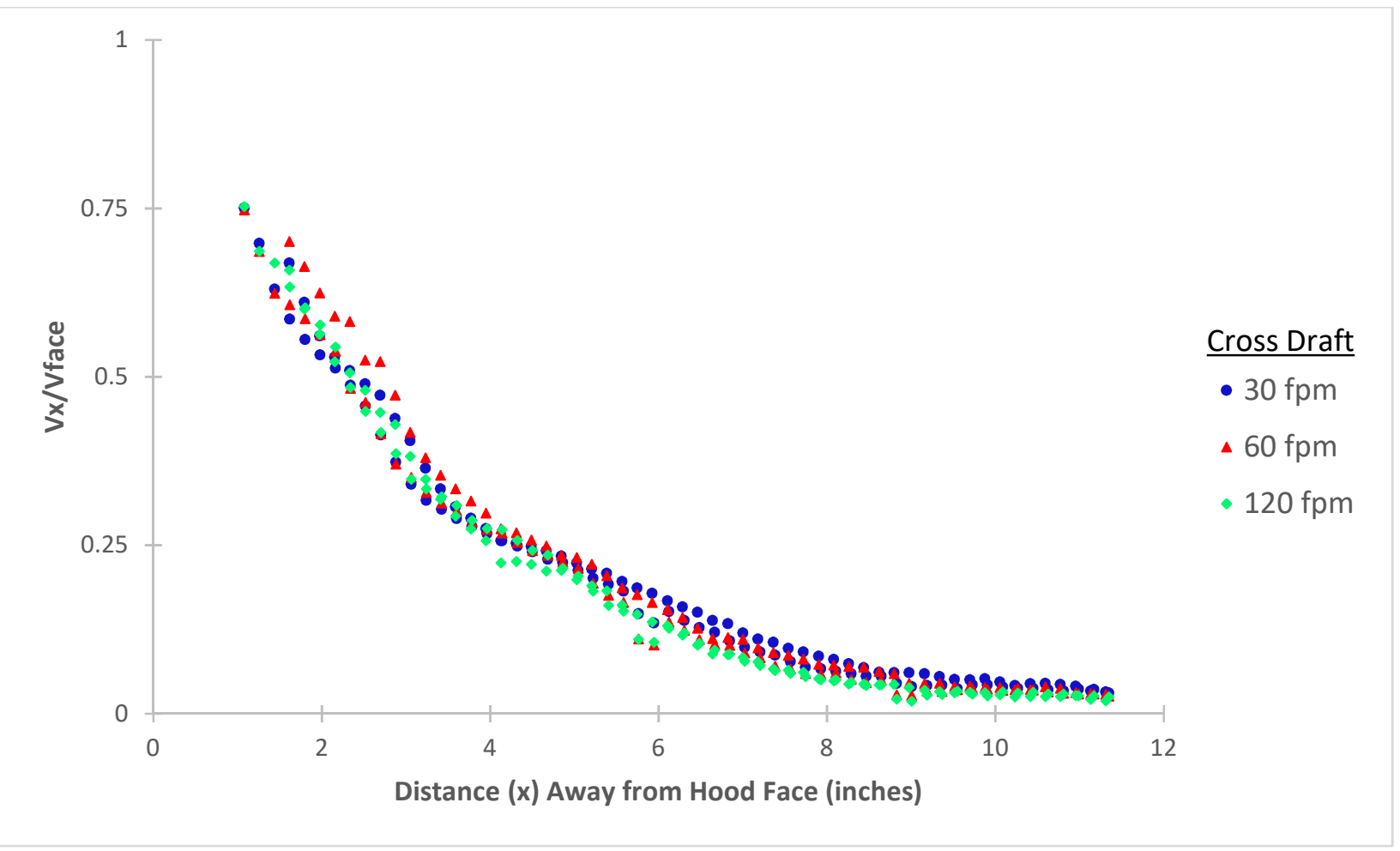

Figure 4-33 Condition: No Manikin $+180^{\circ}+200 \mathrm{fpm} \mathrm{V}_{\text {capnom }}$ 


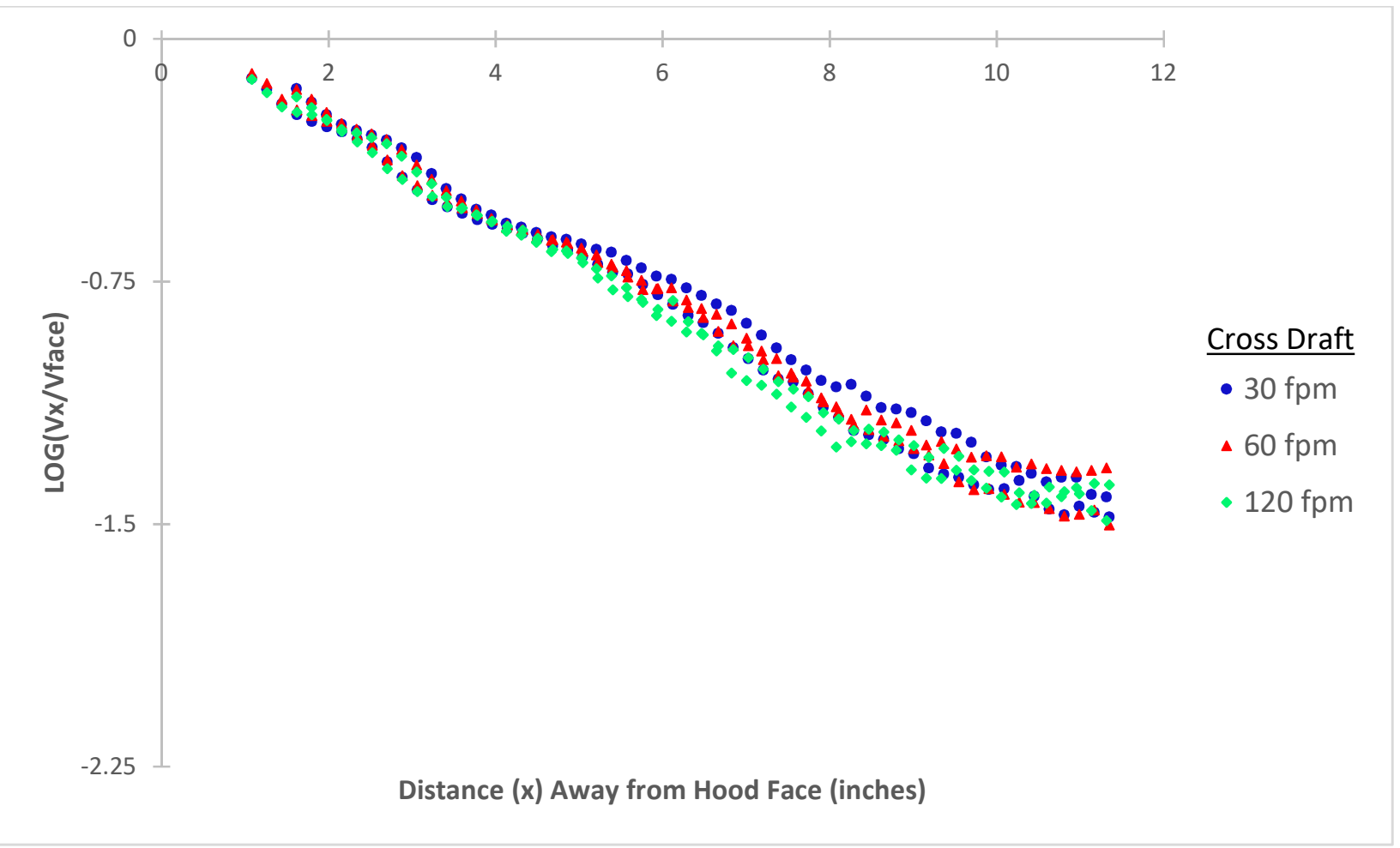

Figure 4-34 Log-Transformed - Condition: Manikin $+180^{\circ}+200 \mathrm{fpm} \mathrm{V}_{\text {capnom }}$

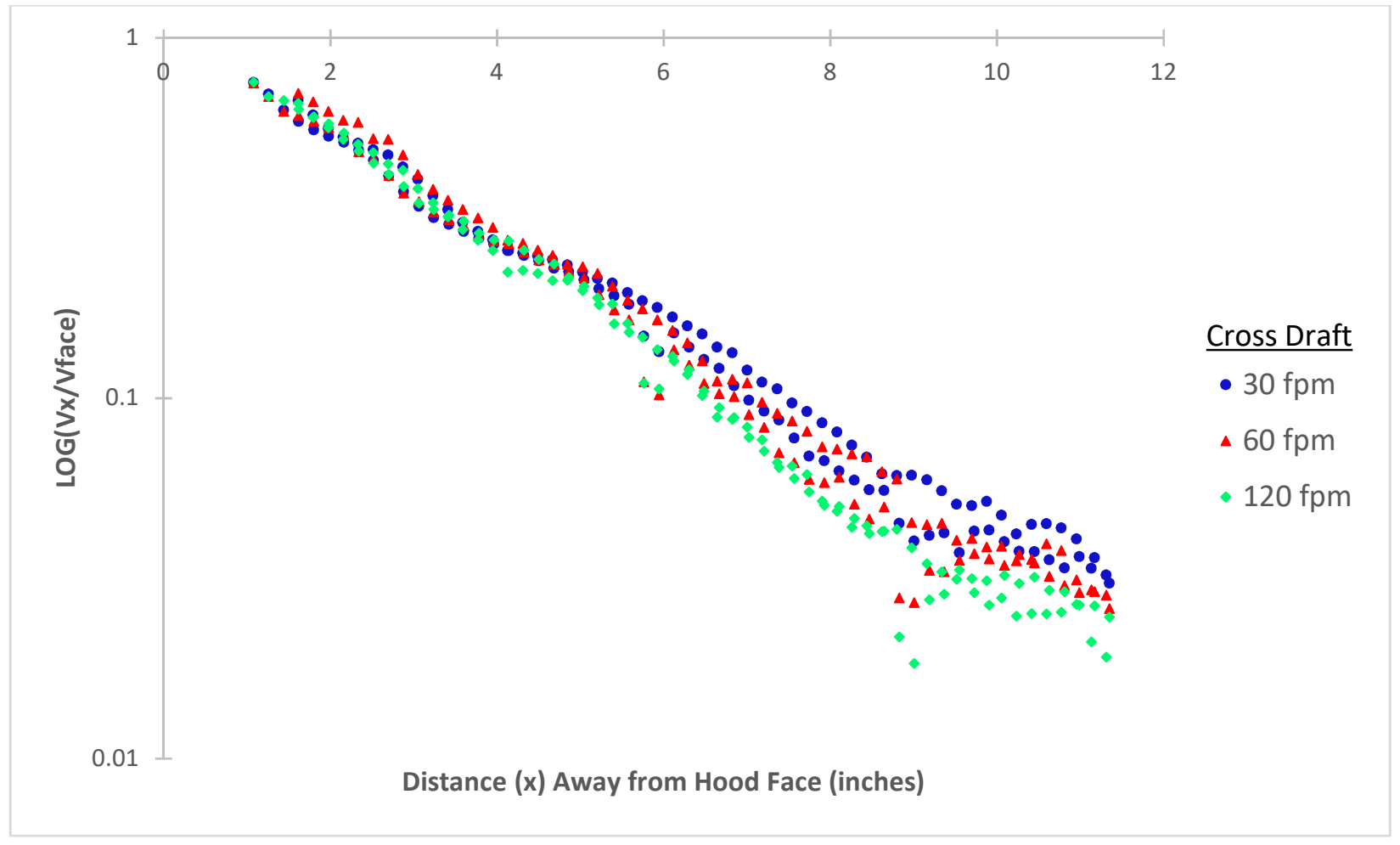

Figure 4-35 Log-Transformed - Condition: No Manikin $+180^{\circ}+200 \mathrm{fpm} \mathrm{V}_{\text {capnom }}$ 
Table 4-10 Percent Difference Between Manikin vs No Manikin (180, $\left.200 \mathrm{~V}_{\text {capnom }}\right)$

\begin{tabular}{cccc}
\hline \multicolumn{3}{c}{ Cross Draft } \\
\hline X(in) & $30 \mathrm{fpm}$ & $60 \mathrm{fpm}$ & $120 \mathrm{fpm}$ \\
\hline 2 & 2.1 & 3.3 & 1.4 \\
3 & 3.3 & 1.1 & 0.6 \\
4 & 2.0 & 3.0 & 2.5 \\
5 & 1.9 & 0.2 & 2.6 \\
6 & 3.7 & 11.2 & 11.7 \\
7 & 7.3 & 14.2 & 17.2 \\
8 & 5.6 & 7.7 & 20.9 \\
9 & 18.7 & 46.3 & 56.8 \\
10 & 1.6 & 20.8 & 33.4 \\
11 & 3.8 & 28.0 & 40.0 \\
\hline
\end{tabular}

Figure 4-36 illustrates the variable effects on $\mathrm{V}_{\text {cap }}$ at the 11" mark. The effect of manikin presence intensifies as the cross draft velocity increases. It is clear this is true for all three orientations.

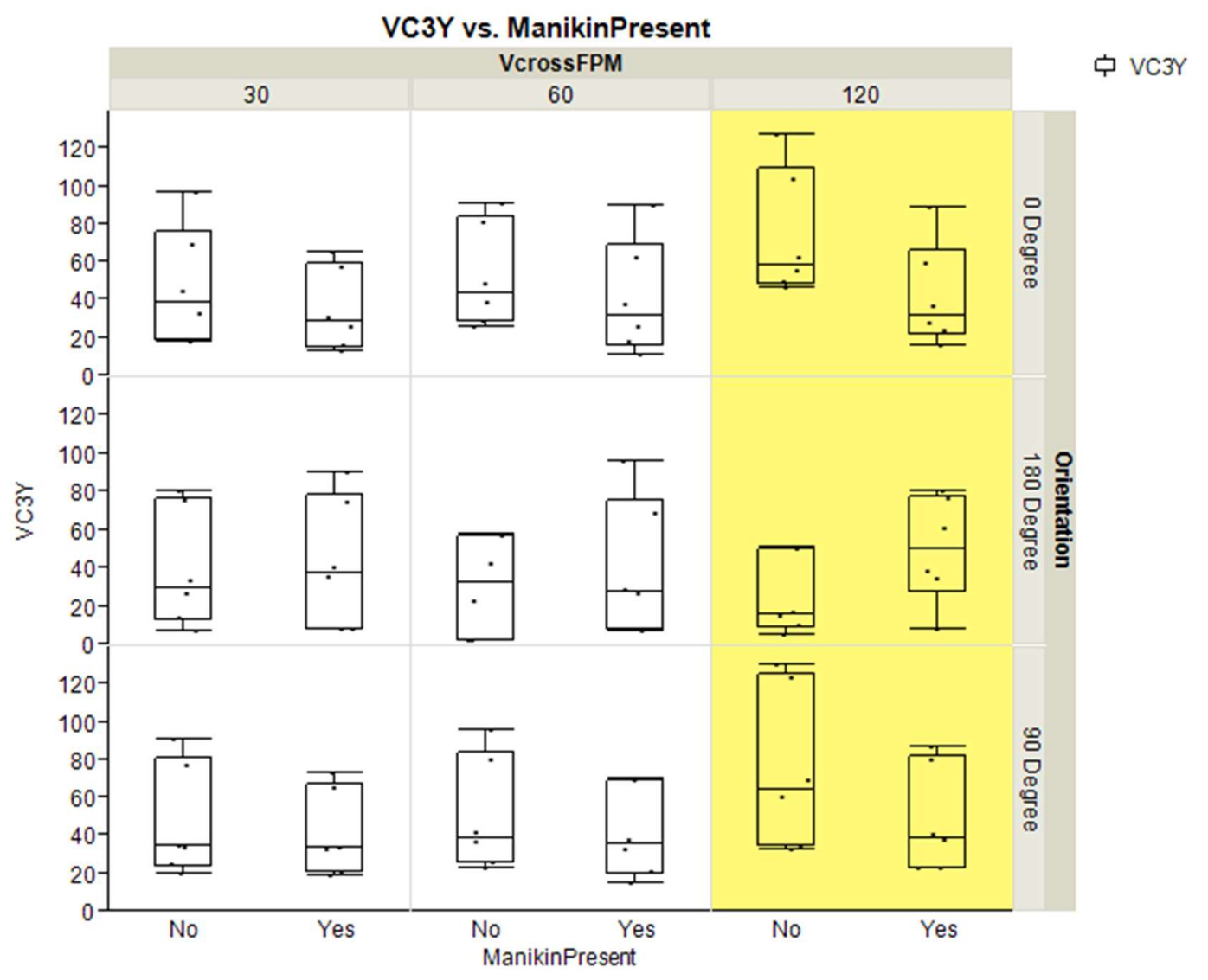

Figure 4-36 Summary Chart of Variable Effects on 11" Capture Velocity 


\subsubsection{Variable Effects on Velocities in Capture Envelope}

Figure 4-37 Illustrates the effects of manikin presence throughout the capture envelope at $0^{\circ}$.

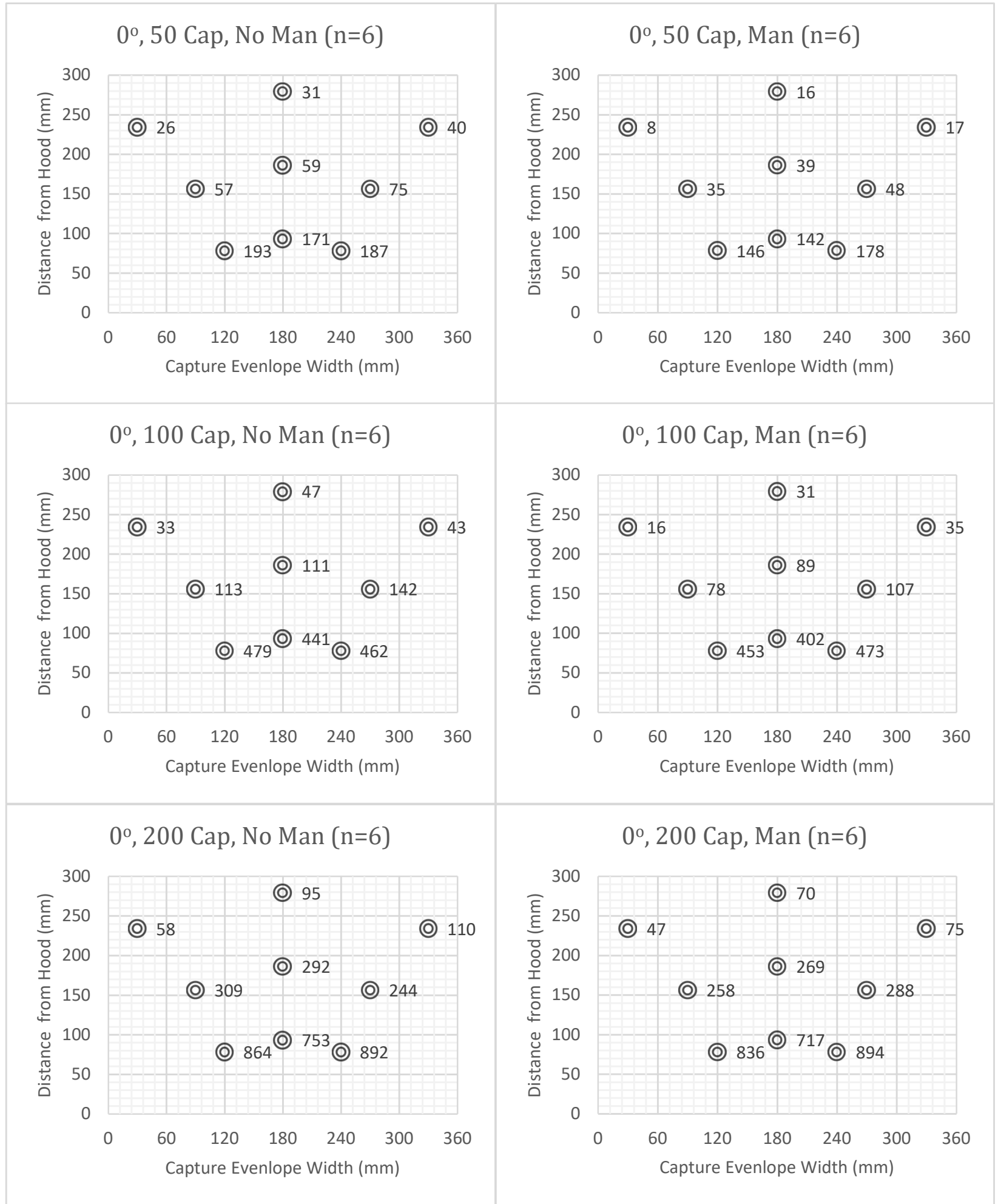

Figure 4-37 Effects of Manikin Presence Throughout Capture Envelope at $0^{\circ}$ 
Figure 4-38 Illustrates the effects of manikin presence throughout the capture envelope at $90^{\circ}$.

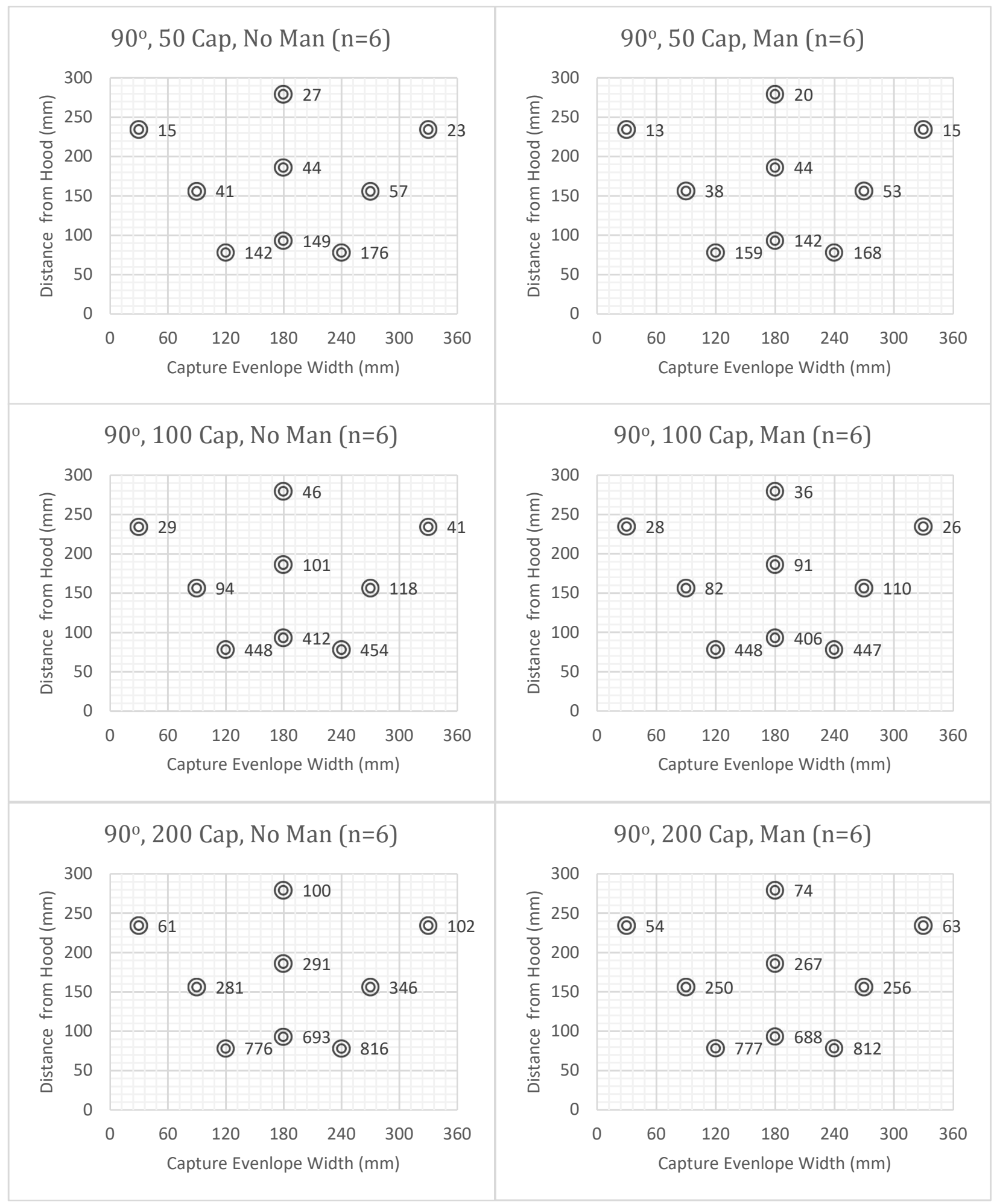

Figure 4-38 Effects of Manikin Presence Throughout Capture Envelope at $90^{\circ}$ 
Figure 4-39 Illustrates the effects of manikin presence throughout the capture envelope at $180^{\circ}$.

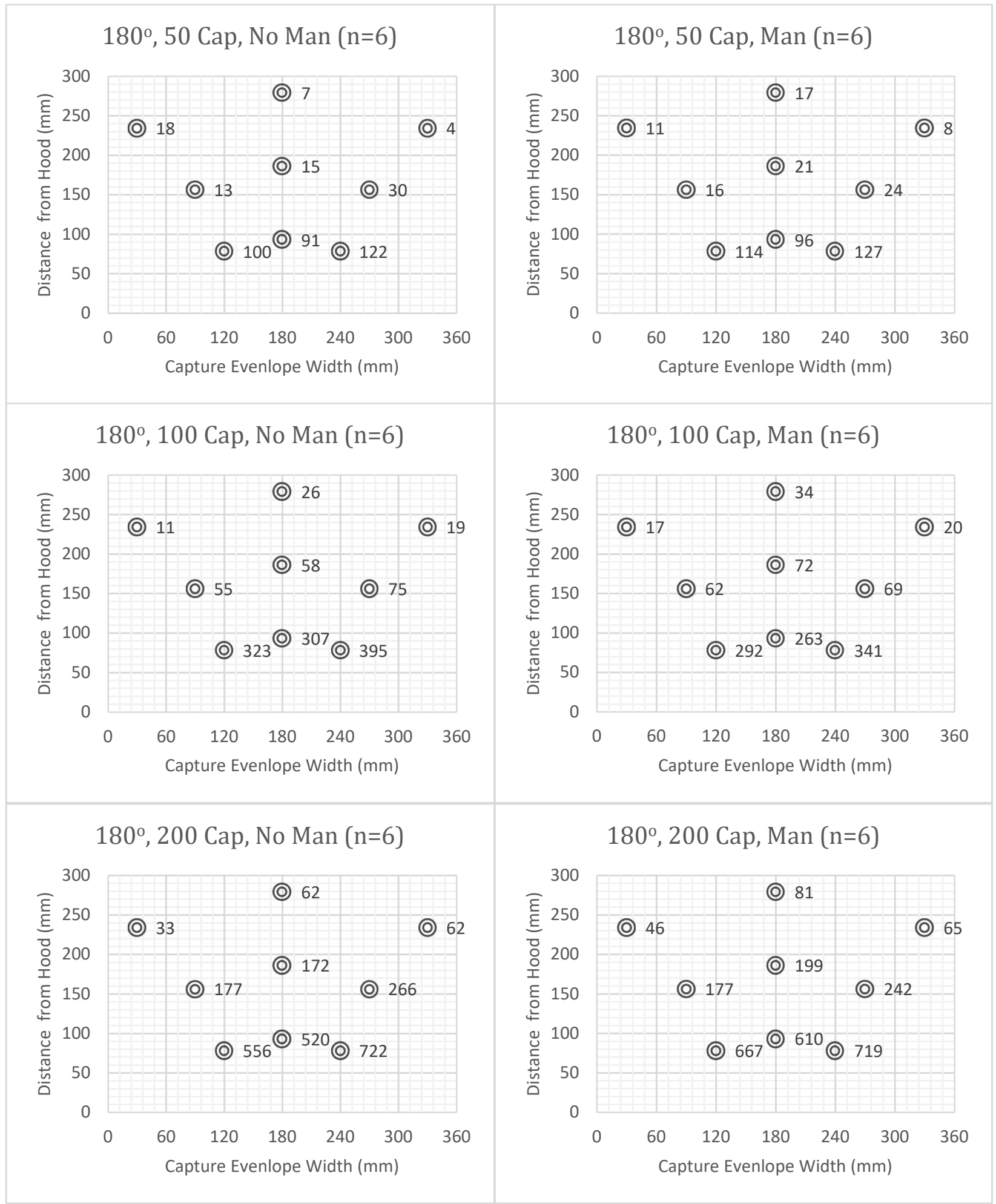

Figure 4-39 Effects of Manikin Presence Throughout Capture Envelope at $180^{\circ}$ 
Table 4-11 Percent Difference Between Manikin vs No Manikin - Capture Envelope

\begin{tabular}{|c|ccc|ccc|ccc|}
\cline { 2 - 10 } \multicolumn{1}{c|}{} & \multicolumn{3}{c|}{$0^{\circ}$} & \multicolumn{3}{c|}{$90^{\circ}$} & \multicolumn{3}{c|}{$180^{\circ}$} \\
\hline Location & $\Delta 50$ & $\Delta 100$ & $\Delta 200$ & $\Delta 50$ & $\Delta 100$ & $\Delta 200$ & $\Delta 50$ & $\Delta 100$ & $\Delta 200$ \\
\hline Face & 1.1 & 0.4 & 2.4 & 3.0 & 1.2 & 0.5 & 1.8 & 0.8 & 2.2 \\
VL1 & 27.5 & 5.6 & 3.3 & 11.3 & 0.1 & 0.2 & 12.3 & 10.1 & 16.4 \\
VC1 & 18.1 & 9.2 & 4.9 & 4.5 & 1.5 & 0.7 & 5.2 & 15.5 & 16.0 \\
VR1 & 5.4 & 2.2 & 0.2 & 4.6 & 1.6 & 0.4 & 3.6 & 14.7 & 0.4 \\
VL2 & 47.1 & 36.7 & 17.8 & 6.3 & 13.3 & 11.7 & 20.1 & 11.4 & 0.3 \\
VC2 & 40.7 & 22.3 & 8.4 & 0.8 & 10.3 & 8.4 & 35.2 & 21.9 & 14.6 \\
VR2 & 43.7 & 28.1 & 16.5 & 6.9 & 6.6 & 30.1 & 20.6 & 8.8 & 9.2 \\
VL3 & 109.1 & 68.0 & 21.9 & 14.5 & 4.7 & 13.1 & 52.0 & 41.4 & 31.8 \\
VC3 & 62.5 & 41.4 & 29.7 & 28.2 & 24.9 & 29.4 & 85.7 & 25.2 & 26.6 \\
VR3 & 80.8 & 20.0 & 37.8 & 42.5 & 44.0 & 47.5 & 64.7 & 8.6 & 6.0 \\
\hline
\end{tabular}

Table 4-12 Statistically Significant Effects Throughout Capture Envelope

\begin{tabular}{|l|c|c|c|c|c|c|c|c|c|}
\hline & VL1 & VC1 & VR1 & VL2 & VC2 & VR2 & VL3 & VC3 & VR3 \\
\hline Orientation & $\checkmark$ & $\checkmark$ & $\checkmark$ & $\checkmark$ & $\checkmark$ & & $\checkmark$ & $\checkmark$ & $\checkmark$ \\
\hline ManikinPresent & & & & $\checkmark$ & & & & $\checkmark$ & $\checkmark$ \\
\hline Orientation*ManikinPresent & & & & $\checkmark$ & $\checkmark$ & & & $\checkmark$ & $\checkmark$ \\
\hline VcrossFPM & & & $\checkmark$ & & & & $\checkmark$ & $\checkmark$ \\
\hline Orientation*VcrossFPM & & & $\checkmark$ & $\checkmark$ & & & $\checkmark$ & $\checkmark$ \\
\hline ManikinPresentVcrossFM & & & & & & & & $\checkmark$ \\
\hline Orientation*ManikinPresent*VcrossFPM & & & & & & & & $\checkmark$ & $\checkmark$ \\
\hline VcapFPM & & $\checkmark$ & $\checkmark$ & $\checkmark$ & $\checkmark$ & $\checkmark$ & $\checkmark$ & $\checkmark$ & $\checkmark$ \\
\hline Orientation*VcapFPM & & & & & & \\
\hline ManikinPresent*VcapFPM & & & $\checkmark$ & $\checkmark$ & $\checkmark$ & & & & \\
\hline Orientation*ManikinPresent*VcapFPM & & & & & & & & \\
\hline VcrossFPM*VcapFPM & & & & & & & & \\
\hline Orientation*VcrossFPM*VcapFPM & & & & & & & $\checkmark$ \\
\hline ManikinPresent*VcrossFPM*VcapFPM & & & & & & & \\
\hline $\begin{array}{l}\text { Orientation*ManikinPresent*VcrossFPM* } \\
\text { VcapFPM }\end{array}$ & & & & & & & \\
\hline
\end{tabular}

Refer to Appendix A for complete statistics for each point throughout the capture envelope. 


\subsection{Study Summary}

The primary focus of this study was to determine the effects of operator presence and hood orientation on centerline velocity and velocity points throughout the capture envelope. Manikin presence was found to have a strong effect on centerline velocity at high cross drafts, regardless of orientation. Manikin presence was found to have the largest effect overall at the 180-degree orientation. This was the only orientation in which $30 \mathrm{fpm}$ cross drafts had an interaction effect with manikin presence.

Manikin presence was also found to have a strong effect at the furthest distances from the hood. Manikin presence was found to have a significant effect at VL2, VC3, and VR3 (see Figure 4-1). Each of these capture points was well fit $\left(\mathrm{R}^{2}>0.91\right)$.

Orientation was also found to have a strong effect throughout the capture envelope. Orientation was found to have a statistically significant effect at every point, except for VR2. Orientation had only a moderately high fit $\left(\mathrm{R}^{2}=0.82\right)$, indicating some other factor(s) outside of the model influenced its measurements. It is possible the duct had a slight effect on the variance between the means. Since the duct exited a side wall in the wind tunnel, it is possible this would have had an effect on the 0 - and 180-degree orientations, but not as much at the 90-degree orientation. 


\section{Chapter 5: CPC vs Tracer}

\subsection{Introduction}

Tracer gases have long been used to quantitatively determine the effectiveness of various types of capture hoods (Ellenbecker, Gampel, and Burgess, 1983; Hampl, 1984; Hampl, 1986; Flynn and Ellenbecker, 1986; Fletcher and Johnson, 1986; Conroy and Ellenbecker, 1989; Woods and McKarns; Kasberger, 2012). Precision and isolation of analysis are the key benefits to the tracer gas method. However, gas analyzing systems are extremely expensive, and the accompanying gases are not cheap. This method is also very time consuming, often taking upwards to nearly one hour per treatment. The combination of these factors lends to a method that is not pragmatic for industrial use and is costly enough in time and money to discourage research.

Another method to quantitatively determine the effectiveness of a capturing hood system is by using an aerosol as the tracer. Salt aerosols and aerosol generators are relatively cheap and are commonly found in respirator fit test kits. Condensation particle counters (CPC) are significantly cheaper than gas analyzing equipment, such as Fourier-transform infrared spectroscopy (FTIR) machines. CPCs are direct read instruments that require very little time to reach sampling equilibrium. The only notable negatives to this method is that CPCs measure all available particles and the particle count concentrations are relative in value. CPCs may not be used when mass needs to be considered. HEPA filters can be used to control the environment in experimental settings, while background measurements would be needed for industrial use.

Studies considering aerosol tracers as a method for determining hood effectiveness are very limited (Bemer et. al., 1998; Dunn et. al, 2014). While both known studies have supported aerosols as a potentially viable tracer surrogate, both tests were conducted inside of an enclosure. Bemer et. al. (1998) did not consider the effects of cross drafts, the effects of varying hood fan rates, the effects of orientation, or the effects of operator presence; only ideal conditions were considered. Dunn et. al. (2014) did not conduct their experiment in a controlled environment. Instead, an air intake system and an air conditioning unit were referenced as "potential disruptive factors." Thus, air current effects on the system would have been poorly controlled and thus 
inconsistent. Their study was conducted inside of an enclosing hood, rather than outside of a capturing hood.

In this CPC vs Tracer study, a sodium chloride and water aerosol and neutrally buoyant mixture of Freon 134-a and helium, respectively, were selected to simulate the traceable contamination source. Contaminant concentrations in the duct $\left(\mathrm{C}_{\text {duct }}\right)$ and breathing zone $\left(\mathrm{C}_{\mathrm{BZ}}\right)$ of a surrogate worker were measured for varying experimental conditions. The experimental concentrations were then compared to accompanying conditions in which the traceable contaminant was released directly into the vent $\left(\mathrm{C}_{\text {duct100 }}\right)$ and whenever the hood was turned off entirely $\left(\mathrm{C}_{\mathrm{BZ} 100)}\right)$.

Prior to the $100 \%$ capture reference, a zero reference was made to ensure there was no accumulation of Freon 134a or any other possible interferences within the wind tunnel. For the CPC system, the wind tunnel was set on high to remove the bulk of background particles. HEPA filters were used pre- and post-ventilation to ensure maximum reduction. The CPC was set to continuous monitoring until the background measurements were negligible.

According to Hampl (1986), duct samples should be taken at least 4 duct diameters (4D) away from the hood face for a system that has two 90 degree elbows to assure sufficient mixing to product a homogenous sample. All duct samples for this study were taken greater than 10D downstream. Measured concentrations in the duct were be verified by using Equation 5-1 (Hampl, 1984).

$$
Q=A V \times C
$$

Where:

$$
\begin{aligned}
& \mathrm{Q}=\text { Tracer Gas Flow Rate } \\
& \mathrm{A}=\text { Duct Cross Section } \\
& \mathrm{V}=\text { Average Duct Velocity } \\
& \mathrm{C}=\text { Concentration in Exhaust Duct }
\end{aligned}
$$

Equation 1-15 was used to estimate the "required" minimum $\mathrm{V}_{\mathrm{x}}$ for the rectangular hood that rests above a workbench used for this study. The required exhaust flow rate (Q) was calculated 
knowing the hood face area and distance from the hood face for each test. The exhaust flow rate was then experimentally validated, prior to the inclusion of drafts and manikin interaction.

\subsection{Research Design}

The study was a randomized full factorial design with two replications for each tracer method. The dependent variables include the concentrations of the contaminant within the breathing zone $\left(\mathrm{C}_{\mathrm{BZ}}\right)$ of the operator and the concentrations of the contaminant located far downstream within the duct $\left(\mathrm{C}_{\text {duct }}\right)$. Since previous studies (Elnahass, 2005; Kasberger, 2012) found sampling at the mouth and nose to be redundant, the breathing zone samples were collected at a single point between the mouth and nose.

The independent variables include three levels of draft velocity $\left(\mathrm{V}_{\text {draft }}\right)$ orientated at the subject's face (180-degree orientation) and three levels of capture velocity ( $\left.\mathrm{V}_{\text {cap }}\right)$, as produced by adjusting the fan frequency. The 180-degree location was selected for this specific study, because preliminary studies found that the 180-degree orientation yielded the most variable conditions. The three levels of $V_{\text {draft }}$ were 30, 60, and $120 \mathrm{fpm}$, which represent the bulk range of industrial work conditions (Baldwin and Maynard, 1998). The three levels of capture velocity were 50,100, and $200 \mathrm{fpm}$, as selected to represent range of values currently recommended by the Industrial Ventilation (ACGIH, 2001). With two subsets to the study (CPC method and tracer gas method), three levels of $\mathrm{V}_{\text {draft, }}$, three levels of $\mathrm{V}_{\text {cap }}$, and two replications, there 36 total randomized treatments within this study. This is shown in Table 5-1.

\section{Table 5-1 CPC vs Tracer Design - Single Replication}

\begin{tabular}{c|ccc|ccc}
\hline & \multicolumn{3}{c}{$\mathrm{CPC}$} & \multicolumn{3}{c}{ Tracer } \\
\hline Test & $\mathrm{V}_{\mathrm{d}}$ & $\mathrm{V}_{\mathrm{x}}$ & $\mathrm{O}$ & $\mathrm{V}_{\mathrm{d}}$ & $\mathrm{V}_{\mathrm{x}}$ & $\mathrm{O}$ \\
\hline 1 & 30 & 50 & 180 & 30 & 50 & 180 \\
2 & 30 & 100 & 180 & 30 & 100 & 180 \\
3 & 30 & 200 & 180 & 30 & 200 & 180 \\
4 & 60 & 50 & 180 & 60 & 50 & 180 \\
5 & 60 & 100 & 180 & 60 & 100 & 180 \\
6 & 60 & 200 & 180 & 60 & 200 & 180 \\
7 & 120 & 50 & 180 & 120 & 50 & 180 \\
8 & 120 & 100 & 180 & 120 & 100 & 180 \\
9 & 120 & 200 & 180 & 120 & 200 & 180 \\
\hline
\end{tabular}

$\mathrm{V}_{\mathrm{x}}=$ Capture Velocity; $\mathrm{V}_{\mathrm{d}}=$ Draft Velocity; $\mathrm{O}=$ Orientation 


\subsection{Methods}

For both measurement systems, the contaminant source was released 11" away from the face of the exterior hood. Samples were collected in the breathing zone at a single-point between the mouth and nose of the manikin (see Figure 3-13). Duct samples were collected well downstream of the hood face to assure adequate mixing.

For the tracer gas method, all samples were collected 4L at a time in Tedlar bags. The bag samples were then analyzed with a Fourier-transform infrared spectroscopy (FTIR) machine, as described in detail in Chapter 3.7.

For the CPC method, all samples were recorded for two minutes. Preliminary studies found that approximately 20 seconds of data recording was all that was truly necessary to obtain replicable results. To avoid errors associated with particle introduction, a solenoid valve system (see Figure 3-12) was devised to alternatively sample between the breathing zone and the duct. The CPC and its accompanying software Aerosol Instrument Manager ${ }^{\circledR}$ were used for immediate analysis.

\subsection{Procedures}

Standard testing procedures for this study are grouped as follows:

- Calibration and Validation

- Tracer Gas Analyzing System Preparation

- Environmental Measurements

- Hood and Wind Tunnel Control Systems Preparation

- Tracer Gas Release System Preparation

- Sampling

- Velocity Measurements

- Analyzing Samples

\subsubsection{Calibration and Validation}

6. Calibrate and validate FTIR system using process described in section 3.3.7.1

7. Validate CPC system using zero check HEPA filter

8. Check sampling bags and pumps for leaks using process described in 3.3.7.1 
9. Check for leaks in gas lines with soap bubble testing method and validation process described in 3.3.6.1

10. Calibrate mass flow controller and meter using process described in section 3.3.6.1

11. Calibrate CTA using TSI 1125 calibrator and validate PIV and sonic anemometer with CTA at same reference points

12. Calibrate PVM-100 micromanometer using process described in section 3.3.3.1

\subsubsection{Tracer Gas Analyzing System Preparation}

4. Turn on FTIR and nitrogen tank

5. Allow sample cell temperature to reach $50^{\circ} \mathrm{C}$. This can be periodically measured by selecting view hardware details within the accompanying software

6. Purge FTIR with nitrogen for five minutes

7. Measure background

8. Purge sampling bags twice prior to use

\subsubsection{Environmental Measurements}

6. Wet the cotton wick of the psychrometer with distilled water

7. Turn psychrometer on inside the wind tunnel as it is enclosed

8. Record wet bulb and dry bulb temperatures

9. Record atmospheric pressure with mercury barometer

\subsubsection{Hood and Wind Tunnel Control Systems Preparation}

3. Turn on the hood and wind tunnel fans

4. Adjust inverter controllers to meet desired testing conditions

\subsubsection{Tracer Gas and Aerosol Release System Preparation}

4. Turn on flow controller and flow meter one hour prior to releasing gases, so they may stabilize

5. Validate flow rates of each gas using DryCal, prior to each unique test date

6. Periodically check system for gas leaks

\subsubsection{Sampling}

4. Turn on sample bag pumps and $\mathrm{CPC}$ at least 10 minutes prior to releasing contaminant to clean the lines and reach sampling equilibrium

5. Connect sample bags to pumps, but keep them closed

6. After gas is on and test is in progress, open the valve between the bag and pump

7. Collect $4 \mathrm{~L}$ in each sample bag

8. Close bag valves after filled 


\subsubsection{Velocity Measurements}

5. While sampling is in progress, conduct ACGIH pitot traverse method for two perpendicular lines of 10 points plus centerlines.

6. Enter all velocity pressure and static pressure data into HvMeasurement software to calculate the average velocity.

\subsubsection{Analyzing Samples}

3. Sample bags in order from least contaminated to most contaminated (i.e. ambient, nose, then duct)

4. Connect first bag up to the FTIR pump connector

5. Select continuous measure and cycle through the bags every minute, with a blank measurement in between bags that exceed $1 \mathrm{ppm}$

6. Record results by hand and locate auto-saved file for additional HvMeasurement analysis

7. Purge all bags at least twice prior to their next usage

8. For CPC system, directly analyze with accompanying Aerosol Instrument Manager ${ }^{\circledR}$ software.

\subsection{Data Analysis}

For direct comparison between the tracer gas method and the CPC method, a simple t-test with confidence interval inclusion was used to compare the two systems for capture and protection efficiency. Determination if there is a significant difference between the means provides a clear indication of whether the CPC method can be used in lieu of the tracer gas method.

\subsection{Results}

The results for the CPC versus Tracer study are shown in Table 5-2. The values represented in the table reflect the average of two replications. The percent difference of the average capture efficiency $\left(\eta_{e}\right)$ values measured for each method was found to be $2 \%$. This close relationship is best illustrated with a nominal capture velocity of $50 \mathrm{fpm}$ at 60 and $120 \mathrm{fpm}$ cross drafts. At these points, there is a significant drop off in hood effectiveness that is reflected similarly with both methods. Slight deviations in Protection Efficiency (PE) between the methods are highlighted most with a nominal capture velocity of $200 \mathrm{fpm}$ at $30 \mathrm{fpm}$ and $120 \mathrm{fpm}$. At these conditions, the tracer gas method and CPC method differ by 3.69 and $5.87 \%$, respectively. In total, though, there only a $2.1 \%$ difference was found between the PE means. 
Table 5-2 CPC vs Tracer Results

\begin{tabular}{c|cccc|cccc|cc}
\hline \multicolumn{1}{c}{ CPC } & \multicolumn{1}{c}{ Tracer } \\
\hline $\begin{array}{c}\text { Treatment } \\
\text { ID }\end{array}$ & $\mathrm{V}_{\mathrm{d}}$ & $\mathrm{V}_{\mathrm{x}}$ & $\begin{array}{c}\eta_{\mathrm{e}} \\
(\mathrm{avg})\end{array}$ & $\mathrm{PE}(\mathrm{avg})$ & $\mathrm{V}_{\mathrm{d}}$ & $\mathrm{V}_{\mathrm{x}}$ & $\begin{array}{c}\eta_{\mathrm{e}} \\
\text { (avg) }\end{array}$ & $\begin{array}{c}\mathrm{PE} \\
(\mathrm{avg})\end{array}$ & $\begin{array}{c}\% \Delta \eta_{\mathrm{e}} \\
\text { (avg) }\end{array}$ & $\begin{array}{c}\% \Delta \mathrm{PE} \\
(\mathrm{avg})\end{array}$ \\
\hline 1 & 30 & 50 & 96.8 & 99.5 & 30 & 50 & 95.2 & 99.9 & 1.67 & 0.40 \\
2 & 30 & 100 & 98.7 & 99.5 & 30 & 100 & 99.6 & 98.7 & 0.91 & 0.81 \\
3 & 30 & 200 & 97.6 & 99.3 & 30 & 200 & 98.7 & 95.7 & 1.12 & 3.69 \\
4 & 60 & 50 & 88.6 & 99.9 & 60 & 50 & 83.7 & 98.1 & 5.67 & 1.82 \\
5 & 60 & 100 & 98.1 & 99.8 & 60 & 100 & 99.3 & 96.9 & 1.22 & 2.95 \\
6 & 60 & 200 & 99.4 & 99.5 & 60 & 200 & 95.7 & 98.6 & 3.79 & 0.91 \\
7 & 120 & 50 & 72.1 & 99.9 & 120 & 50 & 72.9 & 99.5 & 1.10 & 0.40 \\
8 & 120 & 100 & 96.9 & 99.9 & 120 & 100 & 97.9 & 96.8 & 1.02 & 3.15 \\
9 & 120 & 200 & 97.9 & 99.8 & 120 & 200 & 99.5 & 94.1 & 1.62 & 5.87 \\
\hline
\end{tabular}

$\mathrm{V}_{\mathrm{x}}=$ Capture Velocity; $\mathrm{V}_{\mathrm{d}}=$ Draft Velocity; $\eta_{\mathrm{e}}=$ Capture Efficiency; $\mathrm{PE}=$ Protection Efficiency

Figure 5-1 illustrates the capture efficiency recorded using both methods, throughout the randomized design.

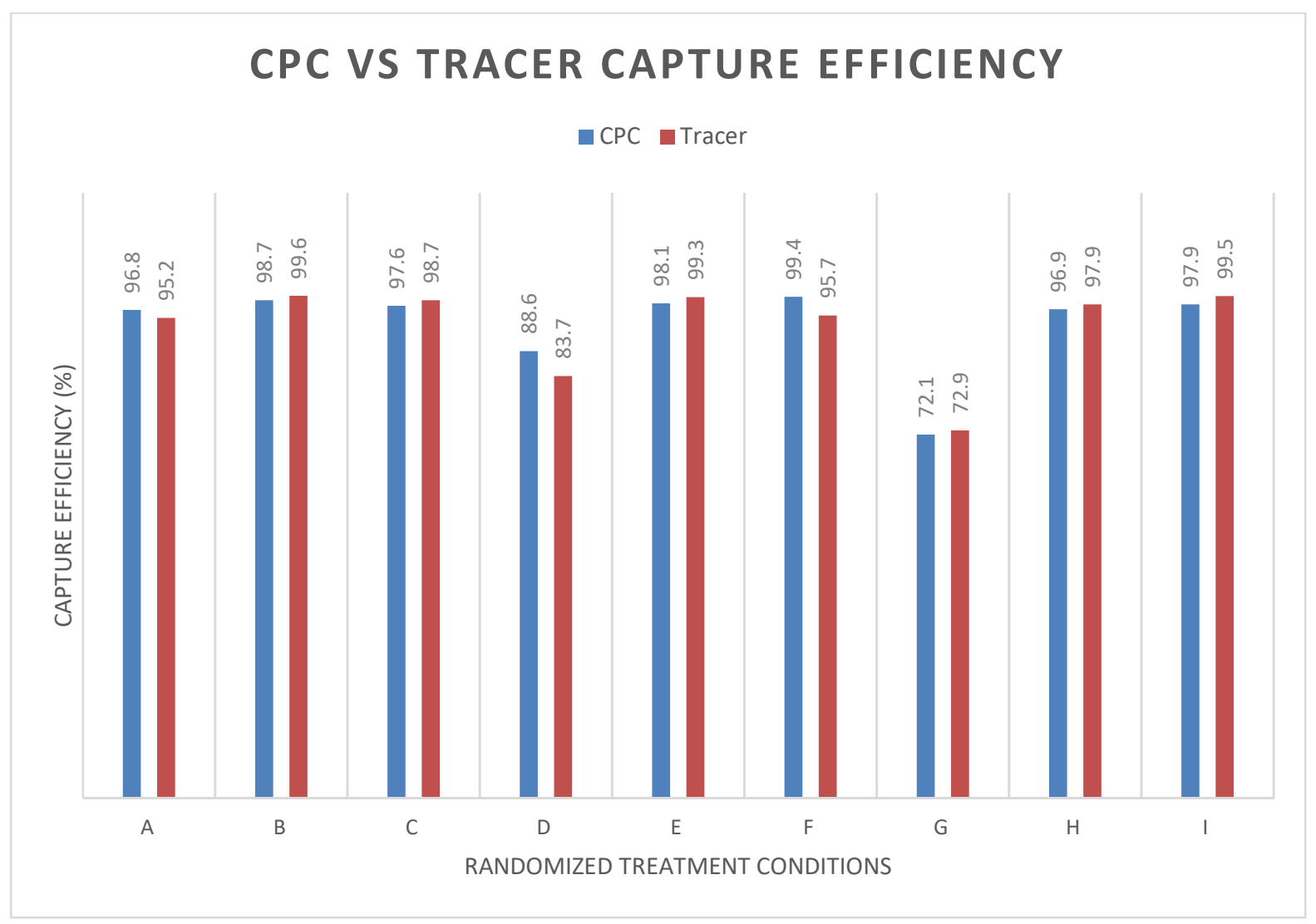

Figure 5-1 CPC vs Tracer Capture Efficiency Comparison 
Figure 5-2 further illustrates how the combination of all factors affect the capture efficiency of the hood. No significant differences are shown at any factor level throughout the design.

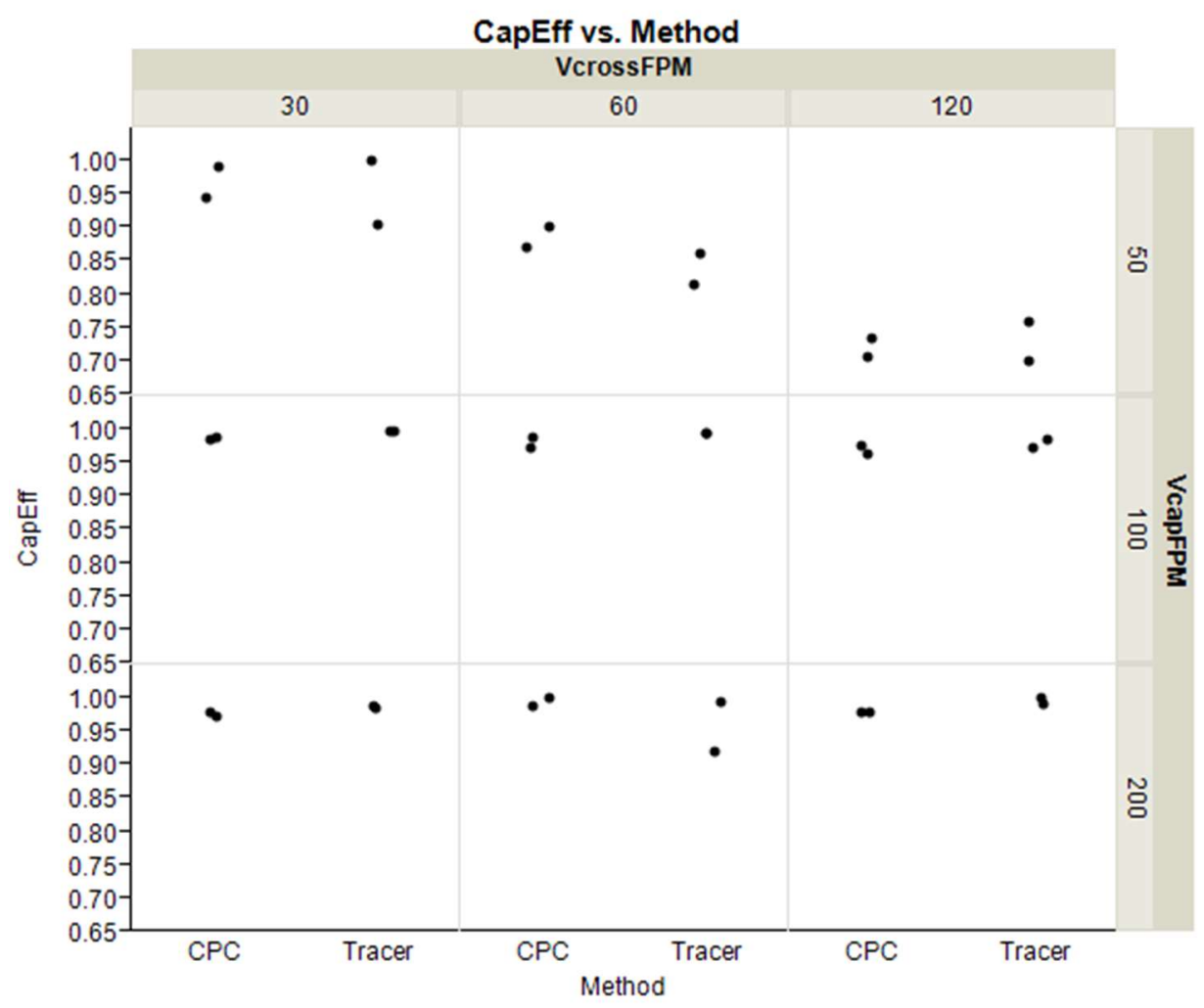

Figure 5-2 Effects of All Factors in CPC vs Tracer Design

A two-sample t-test was conducted to compare the means between the two methods, to determine if the CPC method could be a reliable alternative to the tracer gas method. The difference of the means $\left(\overline{\mathrm{x}}_{\text {tracer }}-\overline{\mathrm{x}}_{\mathrm{CPC}}\right)$ was found to be $=-0.00410$. A 95\% confidence interval provides a range of this difference to be between -0.0648 to 0.0566 . No statistical difference ( $\mathrm{p}=$ 0.8917) was found between the two methods for measuring capture efficiency.

Conversely, a statistical difference between the Tracer and CPC methods for breathing effectiveness was found. However, the percent difference between the means was only $2.1 \%$, and both methods yielded a net mean breathing effectiveness of greater than $97 \%$ efficiency. The slight difference between the two models is likely due to the minimum detection limits of the FTIR vs the CPC. The FTIR reliably measures down to approximately $2 \mathrm{ppm}$, while the CPC has a notable drift below 100 particle counts per cubic centimeter. Due to the nature of the wind 
tunnel acting as a large exhaust system, concentrations otherwise suspended in the air were removed from the tunnel entirely. A typical accumulation effect would presumably result in higher concentrations in the breathing zone, across all experimental conditions. Because of this, the capture efficiency is the more important measurement in wind tunnel experimentation.

\subsection{Study Summary}

The primary focus of this study was to determine if a condensation particle counter could be used as an alternative method for capture and protection efficiency studies. No significant difference $(\mathrm{p}=0.8917)$ was found between the CPC method and the tracer gas method, for measuring the capture efficiency of the hood. However, a statistically significant difference was measured between the two methods in measuring the protection efficiency. While this difference was measured to be statistically significant, only a $2.1 \%$ difference between the means was measured. There was no practical difference found between the two methods; the tracer method was $97 \%$ effective and the CPC method was $99 \%$ effective at removing the theoretical contaminant in the air. The difference was likely caused by a difference in minimum detection between the analyzing equipment. The FTIR measures Freon 134-a reliably down to approximately $2 \mathrm{ppm}$. A notable drift is observed in the CPC below 100 particle counts per cubic centimeter. 


\section{Chapter 6 : Manikin Movements}

\subsection{Introduction}

The effects of body movements on breathing zone concentrations have previously been considered in free field systems (Ljungqvist, 1979; Kim and Flynn, 1992; Welling et. al., 2000; Welling et. al, 2001; Guffey et. al., 2001). However, to the author's knowledge, no studies have considered the effect operator movements have on the effectiveness of a capturing hood system. This is an important consideration, because the Industrial Ventilation manual (ACGIH, 2001) that technicians use to design exterior hood systems does not mention how to factor this into the overall hood design.

In this manikin movement study, a heated and breathing manikin was positioned on a freeflowing turntable. The arms of the manikin were mounted to a workbench with straps and linkages connected to ACDelco $25942547 \mathrm{GM}$ windshield wiper motors. The motors were powered by Kastar LCD AC Adapters 12V 6A and controlled by uniquegoods PWM DC Motor Speed Controllers, set to $30 \mathrm{rpm}$ per arm.

A sodium chloride and water aerosol was used as the tracer contaminant. Contaminant concentrations in the duct $\left(\mathrm{C}_{\text {duct }}\right)$ and breathing zone $\left(\mathrm{C}_{\mathrm{BZ}}\right)$ of a surrogate worker were measured for varying experimental conditions with a condensation particle counter (CPC). The experimental concentrations were then compared to accompanying conditions in which the traceable contaminant was released directly into the vent $\left(\mathrm{C}_{\text {duct } 100}\right)$ and whenever the hood was turned off entirely $\left(\mathrm{C}_{\mathrm{BZ} 100}\right)$. The ratios of these measurements were then used to determine the effectiveness of the hood system.

\subsection{Research Design}

The study was a randomized full factorial design with two replications. The dependent variables include the concentrations of the contaminant within the breathing zone $\left(\mathrm{C}_{\mathrm{BZ}}\right)$ of the operator and the concentrations of the contaminant located far downstream within the duct $\left(\mathrm{C}_{\text {duct }}\right)$. The breathing zone samples were collected at a single point between the mouth and nose. 
The independent variables include two levels of draft velocity $\left(\mathrm{V}_{\text {draft }}\right)$, three levels of hood orientation, and two levels of manikin movement. The capture velocity $\left(\mathrm{V}_{\text {cap }}\right)$ was held constant at a nominal $50 \mathrm{fpm}$, because previous studies found that this setting yields the most variability. The two levels of $V_{\text {draft }}$ were 30 and $120 \mathrm{fpm}$. The three levels of hood orientation were $0^{\circ}, 90^{\circ}$, and $180^{\circ}$, with cross drafts blowing at the operator's back, side, and front, respectively. The two levels of manikin movement were the manikin moving its arms at a rate of $30 \mathrm{rpm}$ and the manikin not moving at all. With two levels of $\mathrm{V}_{\text {draft, }}$ three levels of hood orientation, two levels of manikin movement, and two replications, there 24 total randomized treatments within this study. This is shown in Table 6-1.

Table 6-1 Manikin Movement Full Design - Single Replication

\begin{tabular}{c|cccc}
\hline Test & $\mathrm{O}$ & $\mathrm{V}_{\mathrm{d}}$ & Move & $\mathrm{V}_{\mathrm{x}}$ \\
\hline 1 & 0 & 30 & Yes & 50 \\
2 & 0 & 30 & No & 50 \\
3 & 0 & 120 & Yes & 50 \\
4 & 0 & 120 & No & 50 \\
5 & 90 & 30 & Yes & 50 \\
6 & 90 & 30 & No & 50 \\
7 & 90 & 120 & Yes & 50 \\
8 & 90 & 120 & No & 50 \\
9 & 180 & 30 & Yes & 50 \\
10 & 180 & 30 & No & 50 \\
11 & 180 & 120 & Yes & 50 \\
12 & 180 & 120 & No & 50 \\
\hline
\end{tabular}

$\mathrm{O}=$ Orientation; $\mathrm{V}_{\mathrm{d}}=$ Draft Velocity; Move = Manikin Movement; $\mathrm{V}_{\mathrm{x}}=$ Capture Velocity

\subsection{Methods}

The methods for measurement used in this study are largely the same as those used in the CPC vs Tracer study, in Chapter 5.3. The key difference is that this study only used the CPC method for analysis.

\subsection{Procedures}

Standard testing procedures for this study are grouped as follows:

- Calibration and Validation

- Environmental Measurements 
- Hood and Wind Tunnel Control Systems Preparation

- Aerosol Release System Preparation

- Manikin Preparation

- Sampling

- Velocity Measurements

- Analyzing Samples

\subsubsection{Calibration and Validation}

1. Validate CPC system using zero check HEPA filter

2. Verify manikin arm motors running at $30 \mathrm{rpm}$

3. Calibrate PVM-100 micromanometer using process described in section 3.3.3.1

\subsubsection{Environmental Measurements}

1. Wet the cotton wick of the psychrometer with distilled water

2. Turn psychrometer on inside the wind tunnel as it is enclosed

3. Record wet bulb and dry bulb temperatures

4. Record atmospheric pressure with mercury barometer

5. Record manikin body temperature at both arms and center of chest

\subsubsection{Hood and Wind Tunnel Control Systems Preparation}

1. Turn on the hood and wind tunnel fans

2. Adjust inverter controllers to meet desired testing conditions

\subsubsection{Aerosol Release System Preparation}

1. Refill TSI 8026 particle generator prior to every unique sampling day

2. Validate flow rates using DryCal, prior to study

3. Periodically check particle generator to ensure proper hose connection

\subsubsection{Sampling}

1. Turn on CPC at least 10 minutes prior to releasing contaminant to clean the lines and reach sampling equilibrium

2. Ensure proper solenoid valve is open for desired sampling location

3. Record each sample for two minutes 


\subsubsection{Velocity Measurements}

7. While sampling is in progress, conduct ACGIH pitot traverse method for two perpendicular lines of 10 points plus centerlines.

8. Enter all velocity pressure and static pressure data into HvMeasurement software to calculate the average velocity.

\subsubsection{Analyzing Samples}

1. Directly analyze with accompanying Aerosol Instrument Manager ${ }^{\circledR}$ software.

2. Verify sampling curve has reached equilibrium before collecting next sample.

\subsection{Data Analysis}

An analysis of variance (ANOVA) model with fixed effects was used to determine if there were any significant effects of the independent variables (hood orientation, $\mathrm{V}_{\text {draft, }}$ and manikin movement) on the response of the dependent variables ( $\eta_{e}$, PE). JMP was used to establish the effects test and accompanying parameter estimates to determine which variables have the greatest effect. Emphasis was placed on the effects of manikin movements on capture and breathing efficiency.

\subsection{Results}

The results for the Manikin Movement study are shown in Table 6-2. The values represented in the table reflect the average of two replications. The percent difference of the average capture efficiency $\left(\eta_{\mathrm{e}}\right)$ values measured for each method was found to be $1.9 \%$. This close relationship is best illustrated when comparing the capture efficiency with and without manikin movements with a $120 \mathrm{fpm}$ cross draft at the 180-degree orientation. At these points, there is a significant drop off in hood effectiveness that is reflected similarly with both methods. The percent difference found between the manikin presence Protection Efficiency $(\mathrm{PE})$ was only found to be $0.4 \%$. The new protection factor method yielded the highest deviation between the means. The average percent difference measured for $\mathrm{P}_{\mathrm{APF}}$ was $12.2 \%$. The deviation can best be observed and $30 \mathrm{fpm}$ cross draft at the 90-degree orientation and $120 \mathrm{fpm}$ cross draft at the 180-degree orientation. 
Table 6-2 Manikin Movement Results

\begin{tabular}{|c|c|c|c|c|c|c|c|c|c|}
\hline & & & & & & & \multicolumn{3}{|c|}{ Mankin Movemenet } \\
\hline $\begin{array}{c}\text { Treatment } \\
\text { ID }\end{array}$ & $\mathrm{O}$ & $\mathrm{V}_{\mathrm{d}}$ & Move & $\eta_{\mathrm{e}}(\mathrm{avg})$ & $\begin{array}{c}\mathrm{PE} \\
(\mathrm{avg})\end{array}$ & $\begin{array}{l}\mathrm{P}_{\mathrm{APF}} \\
\text { (avg) }\end{array}$ & $\% \Delta \eta_{\mathrm{e}}(\mathrm{avg})$ & $\begin{array}{c}\% \Delta P E \\
\text { (avg) }\end{array}$ & $\begin{array}{c}\% \Delta \mathrm{P}_{\mathrm{APF}} \\
(\mathrm{avg})\end{array}$ \\
\hline 1 & 0 & 30 & Yes & 97.9 & 98.1 & 98.0 & \multirow{2}{*}{0.61} & \multirow{2}{*}{0.81} & \multirow{2}{*}{1.02} \\
\hline 2 & 0 & 30 & No & 98.5 & 98.9 & 99.0 & & & \\
\hline 3 & 0 & 120 & Yes & 97.8 & 97.3 & 99.4 & \multirow{2}{*}{0.00} & \multirow{2}{*}{1.24} & \multirow{2}{*}{0.40} \\
\hline 4 & 0 & 120 & No & 97.8 & 96.1 & 99.0 & & & \\
\hline 5 & 90 & 30 & Yes & 96.4 & 99.5 & 63.5 & \multirow{2}{*}{0.83} & \multirow{2}{*}{0.10} & \multirow{2}{*}{25.43} \\
\hline 6 & 90 & 30 & No & 97.2 & 99.6 & 82.0 & & & \\
\hline 7 & 90 & 120 & Yes & 98.3 & 99.8 & 90.9 & \multirow{2}{*}{0.61} & \multirow{2}{*}{0.00} & \multirow{2}{*}{3.35} \\
\hline 8 & 90 & 120 & No & 97.7 & 99.8 & 94.0 & & & \\
\hline 9 & 180 & 30 & Yes & 95.8 & 98.4 & 99.6 & \multirow{2}{*}{1.14} & \multirow{2}{*}{0.30} & \multirow{2}{*}{0.81} \\
\hline 10 & 180 & 30 & No & 96.9 & 98.7 & 98.8 & & & \\
\hline 11 & 180 & 120 & Yes & 72.4 & 99.4 & 53.4 & \multirow{2}{*}{8.21} & \multirow{2}{*}{0.20} & \multirow{2}{*}{42.01} \\
\hline 12 & 180 & 120 & No & 78.6 & 99.2 & 81.8 & & & \\
\hline
\end{tabular}

$\mathrm{O}=$ Orientation $; \mathrm{V}_{\mathrm{d}}=$ Draft Velocity; Move = Manikin Movement; $\eta_{\mathrm{e}}=$ Capture Efficiency; PE $=$ Protection Efficiency;

$\mathrm{P}_{\mathrm{APF}}=$ Protection Factor

\subsubsection{Means Analysis of Manikin Movement Effect}

Figure 6-1 illustrates the effects of manikin movement on the raw concentration measured within the duct at all conditions. Despite some deviation and outliers, the difference between the means is negligible.

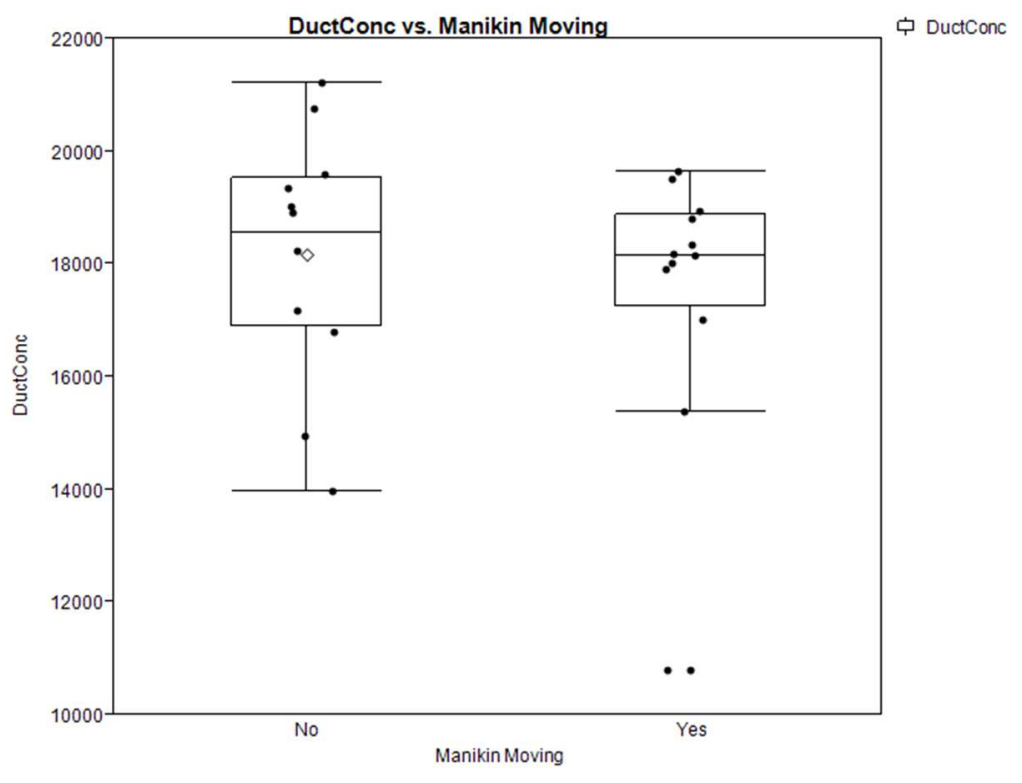

Figure 6-1 Effects of Manikin Movement on Duct Concentration 
Figure 6-2 provides a more detailed illustration of how all the combined factors in this study, with respect to manikin presence, effect the raw concentration in measured within the duct. Negligible deviation can be observed at any level of any factor, relative to manikin presence.

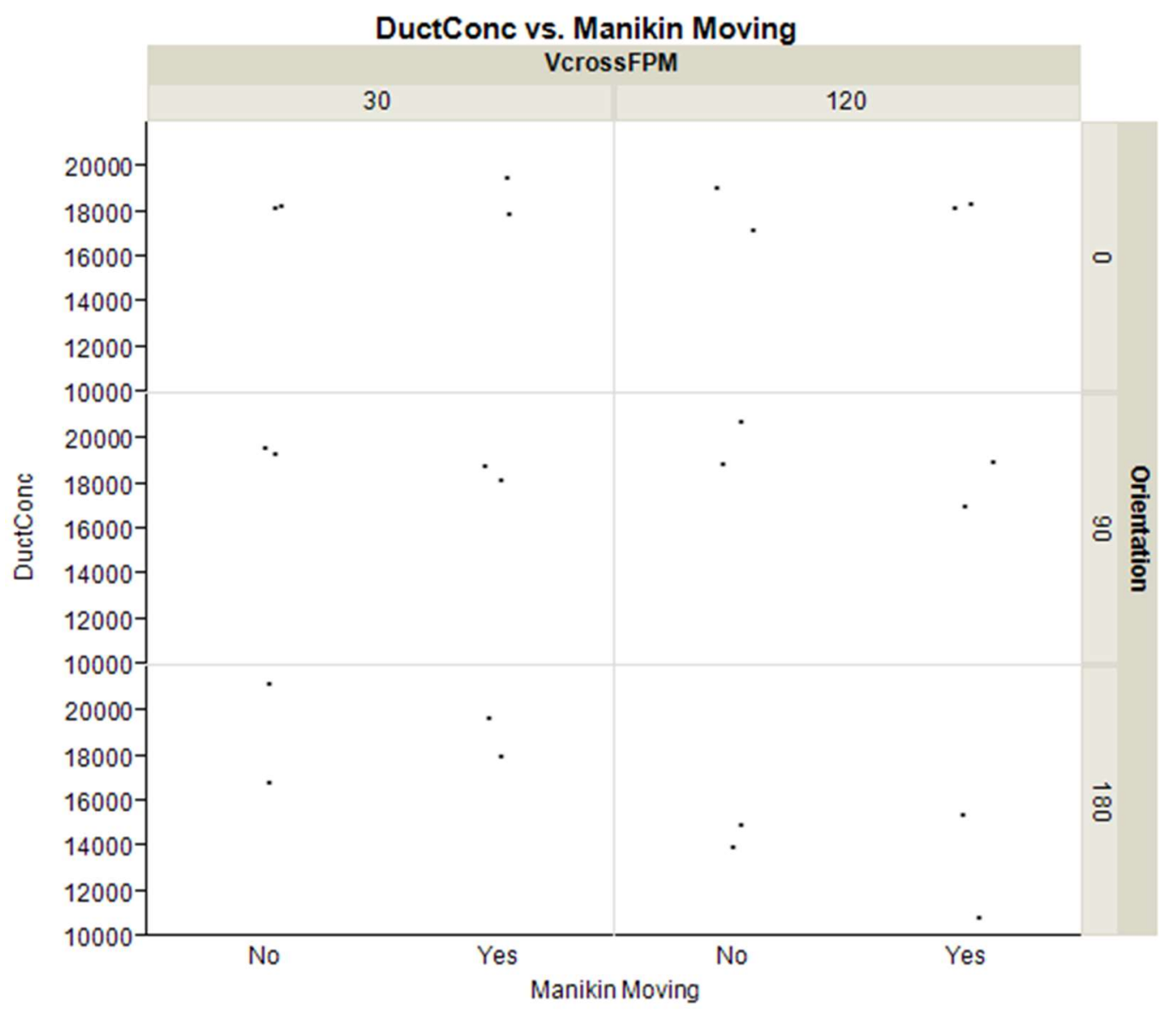

Figure 6-2 Detailed Effects of Manikin Movement on Duct Concentration

Figure 6-3 illustrates the effects of manikin movement on the raw concentration measured within the breathing zone. Despite some deviation and outliers, the difference between the means is negligible. 


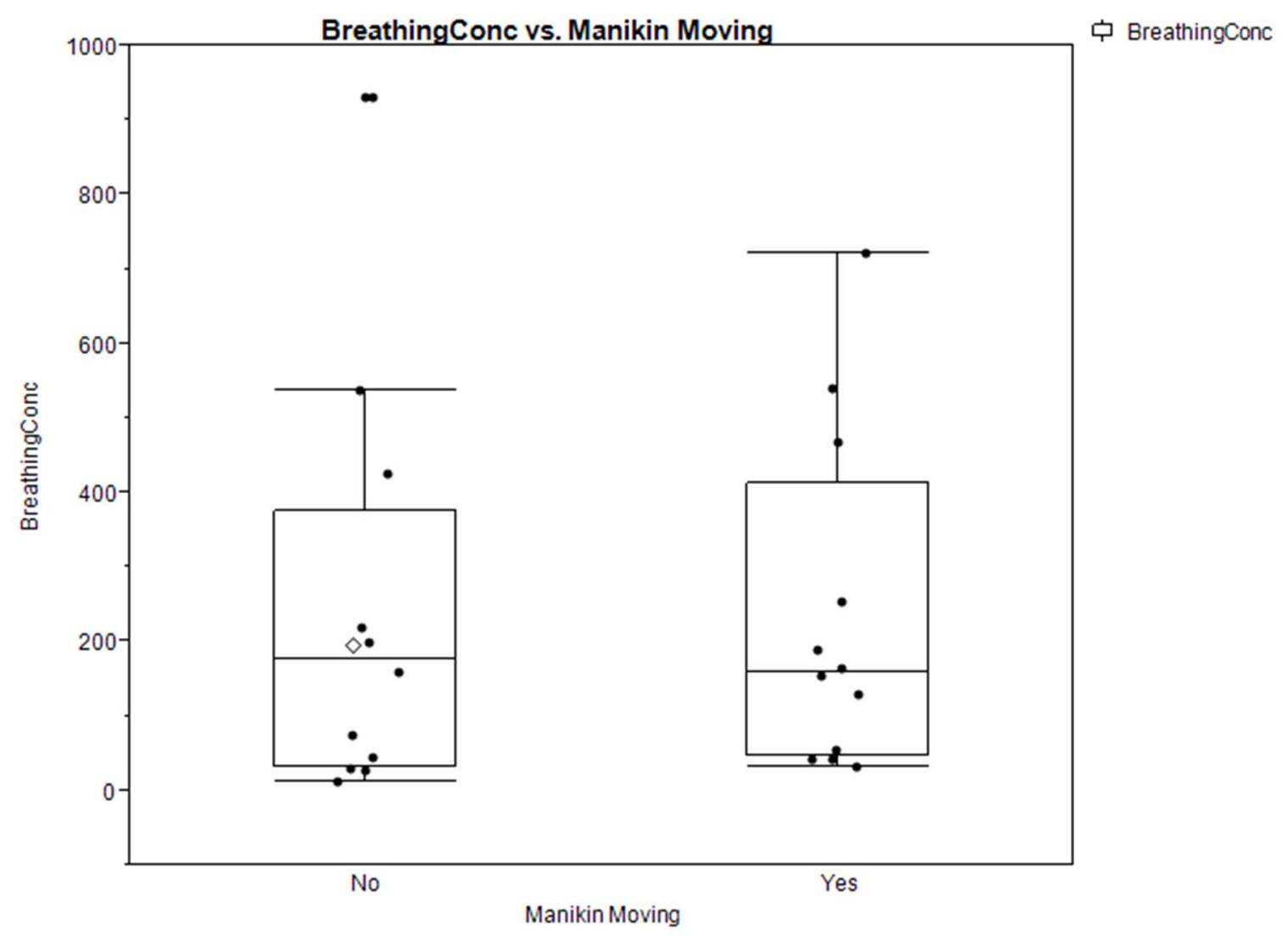

Figure 6-3 Effects of Manikin Movement on Breathing Concentration

Figure 6-4 provides a more detailed illustration of how all the combined factors in this study, with respect to manikin presence, effect the raw concentration measured within the breathing zone. The only notable deviation is found with a $30 \mathrm{fpm}$ cross draft at the 0 -degree orientation, without the presence of a manikin. 


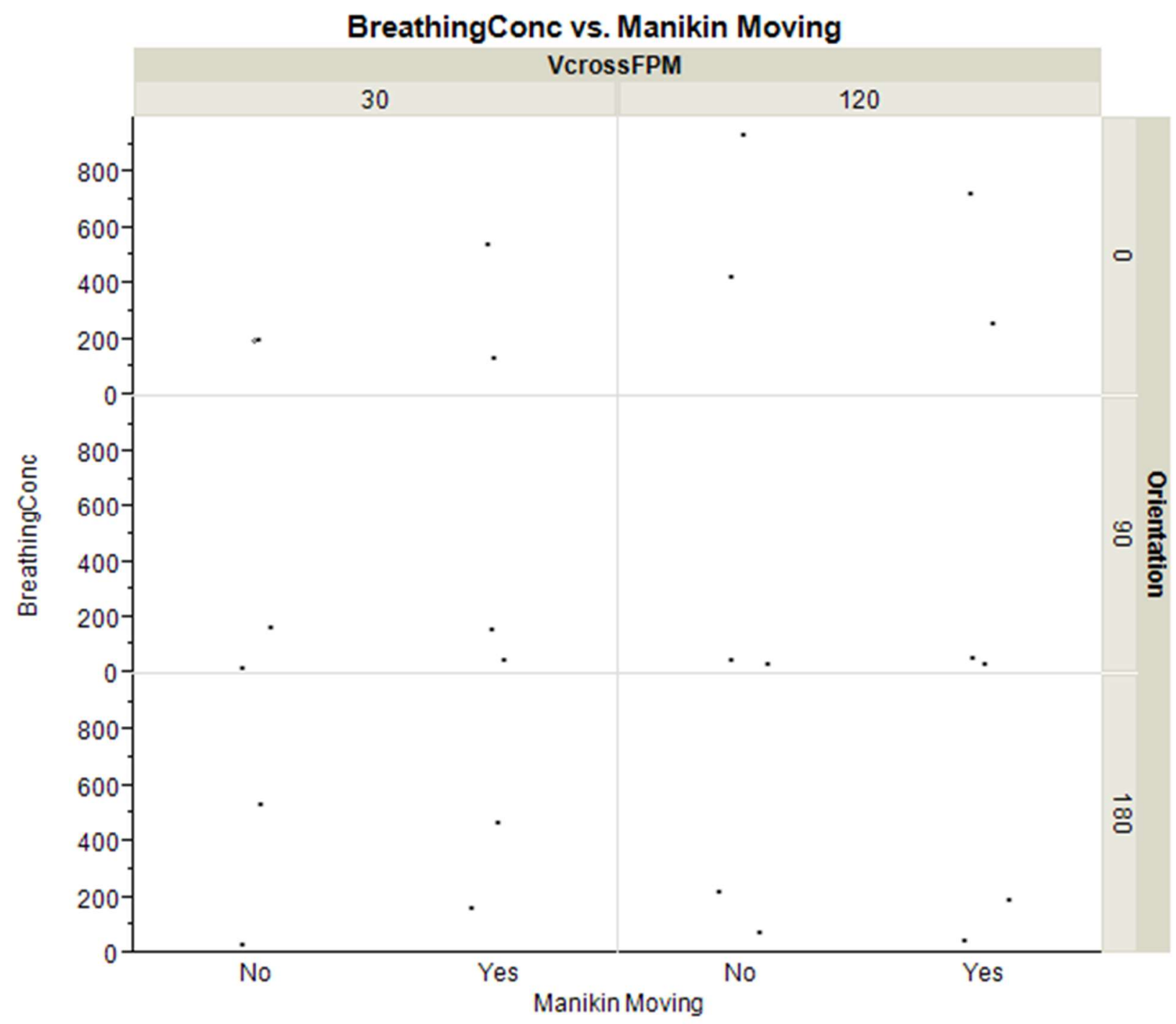

Figure 6-4 Detailed Effects of Manikin Movement on Breathing Concentration

Figure 6-5 illustrates the effects of manikin movement on the Breathing Protection Factor for all conditions. A notable difference is observed between the differences of the means 


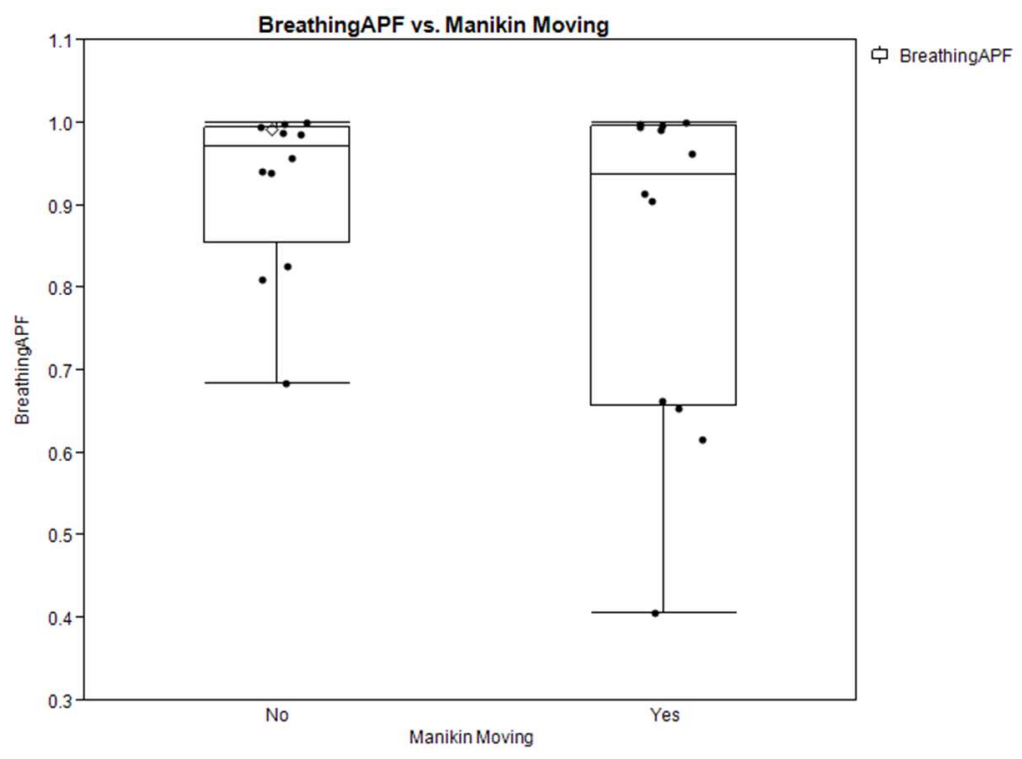

Figure 6-5 Effects of Manikin Movement on Breathing Protection Factor

Figure 6-6 provides a more detailed illustration of how all the combined factors in this study, with respect to manikin movement, effect the Breathing Protection Factor. Large deviations are clear with a $120 \mathrm{fpm}$ cross draft at the 180-degree orientation, and a modest deviation is shown at $30 \mathrm{fpm}$ cross draft at the 90-degree orientation

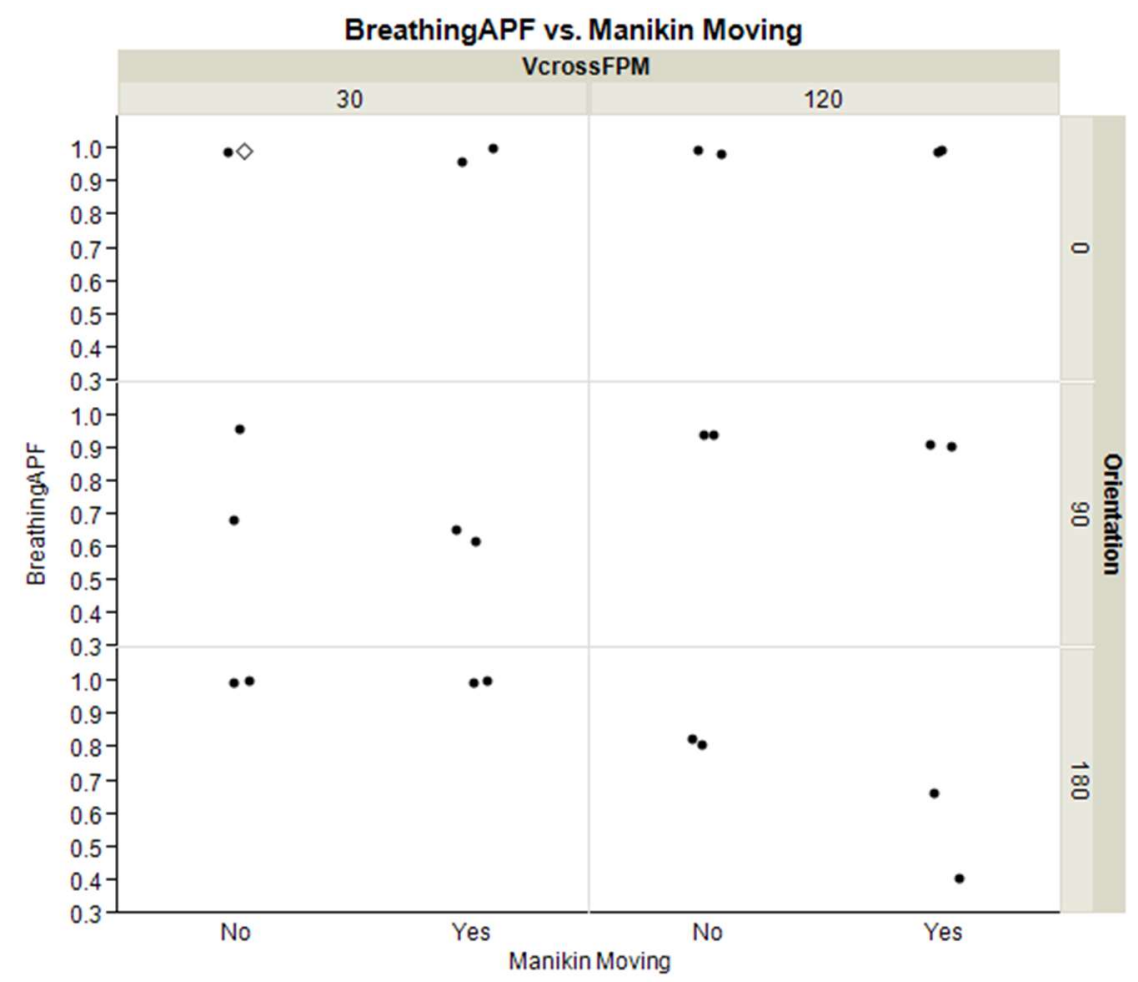

Figure 6-6 Detailed Effects of Manikin Movement on Breathing Protection Factor 
Figure 6-7 illustrates the effects of manikin movement on the Breathing Efficiency for all conditions. Despite some deviation and outliers, the difference between the means is negligible.

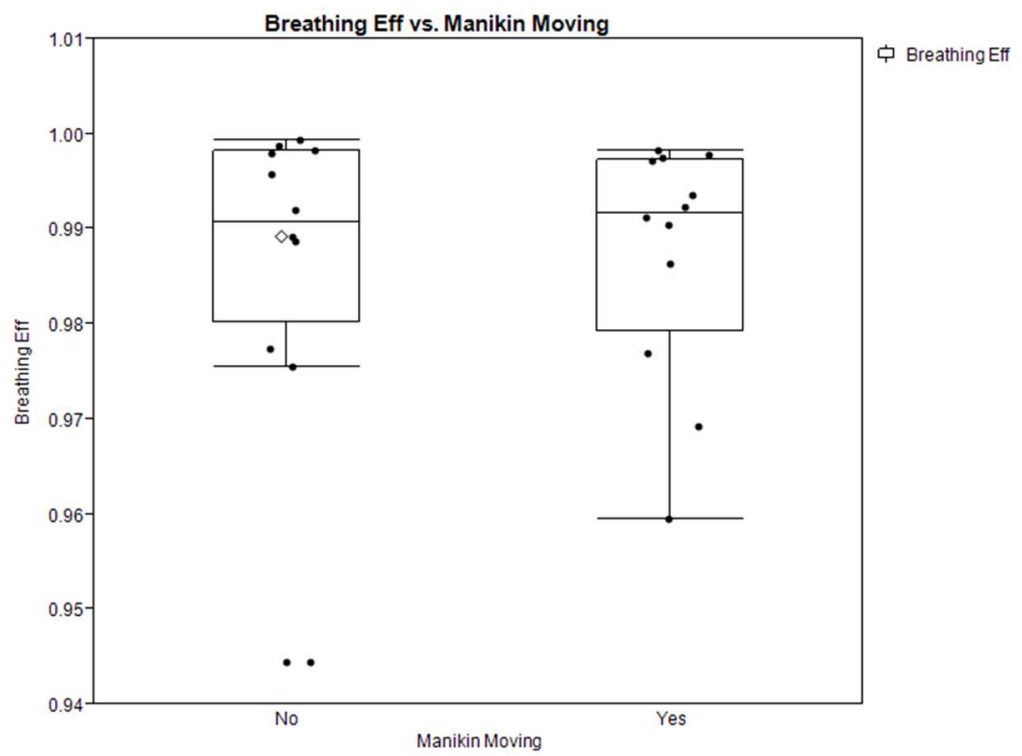

Figure 6-7 Effects of Manikin Movement on Breathing Efficiency

Figure 6-8 provides a more detailed illustration of how all the combined factors in this study, with respect to manikin presence, effect the Breathing Efficiency. Slight deviations can be observed at both 30 and $120 \mathrm{fpm}$ cross drafts at the 0 -degree orientation.

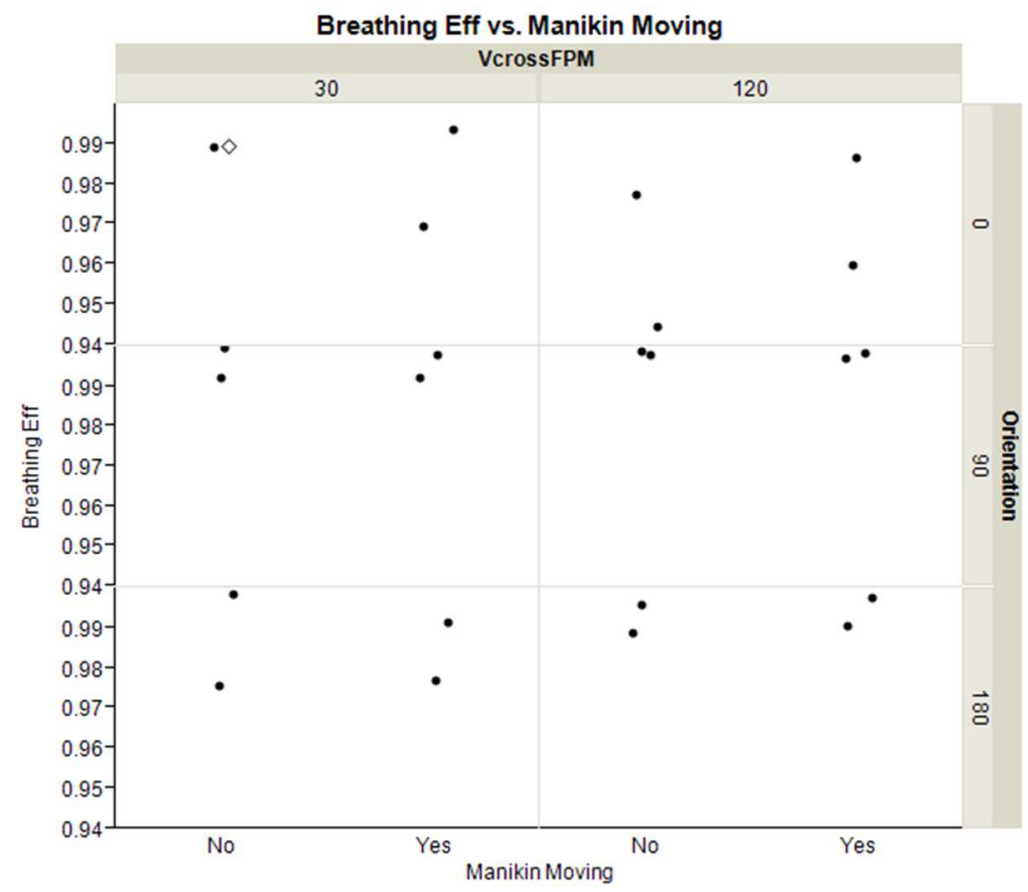

Figure 6-8 Detailed Effects of Manikin Movement on Breathing Efficiency 
Figure 6-9 illustrates the effects of manikin movement on the Capture Efficiency for all conditions. There are no observable differences between the two means.

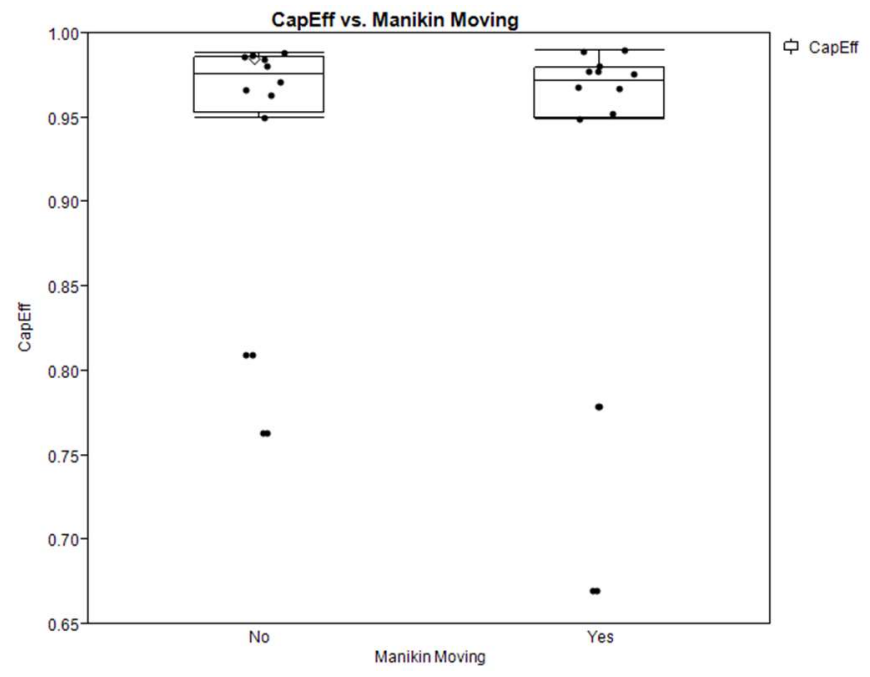

Figure 6-9 Effects of Manikin Movement on Capture Efficiency

Figure 6-10 provides a more detailed illustration of how all the combined factors in this study, with respect to manikin presence, effect the Capture Efficiency. No noticeable differences are observed for manikin presence for capture efficiency.

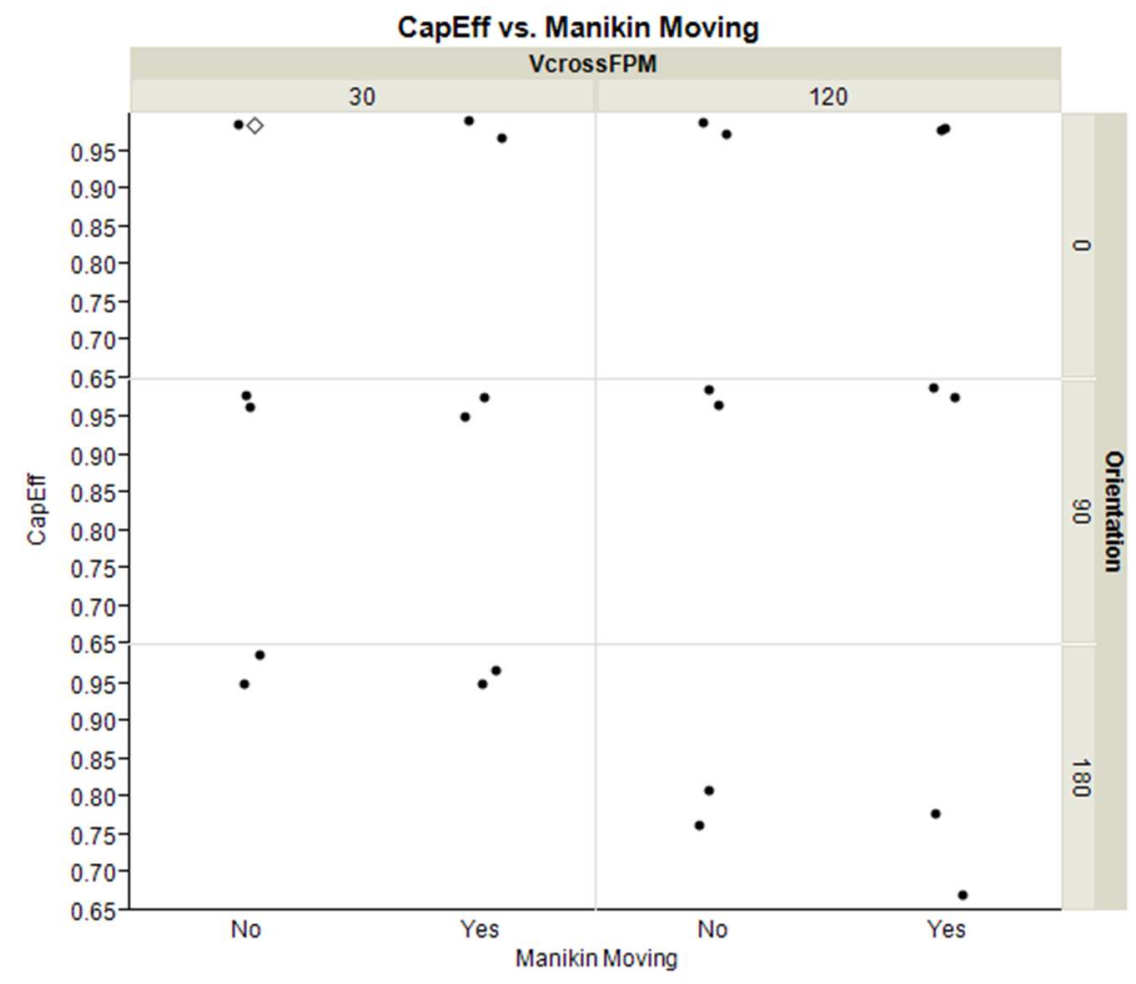

Figure 6-10 Detailed Effects of Manikin Movement on Capture Efficiency 


\subsubsection{Variables Affecting Capture Efficiency}

Figure 6-11 and the accompanying Table 6-3 summarize the model fit for predicting capture efficiency. $\mathrm{R}^{2}=0.95$, demonstrates an excellent fit; almost all of the variance is explained by this model.

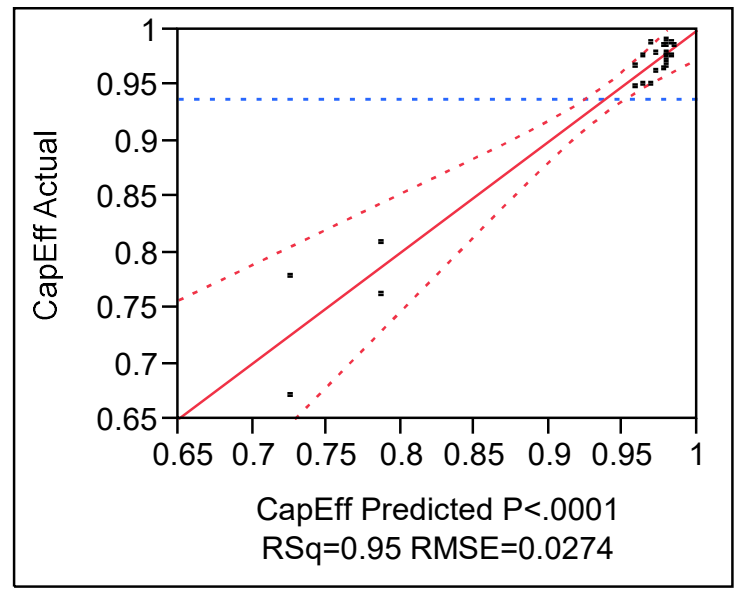

Figure 6-11 Actual by Predicted Plot for Capture Efficiency

Table 6-3 Summary of Fit for Capture Efficiency

$\begin{array}{lr}\text { RSquare } & 0.948206 \\ \text { RSquare Adj } & 0.900727 \\ \text { Root Mean Square Error } & 0.027398 \\ \text { Mean of Response } & 0.93775 \\ \text { Observations (or Sum Wgts) } & 24\end{array}$

Table 6-4 Capture Efficiency ANOVA

$\begin{array}{lrrrr}\text { Source } & \text { DF } & \text { Sum of Squares } & \text { Mean Square } & \text { F Ratio } \\ \text { Model } & 11 & 0.16491050 & 0.014992 & 19.9714 \\ \text { Error } & 12 & 0.00900800 & 0.000751 & \text { Prob }>\text { F } \\ \text { C. Total } & 23 & 0.17391850 & & <.0001^{*}\end{array}$

Since the ANOVA found a significant difference between the means, the next step was checking the effects test to determine which variables have a significant effect on the capture efficiency. As shown in Table 6-5 orientation, cross draft, and their interaction was found to have a significant effect on capture efficiency. Manikin movement had a noticeable effect on the capture efficiency, but it was not found to be significant. 


\section{Table 6-5 Capture Efficiency Effects Test}

\begin{abstract}
Source
Orientation

VcrossFPM

Orientation* ${ }^{*}$ crossFPM

Manikin Moving

Orientation*Manikin Moving

VcrossFPM*Manikin Moving

Orientation ${ }^{*}$ crossFPM Manikin $^{*}$

Moving
\end{abstract}

$\begin{array}{rrrrr}\text { Nparm } & \text { DF } & \begin{array}{r}\text { Sum of } \\ \text { Squares }\end{array} & \text { F Ratio } & \text { Prob > F } \\ & 2 & 0.07363300 & 49.0451 & <.0001^{*} \\ 1 & 1 & 0.02653350 & 35.3466 & <.0001^{*} \\ 2 & 2 & 0.06071700 & 40.4421 & <.0001^{*} \\ 1 & 1 & 0.00104017 & 1.3857 & 0.2620 \\ 2 & 2 & 0.00157033 & 1.0460 & 0.3813 \\ 1 & 1 & 0.00016017 & 0.2134 & 0.6524 \\ 2 & 2 & 0.00125633 & 0.8368 & 0.4569\end{array}$

Table 6-6 shows more detail in how significant each level of the factor was in effecting capture efficiency.

Table 6-6 Capture Efficiency Scaled Estimates

\begin{tabular}{|c|c|c|c|c|c|}
\hline Term & $\begin{array}{c}\text { Scaled } \\
\text { Estimate }\end{array}$ & Plot Estimate & $\begin{array}{r}\text { Std } \\
\text { Error }\end{array}$ & $\begin{array}{r}t \\
\text { Ratio }\end{array}$ & Prob $>|t|$ \\
\hline Intercept & 0.93775 & $\bar{E}$ & 0.005593 & 167.68 & $<.0001^{*}$ \\
\hline Orientation[0] & 0.04225 & & 0.007909 & 5.34 & $0.0002^{*}$ \\
\hline Orientation[90] & 0.03600 & 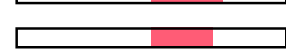 & 0.007909 & 4.55 & $0.0007^{*}$ \\
\hline Orientation[180] & -0.07825 & & 0.007909 & -9.89 & $<.0001^{*}$ \\
\hline VcrossFPM[30] & 0.03325 & 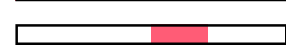 & 0.005593 & 5.95 & $<.0001^{*}$ \\
\hline VcrossFPM[120] & -0.03325 & 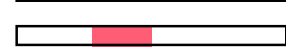 & 0.005593 & -5.95 & $<.0001^{*}$ \\
\hline Orientation[0]*VcrossFPM[30] & -0.03175 & $=$ & 0.007909 & -4.01 & $0.0017^{*}$ \\
\hline Orientation[0] ${ }^{*}$ VcrossFPM[120] & 0.03175 & ב= & 0.007909 & 4.01 & $0.0017^{*}$ \\
\hline Orientation[90] ${ }^{*}$ crossFPM[30] & -0.03925 & 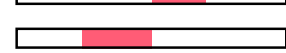 & 0.007909 & -4.96 & $0.0003^{*}$ \\
\hline Orientation $[90]^{*} V \operatorname{crossFPM}[120]$ & 0.03925 & $\bar{\square}$ & 0.007909 & 4.96 & $0.0003^{*}$ \\
\hline Orientation[180]* ${ }^{*}$ crossFPM[30] & 0.07100 & & 0.007909 & 8.98 & $<.0001^{*}$ \\
\hline Orientation $[180]^{\star} V \operatorname{crossFPM}[120]$ & -0.07100 & & 0.007909 & -8.98 & $<.0001^{*}$ \\
\hline
\end{tabular}




\subsubsection{Variables Affecting Protection Efficiency}

Figure 6-12 and the accompanying Table 6-7 summarize the model fit for predicting breathing efficiency. $\mathrm{R}^{2}=0.63$, demonstrates only a moderate fit; a large portion of the variance is not explained by this model.

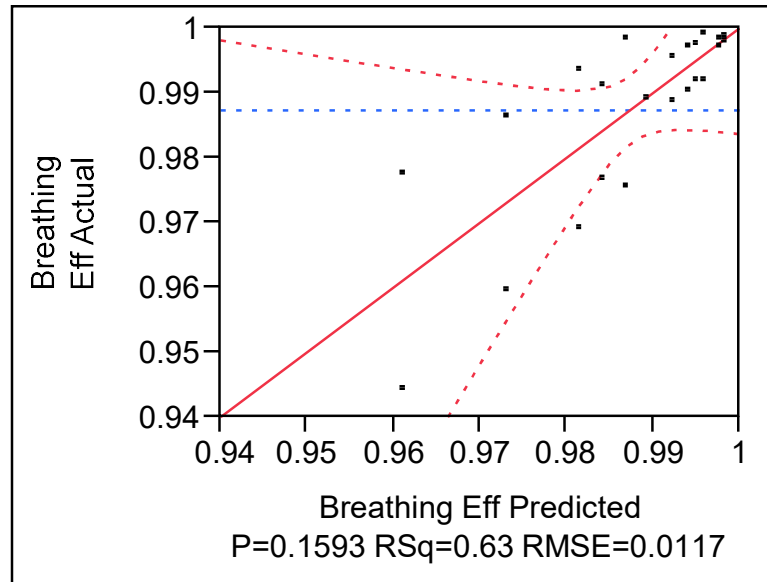

Figure 6-12 Actual by Predicted Plot for Breathing Efficiency

Table 6-7 Summary of Fit for Protection Efficiency

$\begin{array}{lr}\text { RSquare } & 0.625094 \\ \text { RSquare Adj } & 0.281431 \\ \text { Root Mean Square Error } & 0.011738 \\ \text { Mean of Response } & 0.987326 \\ \text { Observations (or Sum Wgts) } & 24\end{array}$

Table 6-8 ANOVA Protection Efficiency

$\begin{array}{lrrrr}\text { Source } & \text { DF } & \text { Sum of Squares } & \text { Mean Square } & \text { F Ratio } \\ \text { Model } & 11 & 0.00275689 & 0.000251 & 1.8189 \\ \text { Error } & 12 & 0.00165347 & 0.000138 & \text { Prob > F } \\ \text { C. Total } & 23 & 0.00441036 & & 0.1593\end{array}$

The ANOVA failed to find a significant difference between the means. 


\subsubsection{Variables Affecting Protection Factor}

Figure 6-13 and the accompanying Table 6-13 summarize the model fit for predicting the breathing factor. $\mathrm{R}^{2}=0.88$, demonstrates a strong fit; most of the variance is explained by this model.

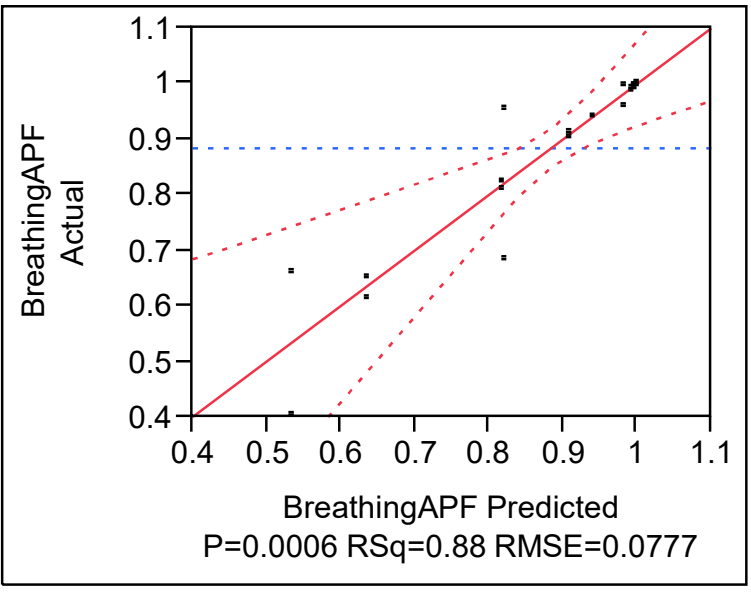

Figure 6-13 Actual by Predicted Plot for Breathing Factor

Table 6-9 Summary of Fit for Breathing Protection Factor

$\begin{array}{lr}\text { RSquare } & 0.880056 \\ \text { RSquare Adj } & 0.770108 \\ \text { Root Mean Square Error } & 0.077738 \\ \text { Mean of Response } & 0.883667 \\ \text { Observations (or Sum Wgts) } & 24\end{array}$

Table 6-10 ANOVA Protection Factor

$\begin{array}{lrrrr}\text { Source } & \text { DF } & \text { Sum of Squares } & \text { Mean Square } & \text { F Ratio } \\ \text { Model } & 11 & 0.53209033 & 0.048372 & 8.0043 \\ \text { Error } & 12 & 0.07251900 & 0.006043 & \text { Prob > F } \\ \text { C. Total } & 23 & 0.60460933 & & 0.0006^{*}\end{array}$

Since the ANOVA found a significant difference between the means, the next step was to check the effects test to determine which variables have a significant effect on the protection factor. As shown in Table 6-11 orientation, manikin movement, the interaction of orientation and cross drafts, and the interaction of orientation, manikin movement, and cross drafts all were found to have a significant effect on the protection factor. 
Table 6-11 Protection Factor Effects Test

\begin{tabular}{|c|c|c|c|c|c|}
\hline Source & Nparm & DF & $\begin{array}{r}\text { Sum of } \\
\text { Squares }\end{array}$ & F Ratio & Prob $>$ F \\
\hline Orientation & 2 & 2 & 0.13201758 & 10.9227 & $0.0020^{*}$ \\
\hline VcrossFPM & 1 & 1 & 0.00920417 & 1.5230 & 0.2408 \\
\hline Orientation ${ }^{*}$ VcrossFPM & 2 & 2 & 0.27490808 & 22.7451 & $<.0001^{*}$ \\
\hline Manikin Moving & 1 & 1 & 0.04318017 & 7.1452 & $0.0203^{*}$ \\
\hline Orientation*Manikin Moving & 2 & 2 & 0.02121008 & 1.7549 & 0.2145 \\
\hline VcrossFPMManikin Moving & 1 & 1 & 0.00216600 & 0.3584 & 0.5605 \\
\hline Orientation*VcrossFPM*Manikin & 2 & 2 & 0.04940425 & 4.0876 & $0.0443^{*}$ \\
\hline
\end{tabular}

The least squares means, as shown in Table 6-12 provides a detailed look of the specific conditions with the largest effect. Conditions with comparable means are grouped by letter with moderately different values sharing the same letter to illustrate overlap in effect.

\section{Table 6-12 Protection Factor Least Squares Mean}

$\begin{array}{lllll}\text { Level } & & & & \text { Least Sq Mean } \\ 180,30, \text { No } & \text { A } & & & 0.99850000 \\ 180,30, \text { Yes } & \text { A } & & & 0.99600000 \\ 0,120, \text { Yes } & \text { A } & & & 0.99350000 \\ 0,30, \text { No } & \text { A } & & & 0.99000000 \\ 0,120, \text { No } & \text { A } & & & 0.99000000 \\ 0,30, \text { Yes } & \text { A } & & & 0.98000000 \\ \text { 90,120,No } & \text { A } & & & 0.94000000 \\ \text { 90,120,Yes } & \text { A } & & & 0.90900000 \\ \text { 90,30,No } & & \text { B } & & 0.82000000 \\ \text { 180,120,No } & & \text { B } & & 0.81800000 \\ \text { 90,30,Yes } & & \text { C } & 0.63500000 \\ \text { 180,120,Yes } & & \text { C } & & 0.53400000\end{array}$

Levels not connected by same letter are significantly different.

\subsection{Study Summary}

The primary focus of this study was to determine the effects of worker movement on the hood capture efficiency, breathing zone protection efficiency, and overall breathing zone protection factor of the worker. While worker movement had a modest effect on capture efficiency, this was not found to be statistically significant. Worker movement was found to have a significant effect on the breathing zone protection factor but not on capture efficiency or the traditional breathing efficiency. 
Based on the models produced in this study, the prediction profiler, shown in Figure 6-14, estimates what the capture efficiency, protection factor, and the protection efficiency would be by modifying the various conditions. The specific example shown is for the condition in which the manikin is moving at the 180 -degree orientation with a $120 \mathrm{fpm}$ cross draft. Under these conditions, the models predict a capture efficiency of $72.5 \%$, a protection factor of $53.4 \%$, and a breathing efficiency of $99.3 \%$. As illustrated, modifying the manikin movement variable has a significant effect only on the breathing protection factor.

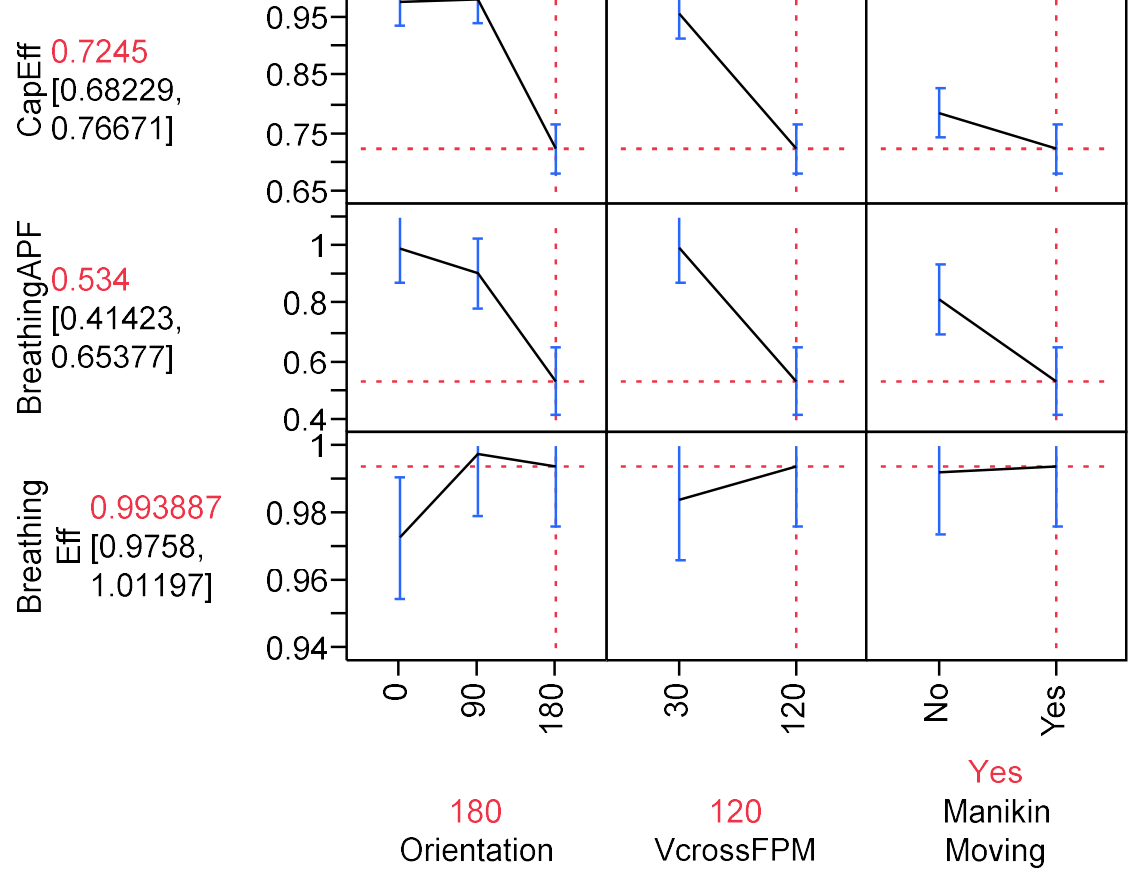

Figure 6-14 Prediction Profiler for Manikin Movement Model 


\section{Chapter 7 : Operator Presence \& Hood Orientation}

\subsection{Introduction}

Though several studies (Ljungqvist, 1979; Kim and Flynn, 1992; Johnson, Fletcher, and Saunders, 1996; Welling, Andersson, Rosen, Räisänen, Mielo, Marttinen, and Niemelä, 2000; Welling, Kulmala, Andersson, Rosen, Räisänen, Mielo, Niemelä, 2001; El-Sotouhy, 2008; Lewis, 2010) have shown the presence of a worker to significantly alter air currents, only one study (Kasberger, 2012) considered the effects the worker has on the capture efficiency of an exterior hood. The Kasberger study did not consider the actual effects the manikin had on the effectiveness of the capturing system

Similarly, the effects of worker orientation with respect to cross drafts has been little studied (Guffey, Flanagan, and Belle, 2001). Their study considered the effects of orientation on the contaminant concentrations measured in the breathing zone within a free field system. To the author's knowledge, no studies have been conducted to determine the effects of hood orientation on the effectiveness of a capturing hood system.

These are both important considerations, because the Industrial Ventilation manual (ACGIH, 2001) does not mention how to factor worker presence or hood orientation into the overall hood design.

In this hood orientation and operator presence study, a heated and breathing manikin was positioned on a free-flowing turntable for conditions in which the manikin was present. The arms of the manikin were mounted to the workbench and set to move $30 \mathrm{rpm}$ per arm for all conditions in which the manikin was present. The manikin was removed entirely from the capturing hood system for the other half of the treatments.

A sodium chloride and water aerosol was used as the tracer contaminant. Contaminant concentrations in the duct $\left(\mathrm{C}_{\text {duct }}\right)$ and breathing zone $\left(\mathrm{C}_{\mathrm{BZ}}\right)$ of a surrogate worker were measured for varying experimental conditions with a condensation particle counter (CPC). The experimental concentrations were then compared to accompanying conditions in which the 
traceable contaminant was released directly into the vent $\left(\mathrm{C}_{\text {duct100 }}\right)$ and whenever the hood was turned off entirely $\left(\mathrm{C}_{\mathrm{BZ100}}\right)$. The ratio of these measurements was then used to determine the effectiveness of the hood system. Since measuring the breathing zone effectiveness is not possible for conditions in which the manikin was not present, worker protection efficiency calculations were limited to the orientation subset of this study.

\subsection{Research Design}

The study was a randomized full factorial design with two replications. The dependent variables for the orientation subset of this study include the concentrations of the contaminant within the breathing zone $\left(\mathrm{C}_{\mathrm{BZ}}\right)$ of the operator and the concentrations of the contaminant located far downstream within the duct $\left(\mathrm{C}_{\text {duct }}\right)$. The breathing zone samples were collected at a single point between the mouth and nose. $\mathrm{C}_{\text {duct }}$ was the only dependent variable for the subset considering the effects of operator presence.

The independent variables include four levels of draft velocity $\left(V_{\text {draft }}\right)$, three levels of capture velocity $\left(\mathrm{V}_{\text {cap }}\right)$, three levels of hood orientation, and two levels of manikin presence. Since manikin movement was previously found to effect breathing concentrations, the manikin was moving in all conditions in which it was present. The four levels of $\mathrm{V}_{\text {draft }}$ were $0,30,60$, and 120 fpm. The three levels of $\mathrm{V}_{\text {cap }}$ were 50, 100, and $200 \mathrm{fpm}$. The three levels of hood orientation were $0^{\circ}, 90^{\circ}$, and $180^{\circ}$, with cross drafts blowing at the operator's back, side, and front, respectively. The two levels of manikin presence were simply present vs not. With four levels of $\mathrm{V}_{\text {draft, }}$, three levels of $\mathrm{V}_{\text {cap }}$, three levels of hood orientation, two levels of manikin presence, and two replications, there were 144 total randomized treatments within this study. This was shown in Table 1-1.

\subsection{Methods}

The methods for measurement used in this study are largely the same as those used in the CPC vs Tracer study, in Chapter 5.3. The key difference is that this study only used the CPC method for analysis. Additionally, this study does not include sampling within the breathing zone for all conditions. 


\subsection{Procedures}

The procedures for this study are mostly the same as the manikin movement study, as described in detail in Chapter 6.4. The only notable difference in the procedures for this study is validating that the table and manikin are appropriately in line with the marks left to ensure minimal difference between replications.

\subsection{Data Analysis}

An analysis of variance (ANOVA) model with fixed effects was used to determine if there were any significant effects of the independent variables $\left(V_{d r a f t}, V_{c a p}\right.$, hood orientation, and manikin presence) on the response of the dependent variables $\left(\eta_{e}, P E\right)$. The effects of manikin presence were analyzed only to determine its response on $\eta_{\mathrm{e}}$. JMP was used to establish the effects test and accompanying parameter estimates to determine which variables have the greatest effect. A key emphasis was placed on the effects of manikin presence on capture efficiency and orientation on capture and breathing efficiency.

\subsection{Results}

The results for the main study are shown in Table 7-1. The values represented in the table reflect the average of two replications. The overall average percent difference of the capture efficiency $\left(\eta_{\mathrm{e}}\right)$ was found to be a modest relative $5.8 \%$. The average percent difference of capture efficiency was found to be $1.9 \%, 1.8 \%$, and $13.7 \%$ for the $0^{\circ}, 90^{\circ}$, and $180^{\circ}$, respectively. The largest effect (64.5\% difference) of manikin presence was observed with a $120 \mathrm{fpm}$ cross draft and a nominal $50 \mathrm{fpm}$ capture velocity at the $180^{\circ}$ orientation. The next largest effect $(55.2 \%$ difference) of manikin presence was observed with a $60 \mathrm{fpm}$ cross draft and a nominal $50 \mathrm{fpm}$ capture velocity at the $180^{\circ}$ orientation. 
Table 7-1 Main Study Results

\begin{tabular}{|c|c|c|c|c|c|c|c|c|}
\hline $\begin{array}{l}\text { Treatment } \\
\text { ID }\end{array}$ & $\mathrm{O}$ & $\mathrm{V}_{\mathrm{x}}$ & $\mathrm{V}_{\mathrm{d}}$ & Man & $\eta_{\mathrm{e}}(\operatorname{avg})$ & $\begin{array}{c}\text { PE } \\
\text { (avg) }\end{array}$ & $\begin{array}{l}P_{\text {APF }} \\
\text { (avg) }\end{array}$ & $\begin{array}{l}\% \Delta \eta_{\mathrm{e}} \\
\text { (avg) }\end{array}$ \\
\hline 1 & 0 & 50 & 0 & Yes & 95.8 & 97.3 & 99.3 & \multirow{2}{*}{0.9} \\
\hline 2 & 0 & 50 & 0 & No & 94.9 & - & - & \\
\hline 3 & 0 & 50 & 30 & Yes & 99.5 & 99.2 & 99.7 & \multirow{2}{*}{1.2} \\
\hline 4 & 0 & 50 & 30 & No & 98.3 & - & - & \\
\hline 5 & 0 & 50 & 60 & Yes & 95.8 & 99.4 & 99.9 & \multirow{2}{*}{0.2} \\
\hline 6 & 0 & 50 & 60 & No & 96.0 & - & - & \\
\hline 7 & 0 & 50 & 120 & Yes & 92.9 & 93.4 & 98.7 & \multirow{2}{*}{0.2} \\
\hline 8 & 0 & 50 & 120 & No & 93.1 & - & - & \\
\hline 9 & 0 & 100 & 0 & Yes & 93.4 & 98.3 & 99.8 & \multirow{2}{*}{2.3} \\
\hline 10 & 0 & 100 & 0 & No & 95.6 & - & - & \\
\hline 11 & 0 & 100 & 30 & Yes & 92.8 & 96.6 & 99.5 & \multirow{2}{*}{3.3} \\
\hline 12 & 0 & 100 & 30 & No & 95.9 & - & - & \\
\hline 13 & 0 & 100 & 60 & Yes & 95.2 & 99.4 & 100 & \multirow{2}{*}{1.9} \\
\hline 14 & 0 & 100 & 60 & No & 93.4 & - & - & \\
\hline 15 & 0 & 100 & 120 & Yes & 91.2 & 98.5 & 99.8 & \multirow{2}{*}{3.1} \\
\hline 16 & 0 & 100 & 120 & No & 94.1 & - & - & \\
\hline 17 & 0 & 200 & 0 & Yes & 98.3 & 90.0 & 99.6 & \multirow{2}{*}{2.2} \\
\hline 18 & 0 & 200 & 0 & No & 96.2 & - & - & \\
\hline 19 & 0 & 200 & 30 & Yes & 96.2 & 97.9 & 99.8 & \multirow{2}{*}{0.4} \\
\hline 20 & 0 & 200 & 30 & No & 96.6 & - & - & \\
\hline 21 & 0 & 200 & 60 & Yes & 98.8 & 97.4 & 99.9 & \multirow{2}{*}{5.6} \\
\hline 22 & 0 & 200 & 60 & No & 93.4 & - & - & \\
\hline 23 & 0 & 200 & 120 & Yes & 95.8 & 98.4 & 99.9 & \multirow{2}{*}{1.0} \\
\hline 24 & 0 & 200 & 120 & No & 96.8 & - & - & \\
\hline 25 & 90 & 50 & 0 & Yes & 95.1 & 97.8 & 99.5 & \multirow{2}{*}{2.0} \\
\hline 26 & 90 & 50 & 0 & No & 97.0 & - & - & \\
\hline 27 & 90 & 50 & 30 & Yes & 88.5 & 98.4 & 68.2 & \multirow{2}{*}{0.79} \\
\hline 28 & 90 & 50 & 30 & No & 89.2 & - & - & \\
\hline 29 & 90 & 50 & 60 & Yes & 94.7 & 99.3 & 81.5 & \multirow{2}{*}{1.9} \\
\hline 30 & 90 & 50 & 60 & No & 96.5 & - & - & \\
\hline 31 & 90 & 50 & 120 & Yes & 96.2 & 99.4 & 47.6 & \multirow{2}{*}{0.1} \\
\hline 32 & 90 & 50 & 120 & No & 96.1 & - & - & \\
\hline 33 & 90 & 100 & 0 & Yes & 95.0 & 97.1 & 99.7 & \multirow{2}{*}{0.4} \\
\hline 34 & 90 & 100 & 0 & No & 95.4 & - & - & \\
\hline 35 & 90 & 100 & 30 & Yes & 99.9 & 99.3 & 76.3 & \multirow{2}{*}{3.9} \\
\hline 36 & 90 & 100 & 30 & No & 96.1 & - & - & \\
\hline 37 & 90 & 100 & 60 & Yes & 96.6 & 99.7 & 85.8 & \multirow{2}{*}{1.8} \\
\hline 38 & 90 & 100 & 60 & No & 94.9 & - & - & \\
\hline 39 & 90 & 100 & 120 & Yes & 92.2 & 99.3 & 32.0 & 1.2 \\
\hline
\end{tabular}




\begin{tabular}{|c|c|c|c|c|c|c|c|c|}
\hline 40 & 90 & 100 & 120 & No & 91.1 & - & - & \multirow{3}{*}{4.2} \\
\hline 41 & 90 & 200 & 0 & Yes & 99.4 & 87.9 & 99.4 & \\
\hline 42 & 90 & 200 & 0 & No & 95.3 & - & - & \\
\hline 43 & 90 & 200 & 30 & Yes & 97.4 & 97.4 & 86.6 & \multirow{2}{*}{0.7} \\
\hline 44 & 90 & 200 & 30 & No & 96.7 & - & - & \\
\hline 45 & 90 & 200 & 60 & Yes & 99.2 & 98.5 & 91.0 & \multirow{2}{*}{0.5} \\
\hline 46 & 90 & 200 & 60 & No & 99.7 & - & - & \\
\hline 47 & 90 & 200 & 120 & Yes & 89.0 & 99.4 & 62.9 & \multirow{2}{*}{4.1} \\
\hline 48 & 90 & 200 & 120 & No & 92.8 & - & - & \\
\hline 49 & 180 & 50 & 0 & Yes & 99.0 & 97.7 & 99.5 & \multirow{2}{*}{1.4} \\
\hline 50 & 180 & 50 & 0 & No & 97.6 & - & - & \\
\hline 51 & 180 & 50 & 30 & Yes & 93.1 & 99.6 & 99.9 & \multirow{2}{*}{4.9} \\
\hline 52 & 180 & 50 & 30 & No & 97.8 & - & - & \\
\hline 53 & 180 & 50 & 60 & Yes & 77.7 & 99.4 & 95.4 & \multirow{2}{*}{55.2} \\
\hline 54 & 180 & 50 & 60 & No & 44.1 & - & - & \\
\hline 55 & 180 & 50 & 120 & Yes & 66.2 & 99.8 & 35.0 & \multirow{2}{*}{64.5} \\
\hline 56 & 180 & 50 & 120 & No & 33.9 & - & - & \\
\hline 57 & 180 & 100 & 0 & Yes & 96.5 & 98.8 & 99.9 & \multirow{2}{*}{2.2} \\
\hline 58 & 180 & 100 & 0 & No & 94.4 & - & - & \\
\hline 59 & 180 & 100 & 30 & Yes & 91.3 & 98.6 & 99.9 & \multirow{2}{*}{0.9} \\
\hline 60 & 180 & 100 & 30 & No & 92.1 & - & - & \\
\hline 61 & 180 & 100 & 60 & Yes & 93.1 & 99.7 & 99.8 & \multirow{2}{*}{3.6} \\
\hline 62 & 180 & 100 & 60 & No & 89.8 & - & - & \\
\hline 63 & 180 & 100 & 120 & Yes & 96.3 & 99.7 & 97.8 & \multirow{2}{*}{12.5} \\
\hline 64 & 180 & 100 & 120 & No & 85.0 & - & - & \\
\hline 65 & 180 & 200 & 0 & Yes & 96.5 & 92.3 & 99.6 & \multirow{2}{*}{1.2} \\
\hline 66 & 180 & 200 & 0 & No & 97.7 & - & - & \\
\hline 67 & 180 & 200 & 30 & Yes & 94.4 & 98.5 & 99.5 & \multirow{2}{*}{2.0} \\
\hline 68 & 180 & 200 & 30 & No & 96.3 & - & - & \\
\hline 69 & 180 & 200 & 60 & Yes & 93.7 & 99.4 & 96.1 & \multirow{2}{*}{5.9} \\
\hline 70 & 180 & 200 & 60 & No & 88.3 & - & - & \\
\hline 71 & 180 & 200 & 120 & Yes & 99.4 & 98.9 & 86.4 & \multirow{2}{*}{10.5} \\
\hline 72 & 180 & 200 & 120 & No & 89.5 & - & - & \\
\hline
\end{tabular}

$\mathrm{O}=$ Orientation; $\mathrm{V}_{\mathrm{x}}=$ Capture Velocity; $\mathrm{V}_{\mathrm{d}}=$ Draft Velocity; Move = Manikin Movement; $\eta_{\mathrm{e}}=$ Capture Efficiency; $\mathrm{PE}=$ Protection Efficiency; $\mathrm{P}_{\mathrm{APF}}=$ Protection Factor

\subsubsection{Effects of Operator Presence on Capture Efficiency}

Figure 7-1 is a detailed illustration of the effect manikin presence had on capture efficiency with respect to cross draft velocity. The yellow panels highlight that the biggest effects can be observed at the 180-degree orientation and at 60 and 120 fpm cross drafts. 


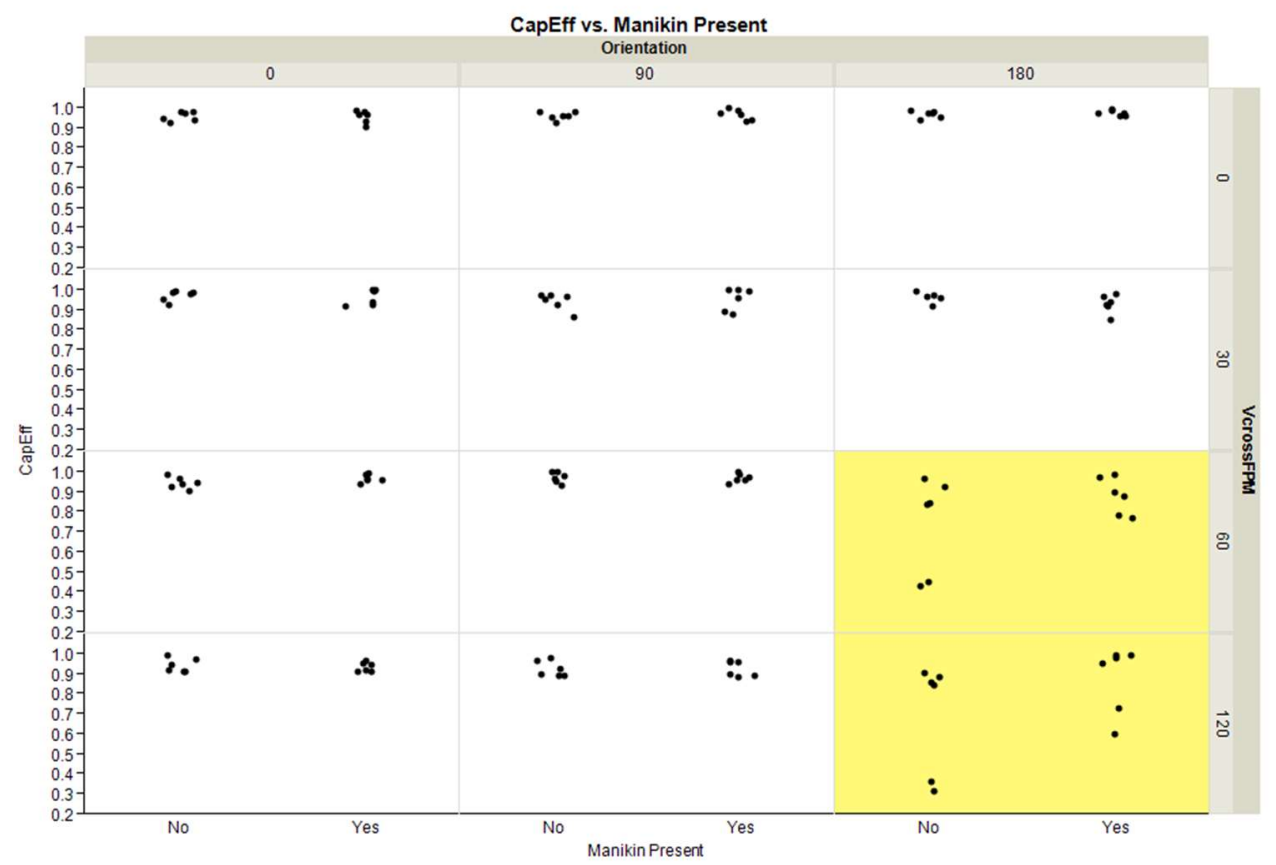

Figure 7-1 Effects of Operator Presence on Capture Efficiency with Respect to Cross Draft

Figure 7-2 is a detailed illustration of the effect manikin presence had on capture efficiency with respect to the capture velocity. The yellow panel highlights that the biggest effects can be observed at the180-degree orientation and at $50 \mathrm{fpm}$ nominal capture velocity.

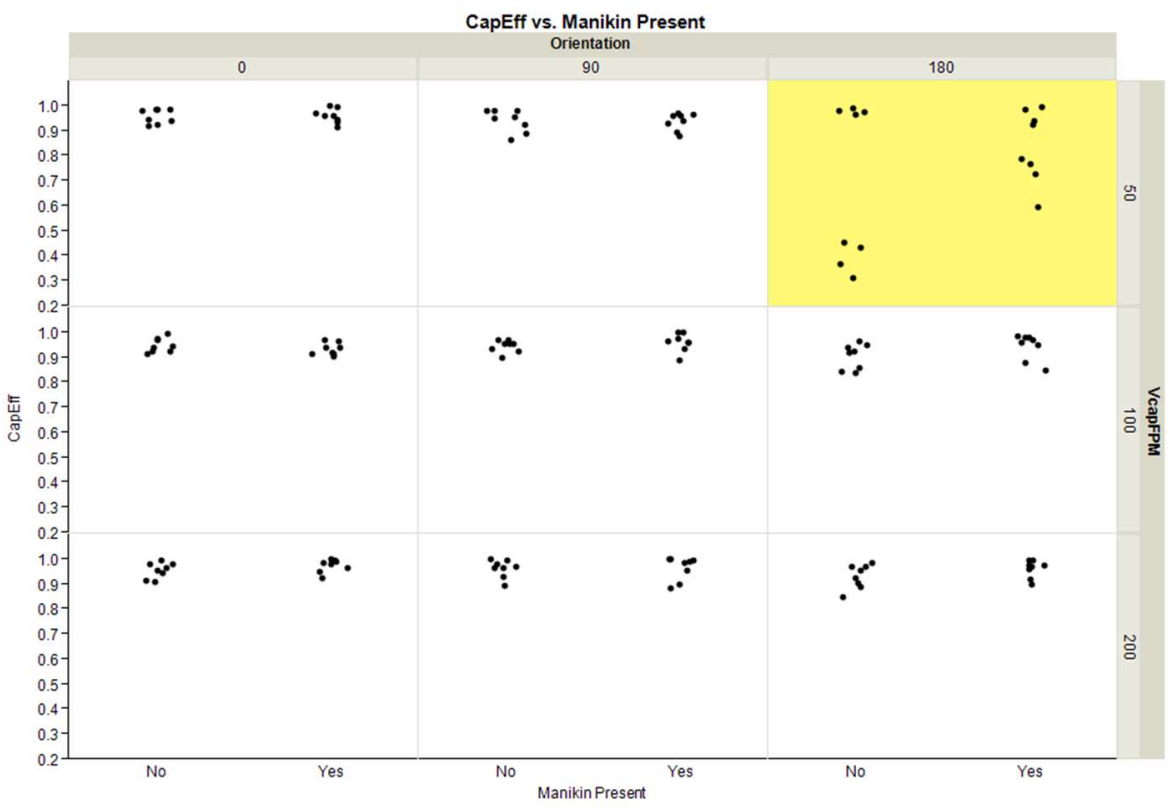

Figure 7-2 Effects of Operator Presence on Capture Efficiency with Respect to Capture Velocity 


\subsubsection{Effects of Hood Orientation on Capture Efficiency}

Figure 7-3 illustrates that the biggest effects of hood orientation on capture efficiency are found with 30,60, and $120 \mathrm{fpm}$ cross drafts at the 180-degree orientation, across all capture velocities. There is also a notable effect with a $120 \mathrm{fpm}$ cross draft at the 90-degree orientation. A modest effect can also be seen at 30,60, and 120 cross drafts with a nominal 200 fpm capture velocity.

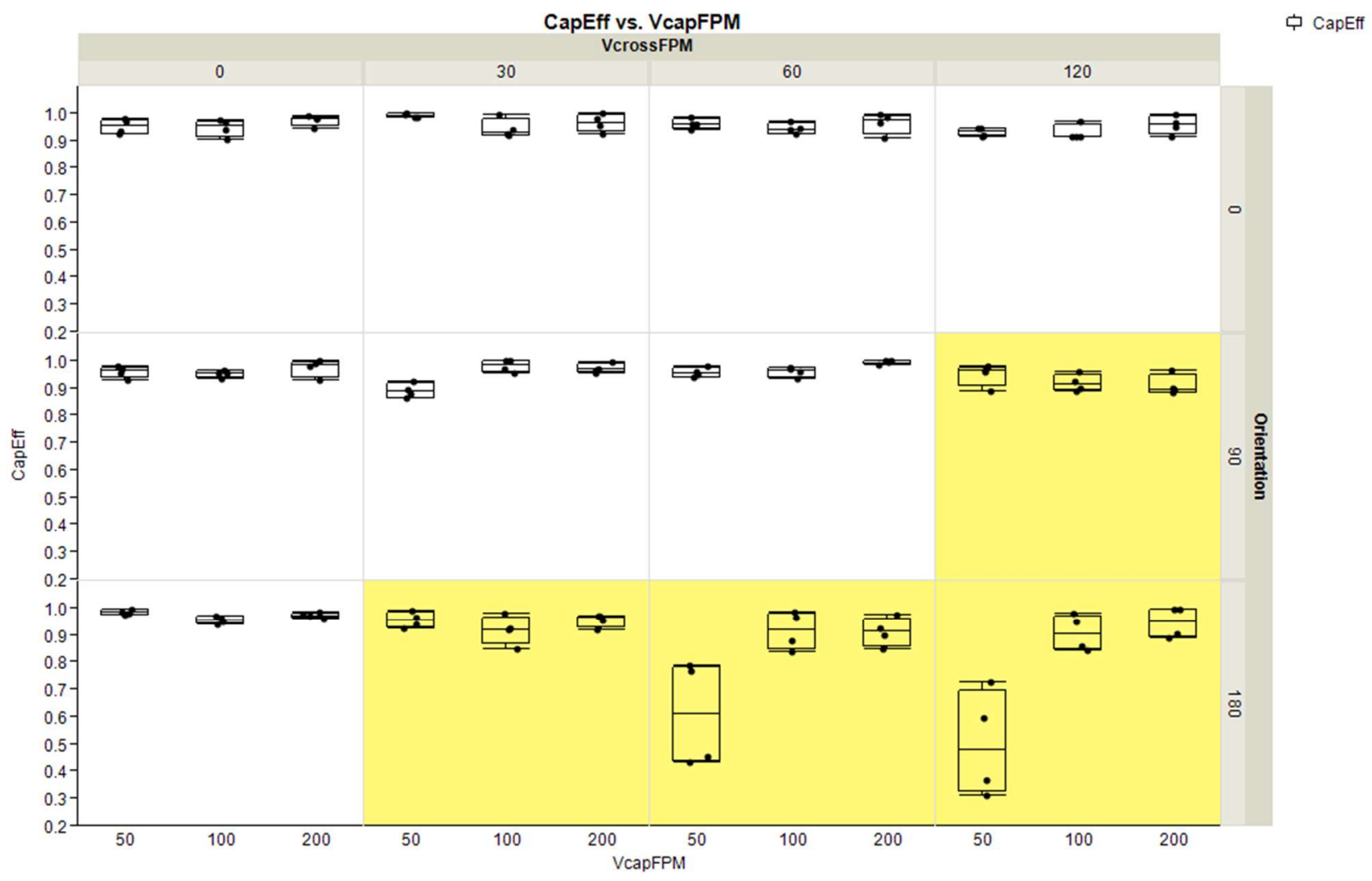

Figure 7-3 Effects of Hood Orientation on Capture Efficiency

\subsubsection{Statistical Analysis of Capture Efficiency}

Table 7-2 summarizes the model fit for predicting the breathing factor. The value of $\mathrm{R}^{2}=0.95$ demonstrates that most of the variance is explained by this model.

Table 7-2 Summary of Fit - Capture Efficiency

RSquare

RSquare Adj

Root Mean Square Error

Mean of Response

Observations (or Sum Wgts)
0.951282

0.903241

0.033103

0.926729 
Table 7-3 ANOVA - Capture Efficiency

$\begin{array}{lrrrr}\text { Source } & \text { DF } & \begin{array}{r}\text { Sum of } \\ \text { Squares }\end{array} & \text { Mean Square } & \text { F Ratio } \\ \text { Model } & 71 & 1.5405999 & 0.021699 & 19.8014 \\ \text { Error } & 72 & 0.0788985 & 0.001096 & \begin{array}{r}\text { Prob }>\text { F } \\ <.0001^{*}\end{array} \\ \text { C. Total } & 143 & 1.6194984 & & <.004\end{array}$

Since the ANOVA found a significant difference between the means, the next step is checking the effects test to determine which variables have a significant effect on the capture efficiency. As shown in Table 7-4 orientation, cross draft, capture velocity, manikin presence, and all interactions were found to have statistical significance.

\section{Table 7-4 Effects Test - Capture Efficiency}

\begin{tabular}{|c|c|c|c|c|}
\hline Source & Nparm & $\begin{array}{r}\text { Sum of } \\
\text { Squares }\end{array}$ & F Ratio & Prob $>$ F \\
\hline Orientation & 2 & 20.18171317 & 82.9125 & $<.0001^{*}$ \\
\hline VcrossFPM & 3 & 30.14776835 & 44.9494 & $<.0001^{*}$ \\
\hline VcapFPM & 2 & 20.13083787 & 59.6990 & $<.0001^{*}$ \\
\hline Manikin Present & 1 & 10.02648756 & 24.1716 & $<.0001^{*}$ \\
\hline Orientation*VcrossFPM & 6 & 60.17921667 & 27.2578 & $<.0001^{*}$ \\
\hline Orientation*VcapFPM & 4 & 40.19902058 & 45.4048 & $<.0001^{*}$ \\
\hline ation*Manikin Present & 2 & 20.04195050 & 19.1413 & $<.0001^{*}$ \\
\hline VcrossFPM* VcapFPM & 6 & 60.11062213 & 16.8250 & $<.0001^{*}$ \\
\hline VcrossFPM*Manikin Present & 3 & 30.02897924 & 8.8151 & $<.0001^{*}$ \\
\hline VcapFPM*Manikin Present & 2 & 20.01102204 & 5.0292 & $0.0090^{*}$ \\
\hline Orientation*VcrossFPM*VcapFPM & 12 & 120.33246292 & 25.2828 & $<.0001^{*}$ \\
\hline tion*VcrossFPM*Manikin Present & 6 & 60.06192478 & 9.4184 & $<.0001^{*}$ \\
\hline Orientation* ${ }^{*}$ capFPM*Manikin Present & 4 & 40.03141433 & 7.1669 & $<.0001^{*}$ \\
\hline VcrossFPM ${ }^{*}$ VcapFPM*Manikin Present & 6 & 60.01807440 & 2.7490 & $0.0184^{*}$ \\
\hline Orientation* ${ }^{*}$ crossFPM ${ }^{\star} V_{c a p F P M}{ }^{*}$ Manikin & 12 & 120.03910539 & 2.9739 & $0.0020^{*}$ \\
\hline
\end{tabular}

\subsubsection{Effects of Hood Orientation on Protection Factor}

Figure 7-3 illustrates that the biggest effects of hood orientation on protection factor are found at 30,60 , and $120 \mathrm{fpm}$ cross drafts at the 90 -degree orientation and $120 \mathrm{fpm}$ cross draft at the 180 degree orientation. 


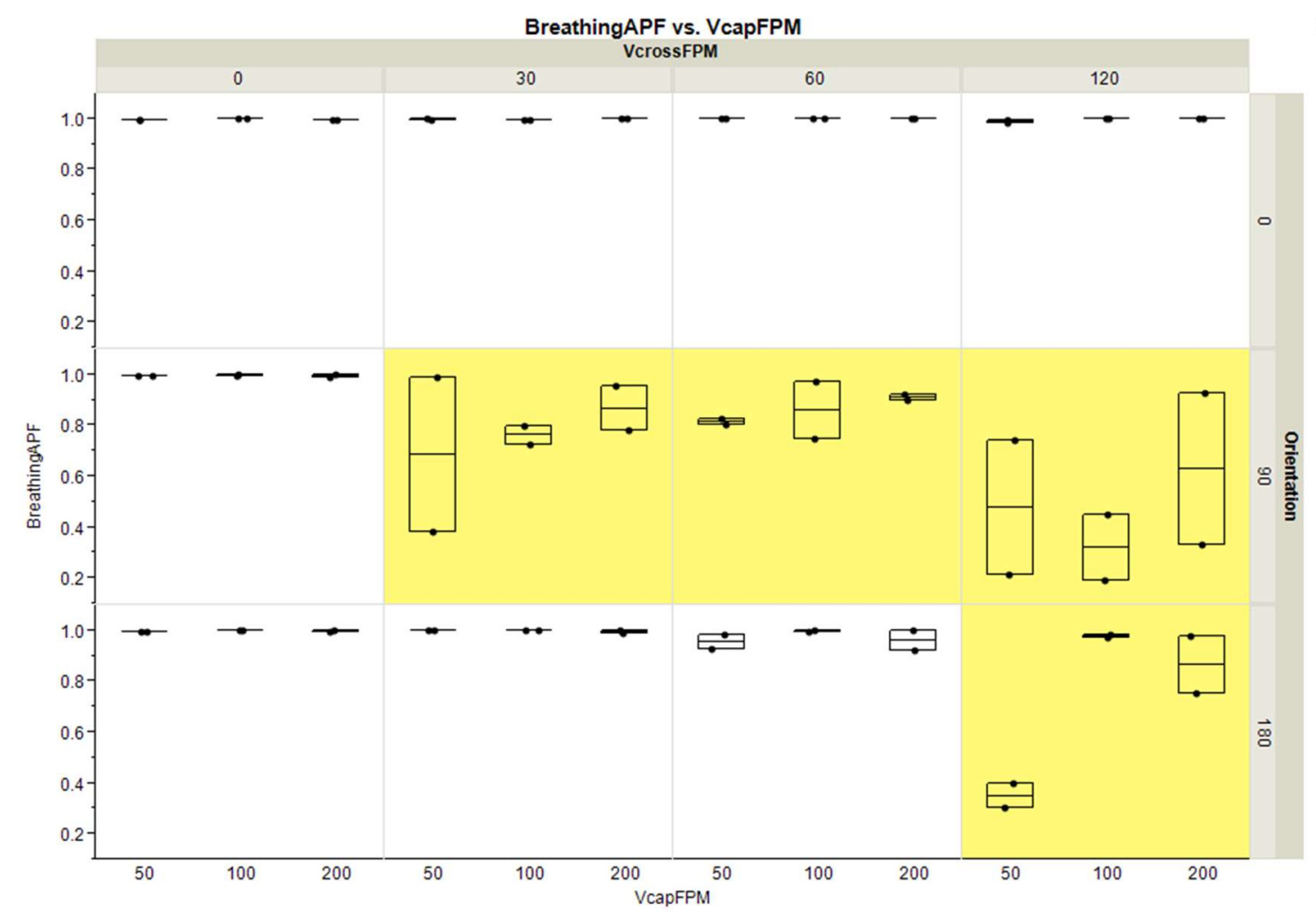

Figure 7-4 Effects of Hood Orientation on Protection Factor

\subsubsection{Statistical Analysis of Protection Factor}

Figure 7-5 and Table 7-5 summarize the model fit for predicting the breathing factor. $\mathrm{R}^{2}=0.8$, demonstrates a reasonably strong fit; most of the variance is explained by this model.

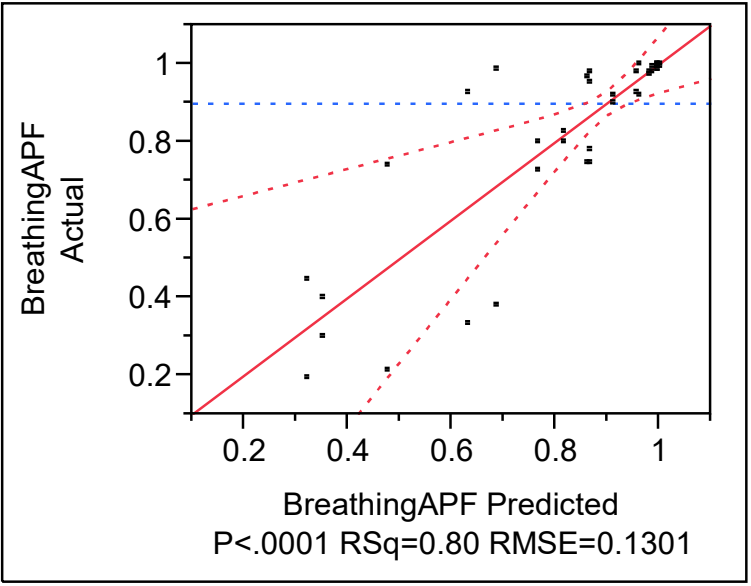

Figure 7-5 Actual by Predicted Plot of Breathing Protection Factor 
Table 7-5 Summary of Fit Breathing Protection Factor

$\begin{array}{lr}\text { RSquare } & 0.796108 \\ \text { RSquare Adj } & 0.597879 \\ \text { Root Mean Square Error } & 0.130061 \\ \text { Mean of Response } & 0.898653 \\ \text { Observations (or Sum Wgts) } & 72\end{array}$

Table 7-6 ANOVA Breathing Protection Factor

$\begin{array}{lrrrr}\text { Source } & \text { DF } & \text { Sum of Squares } & \text { Mean Square } & \text { F Ratio } \\ \text { Model } & 35 & 2.3777648 & 0.067936 & 4.0161 \\ \text { Error } & 36 & 0.6089735 & 0.016916 & \text { Prob > F } \\ \text { C. Total } & 71 & 2.9867383 & & <.0001^{*}\end{array}$

Since the ANOVA found a significant difference between the means, the next step is checking the effects test to determine which variables have a significant effect on the capture efficiency. As shown in Table 7-7 orientation, cross draft, and the interaction of orientation and cross draft were found to have statistical significance.

Table 7-7 Breathing Protection Factor Effects Test

$\begin{array}{lrrrrr}\text { Source } & \text { Nparm } & \text { DF } & \begin{array}{r}\text { Sum of } \\ \text { Squares }\end{array} & \text { F Ratio } & \text { Prob > F } \\ \text { Orientation } & 2 & 2 & 0.61076936 & 18.0531 & <.0001^{*} \\ \text { VcrossFPM } & 3 & 3 & 0.70783815 & 13.9482 & <.0001^{*} \\ \text { Orientation*VcrossFPM } & 6 & 6 & 0.47070331 & 4.6377 & 0.0014^{*} \\ \text { VcapFPM } & 2 & 2 & 0.08047219 & 2.3786 & 0.1071 \\ \text { Orientation*VcapFPM } & 4 & 4 & 0.11019289 & 1.6285 & 0.1883 \\ \text { VcrossFPM*VcapFPM }^{*} & 6 & 6 & 0.09665714 & 0.9523 & 0.4707 \\ \text { Orientation*VcrossFPM*VcapFPM } & 12 & 12 & 0.30113178 & 1.4835 & 0.1758\end{array}$




\subsubsection{Statistical Analysis of Breathing Efficiency}

Figure 7-6 and Table 7-8 summarize the model fit for predicting the breathing efficiency. $\mathrm{R}^{2}=$ 0.65 , demonstrates a moderate fit; a sizable portion of the variance is not explained by this model.

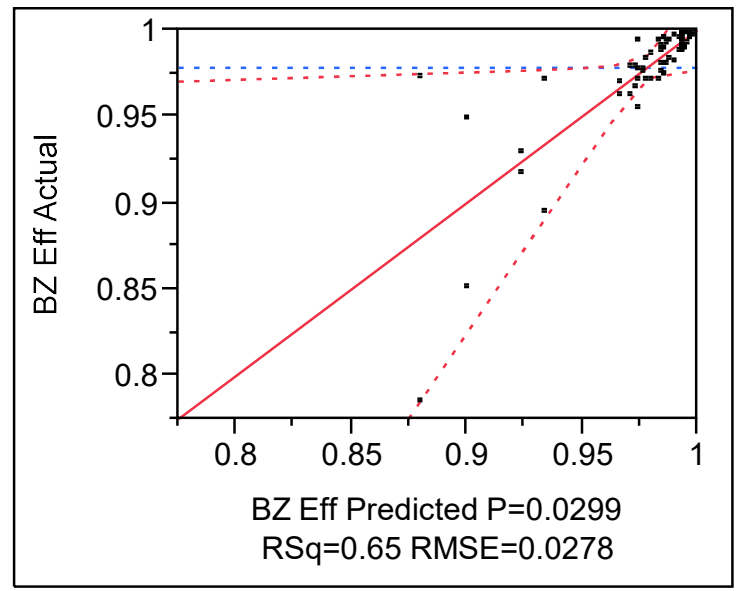

Figure 7-6 Actual by Predicted Plot of Breathing Efficiency

Table 7-8 Summary of Fit Breathing Efficiency

$\begin{array}{lr}\text { RSquare } & 0.64845 \\ \text { RSquare Adj } & 0.306666 \\ \text { Root Mean Square Error } & 0.027811 \\ \text { Mean of Response } & 0.978269 \\ \text { Observations (or Sum Wgts) } & 72\end{array}$

Table 7-9 ANOVA Fit Breathing Efficiency

$\begin{array}{lrrrr}\text { Source } & \text { DF } & \text { Sum of Squares } & \text { Mean Square } & \text { F Ratio } \\ \text { Model } & 35 & 0.05135900 & 0.001467 & 1.8972 \\ \text { Error } & 36 & 0.02784368 & 0.000773 & \text { Prob }>\text { F } \\ \text { C. Total } & 71 & 0.07920268 & & 0.0299^{*}\end{array}$

Since the ANOVA found a significant difference between the means, the next step is checking the effects test to determine which variables have a significant effect on the breathing efficiency. As shown in Table 7-10 orientation, cross draft, capture velocity, and the interaction between the cross draft and capture velocity were found to have statistical significance. 
Table 7-10 Breathing Efficiency Effects Tests

$\begin{array}{lrrrrr}\text { Source } & \text { Nparm } & \text { DF } & \begin{array}{r}\text { Sum of } \\ \text { Squares }\end{array} & \text { F Ratio } & \text { Prob > F } \\ \text { Orientation } & 2 & 2 & 0.00232030 & 1.5000 & 0.2367 \\ \text { VcrossFPM } & 3 & 3 & 0.01650121 & 7.1117 & 0.0007^{*} \\ \text { Orientation*VcrossFPM } & 6 & 6 & 0.00218388 & 0.4706 & 0.8255 \\ \text { VcapFPM } & 2 & 2 & 0.00802006 & 5.1847 & 0.0105^{*} \\ \text { Orientation*VcapFPM } & 4 & 4 & 0.00064546 & 0.2086 & 0.9320 \\ \text { VcrossFPM*VcapFPM } & 6 & 6 & 0.01767093 & 3.8079 & 0.0049^{*} \\ \text { Orientation*VcrossFPM*VcapFPM } & 12 & 12 & 0.00401716 & 0.4328 & 0.9392\end{array}$

\subsection{Study Summary}

The primary focus of this study was to determine the effects of worker presence and hood orientation on the hood capture efficiency, breathing zone protection efficiency, and overall breathing zone protection factor of the worker.

Hood orientation, cross draft, capture velocity, manikin presence, and all interactions were found to have a statistically significant effect on capture efficiency. The largest effect of manikin presence on capture efficiency was observed at the 180-degree orientation and at 60 and $120 \mathrm{fpm}$ cross drafts. The biggest effect of capture velocity on capture efficiency was observed at the 180degree orientation and at $50 \mathrm{fpm}$ nominal capture velocity. 


\section{Chapter 8 : Conclusions}

For most conditions, the small rectangular exterior hood proved to be a highly efficient engineering control with capture efficiencies generally above $90 \%$. The hood performed most effectively at the 0 -degree orientation. Even $50 \mathrm{fpm}$ nominal capture velocities were found to be sufficient almost all of the study conditions at that orientation.

The capture hood was least effective at the 180-degree orientation. The worst possible combinations included low capture velocities and high cross draft speeds at the 180-degree orientation. The capture efficiency was measured as low at $31 \%$ at a nominal capture velocity of $50 \mathrm{fpm}, 120 \mathrm{fpm}$ cross, and at the 180-degree orientation. The PIV measured several negative velocities at these conditions. Negative numbers indicate that the contaminated air is going in the opposite direction as the hood, escaping the capture envelope.

Overall, hood orientation, manikin presence, cross drafts, and capture velocity all had statistically significant effects on the capture efficiency of this exterior hood. Orientation and cross draft velocities were found to have significant effects on the breathing protection factor. Cross draft velocities were found to have a significant effect on breathing efficiency.

The condensation particle counter (CPC) was found to be a reliable substitute for the tracer gas method in analysis of the capture efficiency. A free field study would help further support the reliability and compatibility of $\mathrm{CPC}$ being used to measure breathing zone concentrations in hood design.

\subsection{Recommendations}

- Since the 180-degree orientation has been found to have the most disruptive currents, more studies need to be conducted specifically at this orientation

- An industrial case study should be conducted to further compare CPC vs Tracer

- Consider constructing a cross draft system that blows and exhausts at rates much more commonly experienced in industry to consider accumulation effects. 


\subsection{Caveats}

- Only one type of hood was analyzed. Results for this study may not apply to other exterior hoods

- The wind tunnel acts a very large exhaust system. It does not produce much large scale mixing, which is commonly present in real workplaces. For this reason, the air exchange rate is high, and thus the clearance time for contaminants is very brief. Contaminants that would otherwise accumulate instead quickly escaped from the room. As a result, breathing zone concentrations are probably lower than in the workplace.

- The cross drafts in this system were all from the same direction and were held constant at specific levels. Real-life cross drafts are likely to be highly variable in magnitude and direction..

- The wind tunnel used in these studies provided a maximum cross draft of approximately 130 feet per minute. Cross drafts in industry may be much higher.

- Studies for which orientation was varied were blocked around orientation. Hence, these studies were not completely random. The blocks were randomized and the treatments within each block were also randomized. Changing the orientation for every test was infeasible. 


\section{References}

ACGIH. (2001). Industrial ventilation: A manual of recommended practice (24th ed.).

Cincinnati, Ohio: American Conference of Governmental Industrial Hygienists.

Baldwin, P., \& Maynard, A. (1998). A Survey of Wind Speeds in Indoor Workplaces. Annals of Occupational Hygiene, 42(5), 303-313.

Beamer, D., Muller, J. P., \& Dessagne, J. M. (1998). Comparison of Capture Efficiencies Measured by Tracer Gas and Aerosol Tracer Techniques. Indoor Air, 8(1), 47-60

Brandt, A. (1947). Industrial Health Engineering. New York: John Wiley \& Sons.

Brohus, H. (1997). Measurement of Personal Exposure Using a Breathing Thermal Manikin. Proceedings of Ventilation' 97, 2, 781-791.

Burgess, W., \& Murrow, J. (1976). Evaluation of Hoods for Low Volume-High Velocity Exhaust Systems. American Industrial Hygiene Association Journal, 37(9), 546-549.

Burgess, W., Ellenbecker, M., \& Treitman, R. (2004). Ventilation for Control of the Work Environment (2nd ed.). Hoboken, N.J.: Wiley-Interscience.

Chatterjee, B., Williams, M., Walford, J., \& King, E. (1969). The Location of Personal Sampler Filter Heads. American Industrial Hygiene Association Journal, 30(6), 643-645.

Cohen, B., Chang, A., Harley, N., \& Lippmann, M. (1982). Exposure estimates from personal lapel monitors. American Industrial Hygiene Association Journal, 43(4), 239-243.

Conroy, L., Ellenbecker, M., \& Flynn, M. (1988). Prediction and Measurement of Velocity into Flanged Slot Hoods. AIHA Journal, 49(5), 226-234.

Conroy, L., \& Ellenbecker, M. (1989). Capture Efficiency of Flanged Slot Hoods under the Influence of a Uniform Cross Draft: Model Development and Validation. Applied Industrial Hygiene, 4(6), 135-142. 
DallaValle, J. (1930). Thesis for Sc.D. In Studies in the Design of Local Exhaust Hoods. Boston, MA: Harvard.

DallaValle, J. (1952). Exhaust Hoods (2nd ed.). New York: The Industrial Press.

Donaldson, H., \& Stringer, W. (1980). Beryllium Sampling Methods. American Industrial Hygiene Association Journal, 41(2), 85-90.

Dunn, K. H., Tsai, C. S., Woskie, S. R., Bennett, J. S., Garcia, A., \& Ellenbecker, M. J. (2014). Evaluation of Leakage From Fume Hoods Using Tracer Gas, Tracer Nanoparticles and Nanopowder Handling Test Methodologies. Journal of Occupational and Environmental Hygiene, 11(10)

El-Sotouhy, A. (2008). Dissertation. In Effect of Breathing, Posture, and Air Velocity on Breathing Zone Gas Concentrations for Human Subjects in a Wind Tunnel. Morgantown, WV: West Virginia University.

Ellenbecker, M., Gempel, R., \& Burgess, W. (1983). Capture Efficiency of Local Exhaust Ventilation Systems. American Industrial Hygiene Association Journal, 44(10), 752755.

Elnahass, W. (2005). Dissertation. In Effects of heating, breathing, hair style, posture, and air velocity on breathing zone concentrations for an anthropometrically-correct manikin in a wind tunnel. Morgantown, WV: West Virginia University.

Fletcher, B. (1977). Centreline Velocity Characteristics Of Rectangular Unflanged Hoods And Slots Under Suction. Annals of Occupational Hygiene, 20(2), 141-146.

Fletcher, B. (1978). Centreline Velocity Characteristics Of Rectangular Unflanged Hoods And Slots Under Suction. Annals of Occupational Hygiene, 21(3), 141-146.

Fletcher, B., \& Johnson, A. (1986). The Capture Efficiency of Local Exhaust Ventilation Hoods 
and the Role of Capture Velocity. Chemical Engineering Monographs, 369-390.

Fletcher, B., \& Johnson, A. (1989). Comparison of Personal and Area Concentration of Measurements, and the Use of a Manikin in Sampling. Proceedings of Ventilation ' 88. Flynn, M., \& Ellenbecker, M. (1985). The Potential Flow Solution for Air Flow into a Flanged Circular Hood. AIHA Journal, 46(6), 318-322.

Flynn, M., \& Ellenbecker, M. (1986). Capture Efficiency Of Flanged Circular Local Exhaust Hoods. Annals of Occupational Hygiene, 30(4), 497-513.

Flynn, M., \& Ellenbecker, M. (1987). Empirical Validation of Theoretical Velocity Fields into Flanged Circular Hoods. AIHA Journal, 48(4), 380-389.

Fryar, C., Gu, Q., \& Ogden, C. (2012). Anthropometric Reference Data for Children and Adults: United States, 2007-2010. Centers for Disease Control and Prevention - National Center for Health Statistics, Vital Health Stat 11(252).

Garrison, R. (1981). Centerline velocity gradients for plain and flanged local exhaust inlets. American Industrial Hygiene Association Journal, 42(10), 739-746.

Garrison, R., \& Park, C. (1989). Evaluation of Models for Local Exhaust Velocity Characteristics — Part Two: Velocity Gradients for an Inlet near a Boundary Surface. American Industrial Hygiene Association Journal, 50(4), 204-209.

Guffey, S., \& Barnea, N. (1994). Effects of Face Velocity, Flanges, and Mannikin Position on the Effectiveness of a Benchtop Enclosing Hood in the Absence of Cross-Drafts. American Industrial Hygiene Association Journal, 55(2), 132-139.

Guffey, S., Flanagan, M., \& Belle, G. (2001). Air Sampling at the Chest and Ear as Representative of the Breathing Zone. AIHAJ - American Industrial Hygiene Association, 62(4), 416-427. 
Hampl, V. (1984). Evaluation of Industrial Local Exhaust Hood Efficiency by a Tracer Gas Technique. American Industrial Hygiene Association Journal, 45(7), 485-490.

Hampl, V., Niemelä, R., Shulman, S., \& Bartley, D. (1986). Use of Tracer Gas Technique for Industrial Exhaust Hood Efficiency Evaluation-Where to Sample? American Industrial Hygiene Association Journal, 47(5), 281-287.

Hans-Rudolf (2010). 1101 Breathing Simulator Manual. Shawnee, KA: Hans-Rudolf., Inc. Heist, D., Eisner, A., Mitchell, W., \& Wiener, R. (2003). Airflow Around a Child-Size Manikin in a Low-Speed Wind Environment. Aerosol Science and Technology, 37(4), 303-314.

Hemeon, W. (1963). Plant and Process Ventilation (p. 481). New York: The Industrial Press.

Hitchin, E., \& Wilson, C. (1967). A review of experimental techniques for the investigation of natural ventilation in buildings. Building Science, 2(1), 59-82.

Huang, R., Chen, J., Chen, Y., Chen, C., Yeh, W., \& Chen, C. (2001). The Capture Envelope of a Flanged Circular Hood in Cross Drafts. AIHAJ - American Industrial Hygiene Association, 62(2), 199-207.

Jansson, A. (1982). The Capture of Contaminants by Exhausts. Arbete Och Hälsa.

Johnson, A., Fetcher, B., \& Saunders, C. (1996). Air Movement Around A Worker In A LowSpeed Flow Field. Annals of Occupational Hygiene, 40(1), 57-64.

Kasberger, S. (2012). Thesis. In Effectiveness of a Flanged and Unflanged Small Rectangular Capturing Hood. Morgantown, WV: West Virginia University.

Kim, T., \& Flynn, M. (1991). Airflow Pattern Around A Worker In A Uniform Freestream. American Industrial Hygiene Association Journal, 52(7), 287-296.

Kim, T., \& Flynn, M. (1992). The Effect Of Contaminant Source Momentum On A Worker's Breathing Zone Concentration In A Uniform Freestream. American Industrial Hygiene 
Association Journal, 53(12), 757-766.

Lewis, B. (2010). Thesis. In Effects of $0^{\circ}$ Cross Draft Velocity and the Presence of a Table and Manikin on Midline Velocities in Front of a Rectangular Capture Hood. Morgantown, WV: West Virginia University.

Ljungqvist, B. (1979). Some observations on the interaction between air movements and the dispersion of pollution. Document - Swedish Council for Building Research, D8.

Madsen, U., Breum, N., \& Nielsent, P. (1993). A Numerical And Experimental Study Of Local Exhaust Capture Efficiency. Annals of Occupational Hygiene, 37(6), 593-605.

Malek, R., Daisy, J., \& Cohen, B. (1999). Breathing Zone Concentration Variations in the Reinforced Plastic Industry; Field Measurements in a Boat Manufacturing Plant. Applied Occupational and Environmental Hygiene, 14(11), 777-784.

Military Standard 1472G - 4.4.4 Accomodation. (2012). Department of Defense Design Criteria - Standard Human Engineering.

Niemelä, R., Lefevre, A., Muller, J., \& Aubertin, G. (1991). Comparison Of Three Tracer Gases For Determining Ventilation Effectiveness And Capture Efficiency. Annals of Occupational Hygiene, 35(4), 405-417.

OSHA Technical Manual (OTM) | Section II: Chapter 1 - Personal Sampling for Air Contaminants. (1999, January 20). Retrieved December 10, 2014, from https://www.osha.gov/dts/osta/otm/otm ii/otm ii 1.html

Raffel, M., Willert, C. E., \& Kompenhans, J. (1998). Particle image velocimetry: a practical guide. Berlin: Springer.

Silverman, L. (1942). Centerline Velocity Characteristics of Round Openings Under Suction. Journal of Industrial Hygiene and Toxocology, 24(9), 259-266. 
Thomas, F. (1950). Design Characteristics of Canopy Exhaust Hoods. Heating and Ventilatin. Tielemans, E., Schneider, T., Goede, H., Tischer, M., Warren, N., Kromhout, H., ... Cherrie, J. (2008). Conceptual Model for Assessment of Inhalation Exposure: Defining Modifying Factors. Annals of Occupational Hygiene, 52(7), 577-586.

Tseng, L., Huang, R., Chen, C., \& Chang, C. (2006). Correlation Between Airflow Patterns and Performance of a Laboratory Fume Hood. Journal of Occupational and Environmental Hygiene, 3(12), 694-706.

Welling, I., Andersson, I., Rosen, G., Räisänen, J., Mielo, T., Marttinen, K., \& Niemelä, R. (2000). Contaminant dispersion in the vicinity of a worker in a uniform velocity field. Annals of Occupational Hygiene, 44(3), 219-225.

Welling, I., Kulmala, I., Andersson, I., Rosen, G., Räisänen, J., Mielo, T., ... Niemelä, R. (2001). Extent of the Reverse Flow Wake Region Produced by a Body in a Uniform Flow Field. Applied Occupational and Environmental Hygiene, 16(9), 900-904.

Woods, J., \& Mckarns, J. (1995). Evaluation of Capture Efficiencies of Large Push-Pull Ventilation Systems with Both Visual and Tracer Techniques. American Industrial Hygiene Association Journal, 56(12), 1208-1214. 


\section{Appendix A - Capture Envelope Stats}

\section{Summary of Fit of Face Velocity}

RSquare

RSquare Adj

Root Mean Square Error

Mean of Response

Observations (or Sum Wgts)
0.997855

0.995751

42.66417

1207.139

108

\section{Analysis of Variance of Face Velocity}

$\begin{array}{lrr}\text { Source } & \text { DF } & \text { Sum of Squares } \\ \text { Model } & 53 & 45734988 \\ \text { Error } & 54 & 98293 \\ \text { C. Total } & 107 & 45833281\end{array}$
Mean Square
862924
1820

F Ratio

474.0739

Prob $>$ F

$<.0001^{*}$

\section{Effect Tests of Face Velocity}

\author{
Source \\ Orientation \\ ManikinPresent \\ Orientation*ManikinPresent \\ VcrossFPM \\ Orientation* VcrossFPM \\ ManikinPresent ${ }^{\star} V$ crossFPM \\ Orientation* ManikinPresent ${ }^{*} \vee$ crossFPM \\ VcapFPM \\ Orientation*VcapFPM \\ ManikinPresent* ${ }^{*}$ capFPM \\ Orientation*ManikinPresent ${ }^{*} \vee$ capFPM \\ VcrossFPM* ${ }^{*}$ capFPM \\ Orientation*VcrossFPM* ${ }^{*}$ capFPM \\ ManikinPresent ${ }^{*} V$ crossFPM ${ }^{*} \vee$ capFPM \\ Orientation*ManikinPresent ${ }^{*}$ VcrossFPM* ${ }^{*}$ capFPM
}

$\begin{array}{rrrrr}\text { Nparm DF } & \begin{array}{r}\text { Sum of } \\ \text { Squares }\end{array} & \text { F Ratio } & \begin{array}{r}\text { Prob > } \\ \mathbf{F}\end{array} \\ 2 & 2 & 9930 & 2.7278 & 0.0744 \\ 1 & 1 & 3663 & 2.0126 & 0.1617 \\ 2 & 2 & 1034 & 0.2842 & 0.7538 \\ 2 & 2 & 24975 & 6.8604 & 0.0022^{*} \\ 4 & 4 & 22490 & 3.0888 & 0.0231^{*} \\ 2 & 2 & 4153 & 1.1408 & 0.3271 \\ 4 & 4 & 3011 & 0.4135 & 0.7982 \\ 2 & 2 & 45570551 & 12517.79 & <.0001^{*} \\ 4 & 4 & 28230 & 3.8772 & 0.0077^{*} \\ 2 & 2 & 3640 & 0.9998 & 0.3747 \\ 4 & 4 & 7301 & 1.0028 & 0.4142 \\ 4 & 4 & 8770 & 1.2045 & 0.3196 \\ 8 & 8 & 36505 & 2.5069 & 0.0215^{*} \\ 4 & 4 & 5109 & 0.7016 & 0.5942 \\ 8 & 8 & 5626 & 0.3863 & 0.9233\end{array}$




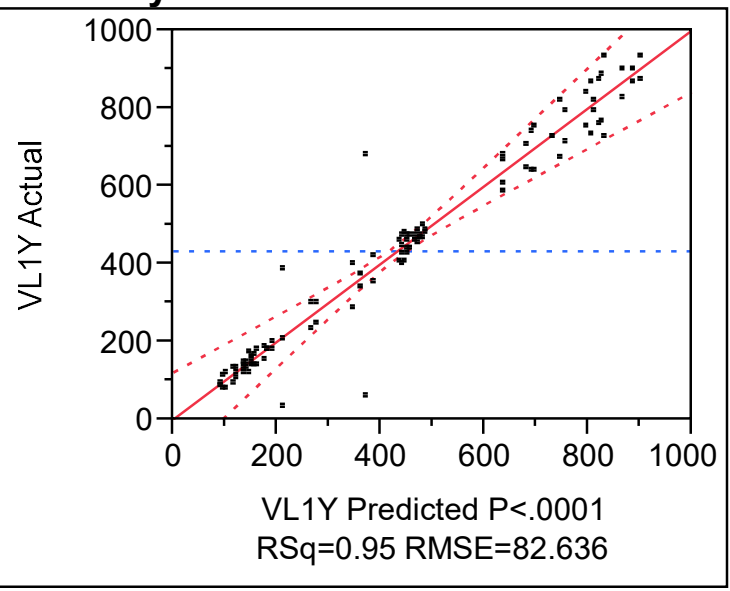

\section{Summary of Fit of VL1Y}

RSquare

RSquare Adj

Root Mean Square Error

Mean of Response

Observations (or Sum Wgts)
0.952668

0.906212

82.63563

432.2778

108

\section{Analysis of Variance of VL1Y}

$\begin{array}{lrrrr}\text { Source } & \text { DF } & \text { Sum of Squares } & \text { Mean Square } & \text { F Ratio } \\ \text { Model } & 53 & 7421878.7 & 140035 & 20.5071 \\ \text { Error } & 54 & 368747.0 & 6829 & \text { Prob > F } \\ \text { C. Total } & 107 & 7790625.7 & & <.0001^{*}\end{array}$

\section{Effect Tests of VL1Y}

\section{Source}

Orientation

ManikinPresent

Orientation*ManikinPresent

VcrossFPM

Orientation* VcrossFPM

ManikinPresent ${ }^{\star} V$ crossFPM

Orientation*ManikinPresent ${ }^{*} V$ crossFPM

VcapFPM

Orientation*VcapFPM

ManikinPresent ${ }^{*}$ capFPM

Orientation* ManikinPresent ${ }^{*} \vee$ capFPM

VcrossFPM $^{*}$ VcapFPM

Orientation ${ }^{*}$ VcrossFPM ${ }^{*} V$ capFPM

ManikinPresent ${ }^{*}$ VcrossFPM* ${ }^{*}$ capFPM

Orientation*ManikinPresent ${ }^{*}{ }^{*}$ crossFPM* ${ }^{*}$ capFPM

$\begin{array}{rrrrr}\text { Nparm DF } & \begin{array}{r}\text { Sum of } \\ \text { Squares }\end{array} & \text { F Ratio } & \begin{array}{r}\text { Prob > } \\ \text { F }\end{array} \\ 2 & 2 & 449947.6 & 32.9456 & <.0001^{*} \\ 1 & 1 & 2.6926 e-28 & 0.0000 & 1.0000 \\ 2 & 2 & 17334.9 & 1.2693 & 0.2893 \\ 2 & 2 & 18024.0 & 1.3197 & 0.2757 \\ 4 & 4 & 45217.9 & 1.6555 & 0.1738 \\ 2 & 2 & 7502.9 & 0.5494 & 0.5805 \\ 4 & 4 & 26487.7 & 0.9697 & 0.4317 \\ 2 & 2 & 6629686.7 & 485.4319 & <.0001^{*} \\ 4 & 4 & 98028.9 & 3.5889 & 0.0115^{*} \\ 2 & 2 & 9024.4 & 0.6608 & 0.5206 \\ 4 & 4 & 19312.6 & 0.7070 & 0.5906 \\ 4 & 4 & 6982.9 & 0.2556 & 0.9050 \\ 8 & 8 & 55535.6 & 1.0166 & 0.4349 \\ 4 & 4 & 11512.7 & 0.4215 & 0.7924 \\ 8 & 8 & 27279.8 & 0.4994 & 0.8513\end{array}$




\section{Actual by Predicted Plot of VC1Y}

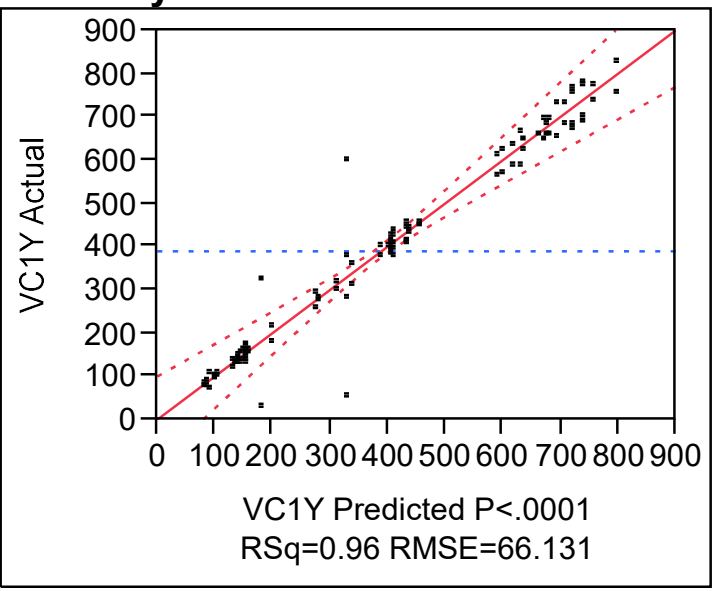

\section{Summary of Fit of VC1Y}

RSquare

RSquare Adj

Root Mean Square Error

Mean of Response

Observations (or Sum Wgts)
0.959969

0.920679

66.1309

388.9444

108

\section{Analysis of Variance of VC1Y}

\section{Source}

Model

Error

C. Total
DF

53

54

107
Sum of Squares

5663215.7

236158.0

5899373.7
Mean Square

106853

4373
F Ratio

24.4331

Prob $>$ F

$<.0001^{*}$

\section{Effect Tests of VC1Y}

\section{Source}

Orientation

ManikinPresent

Orientation*ManikinPresent

VcrossFPM

Orientation*VcrossFPM

ManikinPresent ${ }^{*}$ VcrossFPM

Orientation*ManikinPresent ${ }^{*}$ VcrossFPM

VcapFPM

Orientation* ${ }^{*}$ capFPM

ManikinPresent ${ }^{*}$ capFPM

Orientation* ManikinPresent ${ }^{*} \vee$ capFPM

VcrossFPM $^{*}$ VcapFPM

Orientation ${ }^{*}$ VcrossFPM ${ }^{\star} V$ capFPM

ManikinPresent ${ }^{*}$ VcrossFPM ${ }^{*} \vee$ capFPM

Orientation ${ }^{*}$ ManikinPresent ${ }^{*}$ crossFPM $^{*}{ }^{*}$ capFPM

$\begin{array}{rrrrr}\text { Nparm DF } & \begin{array}{r}\text { Sum of } \\ \text { Squares }\end{array} & \text { F Ratio } & \begin{array}{r}\text { Prob > } \\ \mathbf{F}\end{array} \\ 2 & 2 & 310258.7 & 35.4720 & <.0001^{*} \\ 1 & 1 & 1602.4 & 0.3664 & 0.5475 \\ 2 & 2 & 11982.4 & 1.3699 & 0.2628 \\ 2 & 2 & 6880.4 & 0.7866 & 0.4605 \\ 4 & 4 & 41352.4 & 2.3639 & 0.0644 \\ 2 & 2 & 4006.4 & 0.4580 & 0.6350 \\ 4 & 4 & 28844.4 & 1.6489 & 0.1754 \\ 2 & 2 & 5104443.7 & 583.5923 & <.0001^{*} \\ 4 & 4 & 41012.2 & 2.3445 & 0.0662 \\ 2 & 2 & 9639.2 & 1.1021 & 0.3395 \\ 4 & 4 & 18487.0 & 1.0568 & 0.3868 \\ 4 & 4 & 6555.7 & 0.3748 & 0.8256 \\ 8 & 8 & 50672.0 & 1.4483 & 0.1982 \\ 4 & 4 & 6384.5 & 0.3650 & 0.8325 \\ 8 & 8 & 21094.2 & 0.6029 & 0.7713\end{array}$




\section{Actual by Predicted Plot of VR1Y}

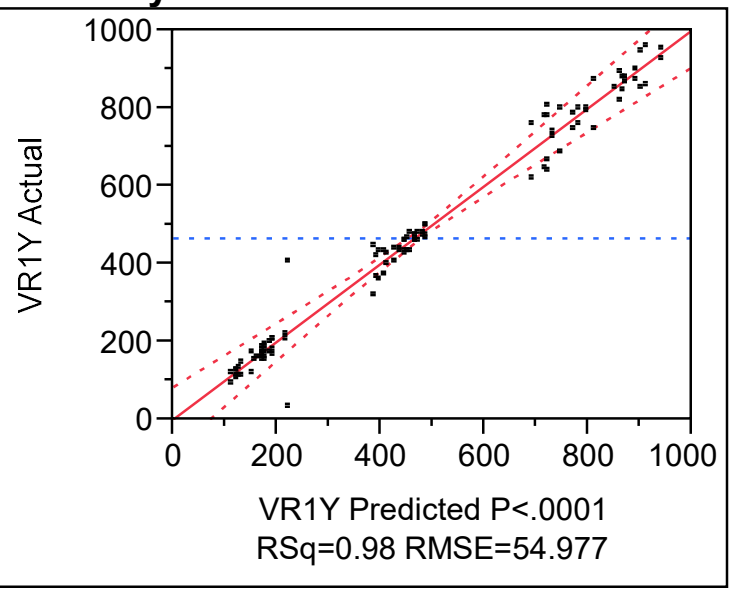

\section{Summary of Fit of VR1Y}

RSquare

RSquare Adj

Root Mean Square Error

Mean of Response

Observations (or Sum Wgts)
0.980092

0.960554

54.97659

465.7222

108

Analysis of Variance of VR1Y

$\begin{array}{lrrrr}\text { Source } & \text { DF } & \text { Sum of Squares } & \text { Mean Square } & \text { F Ratio } \\ \text { Model } & 53 & 8035238.7 & 151608 & 50.1611 \\ \text { Error } & 54 & 163211.0 & 3022 & \text { Prob > F } \\ \text { C. Total } & 107 & 8198449.7 & & <.0001^{*}\end{array}$

\section{Effect Tests of VR1Y}

\section{Source}

Orientation

ManikinPresent

Orientation*ManikinPresent

VcrossFPM

Orientation* VcrossFPM

ManikinPresent ${ }^{\star} V$ crossFPM

Orientation*ManikinPresent* ${ }^{*}$ crossFPM

VcapFPM

Orientation*VcapFPM

ManikinPresent ${ }^{*}$ VcapFPM

Orientation*ManikinPresent ${ }^{*} \vee$ capFPM

VcrossFPM*VcapFPM

Orientation* VcrossFPM* ${ }^{*}$ capFPM

ManikinPresent ${ }^{*}$ VcrossFPM ${ }^{*} V$ capFPM

Orientation ${ }^{*}$ ManikinPresent ${ }^{*}{ }$ crossFPM $^{*}$ VcapFPM

$\begin{array}{rrrrr}\text { Nparm DF } & \begin{array}{r}\text { Sum of } \\ \text { Squares }\end{array} & \text { F Ratio } & \begin{array}{r}\text { Prob > } \\ \mathbf{F}\end{array} \\ 2 & 2 & 226706.1 & 37.5040 & <.0001^{*} \\ 1 & 1 & 1556.5 & 0.5150 & 0.4761 \\ 2 & 2 & 1542.1 & 0.2551 & 0.7758 \\ 2 & 2 & 29606.2 & 4.8978 & 0.0111^{*} \\ 4 & 4 & 14249.2 & 1.1786 & 0.3306 \\ 2 & 2 & 4805.6 & 0.7950 & 0.4568 \\ 4 & 4 & 7625.6 & 0.6308 & 0.6427 \\ 2 & 2 & 7666914.4 & 1268.338 & <.0001^{*} \\ 4 & 4 & 42463.2 & 3.5123 & 0.0128^{*} \\ 2 & 2 & 1219.7 & 0.2018 & 0.8179 \\ 4 & 4 & 5571.0 & 0.4608 & 0.7641 \\ 4 & 4 & 5624.7 & 0.4652 & 0.7609 \\ 8 & 8 & 13873.3 & 0.5738 & 0.7948 \\ 4 & 4 & 1664.2 & 0.1377 & 0.9676 \\ 8 & 8 & 11816.7 & 0.4887 & 0.8589\end{array}$




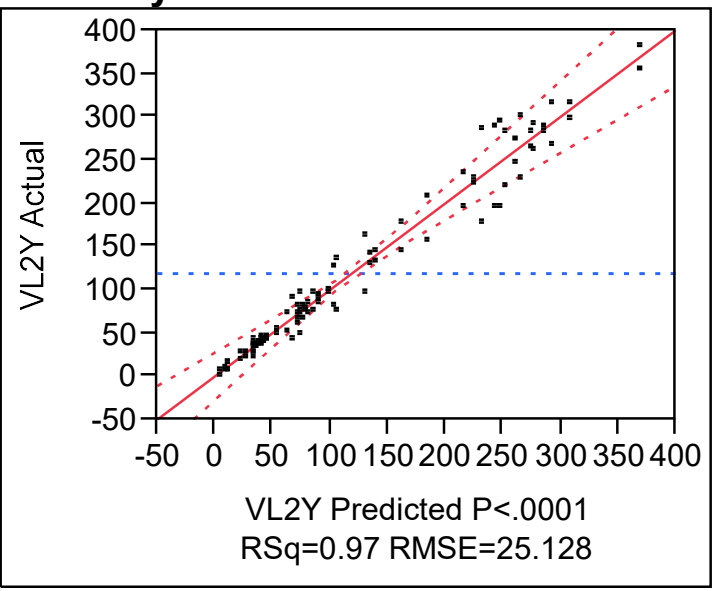

\section{Summary of Fit of VL2Y}

RSquare

RSquare Adj

Root Mean Square Error

Mean of Response

Observations (or Sum Wgts)
0.967564

0.935728

25.12801

118.713

\section{Analysis of Variance of VL2Y}

\begin{tabular}{lrrrr} 
Source & DF & $\begin{array}{r}\text { Sum of } \\
\text { Squares }\end{array}$ & Mean Square & F Ratio \\
Model & 53 & 1017087.6 & 19190.3 & 30.3925 \\
Error & 54 & 34096.5 & 631.4 & $\begin{array}{r}\text { Prob > F } \\
\text { C. Total }\end{array}$ \\
\hline 107 & 1051184.1 & & $<.0001^{*}$
\end{tabular}

\section{Effect Tests of VL2Y}

\section{Source}

Orientation

ManikinPresent

Orientation*ManikinPresent

VcrossFPM

Orientation* VcrossFPM

ManikinPresent ${ }^{\star} V$ crossFPM

Orientation*ManikinPresent ${ }^{*} V$ crossFPM

VcapFPM

Orientation*VcapFPM

ManikinPresent ${ }^{*}$ capFPM

Orientation* ManikinPresent ${ }^{*} \vee$ capFPM

VcrossFPM $^{*}$ VcapFPM

Orientation ${ }^{*}$ VcrossFPM ${ }^{*} V$ capFPM

ManikinPresent ${ }^{*} V_{\text {crossFPM }}{ }^{*} \vee$ capFPM

Orientation*ManikinPresent ${ }^{*}{ }^{*}$ crossFPM* ${ }^{*}$ capFPM

$\begin{array}{rrrrr}\text { Nparm DF } & \begin{array}{r}\text { Sum of } \\ \text { Squares }\end{array} & \text { F Ratio } & \begin{array}{r}\text { Prob > } \\ \text { F }\end{array} \\ 2 & 2 & 70055.35 & 55.4747 & <.0001^{*} \\ 1 & 1 & 6864.08 & 10.8709 & 0.0017^{*} \\ 2 & 2 & 6777.39 & 5.3668 & 0.0075^{*} \\ 2 & 2 & 9298.13 & 7.3629 & 0.0015^{*} \\ 4 & 4 & 9420.04 & 3.7297 & 0.0094^{*} \\ 2 & 2 & 1401.17 & 1.1095 & 0.3371 \\ 4 & 4 & 1419.44 & 0.5620 & 0.6912 \\ 2 & 2 & 863018.69 & 683.3987 & <.0001^{*} \\ 4 & 4 & 24363.81 & 9.6465 & <.0001^{*} \\ 2 & 2 & 1928.39 & 1.5270 & 0.2264 \\ 4 & 4 & 667.56 & 0.2643 & 0.8996 \\ 4 & 4 & 9857.70 & 3.9030 & 0.0074^{*} \\ 8 & 8 & 6968.13 & 1.3795 & 0.2265 \\ 4 & 4 & 1537.78 & 0.6089 & 0.6580 \\ 8 & 8 & 3509.94 & 0.6949 & 0.6944\end{array}$




\section{Actual by Predicted Plot of VC2Y}

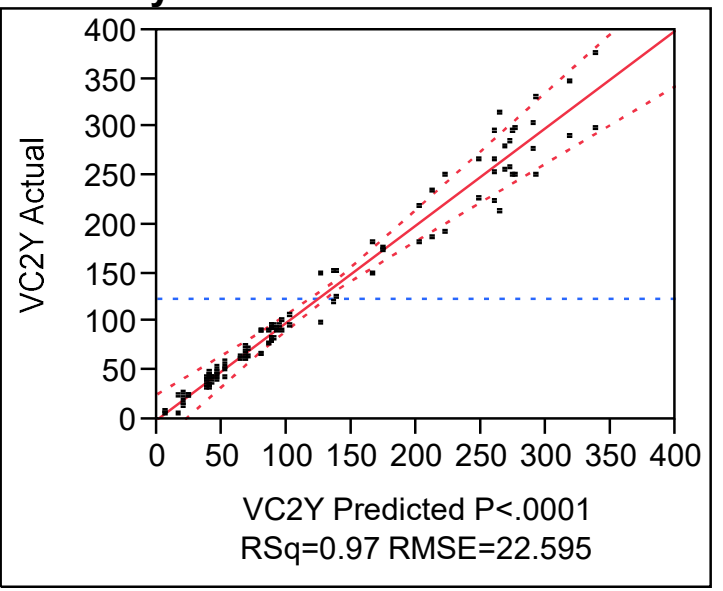

\section{Summary of Fit of VC2Y}

RSquare

RSquare Adj

Root Mean Square Error

Mean of Response

Observations (or Sum Wgts)
0.973187

0.94687

22.59507

123.963

108

Analysis of Variance of VC2Y

$\begin{array}{lrrrr}\text { Source } & \text { DF } & \text { Sum of Squares } & \text { Mean Square } & \text { F Ratio } \\ \text { Model } & 53 & 1000620.9 & 18879.6 & 36.9800 \\ \text { Error } & 54 & 27569.0 & 510.5 & \text { Prob > F } \\ \text { C. Total } & 107 & 1028189.9 & & <.0001^{*}\end{array}$

\section{Effect Tests of VC2Y}

\section{Source}

Orientation

ManikinPresent

Orientation*ManikinPresent

VcrossFPM

Orientation* VcrossFPM

ManikinPresent ${ }^{\star} V$ crossFPM

Orientation*ManikinPresent* ${ }^{*}$ crossFPM

VcapFPM

Orientation*VcapFPM

ManikinPresent ${ }^{*}$ VcapFPM

Orientation*ManikinPresent ${ }^{*} \vee$ capFPM

VcrossFPM*VcapFPM

Orientation* ${ }^{*}$ crossFPM* ${ }^{*}$ capFPM

ManikinPresent ${ }^{*}$ VcrossFPM ${ }^{*} V$ capFPM

Orientation*ManikinPresent ${ }^{*}{ }^{*}$ crossFPM $^{*}{ }^{*}$ capFPM

$\begin{array}{rrrrr}\text { Nparm DF } & \begin{array}{r}\text { Sum of } \\ \text { Squares }\end{array} & \text { F Ratio } & \begin{array}{r}\text { Prob > } \\ \text { F }\end{array} \\ 2 & 2 & 65085.35 & 63.7420 & <.0001^{*} \\ 1 & 1 & 889.81 & 1.7429 & 0.1923 \\ 2 & 2 & 6800.80 & 6.6604 & 0.0026^{*} \\ 2 & 2 & 2409.57 & 2.3598 & 0.1041 \\ 4 & 4 & 12248.59 & 5.9979 & 0.0005^{*} \\ 2 & 2 & 1395.80 & 1.3670 & 0.2636 \\ 4 & 4 & 2679.93 & 1.3123 & 0.2771 \\ 2 & 2 & 878703.57 & 860.5679 & <.0001^{*} \\ 4 & 4 & 21702.26 & 10.6272 & <.0001^{*} \\ 2 & 2 & 17.57 & 0.0172 & 0.9829 \\ 4 & 4 & 1455.81 & 0.7129 & 0.5867 \\ 4 & 4 & 904.04 & 0.4427 & 0.7772 \\ 8 & 8 & 5165.96 & 1.2648 & 0.2812 \\ 4 & 4 & 824.48 & 0.4037 & 0.8051 \\ 8 & 8 & 337.30 & 0.0826 & 0.9995\end{array}$




\section{Actual by Predicted Plot of VR2Y}

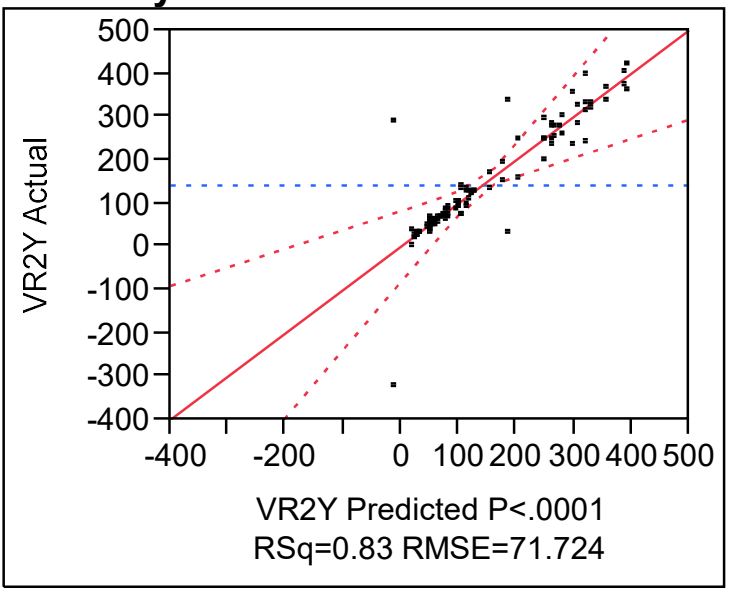

\section{Summary of Fit of VR2Y}

RSquare

RSquare Adj

Root Mean Square Error

Mean of Response

Observations (or Sum Wgts)
0.8262

0.655618

71.72401

141.6111

108

Analysis of Variance of VR2Y

$\begin{array}{lrrrr}\text { Source } & \text { DF } & \text { Sum of Squares } & \text { Mean Square } & \text { F Ratio } \\ \text { Model } & 53 & 1320559.7 & 24916.2 & 4.8434 \\ \text { Error } & 54 & 277794.0 & 5144.3 & \text { Prob > F } \\ \text { C. Total } & 107 & 1598353.7 & & <.0001^{*}\end{array}$

\section{Effect Tests of VR2Y}

\section{Source}

Orientation

ManikinPresent

Orientation*ManikinPresent

VcrossFPM

Orientation* VcrossFPM

ManikinPresent ${ }^{\star} V$ crossFPM

Orientation*ManikinPresent* ${ }^{*}$ crossFPM

VcapFPM

Orientation*VcapFPM

ManikinPresent ${ }^{*}$ capFPM

Orientation*ManikinPresent ${ }^{*} \vee$ capFPM

VcrossFPM*VcapFPM

Orientation* VcrossFPM* ${ }^{*}$ capFPM

ManikinPresent ${ }^{*}$ VcrossFPM ${ }^{*} V$ capFPM

Orientation*ManikinPresent ${ }^{*}{ }^{*}$ crossFPM $^{*}{ }^{*}$ capFPM

$\begin{array}{rrrrr}\text { Nparm DF } & \begin{array}{r}\text { Sum of } \\ \text { Squares }\end{array} & & \begin{array}{r}\text { F Ratio } \\ \text { F }\end{array} \\ 2 & 2 & 32276.17 & 3.1371 & 0.0514 \\ 1 & 1 & 8008.33 & 1.5567 & 0.2175 \\ 2 & 2 & 3922.39 & 0.3812 & 0.6848 \\ 2 & 2 & 28433.72 & 2.7636 & 0.0720 \\ 4 & 4 & 41871.78 & 2.0348 & 0.1024 \\ 2 & 2 & 18206.17 & 1.7695 & 0.1802 \\ 4 & 4 & 20070.78 & 0.9754 & 0.4287 \\ 2 & 2 & 997243.72 & 96.9264 & <.0001^{*} \\ 4 & 4 & 9116.28 & 0.4430 & 0.7770 \\ 2 & 2 & 584.39 & 0.0568 & 0.9448 \\ 4 & 4 & 25712.06 & 1.2495 & 0.3012 \\ 4 & 4 & 23806.39 & 1.1569 & 0.3401 \\ 8 & 8 & 64751.61 & 1.5734 & 0.1547 \\ 4 & 4 & 22607.28 & 1.0986 & 0.3667 \\ 8 & 8 & 23948.61 & 0.5819 & 0.7883\end{array}$


Actual by Predicted Plot of VL3Y

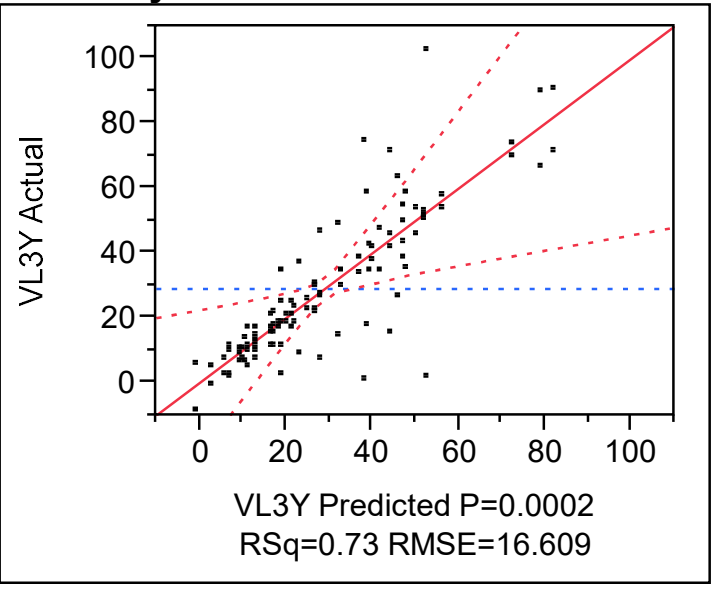

\section{Summary of Fit of VL3Y}

RSquare

RSquare Adj

Root Mean Square Error

Mean of Response

Observations (or Sum Wgts)
0.72519

0.45547

16.60851

28.99074

108

\section{Analysis of Variance of VL3Y}

$\begin{array}{lrrrr}\text { Source } & \text { DF } & \text { Sum of Squares } & \text { Mean Square } & \text { F Ratio } \\ \text { Model } & 53 & 39307.491 & 741.651 & 2.6887 \\ \text { Error } & 54 & 14895.500 & 275.843 & \text { Prob > F } \\ \text { C. Total } & 107 & 54202.991 & & 0.0002^{*}\end{array}$

\section{Effect Tests of VL3Y}

\section{Source}

Orientation

ManikinPresent

Orientation*ManikinPresent

VcrossFPM

Orientation* VcrossFPM

ManikinPresent ${ }^{\star} V$ crossFPM

Orientation*ManikinPresent* ${ }^{*}$ crossFPM

VcapFPM

Orientation* VcapFPM

ManikinPresent ${ }^{*}$ VcapFPM

Orientation*ManikinPresent ${ }^{*} \vee$ capFPM

VcrossFPM*VcapFPM

Orientation* VcrossFPM* ${ }^{*}$ capFPM

ManikinPresent ${ }^{*}$ VcrossFPM ${ }^{*} V$ capFPM

Orientation*ManikinPresent ${ }^{*}{ }^{*}$ crossFPM $^{*}{ }^{*}$ capFPM

$\begin{array}{rrrrr}\text { Nparm DF } & \begin{array}{r}\text { Sum of } \\ \text { Squares }\end{array} & & \begin{array}{r}\text { F Ratio } \\ \text { Prob }\end{array} \\ 2 & 2 & 2288.963 & 4.1490 & 0.0211^{*} \\ 1 & 1 & 710.454 & 2.5756 & 0.1144 \\ 2 & 2 & 1655.630 & 3.0010 & 0.0581 \\ 2 & 2 & 415.019 & 0.7523 & 0.4762 \\ 4 & 4 & 602.926 & 0.5464 & 0.7023 \\ 2 & 2 & 207.241 & 0.3757 & 0.6886 \\ 4 & 4 & 2568.926 & 2.3283 & 0.0677 \\ 2 & 2 & 24144.296 & 43.7646 & <.0001^{*} \\ 4 & 4 & 1181.815 & 1.0711 & 0.3799 \\ 2 & 2 & 236.074 & 0.4279 & 0.6541 \\ 4 & 4 & 525.593 & 0.4764 & 0.7529 \\ 4 & 4 & 1271.926 & 1.1528 & 0.3419 \\ 8 & 8 & 357.796 & 0.1621 & 0.9949 \\ 4 & 4 & 198.815 & 0.1802 & 0.9477 \\ 8 & 8 & 2942.019 & 1.3332 & 0.2474\end{array}$




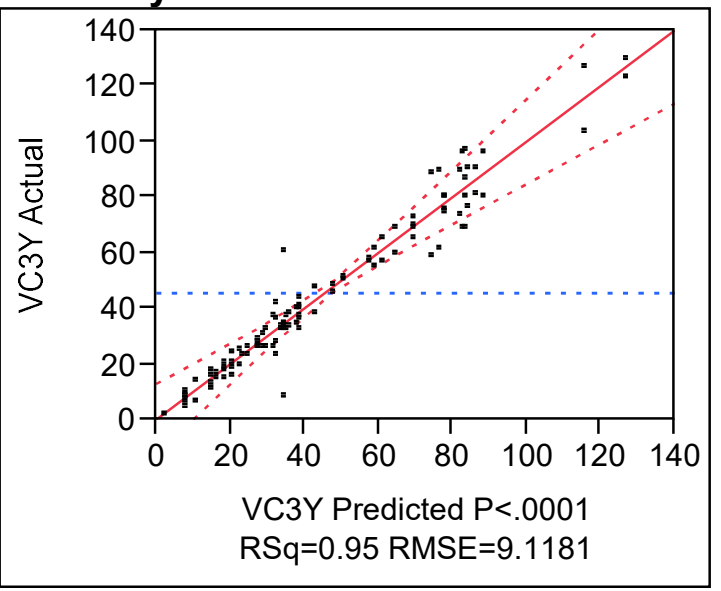

\section{Summary of Fit of VC3Y}

RSquare

RSquare Adj

Root Mean Square Error

Mean of Response

Observations (or Sum Wgts)
0.952482

0.905845

9.118053

45.43519

108

Analysis of Variance of VC3Y

$\begin{array}{lrrrr}\text { Source } & \text { DF } & \text { Sum of Squares } & \text { Mean Square } & \text { F Ratio } \\ \text { Model } & 53 & 89991.046 & 1697.94 & 20.4230 \\ \text { Error } & 54 & 4489.500 & 83.14 & \text { Prob > F } \\ \text { C. Total } & 107 & 94480.546 & & <.0001^{*}\end{array}$

\section{Effect Tests of VC3Y}

\section{Source}

Orientation

ManikinPresent

Orientation*ManikinPresent

VcrossFPM

Orientation* VcrossFPM

ManikinPresent ${ }^{\star} V$ crossFPM

Orientation*ManikinPresent* ${ }^{*}$ crossFPM

VcapFPM

Orientation*VcapFPM

ManikinPresent ${ }^{*}$ VcapFPM

Orientation*ManikinPresent ${ }^{*} \vee$ capFPM

VcrossFPM $^{*}$ VcapFPM

Orientation* VcrossFPM* ${ }^{*}$ capFPM

ManikinPresent ${ }^{*}$ VcrossFPM ${ }^{*} V$ capFPM

Orientation ${ }^{*}$ ManikinPresent ${ }^{*}{ }$ crossFPM $^{*}$ VcapFPM

$\begin{array}{rrrrr}\text { Nparm DF } & \begin{array}{r}\text { Sum of } \\ \text { Squares }\end{array} & \text { F Ratio } & \begin{array}{r}\text { Prob > } \\ \mathbf{F}\end{array} \\ 2 & 2 & 3405.241 & 20.4792 & <.0001^{*} \\ 1 & 1 & 1247.120 & 15.0004 & 0.0003^{*} \\ 2 & 2 & 4939.019 & 29.7034 & <.0001^{*} \\ 2 & 2 & 2491.463 & 14.9837 & <.0001^{*} \\ 4 & 4 & 1886.593 & 5.6730 & 0.0007^{*} \\ 2 & 2 & 266.796 & 1.6045 & 0.2104^{*} \\ 4 & 4 & 2025.815 & 6.0917 & 0.0004^{*} \\ 2 & 2 & 70364.130 & 423.1722 & <.0001^{*} \\ 4 & 4 & 100.593 & 0.3025 & 0.8750 \\ 2 & 2 & 194.574 & 1.1702 & 0.3181 \\ 4 & 4 & 794.037 & 2.3877 & 0.0623 \\ 4 & 4 & 141.037 & 0.4241 & 0.7906 \\ 8 & 8 & 1483.741 & 2.2308 & 0.0390^{*} \\ 4 & 4 & 362.259 & 1.0893 & 0.3711 \\ 8 & 8 & 288.630 & 0.4340 & 0.8954\end{array}$




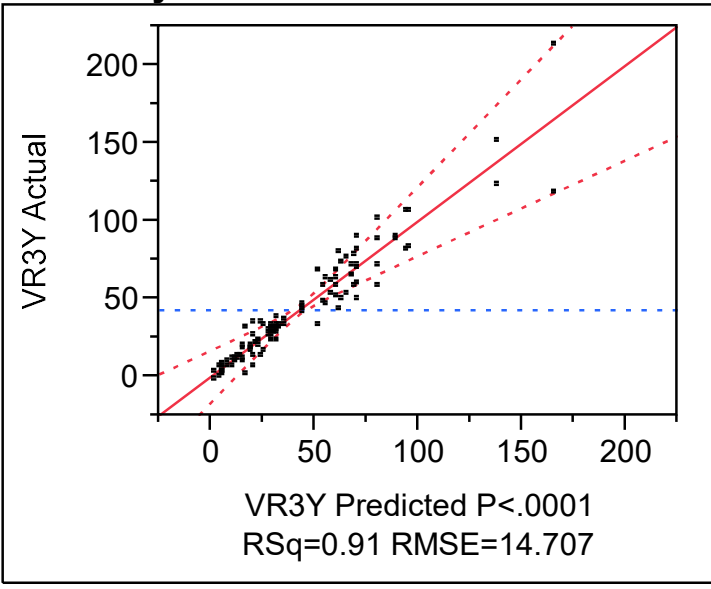

\section{Summary of Fit of VR3Y}

RSquare

RSquare Adj

Root Mean Square Error

Mean of Response

Observations (or Sum Wgts)
0.911624

0.824884

14.70733

42.60185

108

\section{Analysis of Variance of VR3Y}

\section{Source}

Model

Error

C. Total
DF

53

54

107

\author{
Sum of Squares \\ 120487.38 \\ 11680.50 \\ 132167.88
}

\author{
Mean Square \\ 2273.35 \\ 216.31
}

F Ratio

10.5099

Prob $>$ F

$<.0001^{*}$

\section{Effect Tests of VR3Y \\ Source}

Orientation

ManikinPresent

Orientation*ManikinPresent

VcrossFPM

Orientation* VcrossFPM

ManikinPresent ${ }^{\star} V$ crossFPM

Orientation*ManikinPresent ${ }^{*}$ VcrossFPM

VcapFPM

Orientation*VcapFPM

ManikinPresent ${ }^{*}$ VcapFPM

Orientation* ManikinPresent ${ }^{*} \vee c a p F P M$

VcrossFPM*VcapFPM

Orientation* ${ }^{*}$ crossFPM* ${ }^{*}$ capFPM

ManikinPresent ${ }^{*} V$ crossFPM ${ }^{*} V$ capFPM

Orientation*ManikinPresent ${ }^{*}{ }^{*}$ crossFPM ${ }^{*}$ VcapFPM

$\begin{array}{rrrrr}\text { Nparm DF } & \begin{array}{r}\text { Sum of } \\ \text { Squares }\end{array} & \text { F Ratio } & \begin{array}{r}\text { Prob }> \\ \text { F }\end{array} \\ 2 & 2 & 10558.907 & 24.4074 & <.0001^{*} \\ 1 & 1 & 4680.750 & 21.6395 & <.0001^{*} \\ 2 & 2 & 3559.389 & 8.2277 & 0.0008^{*} \\ 2 & 2 & 7307.352 & 16.8913 & <.0001^{*} \\ 4 & 4 & 3216.370 & 3.7174 & 0.0096^{*} \\ 2 & 2 & 2778.167 & 6.4219 & 0.0031^{*} \\ 4 & 4 & 2216.111 & 2.5613 & 0.0487^{*} \\ 2 & 2 & 76626.907 & 177.1265 & <.0001^{*} \\ 4 & 4 & 321.148 & 0.3712 & 0.8282 \\ 2 & 2 & 1445.056 & 3.3403 & 0.0429^{*} \\ 4 & 4 & 1284.889 & 1.4850 & 0.2196 \\ 4 & 4 & 1473.037 & 1.7025 & 0.1629 \\ 8 & 8 & 1834.907 & 1.0604 & 0.4042 \\ 4 & 4 & 1951.111 & 2.2550 & 0.0751 \\ 8 & 8 & 1233.278 & 0.7127 & 0.6792\end{array}$




\section{Appendix B - Cross Draft Validation}

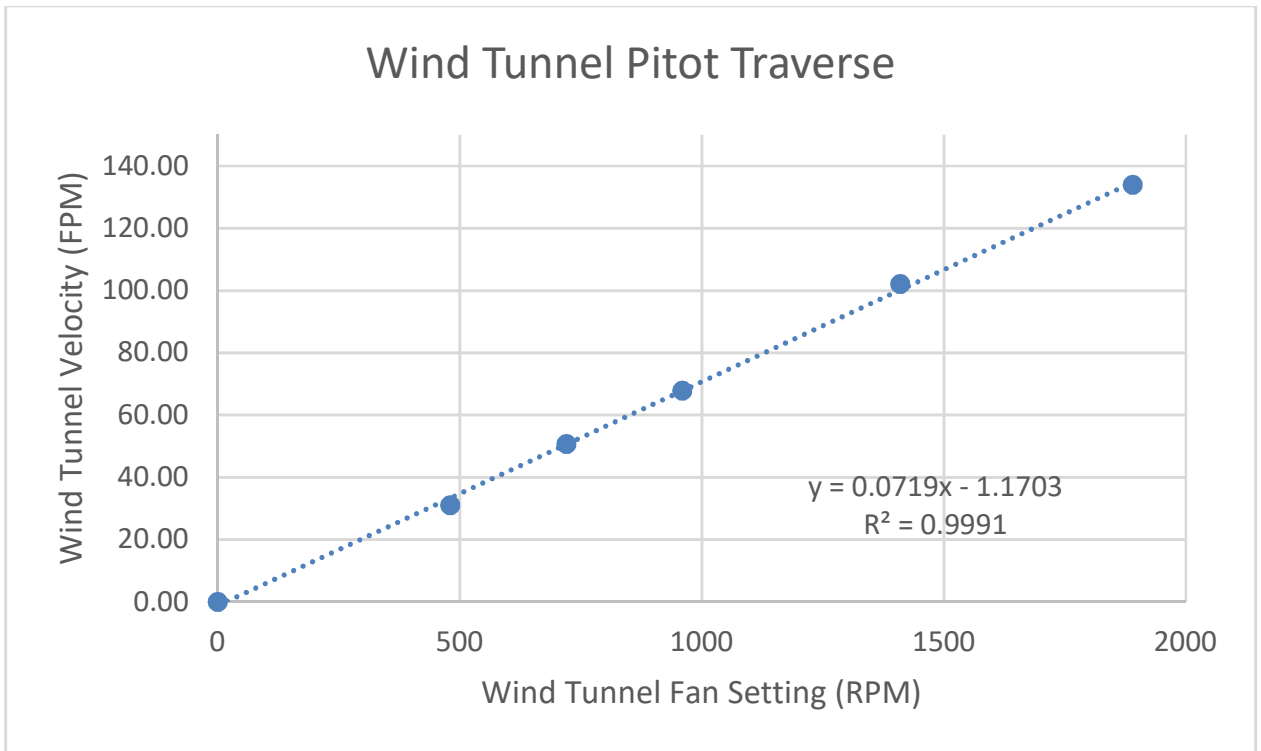

\begin{tabular}{|c|c|c|c|c|}
\hline \multicolumn{5}{|c|}{ Average Velocity within Capture Envelope Measured by Calibrated CTA } \\
\hline $\begin{array}{c}\text { Fan } \\
\text { (RPM) }\end{array}$ & $\begin{array}{c}\text { Average Probe } \\
\text { Voltage }\end{array}$ & $\begin{array}{c}\text { Grid Voltage } \\
\text { STDev }\end{array}$ & $\begin{array}{c}\text { Cross Draft Average } \\
\text { (FPM) }\end{array}$ & $\begin{array}{c}\text { Cross Draft STDev } \\
\text { (FPM) }\end{array}$ \\
\hline 0 & 1.492791 & 0.000790 & 0.98 & 0.38 \\
\hline 150 & 1.501178 & 0.001024 & 9.72 & 0.98 \\
\hline 330 & 1.510291 & 0.002928 & 17.74 & 2.37 \\
\hline 480 & 1.522167 & 0.004194 & 26.36 & 2.69 \\
\hline 630 & 1.536772 & 0.004710 & 32.45 & 2.47 \\
\hline 780 & 1.559749 & 0.007230 & 49.82 & 6.79 \\
\hline 930 & 1.573266 & 0.006277 & 63.29 & 14.11 \\
\hline 1110 & 1.592771 & 0.011568 & 85.82 & 3.54 \\
\hline 1260 & 1.586515 & 0.003005 & 77.94 & 5.87 \\
\hline 1410 & 1.594090 & 0.004741 & 87.08 & 16.60 \\
\hline 1560 & 1.606559 & 0.012771 & 103.56 & 8.01 \\
\hline 1740 & 1.621045 & 0.005564 & 123.41 & 24.81 \\
\hline 1890 & 1.616010 & 0.018295 & 117.12 & 11.63 \\
\hline 2040 & 1.637244 & 0.007409 & 148.24 & \\
\hline
\end{tabular}




\begin{tabular}{|c|c|}
\hline \multicolumn{2}{|c|}{ CTA Calibration } \\
\hline Voltage & Velocity (FPM) \\
\hline 1.493025 & 0.00 \\
\hline 1.501987 & 10.01 \\
\hline 1.515344 & 20.02 \\
\hline 1.530106 & 30.01 \\
\hline 1.552368 & 41.71 \\
\hline 1.559679 & 50.13 \\
\hline 1.569262 & 60.61 \\
\hline 1.579200 & 70.89 \\
\hline 1.587153 & 79.87 \\
\hline 1.595780 & 90.10 \\
\hline 1.604064 & 100.25 \\
\hline 1.611201 & 110.34 \\
\hline 1.618281 & 120.38 \\
\hline 1.625481 & 130.39 \\
\hline 1.632146 & 140.37 \\
\hline 1.638637 & 150.32 \\
\hline 1.644712 & 160.26 \\
\hline 1.650998 & 170.18 \\
\hline 1.656704 & 180.08 \\
\hline 1.662694 & 190.48 \\
\hline 1.668279 & 200.34 \\
\hline 1.673216 & 210.18 \\
\hline 1.678510 & 220.02 \\
\hline 1.683439 & 230.27 \\
\hline 1.687978 & 240.08 \\
\hline 1.692688 & 250.27 \\
\hline 1.696857 & 260.05 \\
\hline 1.701788 & 270.19 \\
\hline 1.706229 & 280.29 \\
\hline 1.710687 & 290.04 \\
\hline 1.715275 & 300.11 \\
\hline
\end{tabular}
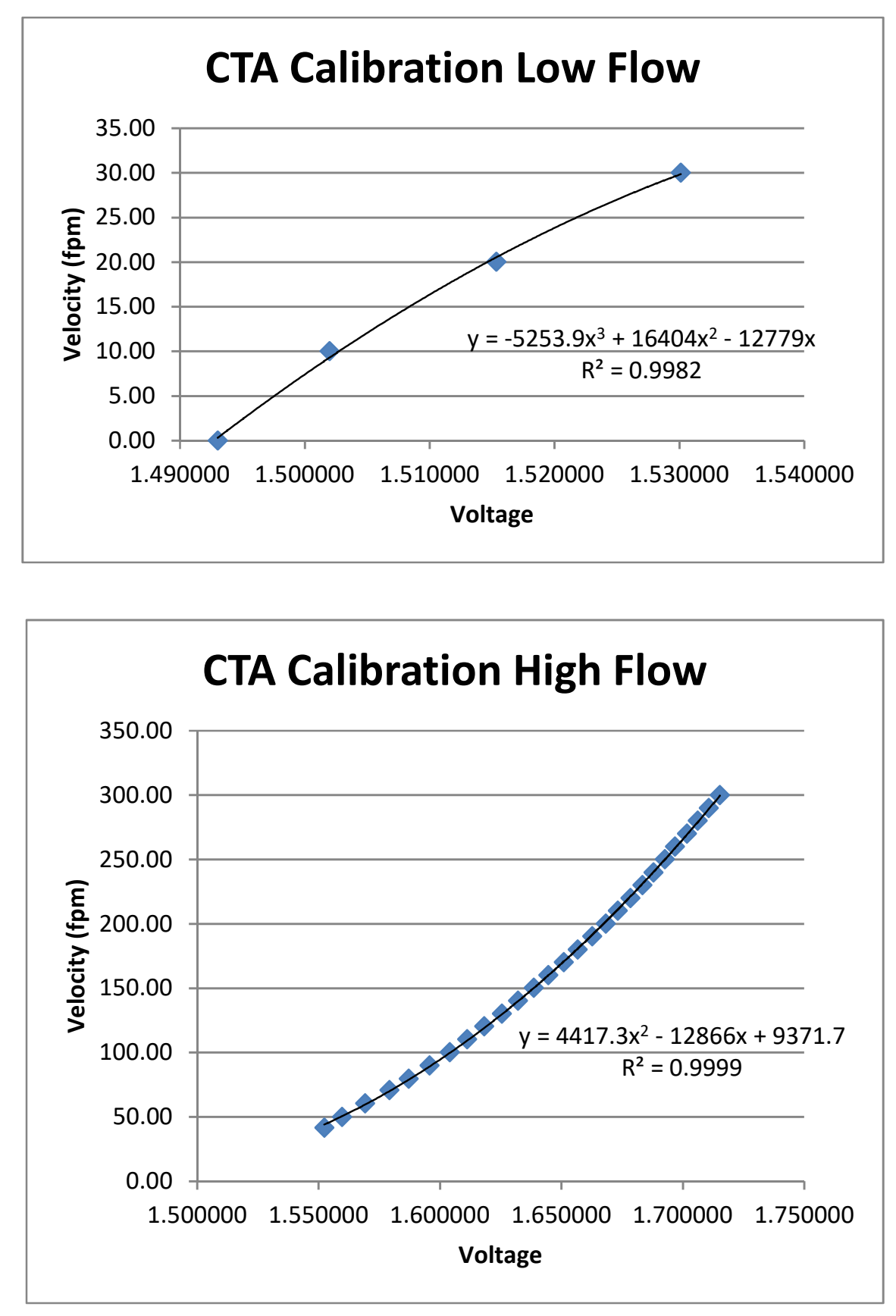